\title{
Planejamento racional de drogas contra tripanosomatídeos: gGAPDH de Trypanosoma cruzi e XPRT de Leishmania major
}

\section{Marcelo Santos Castilho}

\begin{abstract}
Tese apresentada ao Instituto de Física de São Carlos, da Universidade de São Paulo, para obtenção do título de Doutor em Ciências: Física Aplicada, opção Física biomolecular.
\end{abstract}

Orientador: Prof. Dr. Glaucius Oliva 


Castilho, Marcelo Santos
“Planejamento racional de drogas contra tripanosomatídeos: gGAPDH de
Trypanosoma cruzi e XPRT de Leishmania major”
Marcelo Santos Castilho - São Carlos, 2004
Tese (Doutorado) - Área de Física da Universidade de São Paulo,
2004 - Páginas: 181
Orientador: Prof. Dr. Glaucius Oliva
1. Co-cristalização. 2.modelagem molecular.3.gGAPDH. 4.Bisfosfonados.
I. Título


MEMBROS DA COMISSÃO JULGADORA DA TESE DE DOUTORADO DE MARCELO SANTOS CASTILHO APRESENTADA AO INSTITUTO DE FÍSICA DE SÃO CARLOS, UNIVERSIDADE DE SÃO PAULO, EM 27-02-2004.

COMISSÃO JULGADORA:

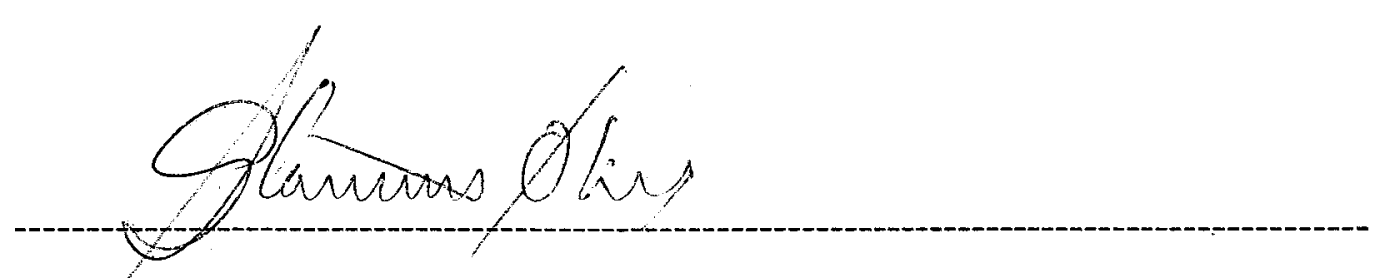

Prof. Dr. Glaucius Oliva (Orientador e Presidente) - IFSC/USP

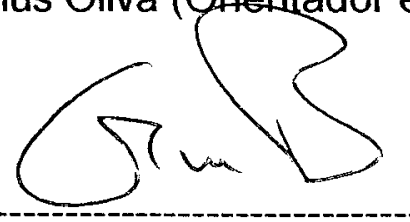

Prof. Dr. Eliezer Jesus de Lacerda Barreiro - UFRJ

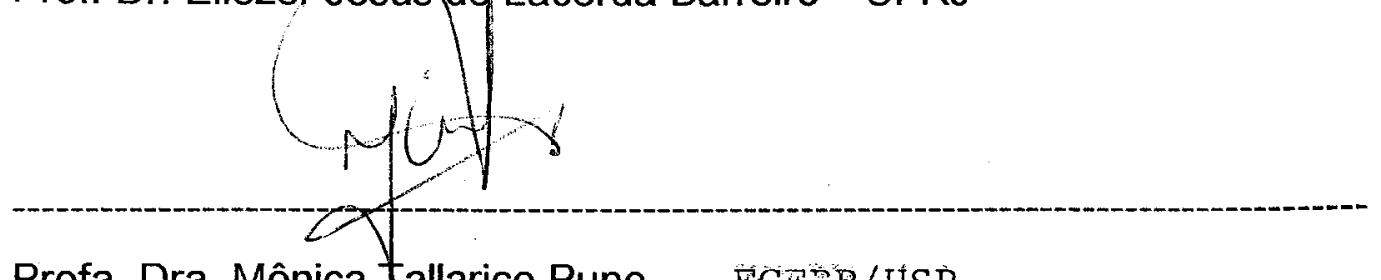

Profa. Dra. Mônica tallarico Pupo-

$$
\text { Could Acontonemi }
$$

Prof. Dr. Carlos Alberto Montanari - UFMG

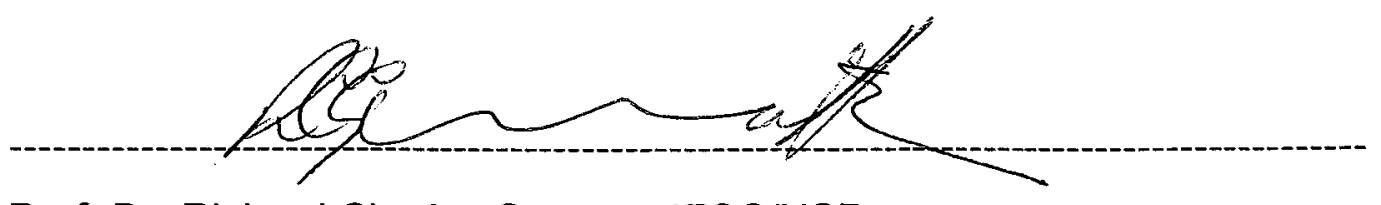

Prof. Dr. Richard Charles Garratt - IFSC/USP 
Aos meus pais Jaime e Sonia que sempre me apoiaram. 


\section{Agradecimentos}

Primeiramente eu gostaria de agradecer ao prof. Glaucius Oliva, pelo apoio, cobrança e pelas discussões sobre cristalografia e planejamento racional de drogas.

Em segundo lugar ao Doutor Fernando Pavão por me ajudar a dar os primeiros passos na purificação e cristalização de proteínas, além da coleta e resolução de dados cristalográficos.

Ao prof. Otávio Henrique Thiemann, agradeço pelo seu apoio e por sua paciência com o lento desenrolar do projeto.

Ao prof. Richard Garrat por suas ótimas aulas e por sua postura como pesquisador/professor um verdadeiro exemplo a ser seguido.

Agradeço também a todos os amigos e colegas do laboratório que sempre colocaram os meus problemas a frente dos seus e proporcionaram um ótimo ambiente de trabalho.

Um agradecimento muito especial a duas pessoas que levo no coração:

Rafael V. C. Guido pela amizade, sinceridade e compania pelo tempo em que dividimos o mesmo teto.

Lilia Simone Rogrigues pelo amor, compreensão, incentivo e, acima de tudo, por me inspirar a ser alguém melhor.

Finalmente, agradeço também à FAPESP pelo apoio financeiro. 


\section{Sumário}

Lista de abreviaturas vii

Lista de Figuras viii

Lista de tabelas xiii

Resumo $\quad x v$

Abstract xvi

\section{Capítulo I- Introdução}

1- A descoberta de novos fármacos 1

2- Doença de Chagas 5

3- Leishmaniose 9

4- Alvos terapêuticos selecionados 11

4.1- A via glicolítica $\quad 12$

4.1.2- gGAPDH 14

4.2- A via de recuperação de purino-cucleotídeos 15

$\begin{array}{ll}\text { 5- Objetivos } & 17\end{array}$

6- Referências bibliográficas 19

Capítulo Il- Identificação de novos inibidores da enzima gGAPDH de $T$. cruzi

1- Introdução 23

1.2- expressão e purificação da enzima gGAPDH 25

de $T$. cruzi

2- Ensaios de atividade enzimática da gGAPDH 25

3- Ensaios de inibição enzimática da gGAPDH com 27

produtos de origem natural 
3.1- Flavonóides 28

3.2- Cardóis, Cardanóis e ácidos anacárdicos 28

3.4- Compostos de origem sintética 30

3.4.1- Derivados de cumarina 30

3.4.2- Derivados de Nucleosídeos 32

3.4.3- Derivados bisfosfonados com atividade 34 tripanocida

4- Referências bibliográficas 36

Capítulo III- Co-cristalização e refinamento

1- Introdução 39

2- Co-cristalização da gGAPDH com derivados de 45 1,3-BPG

3- Coleta de dados e processamento dos dados de $\quad 48$ difração de cristais de gGAPDH em complexo com análogos de 1,3-BPG

4- Resolução das estruturas cristalográficas e 54 refinamento

4.1- Introdução 54

4.2- Resolução da estrutura cristalográfica por 55 substituição molecular

4.3-Refinamento dos modelos obtidos

4.3.1-Introdução 56

4.3.2- Refinamento do complexo gGAPDH-33 58

4.3.2.1- Qualidade da estrutura 64

4.3.2.2 - Análise do complexo gGAPDH-33 65

4.3.3- Refinamento do conjunto de dados gGAPDH-30 70 
4.3.3.2- Análise do complexo gGAPDH-30 73

5- Referências bibliográficas $\quad 81$

Capítulo IV- Modelagem molecular de inibidores da enzima gGAPDH de $T$. cruzi.

1- Introdução

2- Metodologia geral de docking

3- Modelagem molecular de derivados cumarínicos. $\quad 89$

4- Modelagem de compostos bisfosfonados 95

4.1- Resultados de docking obtidos com o 99 programa FLO

4.1.1- Resultados obtidos com Cys ${ }^{166}$ protonada 99

4.1.2- Resultados obtidos com Cys ${ }^{166}$ desprotonada 100

4.2- Resultados de dockig com o programa 101 AUTODOCK

5- Referências bibliográficas

Capítulo V- Clonagem, expressão e purificação da enzima XPRT de L. major Friedling

1- Introdução

2- Amplificação do gene xprt de Leishmania major

3- Clonagem do Gene xprt purificado no Vetor de

Clonagem pGEM-T

4- Inserção do DNA Recombinante pGEM-T/xprt em bactérias Escherichia coli $\mathrm{DH} 5 \alpha$

5- Seleção das bactérias Escherichia coli $\mathrm{DH} 5 \alpha$ Transformada com o DNA Recombinante pGEMT/xprt 
6- Clonagem do Gene xprt no Vetor de Expressão pET29a(+)

7- Inserção do DNA Recombinante pET29a(+)/xprt em bactérias Escherichia coli BL21 (DE3)

8- Seleção das Bactérias Escherichia coli BL21 (DE3) Transformadas com o DNA Recombinante pET29a(+)/xprt

9- Expressão e purificação da proteína XPRT

10- Purificação da XPRT de L. major

10.1- Introdução

10.2- Preciptação com sulfato de amônio

10.3- Purificação cromatográfica da enzima XPRT

de $L$ major

11-Caracterização da enzima XPRT de L. major

11.1- Caracterização cinética da enzima XPRT de

L. major

12- Referências bibliográficas

Capítulo VI- Conclusões

Capítulo VII- Perspectivas

Apêndice $A$

Apêndice $B$

Apêndice $C$

Apêndice D 


\section{Lista de abreviaturas}

$\begin{array}{ll}\text { D.O.600 } & \text { Densidade ótica à } 600 \mathrm{~nm} \\ \text { DNA } & \text { Ácido Desoxirribonucléico (ADN) } \\ \text { DTT } & \text { Dithiotreitol } \\ \text { GMP } & \text { Guanosina monofosfato } \\ \text { HEPES } & \text { Ácido N-[2-Hidroxietil ] piperazina-N'-2-etanosulfonico } \\ \text { IMP } & \text { Inosina monofosfato } \\ \text { IPTG } & \text { Isipropil- } \beta \text {-D-tiogalactopiranosí deo } \\ \text { LB } & \text { Luria-Bertani } \\ \text { OMS } & \text { Organização Mundial da Saúde } \\ \text { PCR } & \text { Reação de polimerização em cadeia } \\ \text { PMSF } & \text { Fluoreto de fenilmetilsulfonil } \\ \text { PPi } & \text { Pirofosfato } \\ \text { PRPP } & \text { 5-fosforribosil-1-pirofosfato } \\ \text { PRTases } & \text { Fosforribosil-transferases } \\ \text { REA } & \text { Relação estrutura-atividade (SAR) } \\ \text { Tris-HCl } & \text { Tris (hidroxometil)metilamina, pH ajustado com HCl } \\ \text { XMP } & \text { Xantina monofosfato } \\ \text { XPRT } & \text { Xantina -fosforribosil-transferase }\end{array}$




\section{Lista de figuras}

\section{Capítulo I}

Figura 1- Esquema do "ciclo de desenho racional de fármacos"

Pág. 4

Figura 2- A) fotomicrografia do Trypanosoma cruzi (ID 9105071).

Pág. 6

B) Rhodnius prolixus (vetor) adulto se alimentando na pele (ID

0005361). Figuras obtidas em

http://www9.who.int/tropical diseases/databases/imagelib.pl

Figura 3- Fármacos utilizados no tratamento da doença de Chagas

Pág. 8

Figura 4- A) fotomicrografia de Leishmania amazonense (ID:

Pág. 9

9106148) B) Phlebotomus dubosci (vetor) alimentando-se na pele

humana (ID: 00061069). Figuras obtidas em

http://www9.who.int/tropical diseases/databases/imagelib.pl

Figura 5- Fármacos utilizados no tratamento da leishmaniose

Pág. 11

Figura 6- Esquema do metabolismo da glicose e glicerol no

Pág. 12 glicossoma..

Figura 7- Estrutura quaternária da enzima GAPDH de T. cruzi

Pág. 15

[Souza, 1998].

Figura 8- Via de recuperação e interconversão, em células de

Pág. 16

Kinetoplastída.

\section{Capítulo II}

Figura 1- Reação de conversão de gliceraldeído-3-fosfato em 1,3bisfosfoglicerato, catalisada pela enzima GAPDH.

Figura 2 - Flavonóides que apresentaram boa atividade inibitória

contra a enzima gGAPDH de $T$. cruzi

Figura 3- Cardóis, Cardanóis e ácidos anacárdicos que apresentaram boa atividade inibitória contra a enzima gGAPDH de T. cruzi

Figura 4- Derivados bifosfonados, provenientes de uma biblioteca de 69 compostos, que apresentaram atividade inibitória contra a enzima gGAPDH. 


\section{Capítulo III}

Figura 1- . Representação esquemática da técnica de gota

Pág. 41 pendurada (a) e de gota sentada (b).

Figura 2- mecanismo catalítico proposto da enzima GAPDH.

Pág. 43

Figura 3- Mecanismo de formação da espécie reativa que pode

Pág. 46

atacar a cisteína catlítica da gGAPDH. Figura adaptada de Maignan (1998)

Figura 4- (Direita) Cristais do possível complexo gGAPDH-30.

Pág. 47

(Esquerda) Cristais do possivel complexo gGAPDH-31

Figura 5- Padrão de difração do cristal gGAPDH-30. À esquerda

Pág. 49

temos uma ampliação da área demarcada na figura da direita.

Figura 6- Mapas de densidade eletrônica 2Fo-Fc, contornados a

Pág. 60

$1,2 \delta$, na região do NAD para os monômeros $D$ (direita) e $B$ (esquerda)..

Figura 7- Mapa de densdade eletrônica 2Fo-Fc, contornado a $0.7 \sigma$ no sítio ativo do monômero $B$.

Figura 8- Diagrama de Ramchandran do complexo gGAPDH-33.

Figura 9- Mecanismos de inibição irreversível possíveis para o Pág. 66 composto 33.

Figura 10- Perfil de interação do composto $3 \mathrm{C}$ no sítio $\mathrm{Pi}$.

Figura 11- Modelo de interação do gliceraldeído 3-fosfato (GAP) no sítio ativo da GAPDH de $E$. coli.

Figura 12- Perfil de interação do composto 33 no sítio

Pág. 69

Figura 13- Mecanismo de interação do composto 33 no sítio ativo da gGAPDH de $T$. cruzi.

Figura 14- Mapa de densidade eletrônica $(2 \mathrm{~m}|\mathrm{Fo}|-\mathrm{D}|\mathrm{Fc}|)$ contornado a $0,8 \sigma$ no sítio ativo do complexo gGAPDH-30.

Figura 15- Perfil de interação do composto 30 no sítio ativo da Pág. 74 enzima gGAPDH de $T$. cruzi.

Figura 16- Comparação das posições cristalográficas dos grupos fosfonato e fosfato em relação as posições previamente descritas para os grupos $\mathrm{SO}_{4}^{-2} \mathrm{em} T$ brucei e $\mathrm{PO}_{4}^{-2} \mathrm{em} \mathrm{L}$. mexicana. 
Figura 17- Comparação da localização dos grupos fosfato e Pág. 75 fosfonato do complexo gGAPDH-30 com as posições dos grupos fosfonato no complexo gGAPDH-33.

Figura 18- Mapas de densidade eletrônica (m|Fol -D|Fc|) Pág. 76 contornados a $1,2 \delta$ (marrom) e $6,0 \delta$ (verde) no sítio ativo do complexo gGAPDH-30.

Figura 19- Comparação dos resultados de modelagem molecular Pág. 79 para os compostos 26-30 no sítio ativo da gGAPDH de $T$. cruzi GAPDH (a) e T. brucei (b).

\section{Capítulo IV}

Figura 1- condições de protonoação da Cys $_{166}$ e tautômeros da Pág. 89 $\mathrm{His}_{194}$ utilizados nos estudos de docking.

Figura 2- Sobreposição estrutural dos derivados cumarínicos com Pág. 90 relação a chalepina.

Figura 3- Modelo de interação de 9 em relação à superfície Pág. 91 acessivel ao solvente (SAS) da enzima gGAPDH.

Figura 4- padrão de interação de $9 \mathrm{com}$ a enzima gGAPDH.

Pág. 93 Segundo o modelo de interação proposto pelo programa FLO.

Figura 5- Sobreposição das soluções encontradas pelo programa Pág. 94 FLO para os compostos 7, 8 e 9.

Figura 6- padrão de interação de $6 \mathrm{com}$ a enzima gGAPDH Pág. 96 segundo o modelo de interação proposto pelo programa FLO.

Figura 7- Sobreposição das soluções encontradas pelo programa FLO para os compostos 7,8 e 9.

Figura 8- Perfil de interação molecular do composto 22 no sítio de ligação do NAD.

Figura 9- Perfil de interação molecular do composto 22.

Pág. 99

Figura 10- Modelo de interação de 22 em relação à superfície acessivel ao solvente (SAS) da enzima gGAPDH.

Figura 11- (esquerda) Perfil de interação molecular do composto

Pág. 101 22. 
Figura 12- Sobreposição da solução encontrada pelo programa

Autodock sobre a solução encontrada pelo programa FLO quando se considera a Cys ${ }^{166}$ desprotonada.

Figura 13- Sobreposição dos contornos de energia para $\mathrm{CH}_{3}$ (-

$3.0 \mathrm{Kcal} / \mathrm{mol})$ em verde e $\mathrm{PO}_{4}^{-2}(-12.0 \mathrm{Kcal} / \mathrm{mol})$ em pink sobre a conformação do composto 79A gerada pelo programa Autodock

Figura 14- Derivados bifosfonados propostos para síntese com

Pág. 103 base no modelo de interação previsto pelos programas FLO e Autodock.

\section{Capítulo V}

Figura 1- Representação esquemática de um experimento de Pág. 107 clonagem em bactéria.

Figura 2- Seqüência de bases dos oligonucleotídeos utilizados Pág. 109 para a amplificação do gene XPRT por PCR.

Figura 3- Gel de agarose comprovando a amplificação do gene

Pág. 110 XPRT de L. major por PCR.

Figura 4- Gel de agarose 1\%.

Pág. 111

Figura 5- Alinhamento da seqüência do gene xprt de L. major depositada no genebank com a seqüência clonada no vetor PGEM-T

Figura 6- Fluxograma das etapas da extração e purificação do DNA recombinante pGEM-T/xprt.

Figura 7- Gel de agarose $1 \%$ mostrando a digestão do vetor pET29a com as enzimas de restrição Nde l e Xho I em diversos clones

Figura 8- Gel SDS-PAGE mostrando a expressão gênica da enzima XPRT à $37^{\circ} \mathrm{C}$ (4 horas) e utilizando $1 \mathrm{mM}$ de IPTG.

Figura 9- Gel SDS-PAGE mostrando a expressão gênica da enzima XPRT quando realizado a $20^{\circ} \mathrm{C}$ (12 horas) e variando-se decrescentemente da esquerda para a direita a quantidade de IPTG (1 $\mathrm{mM}, 0,2 \mathrm{mM}, 0,1 \mathrm{mM}$ e $0,05 \mathrm{mM}$ ).

Figura 10- Fluxograma do protocolo estabelecido para expressar a enzima XPRT recombinante em grande escala. 
Figura 11- Gel SDS-PAGE mostrando a solubilidade da enzima XPRT em concentrações crescentes de sulfato de amônio.

Figura 12- Gel SDS-PAGE mostrando o perfil de purificação da Pág. 123 enzima XPRT.

Figura 13- Gel de focalização isoelétrica da enzima XPRT.

Pág. 124

Figura 14- Efeito do $\mathrm{pH}$ sobre a atividade da XPRT de L. major. As

Pág. 125 medidas foram realizadas em tampão HEPES $50 \mathrm{mM}$ na presença de $100 \mu \mathrm{M}$ de xantina, $1 \mathrm{mM}$ PRPP e $5 \mathrm{mM} \mathrm{Mg}^{+2}$.

Figura 15- Gráfico de Michelis-Menten mostrando os valores de Pág. 126 $V \max (12,88 \pm 0,38 \mu \mathrm{M} / \mathrm{min})$ e $\mathrm{Km}(7,73 \pm 0,51 \mu \mathrm{M})$ para xantina. As concentrações de xantina utilizadas foram $1,8 \mu \mathrm{M}, 2,34 \mu \mathrm{M}$, $3,125 \mu \mathrm{M}, 4,68 \mu \mathrm{M}, 6,25 \mu \mathrm{M} 12,5 \mu \mathrm{M}$ e $25 \mu \mathrm{M}$. A regressão não linear apresenta um $\mathrm{R}^{2}$ de 0,997

Figura 16- Gráfico de Michelis-Menten mostrando os valores de

$V \max (2,29 \pm 0,48 \mu \mathrm{M} / \mathrm{min})$ e $\mathrm{Km}(61,33 \pm 25,94 \mu \mathrm{M})$ para hipoxantina. As concentrações de hipoxantina utilizadas foram $25 \mu \mathrm{M}, 37,5 \mu \mathrm{M}, 50 \mu \mathrm{M}, 75 \mu \mathrm{M}$, e $100 \mu \mathrm{M}$. A regressão não linear apresenta um $\mathrm{R}^{2}$ de 0,954

Figura 17- Gráfico de Michelis-Menten mostrando os valores de $V \max (1,87 \pm 0,16 \mu \mathrm{M} / \mathrm{min})$ e $\mathrm{Km}(209,63 \pm 48,63 \mu \mathrm{M})$ para guanina As concentrações de guanina utilizadas foram $50 \mu \mathrm{M}, 100 \mu \mathrm{M}$, $200 \mu \mathrm{M}, 300 \mu \mathrm{M}, 450 \mu \mathrm{M}, 500 \mu \mathrm{M}$, e $600 \square \mathrm{M}$ A regressão não linear apresenta um $\mathrm{R}^{2}$ de 0,975 


\section{Lista de tabelas}

\section{Capítulo I}

Tabela 1- Redução de $50 \%$ do fluxo glicolítico pela

Pág. 13

inibição individual das enzimas envolvidas no controle da glicólise ${ }^{*}$

\section{Capítulo II}

Tabela 1- Resultados obtidos nos testes in vitro de 3-aril cumarinas frente a enzima gGAPDH de $T$. cruzi.

Tabela 2- Resultados obtidos nos testes in vitro de

derivados de nucleosídeos frente a enzima gGAPDH de T. cruzi

Tabela 3- Derivados bisfosfonados sintetizados no

laboratório do prof Eric. Oldfield que apresentaram atividade inibitória do crescimento de $T$. cruzi in vivo

\section{Capítulo III}

Tabela 1- Inibidores reversiveis e irreversíveis fornecidos pelo Prof. Dr. Jacques Perriè, da Univesité Paul Sabatier, Tolouse, França para estudos de co-cristalização

Tabela 2- parâmetros utilizados durante a integração do Pág. 51 conjunto de dados gGAPDH-27

Tabela 3- parâmetros utilizados durante a integração do conjunto de dados gGAPDH-30

Tabela 4- parâmetros utilizados durante a integração do conjunto de dados gGAPDH-34

Tabela 5- parâmetros utilizados durante a integração do conjunto de dados gGAPDH-33 
Tabela 6- Parâmetros relacionados às coletas de dados e das redes cristalinas de vários cristais coletados, assim como a estatísticas do processamento.

Tabela 7- Soluções encontradas através do programa AMoRe

Tabela 8- Estatisticas do modelo cristalográfico

Pág. 63 gGAPDH-S721 após refinamento.

Tabela 9- Estatísticas do modelo cristalográfico

Pág. 72 gGAPDH-S704 após refinamento.

Tabela 10- Inibição das enzimas gGAPDH $\left(\mathrm{IC}_{50}\right)$ de $T$. Pág. 77 brucei e $T$. cruzi frente aos derivados de 1,3-BPG.

Tabela 11- Distância inter-fosfato após a simulação Pág. 80 computacional no sítios ativos da gGAPDH de $T$. cruzi e de $T$. brucei (entre parênteses)

\section{Capítulo V}

Tabela 1- Reagentes utilizados na amplificação do gene Pág. 109 APTR de L. tarentolae por PCR.

Tabela 2- Protocolo da reação de PCR utilizado na

Pág. 109 amplificação do gene XPTR de L. major

Tabela 3- Reagentes utilizados na ligação do gene Pág. 111 XPRT de $L$. major ao vetor PGEM-T.

Tabela 4- Reagentes utilizados na clivagem do vetor recombinante (pGEM-T/XPRT).

Tabela 5- Reagentes utilizados na ligação do gene XPRT de $L$. tarentolae ao vetor $\mathrm{pET} 29 \mathrm{a}(+)$

Tabela 6- Perfil de purificação de enzima XPRT de $L$. major 


\section{Resumo}

Com o objetivo de descobrir moléculas com atividade inibitória contra enzimas alvo de tripanosomatídeos, as estruturas cristalográficas da enzima gliceraldeído-3-fosfato desidrogenase em complexo com dois análogos de 1,3-bisfosfoglicerato (compostos 30 e 33) foram determinadas por difração de raios $X$, estudos de modelagem molecular foram realizados e o gene xprt (xantina fosforibosiltransferase) de Leishmania major foi clonado e superexpresso em Escherichia coli, e a enzima correspondente foi purificada e carcterizada cinéticamente.

O complexo gGAPDH-33 foi determinado até $2,5 \AA$ e revelou como esse análogo do intermediário tiocetal se liga na enzima. O modelo final da proteína com o inibidor foi refinado utilizando um conjunto de dados com $97,5 \%$ de completeza, com um $\mathrm{R}$ final de 0,20 . Essa estrutura cristalográfica fornece a primeira evidência experimental do mecanismo flip-flop, que descreve como o substrato se desloca do sítio de ligação do fosfato inorgânico para o sítio do fosfato orgânico.

O complexo gGAPDH-30 foi determinado até $2,75 \AA$ de resolução, a partir de um conjunto de dados com $92,4 \%$ de completeza e revela o modo de interação dessa classe de inibidores com a gGAPDH. O modelo final apresenta $\mathrm{R}$ igual a 0,19. Essa estrutura foi utilizada para estudos de modelagem molecular que explicam a diferença de atividade dessa classe de inibidores entre a gGAPDH de Trypanosoma cruzi e de Trypanosoma brucei.

Com relação à XPRT de $L$. major, essa enzima apresenta uma grande afinidade por hipoxantina, quando comparada a enzima homóloga de $L$. donovani. Com a finalidade de tentar entender esse comportamento, estudos de modelagem por homologia estão sendo realizados 


\begin{abstract}
Aiming at discover molecules with good inhibitory activity against tripanosomatides enzymatic targets, the crystallographic structures of glyceraldehydes-3-phosphate dehydrogenase in complex with 1,3 bisfosfoglyceric acid analogues (30 and 33)were solved, molecular modeling studies were undertaken and xprt (xanthine phosphorybosil transferase) gene from Leishmania major was cloned and over-expressed in Escherichia coli. The enzyme thus obtained was purified and kinetically characterized.

.gGAPDH-33 complex, up to $2,5 \AA$ resolution revealed the tioketal intermediate binding mode. The final model was refined to $R 0.20$ from a $97,5 \%$ completeness dataset. The crystallographic structure gives, for the first time, experimental evidence for the flip-flop mechanism, which describes how the substrate goes from inorganic-phosphate binding site to substratephosphate binding site.

gGAPDH-30 complex, solved to $2,75 \AA$ resolution, revealed the inhibitor binding mode. The final model has $\mathrm{R}=0,19$ and was refined from a $92,4 \%$ completeness dataset. This structure was used as the framework upon which modeling studies were performed. Modeling results suggest why these inhibitors show a different inhibitory profile against Trypanosoma brucei and Trypanosoma cruzi.

L. major XPRT shows a high affinity for hypoxanthine, an alternative substrate, when compared to $L$. donovani XPRT, aiming at understand this behavior homology modeling studies are currently under progress.
\end{abstract}




\section{Capítulo I- Introdução}

\section{1- A descoberta de novos fármacos}

Historicamente, a descoberta de fármacos passou por várias etapas, sendo inicialmente ao acaso (por exemplo, a descoberta de benzodiazepínicos, penicilina, etc.). Num segundo momento, utilizou-se a busca aleatória (screening) de substâncias previamente sintetizadas na busca de compostos que apresentassem atividade biológica. Por essa razão, coleções de compostos foram testadas indiscriminadamente a fim de se verificar suas propriedades anti-tumorais, antiinflamatótias, etc. [Silverman, 1992].

Evidentemente, a busca aleatória de moléculas não apresenta um custo benefício adequado à indústria farmacêutica.

Posteriormente, o avanço da bioquímica e biologia molecular possibilitou o acúmulo de conhecimento sobre a fisiopatologia das doenças, tornando possível o planejamento de moléculas bioativas com base no mecanismo de ação 
farmacológico das mesmas. De acordo com essa nova estratégia, denominada "planejamento racional de fármacos", o estudo do reconhecimento molecular em sistemas biológicos assume grande importância, pois ele constitui a base para a seletividade e afinidade dessas moléculas pelos seus receptores.

O reconhecimento do ligante pela macromolécula pode ser estimado qualitativamente pelas interações iônicas, de Van der Walls, hidrofóbicas, ligações de hidrogênio e ligações covalentes existentes entre eles. Além disso, os diversos fatores estereoquímicos que possam garantir, ou favorecer, a conformação ativa do ligante devem ser levados em consideração [Barreiro - 2000].

O planejamento racional de fármacos com base na estrutura do receptor merece citação à parte. Essa metodologia baseia-se na identificação de motivos conformacionais e estruturas comuns de receptores, tanto quanto na análise das interações intermoleculares (macromolécula-ligante) em estruturas de cristais e cocristais de forma a proporcionar informações valiosas para o entendimento do fenômeno de reconhecimento molecular.

Dado o grande número de informações necessárias para essa abordagem, o planejamento racional com base na estrutura do receptor localiza-se na interface de várias áreas de conhecimento, a saber; biologia molecular, bioquímica, cristalografia/ressonância magnética nuclear (RMN), química medicinal, farmacologia, etc. e os profissionais que atuam nessa área devem ter, também, uma formação interdisciplinar que contemple os conhecimentos necessários para o planejamento racional com base na estrutura.

A escolha do alvo terapêutico constitui o primeiro passo no planejamento racional de fármacos. Essa etapa envolve o processo de validação de um alvo terapêutico, através de técnicas como deleção do gene [Harris, 2001], duplo híbrido [Fields \& Song, 1989], etc. Entre os fatores mais importantes na escolha do alvo terapêutico, pode-se destacar: (i) exercer grande controle sobre a via metabólica 
que se deseja modular, ou no caso das parasitoses ser essencial para a sobrevivência do parasita; (ii) ter seu mecanismo catalítico e, preferencialmente, sua estrutura tridimensional conhecidas; (iii) poder ser modulado seletivamente.

$\mathrm{Na}$ etapa seguinte, um estudo detalhado das características estruturais do alvo escolhido através de cristalografia e/ou RMN de macromoléculas é realizado e, a partir das informações assim obtidas, planeja-se de novo novas moléculas que possam apresentar um bom perfil de interação com o alvo escolhido.

Outra estratégia largamente empregada é a busca virtual em bancos de dados por moléculas que apresentem as características físico-químicas e estruturais ideais para interação com o alvo terapêutico escolhido. Essa técnica oferece a vantagem de identificar moléculas comerciais que, após modificações simples na sua estrutura química, podem fornecer bons compostos protótipos (lead compound) a partir dos quais o planejamento racional de fármacos pode ser realizado.

Após a fase inicial de identificação de compostos protótipos, a interação de cada um desses compostos com o alvo terapêutico é estudada detalhadamente e, a partir das informações obtidas, realizam-se modificações no composto original de forma a aperfeiçoar sua interação com o alvo terapêutico.

O conhecimento da estrutura tridimensional de uma proteína e/ou complexo macromolécula-ligante é importante não só na fase de descoberta dos candidatos a novos fármacos, mas também nos estágios posteriores do ciclo de desenvolvimento de fármacos (Figura 1), onde ocorre a otimização do composto protótipo. 
Proteína alvo

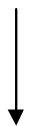

Varredura

Bioquímica de compostos

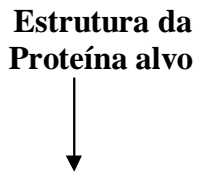

Varredura Computacional de compostos

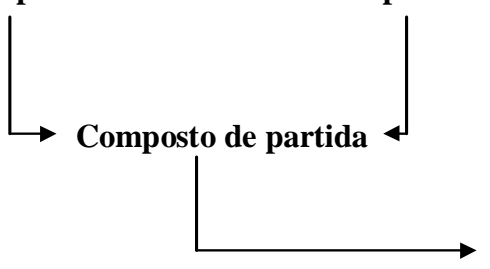

ibidor baseado na estrutura do complexo proteína-ligante

FÁRMACO

Ensaios humanos

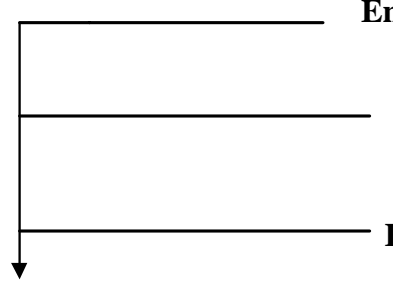

Ensaios hun

Ensaios in vivo

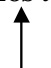

Ensaios in vitro

Síntese do novo inibidor

Figura 1- Esquema do ciclo de desenho racional de fármacos

Isso ocorre porque muitas vezes o composto descoberto apresenta propriedades tóxicas, teratogênicas ou de solubilidade indesejáveis e que devem ser modificadas no decorrer do desenvolvimento do fármaco, utilizando para isso informações provenientes do padrão de interação do ligante com a macromolécula.

Todo esse processo é bastante demorado e pode custar até 802 milhões de dólares [DiMasi et al., 2003]. Por essa razão, a indústria farmacêutica investe preferencialmente em alvos terapêuticos que tenham grande probabilidade de dar retorno financeiro superior a 1 bilhão de dólares anualmente [Knowles \& Gromo, 2003] Esse ideário de mercado explica, pelo menos em parte, o pequeno interesse da indústria farmacêutica por doenças tropicais.

Das 1061 drogas introduzidas no mercado farmacêutico entre 1975 e 1994 menos de 27 tratam especificamente de doenças tropicais [Coura \& Castro, 2002].

Esses dados evidenciam uma realidade onde a descoberta de novos fármacos contra doenças tropicais se concentra em universidades e centros de pesquisas governamentais/estaduais, principalmente, em países em desenvolvimento. 
A baixa disponibilidade orçamentária desses centros torna indispensável a utilização de toda e qualquer ferramenta disponível para o planejamento racional de novas drogas contra doenças tropicais.

Diante desse cenário, o laboratório de cristalografia de macromoléculas e biologia estrutural do Instituto de Física da USP, de São Carlos, tem voltado sua atenção para o planejamento racional, com base na estrutura, de compostos protótipos que possam ser úteis no desenvolvimento de fármacos antitripanosomatídeos.

\section{2- Doença de Chagas}

A doença de Chagas ou tripanossomíase americana é causada pelo protozoário flagelado Trypanosoma cruzi (Figura 2A), que é transmitido ao hospedeiro humano, principalmente pelo vetor hematófago conhecido como "barbeiro" (Figura 2B). Mesmo após 95 anos de sua descoberta, a doença de Chagas continua a representar um sério problema médico. A Organização Mundial da Saúde estima que 200.000 pessoas sejam infectadas anualmente e que 21.000 pessoas cheguem a óbito por complicações decorrentes dessa parasitose [WHO, 2002, Moncayo, 2003]. Essas estatísticas comprovam porque, do ponto de vista global, a doença de Chagas representava em 1998 a terceira parasitose de maior relevância mundial [Wigzel et al., 1998]. 

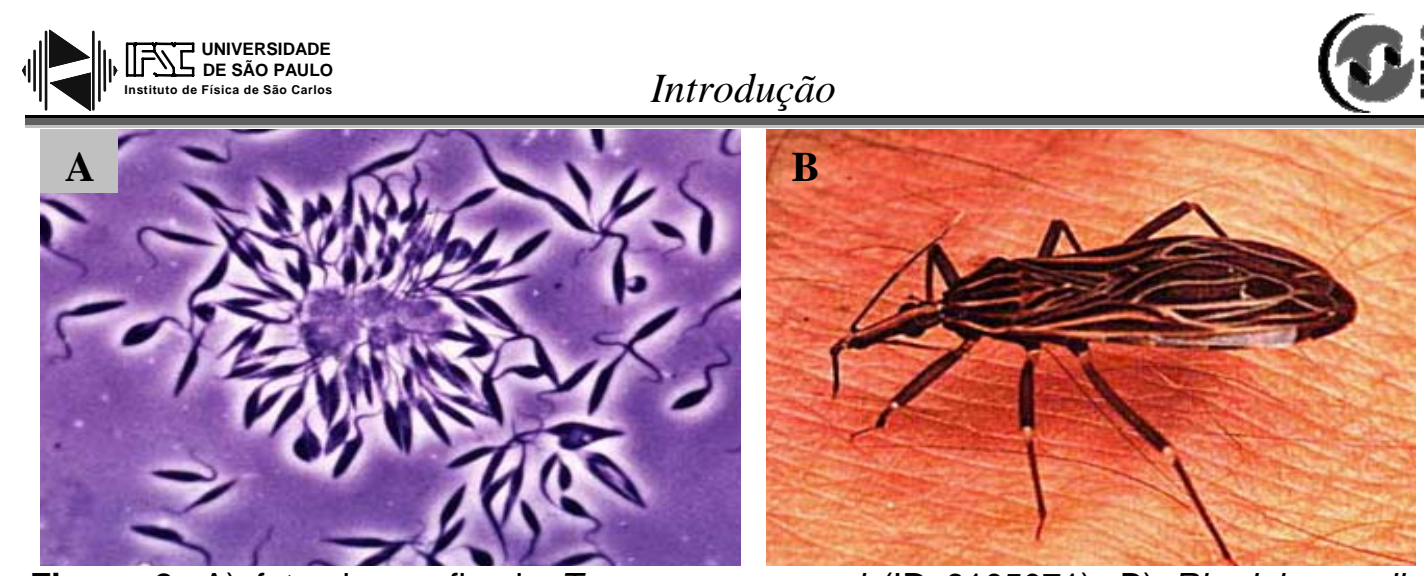

Figura 2- A) fotomicrografia do Trypanosoma cruzi (ID 9105071). B) Rhodnius prolixus (vetor) adulto se alimentando na pele (ID 0005361). Figuras obtidas em http://www9.who.int/tropical diseases/databases/imagelib.pl

No Brasil, a prevalência de pessoas infectadas na faixa etária de 7-14 anos, caiu para 0,04\% em 1999. Esse quadro fornece uma idéia da situação da transmissão vetorial no Brasil e explica porque 8 dos 12 estados endêmicos para essa parasitose foram certificados pela OMS, como livres de transmissão vetorial em 2000 [ Moncayo, 2003]. Entretanto, deve-se ter em mente que existem vários reservatórios silvestres do $T$. cruzi, o que torna a eliminação total do parasita é impossível [Morel - 1999]. Dessa forma, o controle do inseto vetor requer ações de saúde constantes, seja através de aplicação de inseticidas nas regiões endêmicas ou pela contínua educação da população sob risco de contaminação. Infelizmente, é muito comum o relaxamento dessas ações quando se atinge níveis pequenos de transmissão vetorial - caso onde o Brasil se encontra. Outro fator a ser levado em consideração é a crescente descentralização do sistema de saúde, que torna a realização e continuidade das políticas de controle do vetor, por vezes, difícil [Dias e Schofield -1999].

Apesar de todo esforço direcionado para o controle da transmissão da doença de Chagas, pouco tem sido feito para melhorar o tratamento das pessoas já infectadas com essa parasitose.

Atualmente o tratamento da doença de Chagas é mais sintomático do que etiológico. Assim do ponto de vista sintomático procura-se amenizar as diversas manifestações da doença, por exemplo; uso de diuréticos para o tratamento da 
insuficiência cardíaca congestiva. Do ponto de vista etiológico, o Nifurtimox (Lampit, da Bayer) e Benzonidazol (Rochagan, da Roche) (Figura 3) são considerados como fármacos indicados para o tratamento da doença de Chagas. Entretanto o Nifurtimox não é comercializado no Brasil, Argentina, Chile e Uruguai há alguns anos [Fairlamb, 1999]. Além disso, tanto o Benzonidazol como o Nifurtimox apresentam sérios efeitos colaterais como: hiporexia, perda de peso, náuseas, vômitos, alergia cutânea e neuropatia periférica [Veronesi - 1991] e tem eficácia duvidosa, uma vez que algumas cepas estudadas apresentam susceptibilidade diferente para esse tipo de droga [Cinque et al., 1998]. Tendo em vista esse quadro, outros fármacos tiveram sua eficácia no combate a doença de chagas testadas. Entre eles pode-se destacar:

Alopurinol (Figura 3) - Este composto é um análogo de hipoxantina que funciona como um substrato alternativo para a enzima HGPRT. Sua posterior incorporação no RNA leva a formação de nucleotídeos defeituosos e bloqueia a síntese de purino nucleotídeos no parasita. A utilização desse fármaco na fase aguda da doença mostrou-se ineficaz [Lauria-Pires et al., 1988], por outro lado um estudo em pacientes crônicos apresentou um índice de cura de 44\% [Apt et al., 1998]

Cetoconazol (Figura 3) - Esse composto é um derivado de imidazol antifúngico zado como a que apresenta atividade in vitro contra a forma epimastigota do $T$. cruzi, provavelmente devido ao acúmulo dos metabólitos do esterol. Estudos in vivo demonstraram que o cetoconazol é efetivo somente na fase aguda [De Castro 1993]. Contraditoriamente, Brener e colaboradores [Brener et al., 1993] demonstram que essa droga é ineficaz no tratamento de pacientes na fase aguda. Fluoconazol e itraconazol (Figura 3) - Esses compostos são derivados de azois que interferem na síntese do ergosterol [De Castro 1993]. Estudos com pacientes na fase crônica mostram a um índice de cura de 36,5\%. 
<smiles></smiles>

Nifurtimox

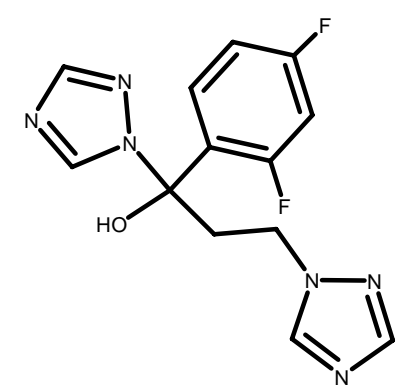

Fluoconazol<smiles>O=C(Cn1ccnc1[N+](=O)[O-])NCc1ccccc1</smiles>

Benzonidazol<smiles>Oc1ncnc2[nH]ncc12</smiles>

Alopurinol<smiles>[R][CH]CCCCCCCC(C)n1ncn(-c2ccc(C)cc2)c1=O</smiles>

Figura 3- Fármacos utilizadas no tratamento da doença de Chagas

Uma revisão completa da quimioterapia disponível para o tratamento da doença de Chagas pode ser encontrada em Coura \& Castro, 2002.

No que diz respeito a prevenção da doença de Chagas, apesar dos inúmeros estudos [Muniz et al., 1946; Pizzi, 1957; Fernandes, 1970; Bua, 1991; Araujo \& Morein - 1991, Luhrs et al., 2003], não existe uma vacina eficaz contra a doença de Chagas. 


\section{3- Leishmaniose}

Um cenário semelhante pode ser descrito para a leishmaniose. Esta parasitose é causada por protozoários do gênero Leishmania (Figura 4A), que são transmitidos ao homem por insetos pertencentes a uma das 30 espécies dos gêneros Phlebotomus e Lutzomya (Figura 4B). Os principais hospedeiros de diversas espécies de Leishmania são os mamíferos, entre eles a população
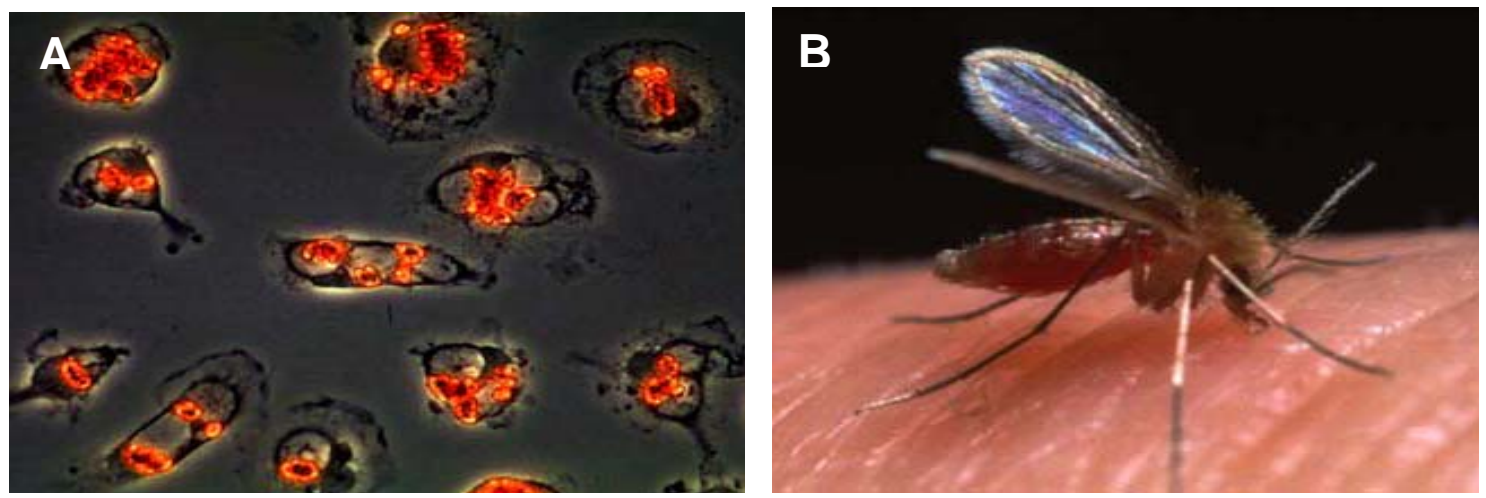

Figura 4- A) fotomicrografia de Leishmania amazonense (ID: 9106148) B) Phlebotomus dubosci (vetor) alimentando-se na pele humana (ID: 00061069). Figuras obtidas em http://www9.who.int/tropical diseases/databases/imagelib.pl

De acordo com os sintomas, as leishmanioses são classificadas em quatro grupos principais. A leishmaniose visceral, também conhecida como calazar, é a forma mais grave e com um alto índice de mortalidade; seus sintomas são: febre alta; perda de peso; anemia e aumento do volume do fígado e baço. As formas cutânea, cutâneo-mucosa e cutâneo-difusa, apesar da gravidade, atacam regiões periféricas do corpo e, mesmo não sendo fatais, na maioria dos casos, essas três formas de leishmaniose causam inúmeras mutilações condenando as pessoas doentes a enfrentar discriminações sociais. Além da preocupação com a leishmaniose em si, nos últimos anos a Organização Mundial da Saúde (OMS), vem se preocupando também com a propagação dessa doença entre pessoas que 
apresentam imunodeficiência. Segundo a OMS, tem aumentado muito os casos de leishmaniose como co-infecção em pacientes com SIDA [Rey, 1991; WHO, 2001].

Dados recentes da OMS indicam que 350 milhões de pessoas em 88 países estão sob risco de contaminação e 12 milhões já estão infectadas. A leishmaniose visceral, forma mais grave da doença, está presente em 19 estados brasileiros com 1.037 municípios atingidos nas regiões: norte; nordeste; centro-oeste e sudeste. Em todo o país, foram notificados 2570 casos em 1997 e 2040 em 1998, sendo 60\% das ocorrências na faixa etária de zero aos 4 anos [WHO, 2001].

As leishmanioses estão entre as doenças parasitárias que ainda não apresentam tratamentos adequados. A quimioterapia para o tratamento da leishmaniose faz uso dos antimoniais pentavalentes como o antimonato de meglumina (Glucantime) (Figura 5) [McGreevy \& Marsden - 1986]. Altas doses diárias, durante longos períodos (até 10 dias), são necessárias em virtude da curta meia-vida (2 horas) do composto na corrente sangüínea. Entretanto, diversas reações de toxicidade são verificadas, podendo chegar até ao choque, à hipersensibilidade e a trombose.

Uma segunda-linha de drogas é empregada no tratamento leishmaniose visceral (anfotericina B) -Figura 5- ou em casos de relapso. Essas formas de tratamento, por sua vez, acarretam efeitos de toxicidade severa [McGreevy \& Marsden - 1986]. Essas características indesejáveis, aliadas ao aparecimento de formas resistentes de Leishmania [Geary - 1989], têm exacerbado a necessidade do estudo de vias alternativas que possam permitir o desenvolvimento futuro de drogas antileishmanióticas. 
<smiles>OCC(O)C(O)C(O)C(O)C[NH2+][C@H](O)[C@H](O)CO</smiles>

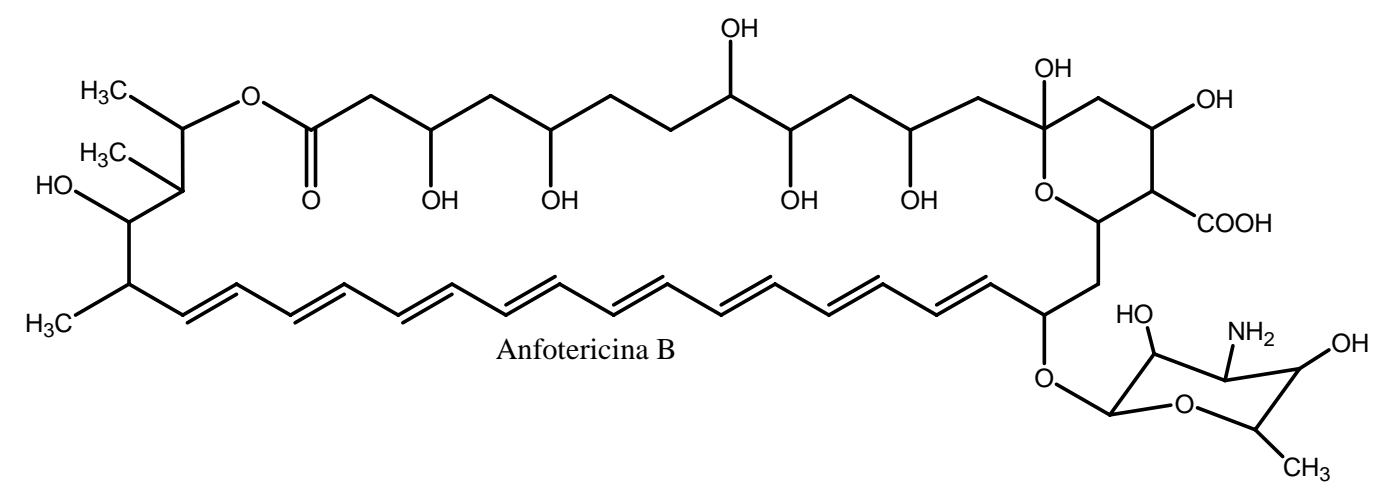

Figura 5- Fármacos utilizados no tratamento da leishmaniose

\section{4- Alvos terapêuticos selecionados}

O processo de planejamento racional de substâncias bioativas com propriedades antiparasitárias baseia-se na investigação bioquímica comparativa entre parasita e hospedeiro, no intuito de se descobrir atividades metabólicas potencialmente diferentes, que possam vir a ser alvo para uma inibição seletiva e na elucidação do modo de interação do composto com o seu alvo terapêutico.

Como muitos parasitas apresentam vias metabólicas extremamente simplificadas, às vezes estes possuem enzimas cuja função pode ser essencial para a sua sobrevivência, enquanto estas mesmas enzimas no hospedeiro não são necessariamente indispensáveis.

Dois exemplos de potenciais alvos terapêuticos que se enquadram nessa descrição são as enzimas gliceraldeído 3-fosfato desidrogenase glicosomal (gGAPDH) de $T$. cruzi e xantina fosforibosil transferase (XPRT) de L. major envolvidas respectivamente na via glicolítica e de recuperação de purinonucleotídeos. 


\section{1- A via glicolítica}

De acordo com Opperdoes [Opperdoes - 1977; 1987], o T. cruzi apresenta uma organela especializada, chamada glicossomo, característica da família Trypanosomatidae, que contém nove enzimas envolvidas nas reações da via glicolítica (Figura 6).

Esta via bioquímica é a principal fonte de energia da forma tripomastigota do $T$. brucei [Clarkson \& Brohn, 1976; Guerra et al., 2002] e estudos recentes mostram que a forma axênica-amastigota do $T$. cruzi também é profundamente dependente dessa via metabólica [kennedy et al., 2001, Coura \& Castro, 2002].

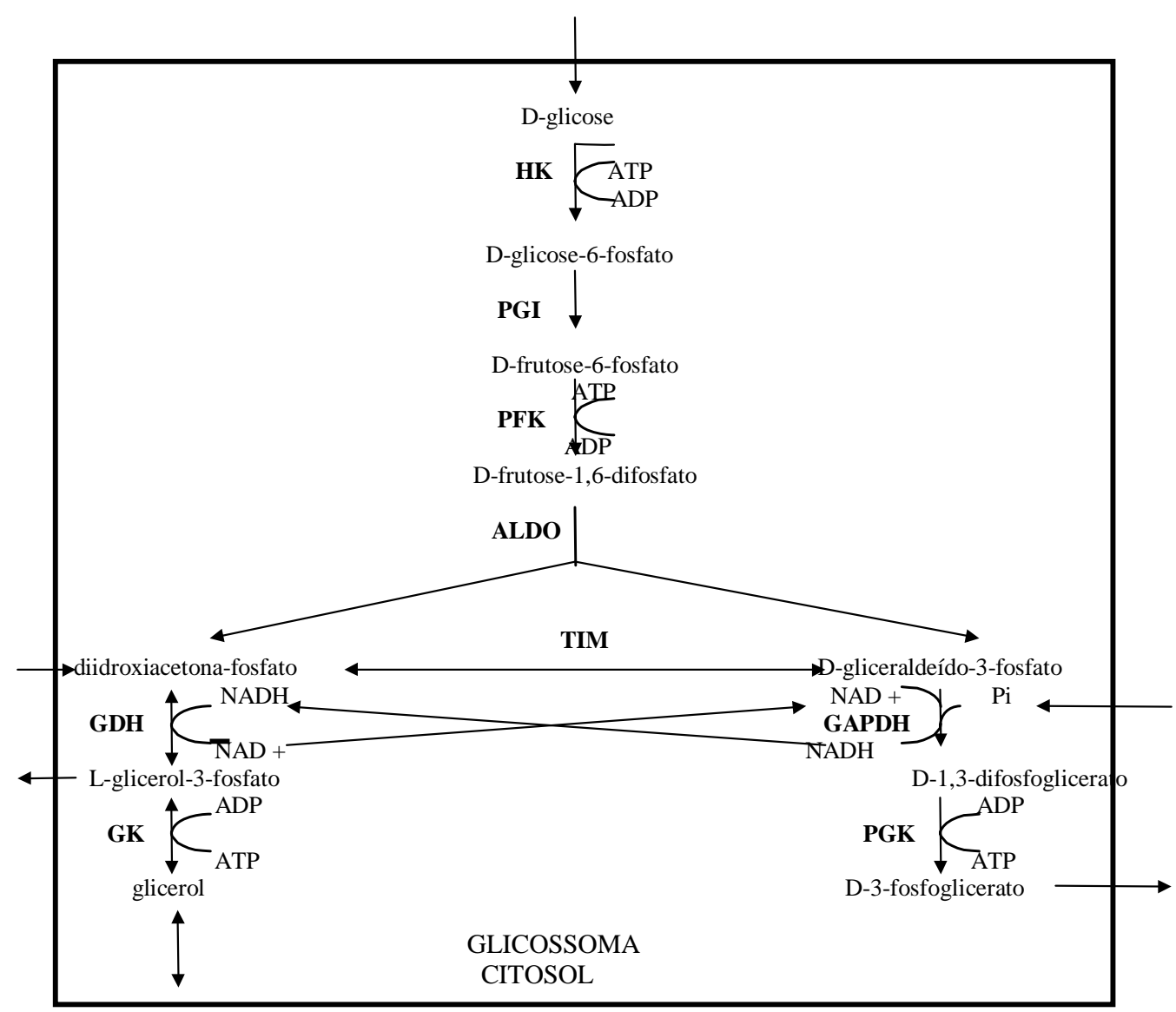

Figura 6- Esquema do metabolismo da glicose e glicerol no glicossoma. As enzimas são: HK - hexokinase; PGI - fosfoglicose isomerase; PFK - 6-fosfofruto-kinase; ALDO frutose-difosfato aldolase; GDH - glicerol-3-fosfato desidrogenase; GK - glicerol kinase; TIM - triosefosfato isomerase; GAPDH - gliceraldeído-3-fosfato desidrogenase; PGK -3-fosfoglicerato kinase. 
Dessa forma, as enzimas envolvidas na glicólise apresentam-se como potenciais alvos para inibição seletiva. De fato, em um estudo sobre o controle do fluxo glicolítico em tripanosomatídeos, Bakker e colaboradores enumeram as enzimas cuja inibição levaria a uma redução significativa da glicólise no parasita(Tabela 1) [Bakker et al.,1999; 2000].

Tabela 1- Enzimas envolvidas no controle da glicólise cuja inibição individual leva a uma redução de $50 \%$ do fluxo glicolítico*

\begin{tabular}{lc}
\hline \multicolumn{1}{c}{ enzima inibida } & Inibição requerida (\%) \\
\hline \hline Transporte de glicose & 51 \\
HK & 93 \\
PFK & 93 \\
ALD & 76 \\
GAPDH & 84 \\
PGK & 85 \\
PYK & 97 \\
GDH & 83
\end{tabular}

*os resultados foram obtidos na presença de $5 \mathrm{mM}$ de glicose e em condições aeróbicas. No hospedeiro humano a concentração de glicose é elevada, o que torna a sua internalização um fator não limitante para a regulação da via glicolítica do parasita. Por essa razão as enzimas ALD, GDH, GAPDH e PGK podem ser consideradas como os melhores alvos para inibição da via glicolítica [Bakker et al., 1999].

De acordo com os dados de Bakker, a enzima gGAPDH exerce grande controle sobre o fluxo glicolítico, razão pela qual ela é explorada como alvo terapêutico por vários grupos de pesquisa [kennedy et al., 2001; Verlinde et al., 2001;2002; Opperdoes \& Michels, 2001]. Vale ressaltar ainda que segundo um modelo de inibição da glicólise em eritrócitos humanos, a inibição das enzimas ALD, GAPDH e PGK em até 95\% não leva a sintomas clínicos [Bakker et al., 1999]. 
As implicações desses resultados no planejamento racional de fármacos são bastante claras e explicam porque a enzima glicossomal gliceraldeido-3-fosfato desidrogenase (gGAPDH) de $T$. cruzi é um bom alvo para o planejamento racional de fármacos contra tripanosomatídeos.

Por esse motivo, essa enzima faz parte de um projeto de longa data do laboratório de cristalografia do IFSC e dentro desse projeto ela já foi clonada, caracterizada cineticamente e teve sua estrutura tridimensional resolvida tanto na forma nativa [Souza et al., 1998], bem como em complexo com uma cumarina de origem natural [Pavão et al., 2002]. Paralelamente a esses estudos, diversos compostos de origem vegetal foram testados contra a enzima gGAPDH na busca de novas moléculas com atividade inibitória [Tomazela et al., 2000; Vieira et. al., 2001].

A partir das informações estruturais e cinéticas reunidas nesses estudos, uma série de derivados cumarínicos e análogos de nucleosídeos foram planejados, muitos dos quais foram objeto de estudo desse trabalho.

O grande desafio nesse momento é completar o ciclo de planejamento racional de fármacos e produzir informações pertinentes que possibilitem o desenvolvimento de inibidores mais potentes e seletivos.

\subsection{2- gGAPDH}

A gGAPDH é uma enzima tetramérica com subunidades de 359 resíduos e peso molecular total de $156 \mathrm{kDa}$ (Figura 7). Esta enzima participa da via glicolítica, tanto no hospedeiro humano como no tripanossomo, catalisando a conversão do gliceraldeído-3-fosfato em 1,3-bisfosfoglicerato, na presença do cofator $\mathrm{NAD}^{+}$ (essencial para a atividade biológica da enzima) e fosfato inorgânico (vide figura 2 a respeito do mecanismo catalítico da enzima gGAPDH no capítulo IV). 


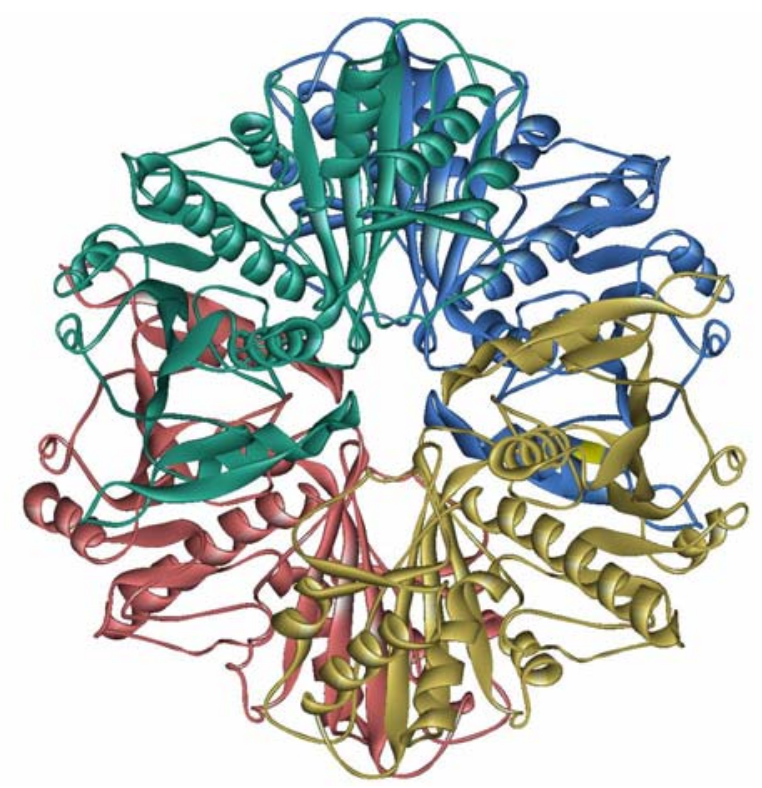

Figura 7- Estrutura quaternária da enzima GAPDH de T. cruzi [Souza et al., 1998].

\section{2- A via de recuperação de purino-nucleotídeos}

O segundo alvo terapêutico explorado nesse projeto leva em consideração uma diferença marcante entre os parasitas protozoários, entre eles os membros do gênero Leishmania, e os hospedeiros mamíferos no que se refere a via de síntese de purino nucleotídeos[Tuttle e Krenitsky - 1979; Jardim et al.,1999].

Os mamíferos podem sintetizar os purino nucleotídeos a partir de duas vias; a primeira envolve dez reações enzimáticas seqüenciais (síntese de novo), a segunda utiliza purino-nucleotídeos pré-formados (via de recuperação).

Os protozoários parasitas, por sua vez, são auxotróficos para purinonucleotídios [Berens et al., 1995; Hassan et al., 1986], ou seja, eles não produzem os purino-nucleotídios necessários a sua sobrevivência. Como conseqüência disso, cada gênero de parasita desenvolveu um conjunto específico de enzimas da via de recuperação que lhe permitem utilizar as purinas pré-formadas pelo hospedeiro.

A via de recuperação em parasitas do gênero Leishmania utiliza 3 enzimas para a conversão das purinas e 5-fosforibosil-1-pirofosfato (PRPP) em nucleosídeo- 
5-monofosfato e pirofosfato: adenina-fosforibosiltransferase-APRT, hipoxantinaguanina-fosforibosiltransferase-HGPRT e xantina-fosforibosiltransferase -XPRT (Figura 8).

Características únicas da via de recuperação em membros dos gêneros Leishmania e Trypanosoma constituem a base para a susceptibilidade destes microrganismos à análogos de purino-nucleotídios [Berens et al., 1995; Hassan et al., 1986; Ullman \& Carter - 1995; 1997] como o alopurinol (4-hidroxipirazol [3,4] pirimidina) ${ }^{\star}$.

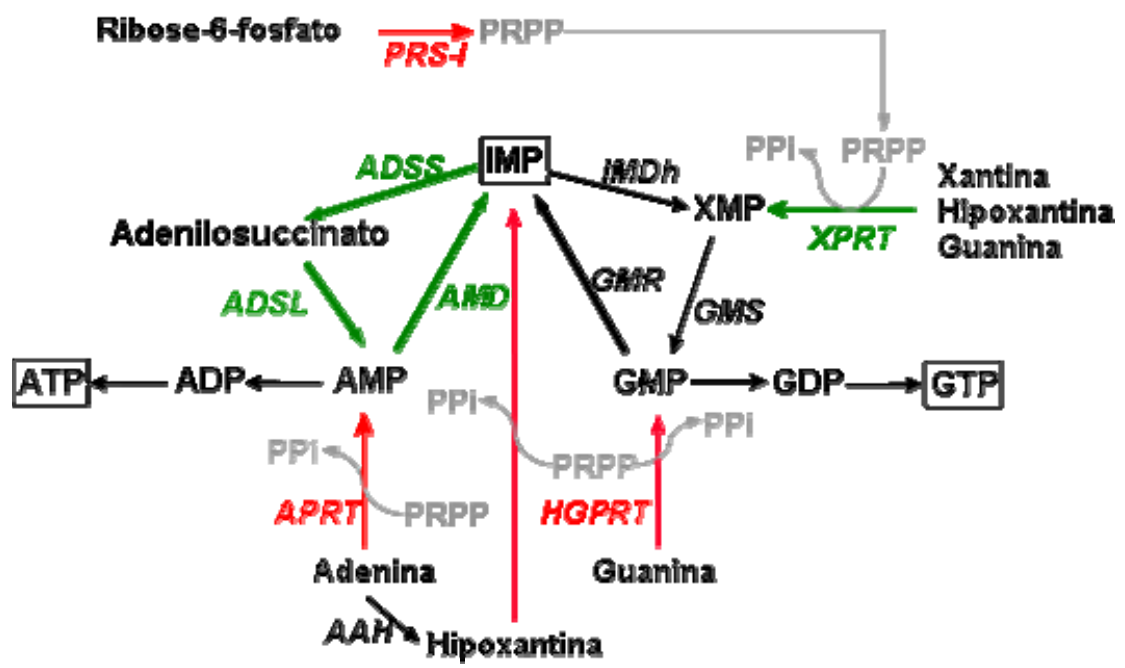

Figura 8- Via de recuperação e interconversão, em células de Kinetoplastída. APRTadenina-fosforribosil-transferase; HGPRT- hipoxantina-guanina-fosforribosiltransferase; XPRT- xantina- fosforribosil-transferase; PRPP- 5'-fosforribosil-1pirofosfato.

As reações catalisadas pelas fosforibosiltransferases (PRTases) são independentes entre si. Por essa razão o estudo dessa via metabólica, como alvo para o desenho racional de fármacos, depende da caracterização cinética e estrutural das três PRTases envolvidas (APRT, HGPRT e XPRT).

\footnotetext{
* Esse fármaco é utilizado extensivamente no tratamento de hiperuricemia (ácido úrico sangüíneo elevado) e artrite aguda (gota) e tem sido explorado clinicamente no tratamento de leishmaniose cutânea e da doença de Chagas [Marr \& Martinez, 1992; Gallerano et al., 1990.
} 
As enzimas APRT e HGPRT de $L$. tarentolae já foram plenamente caracterizadas pelos alunos Marcio Silva ( $\mathrm{N}^{0}$ FAPESP 00/14709-1) e Paulo S. Monzani (N0 FAPESP 98/16378-0) respectivamente.

A enzima XPRT, por sua vez, objeto de estudo desse trabalho, desperta grande interesse para o planejamento racional de fármacos por não ter uma proteína homóloga presente nos humanos.

\section{5- Objetivos}

O trabalho realizado faz parte de um projeto, que visa a obtenção de moléculas com atividade inibitória promissora contra enzimas alvo de tripanosomatídeos.

Visando contribuir para esse objetivo o trabalho foi dividido em duas partes que foram realizadas concomitantemente.

A primeira parte do projeto concentrou-se na descoberta e otimização de compostos com atividade inibitória da enzima gGAPDH de T. cruzi. Esse trabalho envolveu as seguintes etapas:

- Ensaios enzimáticos e de relação-estrutura-atividade (SAR) dos inibidores de gGAPDH de T. cruzi identificados (capítulo II)

- Co-cristalização e resolução da estrutura cristalográfica da enzima gGAPDH em complexo com análogos de 1,3-bisfosfoglicerato, (Capítulo III)

- Estudos de modelagem molecular dos inibidores identificados (Capítulo IV)

A segunda parte do projeto envolveu a clonagem, expressão, purificação e a caracterização cinética da enzima XPRT de L. major Friedling, a fim de explorar as 
informações obtidas nesses estudos para o desenho racional de novos fármacos contra leishmaniose humana.

Esse trabalho envolveu as seguintes etapas:

- Clonagem do gene de xantina-fosforribosil-transferase (xprt) de L. major em vetor de expressão apropriado.

- Super-expressão da enzima XPRT recombinante na forma solúvel e enzimaticamente ativa.

- Purificação da enzima XPRT expressa em E. coli.

- Caracterização cinética da XPRT

Esse trabalho será discutido no capítulo $\mathrm{V}$ 


\section{6- Referências bibliográficas}

Araújo, F. G. \& Morein, B. (1991). "Immunization with Trypanosoma cruzi Epimastigote Antigens Incorporated into ISCOMS Protects Against Lethal Challenge in Mice." Infect. Immun. 59(9): 2909-2914.

Apt W, Aguilera X, Arribada A, Perez C, Miranda C, Sanchez G, Zulantay I, Cortes P, Rodriguez J, Juri D (1998). "Treatment of chronic Chagas disease with itraconazole and allopurinol." Am J Trop Med Hyg 59: 133-138.

Bakker, B. M., Michels, P. A. M., Opperdoes, F. R., Westerhoff, H. V. (1999). "What controls Glycolisis in Bloodstream form Trypanosoma brucei" J. Biol. Chem. 274: 14551-14559

Bakker, B. M., Westerhoff, H. V., Opperdoes, F. R., Michels, P. A. M. (2000) "Metabolic control analysis of glycolysis in trypanosomes as an approach to improve selectivity and effectiveness of drugs" Molec. Biochem. Parasitol, 106, $1-10$

Barreiro, E. J., Fraga, C. A. M., (2001) "Química Medicinal - As Bases Moleculares da ação dos Fármacos" Artmed editora

Berens, R. L., E. C. Krug, and J. J. Marr. (1995). Purine and pyrimidine metabolism. J. J. Marr and M. Muller (ed.), Biochemistry of Parasitic Organisms and its Molecular Foundations. Academic Press, London

Brener Z., Cançado JR., Galvão LM., Da Luz Z.M., Filardi L.S., Pereira M.E., Santos L.M., Cançado C.B. (1993). "An experimental and clinical assay with ketoconazole in the treatment of Chagas disease." Mem. Inst. Oswaldo Cruz 88: 149-153.

Bua, J. (1991). "Trypanosoma cruzi - Cellular and Antibody Reponse Against the Parasite in Mice Immunizes with a 19-Amino Acid Synthetic Peptide." Exp. Parasitol., 72: 54-62.

Cinque G.M., Szajnman S.H., Zhong L., Docampo R., Schvartzapel A.J., Rodriguez J.B., Gros E.G. (1998). "Structure-activity relationship of new growth inhibitors of Trypanosoma cruzi." J. Med. Chem. 41: 1540-1554.

Coura, J. R.; Castro, S. L. (2002) "A Critical Review on Chagas Disease Chemotherapy" Mem. Inst. Oswaldo Cruz, 97, 3.

Castro S.L. (1993). "The challenge of Chagas disease chemotherapy: an update of drugs assayed against Trypanosoma cruzi." Acta Trop. 53: 83-98. 
Dias, J. C. P. e Schofield, C. J. (1999) "The evolution of Chagas Disease ( American Trypanosomiasis) Control after 90 Years since Carlos Chagas Discovery." Mem. Inst. Oswaldo Cruz, 94, Suppl. 1:103-121

DiMasi J.A, Hansen R.W., Grabowski H.G. (2003) "The price of innovation: new estimates of drug development costs." J. Health Econ. 22:151-185.

Fairlamb, A.H. (1999), "Future prospects for the chemotherapy of Chagas disease" Medicina-Buenos Aire, 59179.

Gallerano, R. H.; Sosa, R. R., Marr, J.J. (1990) "Therapeutic efficacy of allopurinol in patients with cronic chagas-disease" J. Trop. Med. 43, 159-166.

Geary, T. G., A. Edgar, J. B. Jensen. (1989). "Drug Resistance in Protozoa." p. 209238. In W. C. Campbell and R. S. Rew (ed.), Chemoterapy of Parasitic Diseases. Plenum Press, New York.

Guerra, G. C., Quijada, L., Clayton C. E. (2002) "Compartmentation of enzymes in a microbody, the glycosome, is essential in Trypanosoma brucei" J. Cell science, 115(13), 2651-2658

Harris S. (2001) "Transgenic knockouts as part of highthroughput, evidence-based target selection and validation strategies." Drug Discov. Today, 6:628-636

Hassan, H. F. and G. H. Coombs. (1986). "A Comparative Study of the Purine- and Pyrimidine-metabolising Enzymes of a Range of Trypanosomatids" Comp. Biochem. Physiol. 84B:217-223.

Jardim, A., Bergeson, S. E., Shih, S., Carter, N., Lucas, R. W., Merlin, G. Mylaer, P. J., Stuart, K., Ullman, B. (1999). "Xantine Phosphoribosiltranferase from Leishmania donovani- Molecular cloning, biochemical characterization and Genetic analysis" J. Biol. Chem. 274: 34403-34410

Fields S., Song O. (1989) "A novel genetic system to detect protein-protein interactions." Nature 340:245-246.

Knowles, J., Gromo, G. (2003) "Target selection in drug discovery" Nature Drug Discovery, 2, 63-69

Kennedy, K. J., Bressi, J. C., Gelb, M. H., (2001). "A disubstituted NAD+ analogue is a Nanomolar Inhibitor of Trypanosomal Glyceraldehide-3-Phosphate Dehydrogenase" Biorg. Med. Chem Lett. 11: 95-98

Marr, J. J., Martinez, S. (1992) "Allopurinol in the treatment of American cutaneous leishmaniose-reply" N. Engl. J. Med. V.326, 741-744.

McGreevy, P. B. and P. D. Marsden. (1986). "Protozoan Infections of Man: American Trypanosomiasis and Leishmaniasis." p. 115-127. In W. C. Campbell and R. S. Rew (ed.), Chemoterapy of Parasitic Diseases. Plenum Press, New York. 
Morel, C. M., (1999). "Chagas Disease, from Discovery to control- and Beyond: History, Myths and Lessons to Take Home" Mem. Inst. Oswaldo Cruz, 94, Suppl. 1, 3-16

Lauria-Pires L, Castro C.N., Emanuel A., Prata A. (1988). "Ineficácia do allopurinol em pacientes na fase aguda da doença de Chagas." Rev. Soc. Méd. Trop. 21: 79

Luhrs, K. A., Fouts, D. L., Manning, J. E. (2003) "Immunization with recombinant paraflagellar rod protein induces protective immunity against Trypanosoma cruzi infection", Vaccine 21, 3058-3069

Moncaio, A (2003) "Chagas Disease: Current Epidemiological Trends after the Interruption of Vectorial and Transfusional Transmission in the Southern Cone Countries" Mem. Inst. Oswaldo Cruz, 98(5), 577-591

Muniz, J.; Nóbrega, G., Cunha, M. (1946). "Ensaios de Vacinação Preventiva e Curativa nas Infecções pelo Scizotrypanum cruzi.", Mem. Inst. Oswaldo Cruz 44: 529-541

Opperdoes, F.R.; Borst, P. (1977). "Localization of Nine Glycolytic Enzymes in a Microbody-like Organelle in Trypanosoma brucei: The glycossome.", FEBS Lett. 80: 360-364.

Opperdoes, F. R. (1987). "Compartmentation of Carbohydrate Metabolism in Trypanosomes.", Ann. Rev. Microbiol. 41: 127-151

Opperdoes, F. R., Michels, P. A. M. (2001) "Enzymes of carbohydrate metabolism as potential drug targets" Int. J. Parasitol, 31(5-6), 482-490

Pavão F., Castilho M.S., Pupo M..T, Dias R.L.A., Correa A.G., Fernandes J.B., da Silva M.F.G.F., Mafezoli J., Vieira .PC., Oliva G. (2002) "Structure of Trypanosoma cruzi glycosomal glyceraldehyde-3-phosphate dehydrogenase complexed with chalepin, a natural product inhibitor, at 1.95 angstrom resolution." FEBS Lett. 520(1-3):13-17.

Rey, L. "Parasitologia" 2.ed., Rio de Janeiro, Guanabara, 1991, 182p.

Silverman, R. B., (1992) "The organic Chemistry of Drug Action" Academic Press Souza, D.H.F., Garrat, R.C., Araújo, A.P.U., Guimarães, B.G., Jesus, W.D.P., Michels, P.A.M., Hannaert, V. and Oliva, G. (1998). "Trypanosoma cruzi Glycosomal Glyceraldehyde-3-Phosphate Dehydrogenase: Structure, Catalytic Mechanism and Targeted Inhibitor Design.", FEBS Lett. 424: 131-135.

Tomazela, D. M.; Pupo, M. T.; Passador, E. A. P.; Silva, M. F. G. F.; Vieira, P. C.; Fernandes, J. B.; Rodrigues Fo., E.; Oliva, G.; Pirani, J. R. (2000) "Pyrano chalcones and flavone from Neoraputia magnifica and their Trypanosoma cruzi 
glicosomal glyceraldehyde-3-phosphate dehydrogenase-inhibitory activity" Phytochem., 55, 643-651.

Tuttle, J. V., Krenitsky (1980). "Purine Phosphoribosyltransferases from Leishmania donovani" J. Biol. Chem. 255: 909-916

Ullman, B., D. Carter. (1995). "Hypoxanthine-guanine Phosphoribosyltransferase as a Therapeutic Target in Protozoal Infections.", Infect. Agents Dis. 4:29-40.

Ullman, B., Carter, D. (1997). "Molecular and Biochemical Studies on the Hypoxanthine-guanine Phosphoribosyltransferases of the Pathogenic Haemoflagellates.", Int. J. Parasitol. 27:203-213.

Verlinde, C. L. M., Hannaert, V., Blonski, C., Willson, M., Perie, J. j., FothergillGilmore, L. A., Opperdoes, F. R., Gelb, M. H., Hol, W. G. J., Michels, P. A. M., "Glycolysis as a target for the design of new anti trypanosome drugs" Drug resist updates, 4(1), 50-65

Verlinde, C. L. M., Bressi, J. C., Choe, J., Suresh, S., Buckner, F. S., Van Voorhis, W. C., Michels, P. A. M., Gelb, M. H., Hol, W. G. J. (2002) "Protein structurebased design of anti-protozoal drugs" J. Braz. Chem Soc., 13(6), 843-848

Veronesi, R. (1991) "Doenças infecciosas e parasitárias" Editora Guanabara Koogan, 8a. edição, 674-705

Vieira PC, Mafezoli J, Pupo MT, Fernandex JB, da Silva MFDF, de Albuquerque S, Oliva G, Pavao F. (2001) "Strategies for the isolation and identification of trypanocidal compounds from the Rutales", Pure Appl. Chem. 73 (3): 617-622

Wigzell H., Nkrumah F.K., Castillo G.T., Amor J. S., Thalwitz W.P. (1998) "Final Report Third External Review of the UNDP/World Bank/WHO Special Programme for Research and Training in Tropical Diseases (TDR)"

World Health Organisation. http:www.who.int/ (Março 2001).

WHO, World Health Organization Statistical Information System Website, http://www.who.ch/whosis/whosis.html, (novembro 2002). 


\section{Capítulo II - Identificação de}

\section{novos inibidores da enzima} gGAPDH de T. cruzi

\section{1- Introdução}

A natureza tem sido uma fonte inesgotável na descoberta de novos fármacos [Hostetmann et al., 2003], entretanto a indústria farmacêutica tem dado maior atenção a síntese combinatória como metodologia para descoberta de novos fármacos. Essa estratégia baseia-se na criação de grandes coleções de compostos que são testados contra alvos terapêuticos pré-definidos [Borman, 2002]. Devido ao grande número de compostos sintetizados por essa metodologia esperava-se um aumento substancial de produtividade, ou seja, um aumento na descoberta de novas moléculas bioativas (new chemical entities, NCEs). 
Contrariamente ao esperado, não houve aumento significativo no número de NCEs introduzidas no mercado farmacêutico entre 1981-2002, mas sim uma estagnação desse número, o qual atingiu seu mínimo em 2001 [Class, 2002].

Apesar de todo esforço da indústria farmacêutica na otimização dos ensaios em larga escala (highthroughput screening, HTS) de compostos originários, principalmente, de síntese combinatória, ainda hoje cerca de 50\% dos compostos líderes descobertos pela indústria farmacêutica são de origem natural [Newman et al., 2003]. De uma maneira geral, das 1031 NCEs aprovadas entre 1981 e 2002, 43\% são de origem sintética, entretanto se descontarmos o número de moléculas que são análogos de produtos naturais (compostos isolados da natureza, substratos/cofatores dos alvos terapêuticos, etc.) esse número cai para $33 \%$. Portanto o número de NCEs provenientes de fonte natural é da ordem de 57-67\% [Newman et al., 2003].

Esse cenário deixa evidente a importância de se explorar a biodiversidade existente no Brasil para a descoberta de moléculas potencialmente promissoras para o desenvolvimento de novos fármacos.

Dessa forma, uma das estratégias utilizadas nesse projeto é a identificação de produtos naturais com atividade inibitória da gGAPDH de $T$. cruzi através de ensaios de atividade enzimáticos in vitro.

Além dos ensaios realizados com produtos naturais, também foram realizados ensaios com compostos sintéticos.

A fim de realizar os ensaios cinéticos para avaliação das propriedades inibitórias dos compostos testados, a enzima gGAPDH teve de ser expressa e purificada rotineiramente. A metodologia empregada nessa tarefa está descrita, resumidamente, a seguir. 


\section{2- Expressão e purificação da enzima gGAPDH de T. cruzi}

O gene que codifica a enzima gGAPDH de $T$. cruzi foi clonado no vetor pET3a por Hannaert e colaboradores [Hannaert et al., 1995] e introduzido em células de $E$. coli da linhagem BL21(DE3)gap-. Os protocolos de expressão e purificação dessa enzima foram descritos por Souza e colaboradores [Souza et al., 1998]. Nesse trabalho duas modificações foram introduzidas no protocolo de purificação

1- A resina da coluna de troca catiônica Phospho Ultrogel AGR (IBF Biotechnics) não é mais produzida comercialmente. Por essa razão, a segunda coluna utilizada no protocolo de purificação foi substituída por uma coluna de celulose fosfato (Whatman). Essa coluna apresenta o mesmo perfil de eluição da coluna Phospho Ultrogel AGR e, portanto, não introduziu modificações significativas na pureza da enzima obtida.

2- Uma vez que parte dos inibidores estudados nesse projeto deveriam ligar-se covalentemente a cisteína catalítica da gGAPDH, o agente redutor DTT foi suprimido das soluções utilizadas no protocolo de purificação. Essa medida foi adotada pois DTT pode reagir com o tampão cacodilato (utilizado nas soluções de cristalização), formando uma espécie reativa que se liga covalentemente a cisteína (vide Figura 3 no capítulo III).

\section{2- Ensaios de atividade enzimática da gGAPDH}

A enzima gGAPDH de $T$. cruzi catalisa a conversão de gliceraldeído-3fosfato em 1,3-bisfosfoglicerato, segundo a reação descrita na figura 1. 


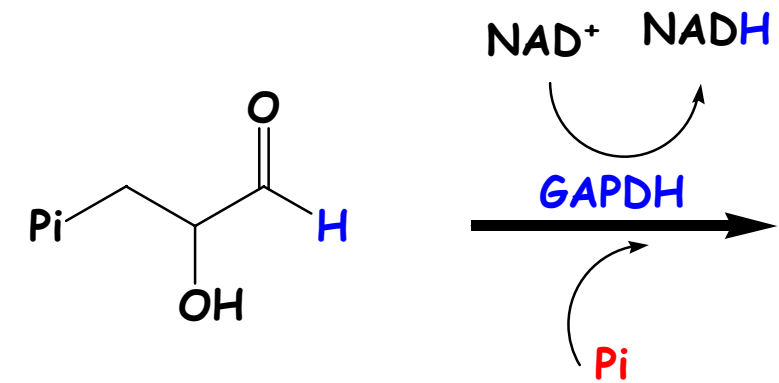

gliceraldeído-3-fosfato<smiles>CCCC(=O)C(O)CP</smiles>

1,3-bisfosfoglicerato

Figura 1- Reação de conversão de gliceraldeído-3-fosfato em 1,3-bisfosfoglicerato, catalisada pela enzima GAPDH.

A atividade enzimática da enzima em questão pode ser medida pelo protocolo descrito por Souza e colaboradores [Souza et al., 1998] e pode ser calculada conforme a equação 1

\section{Equação 1}

Ativ. Espec $(U / m g)=\left[(\Delta\right.$ Abs. $/ \Delta t) X$ vol. da cubeta/ $\varepsilon_{\text {NADH }} X$ vol. da enzima $X$ conc. da enzima $]$

Nos ensaios de inibição enzimática, o mesmo procedimento pode ser utilizado, adicionando-se agora o potencial inibidor. Quando os inibidores não são solúveis em água, eles são dissolvidos em DMSO e adicionados a mistura reacional na concentração final de 10\% (v/v). Nessa concentração, o solvente orgânico não afeta significantemente a atividade específica da enzima [Vieira et al., 2001].

A porcentagem de inibição é calculada conforme a equação 2

\section{Equação 2}

$\%$ inibição= [(Ativ. Espec. (controle)) - Ativ. Espec. (inibidor)/ Ativ. Espec. (controle)] X 100

Todas as medidas são realizadas em triplicata e a média dos valores utilizada para os cálculos descritos acima. Para cada teste de inibição utiliza-se 
como controle negativo (0\% de inibição) uma mistura de reação contendo 10\%(v/v) de DMSO e como controle positivo (100\% inibição) uma solução contendo $200 \mu \mathrm{M}$ de RD17 (uma cumarina sintética cuja inibição frente a gGAPDH é conhecida- $\mathrm{IC}_{50}=$ $80 \mu \mathrm{M})$.

\section{3- Ensaios de inibição enzimática da gGAPDH com produtos de origem natural}

Com a colaboração com o prof. Dr. Paulo Cezar Vieira, do laboratório de produtos naturais do departamento de química da Universidade Federal de São Carlos (UFSCar), o trabalho de busca de inibidores da enzima gGAPDH de $T$. cruzi em plantas da biodiversidade brasileira vem sendo realizado rotineiramente com substância isoladas, além de extratos e frações obtidas durante o fracionamento e purificação das substâncias desejadas. Os testes realizados com extratos e frações visam minimizar o número de substâncias a serem ensaiadas e racionalizar o protocolo de fracionamento, direcionando-o para as frações que apresentem atividade inibitória promissora. Até o presente momento, foram testadas mais de 3000 frações e extratos de plantas nativas do Brasil.

Esse trabalho só foi possível graças ao auxílio técnico de Eli Fernando Pimenta ( $N^{0}$ FAPESP 02/10409-9) e a colaboração dos alunos de mestrado e doutorado do departamento de química da UFSCar que forneceram as frações iniciais, bem como procederam ao fracionamento das mesmas. A seguir temos representadas substâncias isoladas a partir desses extratos ou frações e que apresentam boa atividade inibitória contra a gGAPDH de T. cruzi.

\section{1- Flavonóides}


A exemplo de outros flavonóides já testados contra a enzima gGAPDH [Tomazela et al., 2000; Moraes et al., 2003], os compostos apresentados na figura 2 apresentaram $\mathrm{IC}_{50}$ de ordem micromolar. Entretanto, a série de compostos testados até o presente momento é muita pequena, o que dificulta uma análise adequada da importância do padrão de substituição desses flavonóides sobre a atividade inibitória.<smiles>COc1cc(-c2cc(=O)c3c(OC)cc(OC)c(OC)c3o2)cc(OC)c1OC</smiles>

(1)<smiles>COc1cc(-c2oc3cc(OC)c(OC)c(OC)c3c(=O)c2OC)cc(OC)c1OC</smiles>

(2)

Figura 2 - Flavonóides que apresentaram boa atividade inibitória contra a enzima gGAPDH de T. cruzi

Numa tentativa de suprir essa lacuna, uma coleção de aproximadamente 60 derivados de flavonóides foi planejada e está sendo sintetizada no laboratório da Prof $^{\text {a. }}$ Dr $^{\text {a. }}$ Arlene G. Correa da UFSCar.

\section{2- Cardóis, Cardanóis e ácidos anacárdicos}

A Anacardium occidentale L. é uma planta típica de campos e dunas da costa norte do país, popularmente conhecida como cajueiro. A casca da castanha fornece um óleo industrial que possui majoritariamente constituintes fenólicos, tais como ácido anarcádico (4), cardol (5) e cardanol (6) [Paramashivappa et al., 2001].

Quando testados contra a enzima gGAPDH os compostos representados na figura 3 exibiram bom perfil de inibição (inibição de 50\% em concentrações entre 2$30 \mu \mathrm{M})$. Cabe ressaltar que os ensaios não foram realizados com substâncias puras, mas sim com misturas, cujos constituintes diferiam ora na proporção, ora na 
posição da ligação dupla. Em outras palavras, os resultados referentes, por exemplo, ao ácido anacárdico, referem-se a uma mistura de 4 ácidos anacárdicos que diferem entre si na presença e localização da ligação dupla.<smiles>[R]c1cc(O)cc(O)c1</smiles>

3<smiles>[R]c1cccc(O)c1</smiles>

5
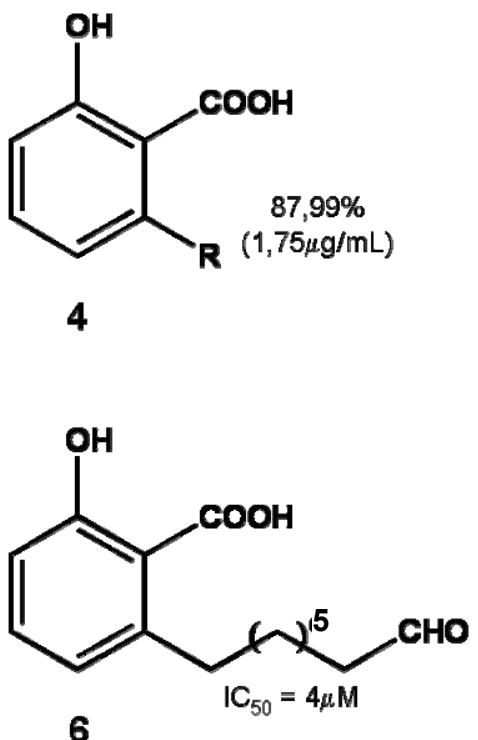

Figura 3- Cardóis, Cardanóis e ácidos anacárdicos que apresentaram boa atividade inibitória contra a enzima gGAPDH de $T$. cruzi. $\mathrm{R}=8 Z, 11 Z, 14 Z$ pentadecatrienil; $8 Z, 11 Z$ pentadecadienil; $8 Z$ pentadecenil; pentadecil

Devido a dificuldades inerentes do processo de separação, não foi possível isolar cada um dos componentes das misturas. Alternativamente, a hidrogenação da ligação dupla da cadeia lateral do ácido anacárdico (composto de maior atividade inibitória da série) foi realizada pela mestranda Richele Severino da UFSCar. $\mathrm{A} I \mathrm{IC}_{50}$ do ácido anacárdico hidrogenado $(28 \mu \mathrm{M})$ demonstra que maior flexibilidade do composto é desfavorável a interação com a enzima, uma vez que quando em mistura a $I C_{50}$ aproximada para esse composto foi estimada em $3 \mu \mathrm{M}$.

Visando contornar esse problema e criar um modelo de interação enzimainibidor que pudesse guiar o planejamento de novos derivados do ácido anacárdico, realizou-se um estudo de modelagem molecular através da técnica de docking (vide capítulo VII). Esse trabalho foi realizado em colaboração com o doutorando Rafael V. C. Guido (N FAPESP 02/12680-1) do IFSC-USP. 
Segundo o modelo de interação sugerido pelos estudos de modelagem molecular, a diminuição da cadeia lateral do ácido anacárdico de 16 para 8 carbonos resultaria num aumento da atividade inibitória*. De fato o composto 6 (Figura 3) apresenta $\mathrm{IC}_{50}=4 \mu \mathrm{M}$.

Nas etapas seguintes do planejamento de derivados do ácido anacárdico, o padrão de substituição do anel aromático será estudado em maior detalhe.

\section{4- Compostos de origem sintética}

Paralelamente aos estudos de inibição com produtos de origem natural, uma série de inibidores sintéticos também foram testados contra a enzima gGAPDH de T. cruzi. Entre eles pode-se destacar; (i) Derivados de cumarina, (ii) Derivados de nucleosídeos, (iii)Derivados bisfosfonados.

As duas primeiras classes de compostos foram planejadas com base na estrutura cristalográfica da enzima gGAPDH nativa [Souza et al., 1998], em complexo com chalepina (cumarina de origem natural) [Pavão et al., 2001] e/ou com base em resultados de inibição enzimática [Tomazela et al., 2000; Vieira et al., 2001]. A terceira classe foi testada com base nas informações obtidas a partir das estruturas cristalográficas discutidas no capítulo IV e em dados da literatura sobre a atividade tripanocida desses compostos [Martin et al., 2001]

\subsection{1- Derivados de cumarina}

A atividade inibitória de cumarinas naturais contra a enzima gGAPDH de $T$. cruzi [Vieira et al., 2001] levou a Professora Dra. Monica T. Pupo da Faculdade de Ciências Farmacêuticas da USP de Ribeirão Preto (FCPRP) a planejar uma série

\footnotetext{
* O padrão de substituição do anel aromático do ácido anacárdico nos levou a testar o ácido acetilsalicílico, como um possível inibidor da enzima gGAPDH de T. cruzi. Entretanto esse composto não demonstrou atividade inibitória quando testado em concentrações 5 vezes superiores a IC50 do ácido anacárdico hidrogenado. Esse resultado é indicativo da importância da cadeia lateral hidrofóbica para a ação inibitória dos derivados de ácido anacárdico
} 
de derivados cumarínicos, nos quais um grupo piperonila seria adicionado à posição 3 do anel cumarínico. A escolha desse grupo foi motivada pela presença desse mesmo grupo em flavonóides que apresentam atividade inibitória da gGAPDH de T. cruzi [Tomazela et al., 2000].

Assim, uma série de compostos foi sintetizada e teve sua atividade inibitória contra a enzima gGAPDH testada através de ensaios enzimáticos in vitro (Tabela 1)

Tabela 1- Resultados obtidos nos testes in vitro de 3-aril cumarinas frente a enzima gGAPDH de T. cruzi.<smiles>[R16]c1ccc(-c2cc3cc(Br)c([R3])c([B])c3oc2=O)c([R6])c1[13CH3]</smiles>

\begin{tabular}{|c|c|c|c|c|c|c|}
\hline Código & R1 & R2 & R3 & \begin{tabular}{l|l} 
R4 &
\end{tabular} & $\begin{array}{l}\text { Conc. } \\
(\mu \mathrm{M})\end{array}$ & $\begin{array}{c}\text { GAPDH } \\
\text { Inib. (\%) }\end{array}$ \\
\hline 7 & $\mathrm{H}$ & $\mathrm{H}$ & $\mathrm{H}$ & $\mathrm{OCH}_{2} \mathrm{O}$ & 50 & 0 \\
\hline 8 & Pir $-\mathrm{CH}=\mathrm{N}$ & $\mathrm{H}$ & $\mathrm{H}$ & $\mathrm{OCH}_{2} \mathrm{O}$ & 45 & 56,8 \\
\hline $8 a$ & $\mathrm{Py}-\mathrm{CH}=\mathrm{N}$ & $\mathrm{H}$ & $\mathrm{H}$ & $\mathrm{OCH}_{2} \mathrm{O}$ & 45 & 14,5 \\
\hline 9 & Tio- $\mathrm{CH}=\mathrm{N}$ & $\mathrm{H}$ & $\mathrm{H}$ & $\mathrm{OCH}_{2} \mathrm{O}$ & 45 & 28,7 \\
\hline 10 & Fur- $\mathrm{CH}=\mathrm{N}$ & $\mathrm{H}$ & $\mathrm{H}$ & $\mathrm{OCH}_{2} \mathrm{O}$ & 45 & 48,3 \\
\hline 11 & Ind $-\mathrm{CH}=\mathrm{N}$ & $\mathrm{H}$ & $\mathrm{H}$ & $\mathrm{OCH}_{2} \mathrm{O}$ & 45 & 46 \\
\hline 12 & $\mathrm{H}$ & $\mathrm{OCOCH}_{3}$ & $\mathrm{H}$ & $\mathrm{OCH}_{2} \mathrm{O}$ & 45 & 0 \\
\hline 13 & $\mathrm{H}$ & $\mathrm{H}$ & $\mathrm{OCOCH}_{3}$ & $\mathrm{OCH}_{2} \mathrm{O}$ & 45 & 59 \\
\hline Cha & lepina & & & & 55,5 & $\mathrm{IC}_{50}$ \\
\hline
\end{tabular}


Estudos de cristalização da gGAPDH na presença desses inibidores tem sido realizada rotineiramente, entretanto sem resultados positivos até o presente momento.

Na tentativa de criar modelos de interação entre esses novos derivados e a enzima gGAPDH, optou-se por realizar estudos de modelagem molecular utilizando a técnica de "docking" (acoplamento) que serão discutidos no capítulo IV

\subsection{2- Derivados de Nucleosídeos}

Uma vez que tanto o $T$. cruzi quanto o ser humano possuem a enzima GAPDH, a questão da seletividade torna-se bastante importante durante 0 planejamento de inibidores. Motivado por essa questão o Prof. Dr. Marcus Mandolesi de Sá da Universidade Federal de Santa Catarina vem sintetizando derivados de nucelosídeos que devem se ligar ao sítio do $\mathrm{NAD}^{+}$, cofator essencial para a atividade da gGAPDH [Sa et al., 2002]. Essa estratégia visa explorar diferenças estruturais entre a enzima humana e do parasita na região de ligação do cofator [Verlinde et al., 1994; Calenbergh et al., 1995], propiciando assim o desenvolvimento de inibidores seletivos da gGAPDH de T. cruzi. A tabela 2 apresenta compostos chave no entendimento das relações estrutura-atividade desses compostos e ilustra o trabalho desenvolvido pelo Prof. Dr. Marcus Mandolesi de Sá. 
Tabela 2- Resultados obtidos nos testes in vitro de derivados de nucleosídeos frente a enzima gGAPDH de $T$. cruzi

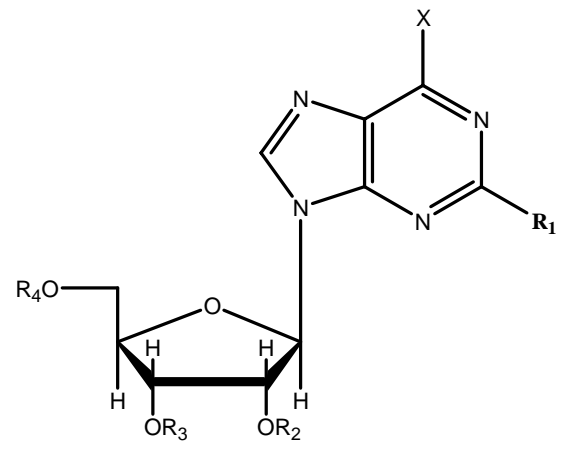

\begin{tabular}{cccccccc}
\hline \hline código & $\mathbf{X}$ & $\mathbf{R}_{\mathbf{1}}$ & $\mathbf{R}_{\mathbf{2}}$ & $\mathbf{R}_{\mathbf{3}}$ & $\mathbf{R}_{\mathbf{4}}$ & Inibição & concentração \\
\hline \hline $\mathbf{1 4}$ & $\mathrm{SH}$ & $\mathrm{H}$ & $\mathrm{PhCO}$ & $\mathrm{PhCO}$ & $\mathrm{PhCO}$ & $50 \%$ & $85 \mu \mathrm{M}$ \\
$\mathbf{1 5}$ & $\mathrm{OH}$ & $\mathrm{H}$ & $\mathrm{PhCO}$ & $\mathrm{PhCO}$ & $\mathrm{PhCO}$ & $50 \%$ & $172 \mu \mathrm{M}$ \\
$\mathbf{1 6}$ & $\mathrm{OH}$ & $\mathrm{H}$ & $\mathrm{ArCO}$ & $\mathrm{ArCO}$ & $\mathrm{ArCO}$ & $50 \%$ & $95 \mu \mathrm{M}$ \\
$\mathbf{1 7}$ & $\mathrm{OH}$ & $\mathrm{PhCONH}$ & $\mathrm{PhCO}$ & $\mathrm{PhCO}$ & $\mathrm{PhCO}$ & $23 \%$ & $140 \mu \mathrm{M}$ \\
$\mathbf{1 8}$ & $\mathrm{OH}$ & $\mathrm{NH}_{2}$ & $\mathrm{PhCO}$ & $\mathrm{PhCO}$ & $\mathrm{PhCO}$ & $50 \%$ & $>340 \mu \mathrm{M}$ \\
$\mathbf{1 9}$ & $\mathrm{OH}$ & $\mathrm{H}$ & $\mathrm{PhCH}_{2}$ & $\mathrm{PhCH}_{2}$ & $\mathrm{PhCH}_{2}$ & $10 \%$ & $186 \mu \mathrm{M}$ \\
$\mathbf{2 0}$ & $\mathrm{SH}$ & $\mathrm{H}$ & $\mathrm{CH}_{3} \mathrm{CCO}$ & $\mathrm{CH}_{3} \mathrm{CCO}$ & $\mathrm{CH}_{3} \mathrm{CCO}$ & $0 \%$ & $244 \mu \mathrm{M}$ \\
$\mathbf{2 1}$ & $\mathrm{OH}$ & $\mathrm{H}$ & $\mathrm{CH}_{3} \mathrm{CCO}$ & $\mathrm{CH}_{3} \mathrm{CCO}$ & $\mathrm{CH}_{3} \mathrm{CCO}$ & $0 \%$ & $380 \mu \mathrm{M}$ \\
\hline \hline
\end{tabular}

${ }^{*} \mathrm{ArCO}=3,5-\left(\mathrm{NO}_{2}\right)_{2} \mathrm{PhCO}$

Comparando-se os resultados dos ensaios de inibição dos compostos 14 e 15 com os resultados de $\mathbf{2 0}$ e $\mathbf{2 1}$ nota-se que grupos volumosos e hidrofóbicos nas posições $R_{2}, R_{3}$ e $R_{4}$ favorecem a interação com a enzima.

Por outro lado, substituições na posição $R_{1}$ levam a uma redução na atividade inibitória desses compostos, como pode ser observado para os compostos 17 e 18.

Esses resultados nos levam a acreditar que esta posição deva estar prensada em uma região onde as exigências estéricas são bastante restritas, ou seja, grupos maiores que hidrogênio não se acomodam na posição adequada para realizarem interações significativas com a enzima. 
A substituição da hidroxila na posição $X$ por um grupo sulfidrila (compostos 14 e 15 respectivamente), também causa uma queda na atividade inibitória desses compostos. Provavelmente isso está relacionado com a maior capacidade do grupo hidroxila de realizar ligações de hidrogênio.

\subsection{3- Derivados bisfosfonados com atividade tripanocida}

Uma terceira classe de compostos que se demonstraram ativos contra a enzima gGAPDH é composta por uma série de compostos bisfosfonados, alguns dos quais apresentam atividade inibidora da enzima farnesil-pirofosfato sintase [Montalvetti et al., 2001]. Esse compostos fazem parte de um biblioteca combinatória disponibilizada pelo prof. Eric Oldfield da Universidade de Urbana Campaign, Ilinóis, EUA para serem testados contra a enzima gGAPDH de $T$ cruzi.

Há relatos na literatura da atividade tripanomicida de alguns desses compostos [Martin et al., 2001] entre eles, alguns apresentam $\mathrm{IC}_{50}$ de ordem nanomolar quando testados in vivo contra a forma amastigota do T. cruzi (tabela 3) (Oldfield - comunicação pessoal). 
Tabela 3- Derivados bisfosfonados sintetizados no laboratório do prof Eric. Oldfield em Urbana Campaign, Ilinóis, que apresentaram atividade inibitória do crescimento de $T$. cruzi in vivo

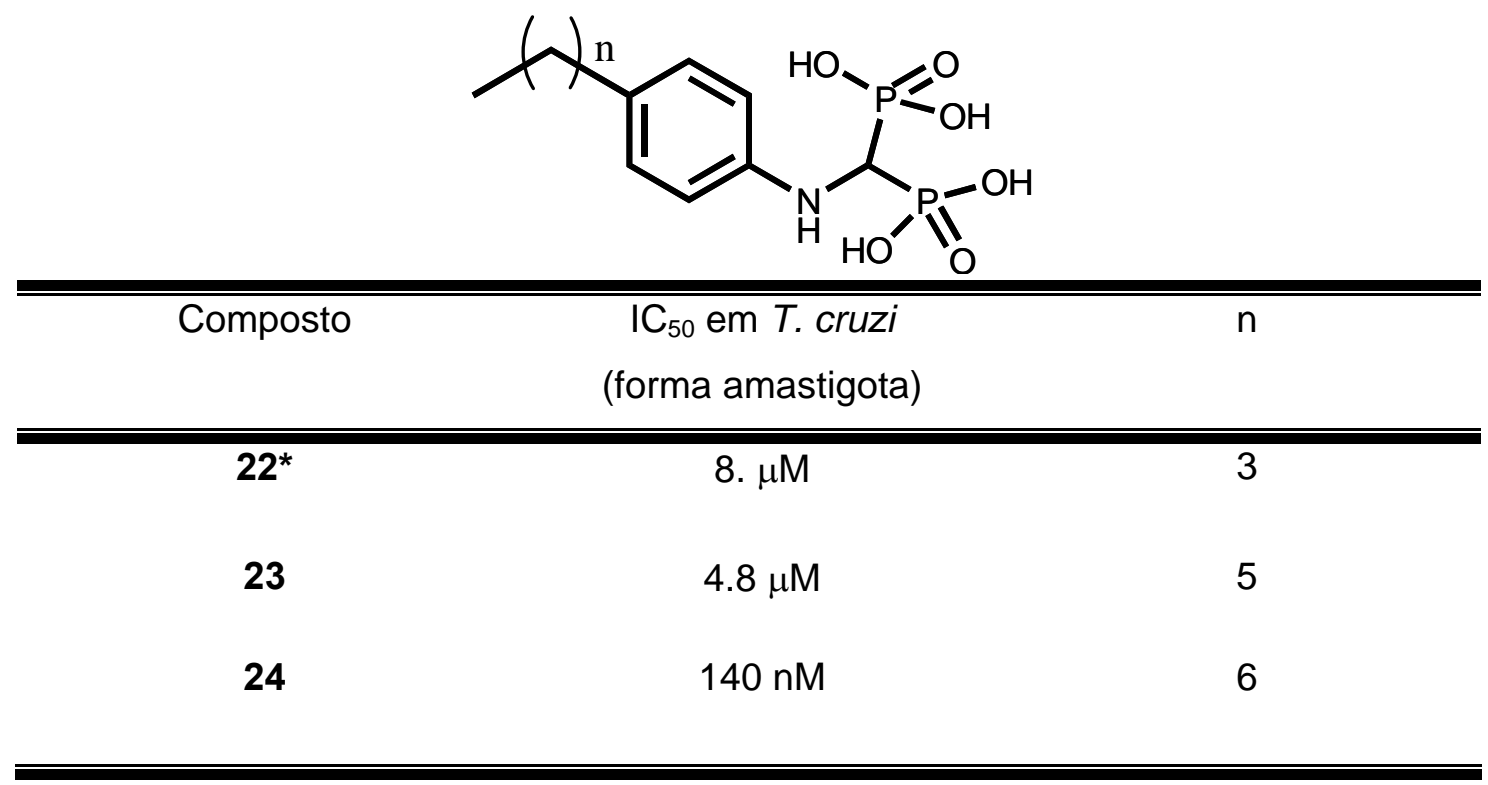

*presente na biblioteca de 69 compostos testados inicialmente contra gGAPDH

Inicialmente 69 compostos, representativos da coleção combinatória, foram testados contra a enzima gGAPDH. Dentre eles, somente dois apresentaram atividade inibitória da enzima (Figura 4).

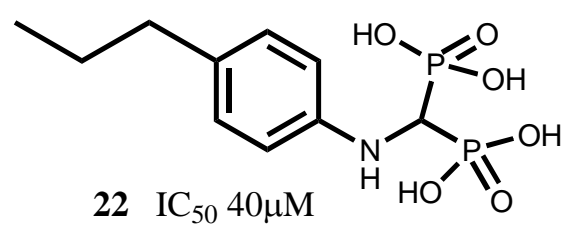<smiles>CCCCCCCCCCCC(P(=O)(O)O)P(=O)(O)O</smiles>

Figura 4- Derivados bifosfonados, provenientes de uma biblioteca de 69 compostos, que apresentaram atividade inibitória contra a enzima gGAPDH.

O composto 22 apresenta um valor de $I_{50}$ comparável a alguns dos melhores inibidores testados em nosso laboratório (chalepina $\left(I_{50}=55,5 \mathrm{M}\right)$ e derivado hidrogenado de ácido anacárdico $\left.\left(\mathrm{IC}_{50}=28 \mathrm{M}\right)\right)$. Além disso, esse inibidor apresenta grupos fosfatos que poderiam interagir nos sítios de ligação do fosfato inorgânico (Pi) e do substrato (Ps) descritos em maior detalhe no capítulo III. 
Devido ao número restrito de inibidores bisfosfonados não é possível, ainda, traçar relações estrutura atividade, contudo optou-se por realizar estudos de modelagem molecular que nos permitissem criar modelos de interação plausíveis entre o composto 22 e a enzima como forma de sugerir novos derivados bisfosfonados que pudessem exibir melhor perfil de inibição frente a enzima gGAPDH de $T$. cruzi. Esses estudos serão abordados no capítulo IV

\section{4- Referências}

Borman, S. (2002) "Combinatorial chemistry" Chem. Eng. News, 80 (45), 43-57. Calembergh, S. V.; Verlinde, C. L. M. J.; Soenens, J.; De Breuyn, A.; Callens, M.; Blaton, N. M.; Peters, O. M.; Rozenski, J.; Hol, W. G. J.; Herdewij, P. (1995). “Synthesis and Structure-Activity Relationships of analogues of 2'-Deoxi-2'-(3methoxybenzamido) adenosine, a Selective Inhibitor of Trypanosomal Glycosomal Glyceraldehyde-3-phosphate Dehidrogenase.", J. Med. Chem. 38: 3838-3849

Class, S. (2002) "Pharma overview" Chem. Eng. News, 80 (48), 39-49.

Hannaert, V., Opperdoes, F. R., Michels, P. A. M., (1995) "Glycosomal Glyceraldehide-3-phosphate Dehidrogenase form Trypanosoma brucei and Trypanosoma cruzi - Expression in Escherichia coli, Purification andc haracterization of the enzymes" Prot. Expr. Purif., 6(3), 244-250

Hostetmann, K., Queiróz, E. F., Vieira, P. C. (2003) "Princípios ativos de plantas superiores" Série de textos da escola de verão em química vol. IV, EduFSCar, $152 p$

Martin M. B.; Grimley, J. S.; Lewis, J. C. ; Heath H. T.; Bailey, B. N.; Kendrick, H.; Vardley, V.; Caldera, A.; Lira, R.; Urbina, J. A.; Moreno, S. N. J.; do Campo, R.; Croft, S. I.; Oldfield, E. (2001) "Biphosphonates inhit the growth of Trypanosoma cruzi, Leishmania donovani, Toxoplasma gondii and Plasmodium falciparum: A potential route to chemotherapy", J. Med. Chem., 44, 909-916

Montalvetti, A., Bailey, B. N., Michel, M. B., Severin, G. W., Oldfield, E. Docampo, R., (2001) "Biphosphonates are potent inhibitors of Trypanosoma cruzi farnesyl pyrophosphate synthase" J. Biol. Chem., 276(36), 33930-33937 
Moraes VRD, Tomazela DM, Ferracin RJ, Garcia CF, Sannomiya M, Soriano MDC, da Silva MFDF, Vieira PC, Fernandes JB, Rodrigues E, Magalhaes EG, Magalhaes AF, Pimenta EF, de Souza DHF, Oliva G (2003) "Enzymatic inhibition studies of selected flavonoids and chemosystematic significance of polymethoxylated flavonoids and quinoline alkaloids in Neoraputia (Rutaceae)" J. Braz. Chem. Soc. 14 (3): 380-387

Newman, D. J., Cragg, G. M., Snader, K. M. (2003) "Natural Products as Sources of New Drugs over the Period 1981-2002" J. Nat. Prod. , 66, 1022-1037

Paramashivappa, R., Kumar, P. P., Vithayathil, P. J., Rao, A. S. (2001) "Novel Method for Isolation of Major Phenolic Constituents from Cashew (Anacardium occidentale L.) Nut Shell Liquid", J. Agric. Food Chem., 49, 2548-2551.

Pavão F., Castilho M.S., Pupo M.T., Dias R.L.A., Correa A.G., Fernandes J.B., da Silva M.F.G.F., Mafezoli J., Vieira .PC., Oliva G. (2002) "Structure of Trypanosoma cruzi glycosomal glyceraldehyde-3-phosphate dehydrogenase complexed with chalepin, a natural product inhibitor, at 1.95 angstrom resolution." FEBS Lett. 520(1-3),13-17.

Sa, M. M., Silveira, G. P., Castilho, M. S., Pavão, F. Oliva, G. (2002) "Synthesis of acylated nucleosides and ribonic-1-4-lactones as inhibitors of trypanosomal glyceraldehydes-3-phosphate dehydrogenase (gGAPDH)" ARKIVOC, 8, 112124

Souza, D.H.F., Garrat, R.C., Araújo, A.P.U., Guimarães, B.G., Jesus, W.D.P., Michels, P.A.M., Hannaert, V. and Oliva, G. (1998). "Trypanosoma cruzi Glycosomal Glyceraldehyde-3-Phosphate Dehydrogenase: Structure, Catalytic Mechanism and Targeted Inhibitor Design.", FEBS Lett. 424,131-135.

Tomazela, D. M.; Pupo, M. T.; Passador, E. A. P.; Silva, M. F. G. F.; Vieira, P. C.; Fernandes, J. B.; Rodrigues F.O., E.; Oliva, G.; Pirani, J. R. (2000) "Pyrano chalcones and flavone from Neoraputia magnifica and their Trypanosoma cruzi glicosomal glyceraldehyde-3-phosphate dehydrogenase-inhibitory activity" Phytochem., 55, 643.

Verlinde, C.L.M.J., Callens, M., Van Calenbergh S., Van Aerschot A., Heredewijn, Hannaert V., Michels P.A.M., Opperdoes F.R., Hol W.G.J. , (1994). "Selective Inhibition of Trypanosomal Glyceraldehyde-3-phosphate Dehydrogenase by Protein Structure-based Design: Toward New Drugs for the Treatment of Sleeping Sickness.", J. Mol. Chem. 37: 3605-361.

Vieira, P. C., Mafezoli, J., Pupo, M. T., Fernandes, J. B., Silva, M. F. G. F, Albuquerque, S., Oliva, G., Pavão, F. (2001) "Strategies for the isolation and 
identification of trypanocidal compounds from the Rutales" Pure Appl. Chem., 73, 617-622. 


\section{Capítulo III- Co-cristalização e}

\section{refinamento}

\section{1- Introdução}

A cristalização de macromoléculas biológicas é considerada uma técnica de tentativa e erro por se tratar de um processo dependente de uma série de variáveis (temperatura, pH, agente precipitante, força iônica, etc) [Drenth, 1995].

O processo de formação dos cristais ocorre a partir de uma solução supersaturada de proteína sendo a velocidade com que se atinge esse estado essencial para formação de cristais, microcristais ou precipitado amorfo. Devido ao fato da grande maioria das proteínas serem muito instáveis e rapidamente perderem sua estrutura nativa, os cristais de proteínas crescem geralmente em 
condições toleráveis de temperatura $\left(4^{\circ} \mathrm{C}-25^{\circ} \mathrm{C}\right)$, força iônica e com pequenas faixas de variação $\mathrm{pH}$, próximas ao pH fisiológico.

Após a determinação das condições que levam a formação de cristais ou microcristais, uma serie de experimentos é realizada de forma a otimizar o processo de formação de cristais.

Existem diversos métodos de cristalização de proteínas, os quais são utilizados de acordo com o tipo da amostra e com as condições do laboratório. O método de Difusão de Vapor é um processo de equilíbrio entre duas soluções através da fase de vapor num meio fechado. A solução menos concentrada perde seu solvente volátil até que os potenciais químicos das duas soluções se igualem. Para se poder controlar a concentração final da solução de proteína, realizamos o experimento de difusão de vapor com um volume pequeno de proteína contra um volume grande de solução precipitante. Assim, uma gota contendo a proteína a ser cristalizada, com o tampão, agentes precipitantes e aditivos, é equilibrada contra um reservatório contendo uma solução do agente precipitante a uma concentração mais alta que a da gota.

O método de difusão de vapor pode ser conduzido de duas maneiras principais: Gota suspensa (Hanging drop) no qual a gota contendo a proteína de interesse é colocada sobre uma lamínula de vidro siliconizada e, posteriormente fixada com graxa na parte superior do poço, de forma que a gota fique interna ao reservatório (ver Figura 1a). Gota sentada (Sitting drop): nesse caso a solução contendo a proteína é colocada em um suporte que está fixado dentro do poço, esse é posteriormente fechado hermeticamente com lamínula de vidro, como se observa na Figura 1b. 


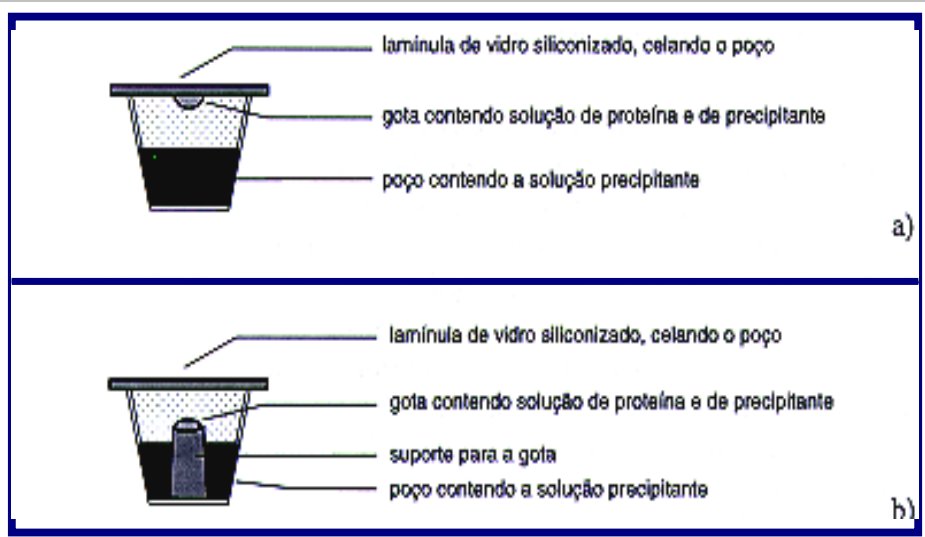

Figura 1- . Representação esquemática da técnica de gota pendurada (a) e de gota sentada (b).

Uma descrição mais detalhada das técnicas e parâmetros envolvidos na cristalização de macromoléculas pode ser encontrada em Drenth, J. (1995) e Ducruix \& Giegé (1992).

No experimento de co-cristalização um dado inibidor ou ligante é adicionado à gota de cristalização contendo a solução de proteína, espera-se portanto que aquele se ligue a esta formando um complexo, que possa cristalizar adequadamente.

Os inibidores podem ser classificados, de uma maneira geral, em duas classes distintas; reversíveis e irreversíveis. Os compostos pertencentes a essa última classe ligam-se covalentemente à proteína.

Entender o balanço das interações entre substrato-macromolécula (inibidormacromolécula) pode ser de grande valia quando se pretende inibir uma enzima em particular. O estudo do mecanismo catalítico da enzima é essencial para esse propósito.

O mecanismo catalítico proposto da enzima gGAPDH já foi extensivamente estudado [Segal \& Boyer, 1953; Harrigan \& Trentham, 1973; Duggleby \& Dennis, 1974] e as diversas etapas do seu processo catalítico podem ser resumidas da seguinte forma (Figura 2); (i) ataque nucleofílico da cisteína ativada à carbonila do substrato (G3P), (ii) transferência de um hidreto do intermetiário tio-hemicetal para o cofator $\left(\mathrm{NAD}^{+}\right)$levando a formação da tioenzima, (iii) fosforilação do tioéster por 
ataque nucleofílico de um fosfato inorgânico à carbonila do grupo tioacil, (iv) formação e subseqüente saída do produto 1,3-bisfosfoglicerato.

Corbier e colaboradores [Corbier et al., 1994] propuseram que o grupo fosfato do substrato (G3P) interage primeiramente no sítio do fosfato inorgânico (sítio Pi) e, num segundo momento, com o sítio do fosfato orgânico (sítio Ps). A mudança conformacional que leva o substrato do sítio Pi ao sítio PS é conhecida como "flip-flop", entretanto até o presente momento não existe evidência direta de como ela ocorra.

Chama atenção, entretanto, a falta de estudos sobre a reação inversa (conversão de 1,3-BPG em G3P).

Essa ausência de informações torna o desenvolvimento de inibidores análogos do produto bastante difícil e explica, do ponto de vista mecanístico, porque os inibidores mais potentes da GAPDH, já descritos, são análogos do cofator [Aronov et al., 1999; Bressi et al., 2001]. 


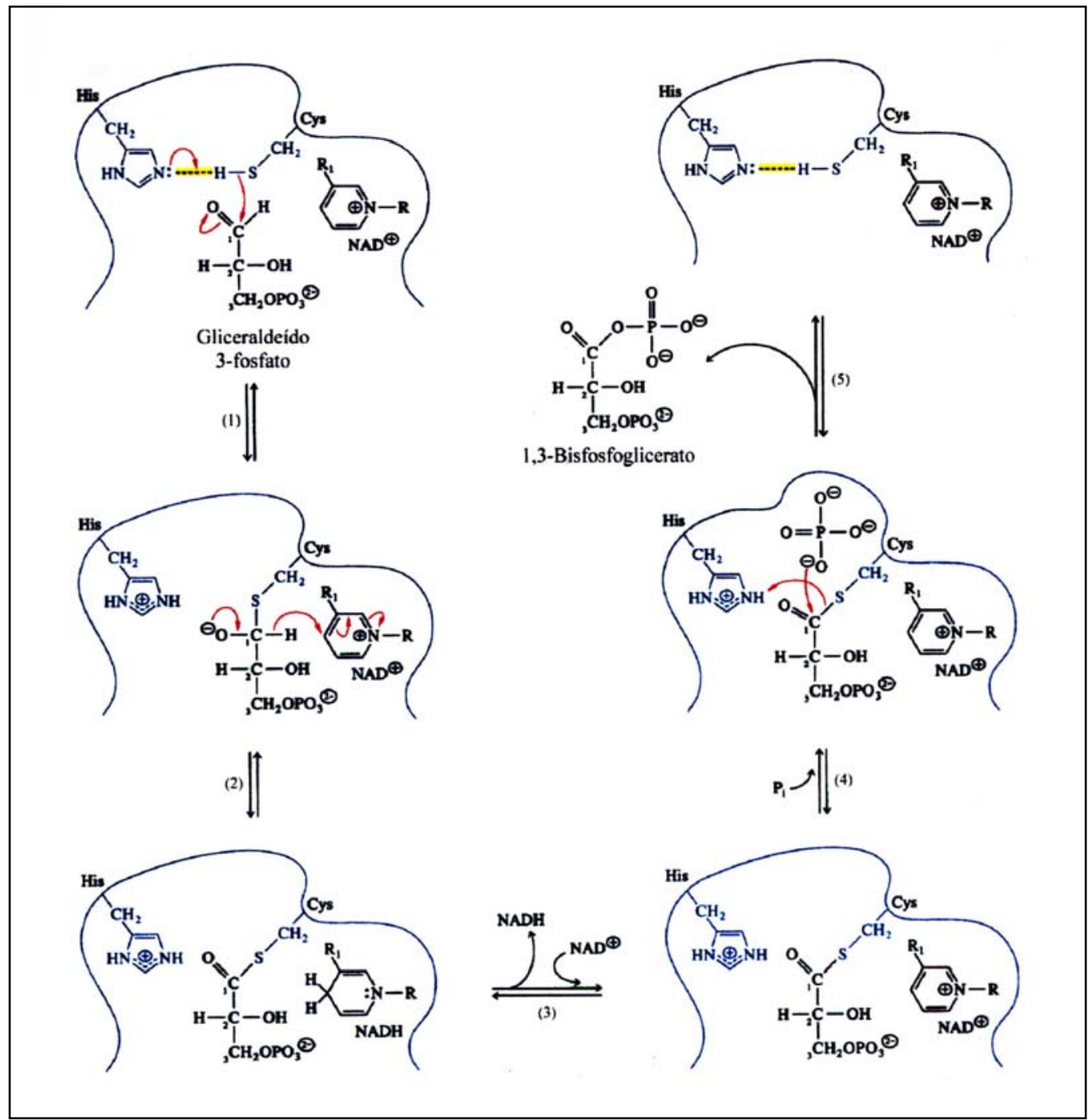

Figura 2- mecanismo catalítico proposto da enzima GAPDH. 1) Grupo sulfidrila da cisteína ionizada ataca o $\mathrm{C} 1$ do G3P, resultando na formação do complexo hemitioacetal; 2) íon hidreto do complexo reduz o $\mathrm{NAD}^{+}$, formando o intermediário tioéster; 3) liberação do NADH e entrada de outra molécula de $\mathrm{NAD}^{+} ; 4$ ) fosfato inorgânico ataca o grupo carbonila do intermediário tioéster, formando o produto 1,3 -bisfosfoglicerato; 5) dissociação do produto. (figura extraída de Moran et al., 1994; cap. 15).

Numa tentativa de suprir essa lacuna, o grupo do Professor Jacques Périé, do laboratório Chimie Organique Biologique da Universidade Paul Sabatier, Toulouse, vem sistematicamente sintetizando análogos do 1,3-bisfosfoglicerato (1,3-BPG) e testando in vitro estes análogos contra a enzima GAPDH dos parasitas Leishmania sp (causador da leishmaniose), Trypanosoma brucei (causador da doença do sono ou tripanosomíase africana) e Trypanosoma cruzi (doença de Chagas). 


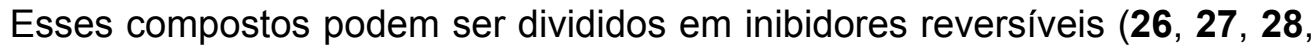
29 e 30) e irreversíveis $(31,32,33$ e 34) (Tabela 1).

A seguir serão discutidos os estudos de co-cristalização da gGAPDH com os inibidores reversíveis e irreversíveis fornecidos pelo prof. Périé.

Tabela 1- Inibidores reversíveis e irreversíveis fornecidos pelo Prof. Dr. Jacques Périé, da Univesité Paul Sabatier, Toulouse, França para estudos de cocristalização

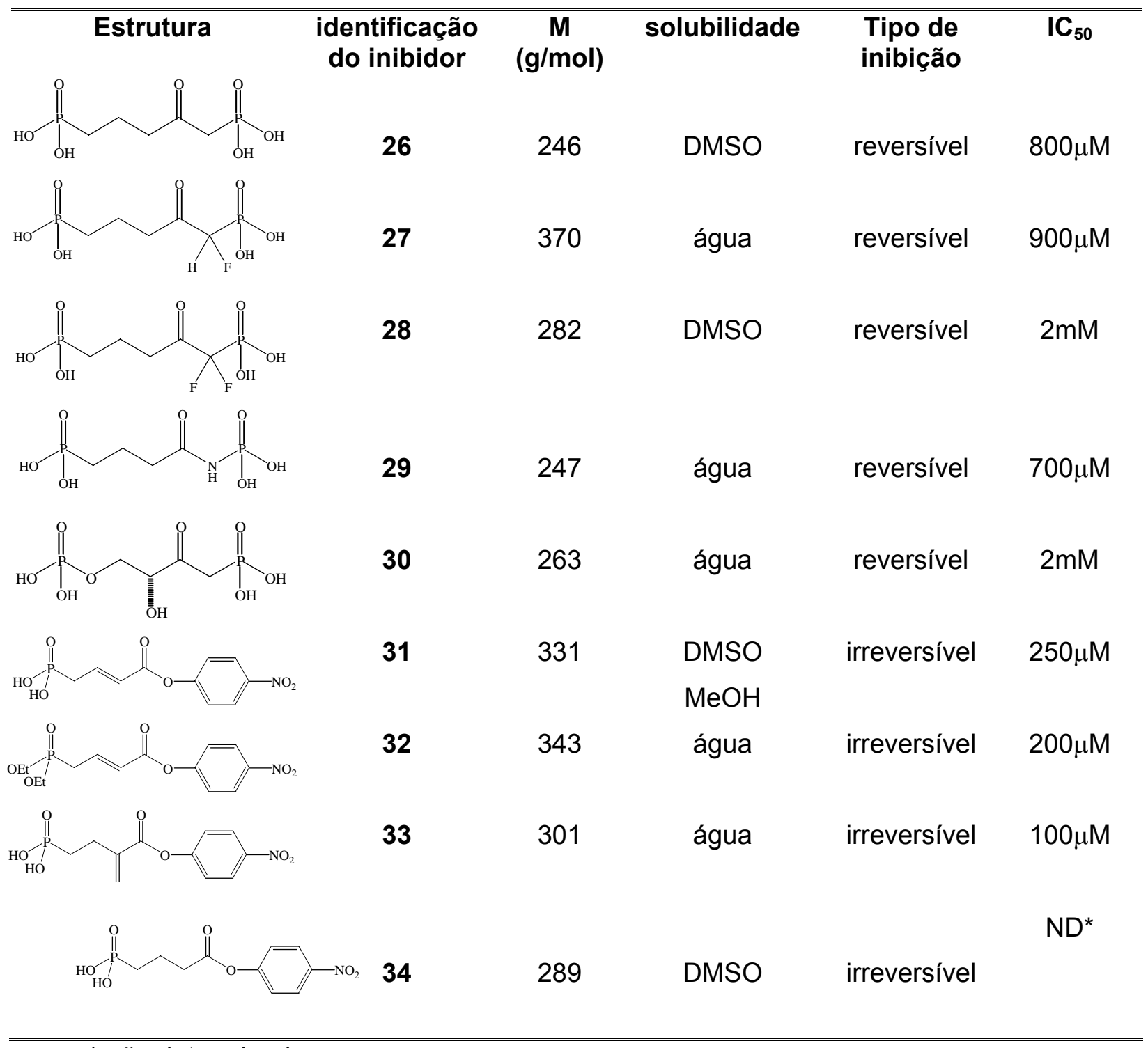

${ }^{*}$ não determinado 


\section{2- Co-cristalização da gGAPDH com derivados de 1,3-BPG}

Como ponto de partida para a co-cristalização dos análogos de 1,3bisfosfoglicerato com a enzima gGAPDH, foram utilizadas condições de cristalização próximas a da forma nativa da enzima, ou seja, tampão $0,1 \mathrm{M}$ de cacodilato de sódio com $0,1 \mathrm{M}$ de acetato de cálcio, 18\% de PEG $800,1 \mathrm{mM}$ de EDTA e 1mM de azida sódica [Souza et al., 1998]. Os experimentos foram realizados em uma sala com temperatura controlada $\left(18^{\circ} \mathrm{C}\right)$ utilizando o método de gota suspensa. A solução de proteína, na qual os derivados de 1,3-bisfosfoglicerato foram adicionados, foi incubada em banho de gelo por 1 hora, centrifugada a $15000 \mathrm{~g}$ por 5 minutos e o sobrenadante, obtido a partir desse processo, utilizado para os experimentos de co-cristalização.

O volume final das gotas foi de $10 \mu \mathrm{L}(5 \mu \mathrm{L}$ da solução de proteína+ inibidor e $5 \mu \mathrm{L}$ da solução do poço).

A fim de reduzir a heterogeneidade na condição de cristalização é importante otimizar o número de moléculas complexadas versus não-complexadas, para tanto é recomendável realizar experimentos à diferentes razões proteínaligante, tipicamente 1:1 até 1:20 [Ducruix \& Giegé, 1992].

Nos experimentos descritos nesse trabalho, utilizou-se uma razão ainda maior, aproximadamente 1:60 para os inibidores solúveis em água $(\mathbf{2 7}, \mathbf{2 9}, \mathbf{3 0}, \mathbf{3 2}$, 33) e 1:30 para inibidores solúveis em acetonitrila $(\mathbf{2 6}, \mathbf{2 8}, \mathbf{3 1}, \mathbf{3 4})$.

Inicialmente, os experimentos de cristalização foram realizados com a proteína na concentração de $14 \mathrm{mg} / \mathrm{mL}$, variando-se $\mathrm{o} \mathrm{pH}$ da solução de cristalização de 6.9 à 7.5 .

Esses experimentos resultaram apenas na formação de precipitado amorfo ou na cristalização da enzima na sua forma nativa.

A formação de precipitado amorfo pode estar relacionada com concentrações elevadas de proteína que estariam atingindo a condição de 
supersaturação muito rapidamente. A fim de minimizar esse problema os experimentos subseqüentes foram realizados com proteína mais diluída(8,0-12,0 $\mathrm{mg} / \mathrm{mL})$.

A cristalização da enzima apenas na sua forma nativa por sua vez pode estar associada a fatores intrínsecos da condição de cristalização. O tampão cacodilato, utilizado nos experimentos de cristalização pode reagir com o DTT (agente redutor, utilizado no tampão de purificação) formando uma espécie altamente reativa que ataca cisteínas livres na proteína (Figura 3) [Maignan, 1998]

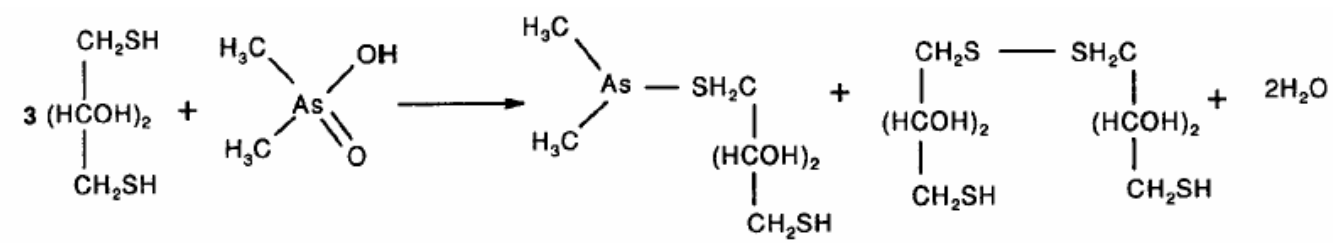

(2)

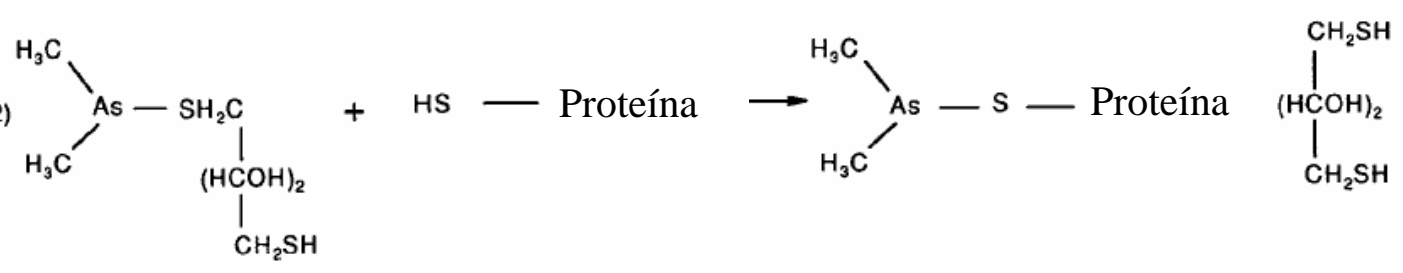

Figura 3- Mecanismo de formação da espécie reativa que pode atacar a cisteína catalítica da gGAPDH. Figura adaptada de Maignan (1998)

A fim de prevenir a reação entre o intermediário reativo e a cisteína catalítica 166, o reagente DTT foi eliminado do tampão de purificação.

Experimentos subseqüentes, outra vez variando-se apenas o pH da solução de cristalização e utilizando-se a enzima na concentração de $9,0 \mathrm{mg} / \mathrm{ml}$ resultaram na formação de pequenos cristais achatados (Figura 4), em pH 7,1 e 7,5, após um período de aproximadamente duas semanas.

Os cristais obtidos correspondem a possíveis complexos da enzima gGAPDH com os inibidores 27, 30 e 31. 

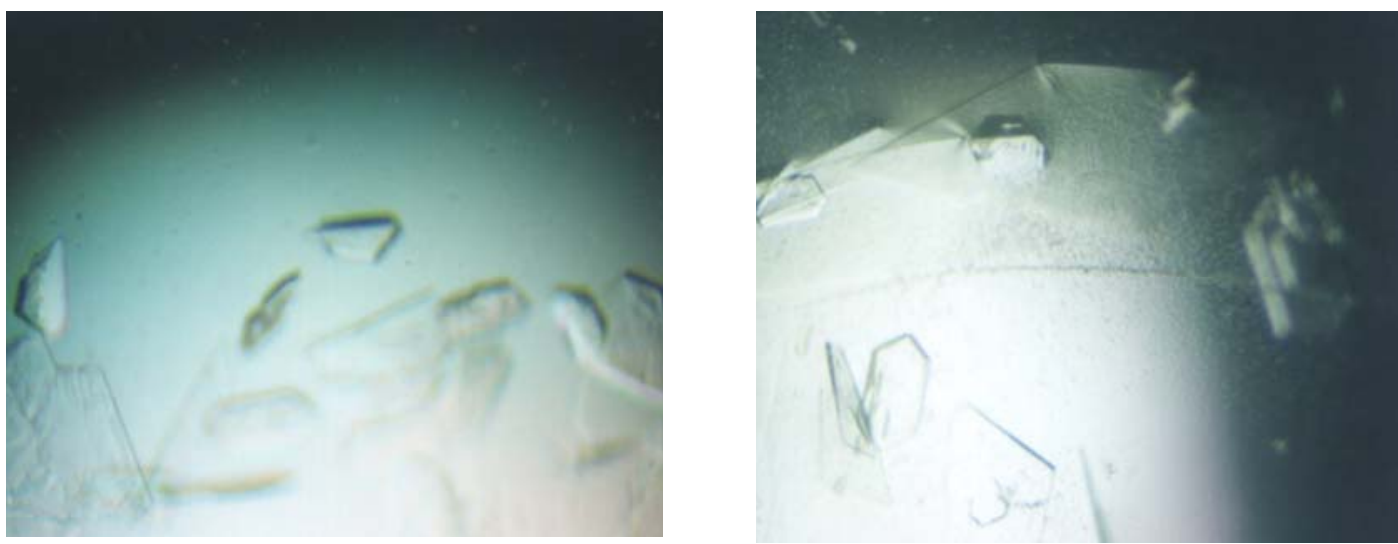

Figura 4- (Direita) Cristais do possível complexo gGAPDH-30. (Esquerda) Cristais do possível complexo gGAPDH-31.

Nos experimentos realizados com enzima a $10,5 \mathrm{mg} / \mathrm{mL}$ obteve-se cristais, pequenos e de formato achatado, bastante semelhantes aqueles mostrados na figura 4, relativos aos inibidores irreversíveis 33 e 34 .

Devido à baixa qualidade dos cristais obtidos, a melhor opção para coleta dos dados de difração de raios $X$ consiste na utilização de fontes de luz síncroton. Por essa razão, todas as coletas de dados foram realizadas no Laboratório Nacional de Luz Síncroton (LNLS) na cidade de Campinas-SP [Polikarpov et al., 1998].

A fim de facilitar o seu transporte para o LNLS, os cristais obtidos foram montados em loops de nylon, resfriados num fluxo de nitrogênio líquido e armazenados num dewar. 


\section{3- Coleta de dados e processamento dos dados de difração de cristais de gGAPDH em complexo com análogos de 1,3-BPG}

As coletas foram feitas à temperatura de $100 \mathrm{~K}$ para minimizar os danos sofridos pelo cristal devido ao uso dos raios $X$ (radiação ionizante). Este tipo de dano por radiação causa uma diminuição na intensidade dos pontos de difração e é dependente tanto da dose de raios $\mathrm{X}$ recebida pelo cristal quanto do tempo de exposição.

Esse dano ocorre pois quando os fótons de raios $\mathrm{X}$ incidem sobre o cristal, além de difração ocorre também a formação de radicais livres os quais, devido ao alto conteúdo de solvente em cristais de proteína, difundem e reagem ao longo de toda a rede cristalina, destruindo sua ordem interna. À temperatura de $100 \mathrm{~K}$, a difusão destes radicais através da rede cristalina diminui muito, aumentando o tempo de "vida" do cristal, mantendo a qualidade do padrão de difração por muito mais tempo.

A solução crioprotetora utilizada em nossos experimentos é aquela descrita por Guimarães [Guimarães, 1998], consistindo basicamente na adição de $20 \%$ de PEG 400 à composição da solução de cristalização. Os cristais foram deixados submersos nesta solução por cerca de 10 segundos e então rapidamente colocados sob um fluxo de nitrogênio à $100 \mathrm{~K}$.

O método utilizado para a coleta de dados é o de rotação-oscilação [Arndt et al., 1977], onde o cristal sofre pequenas e sucessivas oscilações em torno do eixo perpendicular à direção do feixe de raios $\mathrm{X}$ incidentes.

A figura 5 mostra um padrão de difração típico da gGAPDH 


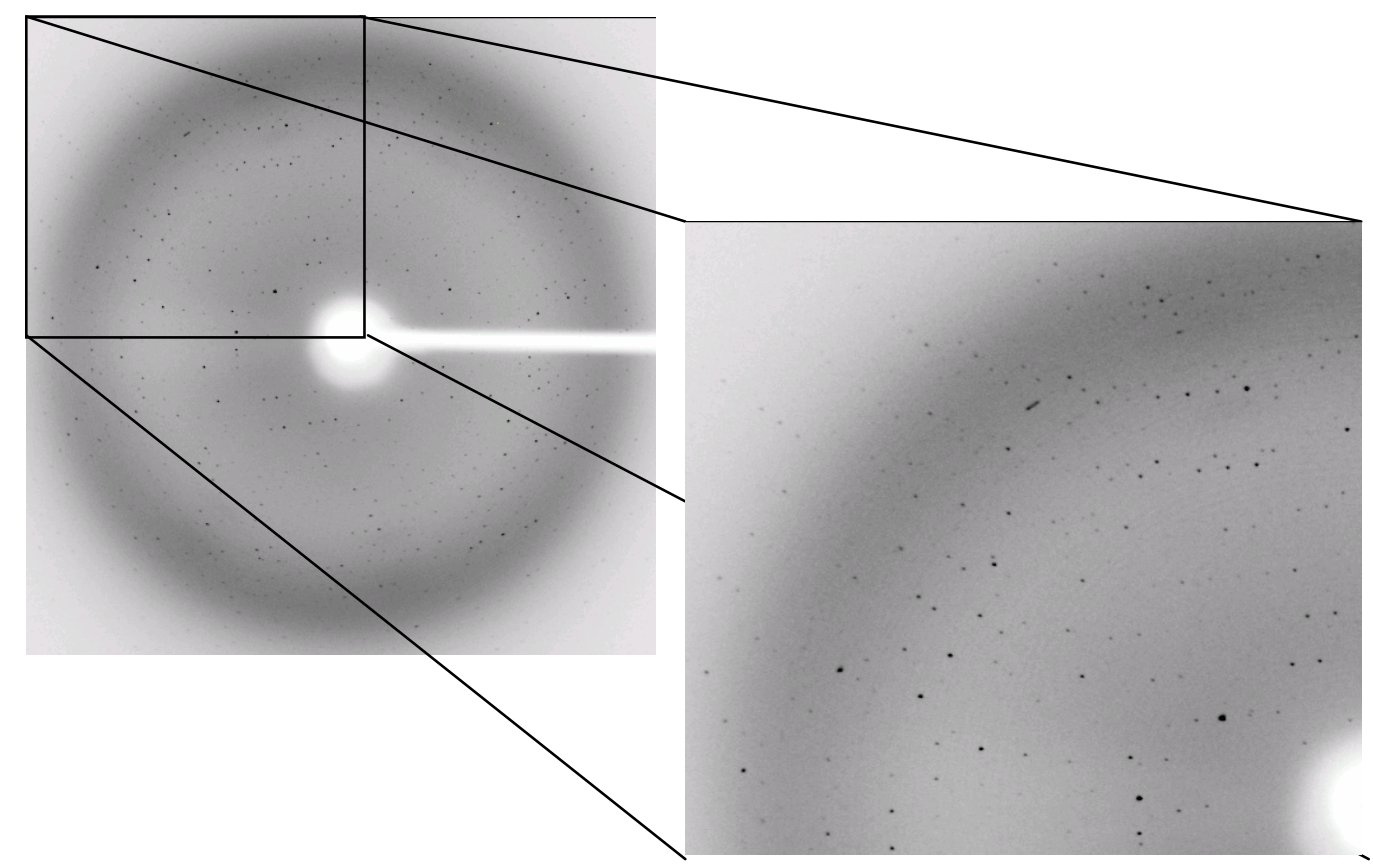

Figura 5- Padrão de difração do cristal gGAPDH-30. À direita temos uma ampliação da área demarcada na figura da esquerda.

A coleta automática foi realizada com um passo angular de $1^{\circ}$. O número total de imagens coletadas para cada cristal foi de 110-120 imagens.

A auto-indexação da primeira imagem de difração de cada conjunto de dados foi realizada pelo programa DENZO [Otwinowsky \& Minor, 1997].

Nesse método calcula-se a distorção da cela unitária, em relação à cela triclínica para cada uma das 14 possíveis redes de Bravais. Devido a pequena distorção do sistema cristalino monoclínico, decidiu-se trabalhar com a hipótese de que os cristais da gGAPH em complexo com análogos de 1,3-BPG pertenciam a esse sistema cristalino ${ }^{\star}$. Essa escolha revelou-se correta, como pôde ser verificado na promediação dos dados.

A avaliação da mosaicidade do cristal foi feita comparando-se visualmente as predições das reflexões com algumas imagens experimentais e ajustando

\footnotetext{
* A gGAPDH nativa também pertence a esse sistema cristalino, mais precisamente ao grupo espacial $\mathrm{P} 2$
} 
sucessivamente o valor da mosaicidade de forma a não excluir reflexões experimentalmente visíveis.

Os valores de mosaicidade bem como alguns parâmetros utilizados durante o processo de integração estão apresentados nas tabelas 2, 3, 4 e 5. 
Tabela 2- parâmetros utilizados durante a integração do conjunto de dados gGAPDH-27

\begin{tabular}{|l|l|}
\hline simetria & Monoclínica primitiva \\
\hline Faixa de resolução & $20-2,3 \AA$ \\
\hline Profile fitting & $25,0 \mathrm{~mm}$ \\
\hline Tamanho da caixa de integração: & $2,0 \times 2,0 \mathrm{~mm}$ \\
\hline mosaicidade & $0,474^{\circ}$ \\
\hline
\end{tabular}

Tabela 3- parâmetros utilizados durante a integração do conjunto de dados gGAPDH-30

\begin{tabular}{|l|l|}
\hline simetria & Monoclínica primitiva \\
\hline Faixa de resolução & $8,0-1,94 \AA$ \\
\hline Profile fitting & $20,0 \mathrm{~mm}$ \\
\hline Tamanho da caixa de integração: & $2,4 \times 2,4 \mathrm{~mm}$ \\
\hline mosaicidade & $0,83^{\circ}$ \\
\hline
\end{tabular}

Tabela 4- parâmetros utilizados durante a integração do conjunto de dados gGAPDH-34

\begin{tabular}{|l|l|}
\hline simetria & Monoclínica primitiva \\
\hline Faixa de resolução & $20-2,23 \AA$ \\
\hline Profile fitting & $25,0 \mathrm{~mm}$ \\
\hline Tamanho da caixa de integração & $2,0 \times 2,0 \mathrm{~mm}$ \\
\hline mosaicidade & $1.0^{\circ}$ \\
\hline
\end{tabular}

Tabela 5- parâmetros utilizados durante a integração do conjunto de dados gGAPDH-33

\begin{tabular}{|l|l|}
\hline simetria & Monoclínica primitiva \\
\hline Faixa de resolução & $20-2,5 \AA$ \\
\hline Profile fitting & $25,0 \mathrm{~mm}$ \\
\hline Tamanho da caixa de integração & $2,0 \times 2,0 \mathrm{~mm}$ \\
\hline mosaicidade & $0,7^{\circ}$ \\
\hline
\end{tabular}


A etapa final do processamento se faz pelo escalonamento das imagens sucessivas e a adição das intensidades integradas das reflexões parcialmente medidas, bem como, a promediação final entre as reflexões equivalentes. Essas etapas estão implementadas no programa SCALEPACK [Otwinowsky \& Minor, 1997] e o resultado de sua aplicação aos conjuntos de dados coletados encontra-se na tabela 5 .

Todos os quatro conjuntos de dados coletados apresentam boa completeza, porém não difratam à alta resolução. Isso está associado principalmente a baixa qualidade dos cristais obtidos (pequenos e achatados).

Os parâmetros da cela unitária dos cristais gGAPDH-30 e gGAPDH-33 estão ligeiramente alterados com relação àqueles da gGAPDH nativa $(a=78.85 \AA, b=84.93 \AA, c=$

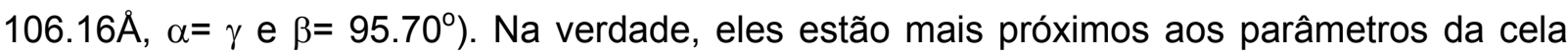
unitária do complexo chalepina-gGAPDH $(a=82.08 \AA, b=84.97 \AA, c=105.24 \AA, \alpha=\gamma$ e $\beta=$ $\left.96.32^{\circ}\right)$. No complexo chalepina-gGAPDH esses parâmetros são resultado da ausência do cofator NAD na estrutura cristalizada [Pavão et al., 2002].

O conjunto de dados gGAPDH-27, por sua vez, apresenta o ângulo $\beta$ bastante diferente daquele encontrado no complexo chalepina-gGAPDH ou na gGAPDH nativa.

Os valores refinados de mosaicidade são inferiores aos valores utilizados durante a integração dos dados (compare os valores de mosaicidade da tabela $6 \mathrm{com}$ os valores das tabelas 2, 3, 4 e 5), assegurando assim que o processo de integração das reflexões não excluiu reflexões parciais presentes nas imagens. 
Tabela 6- Parâmetros relacionados às coletas de dados e das redes cristalinas de vários cristais coletados, assim como a estatísticas do processamento.

\begin{tabular}{|c|c|c|c|c|c|c|c|}
\hline Cristal $^{1}$ & $\begin{array}{c}\text { Grupo } \\
\text { Espacial }\end{array}$ & $\begin{array}{c}\text { Parâmetros da Cela } \\
\text { Unitária } \\
\left(\alpha=\gamma=90^{\circ}\right)\end{array}$ & $\begin{array}{c}\text { Mosaicidade } \\
\left({ }^{0}\right)\end{array}$ & $\begin{array}{l}\mathrm{N}^{\circ} \mathrm{de} \\
\text { reflexões } \\
\text { totais }^{2}\end{array}$ & $\begin{array}{c}\text { Resolução } \\
\text { (A) }\end{array}$ & $\begin{array}{c}\mathbf{R}_{\text {MERGE }}{ }^{4} \\
(\%)\end{array}$ & $\begin{array}{c}\text { Completeza }^{5} \\
(\%)\end{array}$ \\
\hline gGAPDH-27 & P21 & $\begin{array}{ll}\text { - } & a=79,85 \AA \\
\text { - } & b=85,31 \AA \quad \\
\text { - } & c=107,05 \AA\end{array}$ & $0,45^{\circ}$ & $\begin{array}{l}116.865 \\
(46.460)\end{array}$ & $\begin{array}{c}2,5 \\
(2,56-2,50)\end{array}$ & $\begin{array}{c}16,6 \\
(37,5)\end{array}$ & $\begin{array}{c}95,7 \\
(97,7)\end{array}$ \\
\hline gGAPDH-30 & P21 & $\begin{array}{ll}\text { - } & a=81,76 \AA \\
\text { - } & b=85,20 \AA \quad \beta=96,74 \\
\text { - } & c=106,42 \AA\end{array}$ & $0,82^{\circ}$ & $\begin{array}{c}88.606 \\
(33.568)\end{array}$ & $\begin{array}{c}2,75 \\
(2,81-2,75)\end{array}$ & $\begin{array}{c}9,2 \\
(30,4)\end{array}$ & $\begin{array}{c}92,4 \\
(92,8)\end{array}$ \\
\hline gGAPDH-33 & $\mathrm{P} 21$ & $\begin{array}{l}\text { - } a=81,27 \AA \\
\text { - } b=85,14 \AA \quad \beta=95,65 \\
\text { - } c=105,03 \AA\end{array}$ & $0,51^{\circ}$ & $\begin{array}{l}134.297 \\
(48.450)\end{array}$ & $\begin{array}{c}2,5 \\
(2,56-2,50)\end{array}$ & $\begin{array}{c}11,3 \\
(43,8)\end{array}$ & $\begin{array}{c}97,5 \\
(99,0)\end{array}$ \\
\hline gGAPDH-34 & $\mathrm{P} 21$ & $\begin{array}{l}\text { - } a=79,80 \AA \\
\text { - } \quad b=85,38 \AA \quad \beta=96,19 \\
\text { - } c=106,88 \AA\end{array}$ & $0,97^{\circ}$ & $\begin{array}{l}143.716 \\
(56.495)\end{array}$ & $\begin{array}{c}2,3 \\
(2,35-2,3)\end{array}$ & $\begin{array}{c}12,2 \\
(29,4)\end{array}$ & $\begin{array}{c}92,3 \\
(90,4)\end{array}$ \\
\hline
\end{tabular}

${ }^{1}$ código do cristal

${ }^{2}$ entre parênteses o número de reflexões únicas coletadas.

${ }^{3}$ Resolução máxima utilizada no processamento, entre parênteses o valor da última faixa de resolução.

${ }^{4} R_{\text {merge }}$ englobando todas as faixas de resolução, entre parênteses o valor na última faixa de resolução.

${ }^{5}$ Completeza englobando todas as faixas de resolução, entre parênteses o valor na última faixa de resolução. 
As intensidades foram transformadas em módulos de fatores de estrutura através do procedimento descrito por French \& Wilson e implementado no programa TRUNCATE [French \& Wilson, 1978].

\section{4- Resolução das estruturas cristalográficas e refinamento}

\section{1- Introdução}

A determinação dos módulos dos fatores de estrutura não é suficiente para se determinar a estrutura cristalográfica, pois se necessita também do conhecimento das fases dos fatores de estrutura.

Existem a princípio quatro maneiras para se resolver o problema das fases:

1. O método de substituição isomórfica, que requer a avaliação das mudanças nas intensidades difratas quando da inserção de átomos pesados no cristal

2. O método de espalhamento anômalo a múltiplos comprimentos de onda (MAD), que requer a avaliação das mudanças nas intensidades difratadas quando da estimulação de espalhadores anômalos em comprimentos de onda adequados.

3. O método de substituição molecular, baseado na similaridade prevista entre a estrutura da proteína desconhecida e estruturas já conhecidas de proteínas homólogas

4. Os chamados métodos diretos, baseados em tratamentos estatísticos dos fatores de estrutura.

Uma vez que a estrutura cristalográfica da enzima gGAPDH já foi determinada [Souza et al., 1998], pode-se utilizar o método de substituição molecular para se resolver o problema das fases e obter um modelo inicial da estrutura dos possíveis complexos obtidos.

Como descrito acima, esse procedimento é baseado na observação de que proteínas homólogas na sua seqüência de aminoácidos têm um enovelamento de 
suas cadeias polipeptídicas muito similar. Neste método, a molécula de estrutura conhecida, denominada molécula modelo, é posicionada na cela unitária da estrutura desconhecida através da aplicação de seis variáveis, sendo três rotacionais e três translacionais. Resolver a estrutura por substituição molecular resume-se, portanto, em encontrar uma solução para as funções de rotação e translação.

O sucesso do método depende de vários fatores, tais como: completeza e qualidade dos dados, homologia entre o modelo inicial utilizado e a molécula em estudo que constitui o cristal, tamanho do modelo inicial em relação ao conteúdo da cela do cristal, critério usado como indicador da qualidade daquele concordante com o modelo.

\section{2- Resolução da estrutura cristalográfica por substituição molecular}

Como os possíveis co-cristais devem diferir da estrutura nativa da gGAPDH [Souza et al., 1998] principalmente pela presença de inibidor na região do sítio ativo, a estrutura cristalográfica da gGAPDH de T. cruzi foi utilizada como modelo de busca para estimativa inicial das fases ${ }^{\dagger}$

A substituição molecular foi realizada com o programa AMoRe [Navaza et al., 1994], utilizando-se dados de 15 até $2,5 \AA$ de resolução e uma esfera de integração mínima capaz de conter o modelo tetramérico inteiro. As soluções encontradas estão representadas na tabela 7

\footnotetext{
† as moléculas de água e de cofator foram excluídas do modelo de busca.
} 
Tabela 7- Soluções encontradas através do programa AMoRe

\begin{tabular}{|c|c|c|c|c|}
\hline \multirow{2}{*}{$\begin{array}{l}\text { Código dos } \\
\text { conjuntos de } \\
\text { dados }\end{array}$} & \multicolumn{2}{|c|}{$\begin{array}{c}\text { Matrizes de propostas para cada } \\
\text { solução }\end{array}$} & \multirow{2}{*}{$\begin{array}{c}\text { Coeficiente } \\
\text { de } \\
\text { correlação } \\
(\%)\end{array}$} & \multirow[t]{2}{*}{$\begin{array}{c}\text { Fator R } \\
(\%)\end{array}$} \\
\hline & $\begin{array}{l}\text { Rotação } \\
(\alpha, \beta, \delta)^{\circ}\end{array}$ & $\begin{array}{c}\text { Translação } \\
(\mathbf{x}, \mathbf{y}, \mathbf{z}) \AA\end{array}$ & & \\
\hline gGAPDH-27 & $\overline{55,2179,855,0}$ & $34,10,053,0$ & 73,6 & 28,4 \\
\hline gGAPDH-30 & 166.6179 .5165 .9 & 34.80 .052 .5 & 69,7 & 31,8 \\
\hline gGAPDH-33 & $176,6178,4175,9$ & 35.70 .051 .9 & 67,4 & 32,7 \\
\hline gGAPDH-34 & 108.4179 .8108 .3 & 34.20 .052 .8 & 75,5 & 27,2 \\
\hline
\end{tabular}

\section{3-Refinamento dos modelos obtidos}

\subsection{1- Introdução}

O modelo inicial, obtido a partir da substituição molecular, deve ser refinado através do ajuste das coordenadas e fatores de temperatura atômicos de forma a aumentar a concordância com os dados obtidos experimentalmente. O refinamento pode ser realizado através de duas abordagens básicas: (i) refinamento no espaço recíproco, no qual os parâmetros atômicos são modificados de forma a otimizar a concordância entre os módulos dos fatores de estrutura calculados e experimentais; (ii) refinamento no espaço real, no qual o modelo molecular é comparado ao mapa de densidade eletrônica e modificação são feitas no modelo de forma a aumentar sua concordância com a densidade eletrônica observada.

O refinamento no espaço recíproco leva a uma melhora do modelo e, portanto, das fases teóricas. Isso acarreta na melhora progressiva dos mapas de densidade, que por sua vez guiam o refinamento no espaço real. Por essa razão, ciclos interativos alternados de refinamento no espaço recíproco e real são realizados até a convergência do refinamento.

A concordância entre os dados experimentais (|Fo|) e os dados teóricos $(|F c|)$ é expressa através do índice chamado $R_{\text {factor }}$ (vide apêndice A). Estruturas 
protéicas (refinadas) apresentam, de acordo com a qualidade dos dados de difração, valores de $R_{\text {factor }}$ entre 0,15 e 0,20.

Brunger [Brunger, 1992] introduziu um segundo índice $\left(R_{\text {free }}\right)$ utilizado para validação cruzada durante o refinamento do modelo.

Assim a cada ciclo do refinamento os fatores de estrutura calculados são divididos em dois conjuntos; um conjunto maior, contendo cerca de $90-95 \%$ dos dados (conjunto de trabalho) e outro conjunto menor, contendo $5-10 \%$ dos dados (conjunto teste). Os dados do conjunto de trabalho são introduzidos na função de refinamento da estrutura, enquanto o conjunto teste não participa diretamente do processo de refinamento. Segundo esse protocolo, se o refinamento estiver sendo conduzido de forma errônea, o valor de $\mathrm{R}_{\text {free }}$ aumentará, mesmo que o valor de $\mathrm{R}_{\text {factor }}$ diminua.

A função de refinamento empregada no refinamento dos modelos baseia-se no princípio da máxima verossimilhança. Nesse método os fatores de estrutura não são manipulados como valores, mas sim como distribuições de probabilidade cujas variâncias podem representar imperfeições no modelo. Essas imperfeições podem ser estimadas através de uma distribuição condicional dos dados experimentais quando o modelo é conhecido.

Uma das dificuldades do refinamento de macromoléculas advém do baixo número de observações experimentais (reflexões) em relação ao número de parâmetros a serem refinados (coordenadas atômicas $x, y, z$ e fatores de temperatura). Por essa razão, uma série de restrições é incorporada à função de refinamento (restrições estereoquímicas (ângulos e comprimentos de ligação, ângulos diédricos, etc) e as restrições de simetria não cristalográfica ${ }^{\ddagger}$ )

\footnotetext{
‡ A simetria não cristalográfica (NCS) pode ser imposta para fazer com que átomos equivalentes em moléculas cristalograficamente independentes sofram modificações semelhantes durante 0 refinamento. Em outras palavras, a NCS nos diz que cópias monoméricas devem ser tratadas de forma parecida pela função de refinamento.
} 
Outro grande problema geralmente encontrado no refinamento do modelo é sua grande distância do mínimo global da função de refinamento. Dessa maneira, métodos com um raio de convergência grande, capazes de superar mínimos locais, devem ser utilizados para se encontrar o modelo cristalográfico correto.

A metodologia de refinamento por mínimos quadrados [Konnert \& Hendrikson, 1980] frequentemente leva a mínimos locais, somente superados pela intervenção do usuário [Kuriyan et al., 1989]. Uma alternativa para esse problema é o método de refinamento através de anelamento simulado. Essa metodologia aumenta a probabilidade de se encontrar o mínimo global, pois aceita soluções contrárias ao gradiente de minimização, de acordo com a distribuição de Boltzman a uma dada temperatura. Uma das formas de se gerar essa distribuição é através de dinâmica molecular, sendo a temperatura calculada a partir da energia cinética do sistema.

O pacote CNS [Brünger et al., 1998] apresenta duas opções de anelamento simulado. A primeira faz uso de dinâmica molecular cartesiana clássica, ou seja, os átomos se movimentam segundo as leis da mecânica newtoniana. Na segunda opção as distâncias interatômicas e ângulos diédricos são fixos e apenas os ângulos torsionais são modificados. Essa metodologia reduz o número de parâmetros a serem refinados e permite um raio de convergência maior [Brunger \& Rice, 1997].

\subsection{2- Refinamento do complexo gGAPDH-33}

Depois de obtido o modelo inicial do possível co-cristal gGAPDH-33, iniciouse o seu ajuste, uma vez que devido ao método aplicado, as fases são oriundas da posição dos átomos existentes na estrutura utilizada como modelo inicial de busca. 
Antes de iniciar o refinamento propriamente dito, selecionou-se um conjunto de $5 \%$ do total de reflexões independentes para ser usado como parâmetro de acompanhamento do refinamento $\left(R_{\text {free }}\right)$.

No primeiro passo realizou-se um refinamento de corpo rígido, onde somente as coordenadas e ângulos são refinados, ou seja, o modelo é refinado como um todo, permitindo apenas sua rotação e translação. Num segundo momento foi feito um anelamento simulado torsional, onde se elevou a temperatura até $10000 \mathrm{~K}$ com passos de resfriamento lento de 25K. Essa metodologia foi empregada na tentativa de superar mínimos locais que pudessem prejudicar no refinamento do modelo.

A seguir, verificou-se a possibilidade de se usar simetria não cristalográfica (NCS) nos passos posteriores do refinamento. Isso pôde ser feito através da análise de vários ciclos de refinamento, onde o peso da simetria não cristalográfica (NCS) foi alterado, aplicado seletivamente para alguns monômeros do tetrâmero e finalmente não utilizado. O resultado de cada um desses ciclos de refinamento foi analisado segundo as variações nos fatores $R_{\text {factor }}$ e $R_{\text {free }}$ e análise dos mapas de densidade eletrônica gerados em cada um desses ciclos

Por exemplo, a análise da densidade eletrônica, na região correspondente ao $\mathrm{NAD}^{+}$, mostrou que no monômero $\mathrm{D}$ a densidade para esse cofator é contínua, enquanto nos monômeros $\mathrm{B}$ e $\mathrm{C}$ existe densidade descontínua para o $\mathrm{NAD}^{+}$(Figura 6) e no monômero A não existe densidade para o NAD+. 

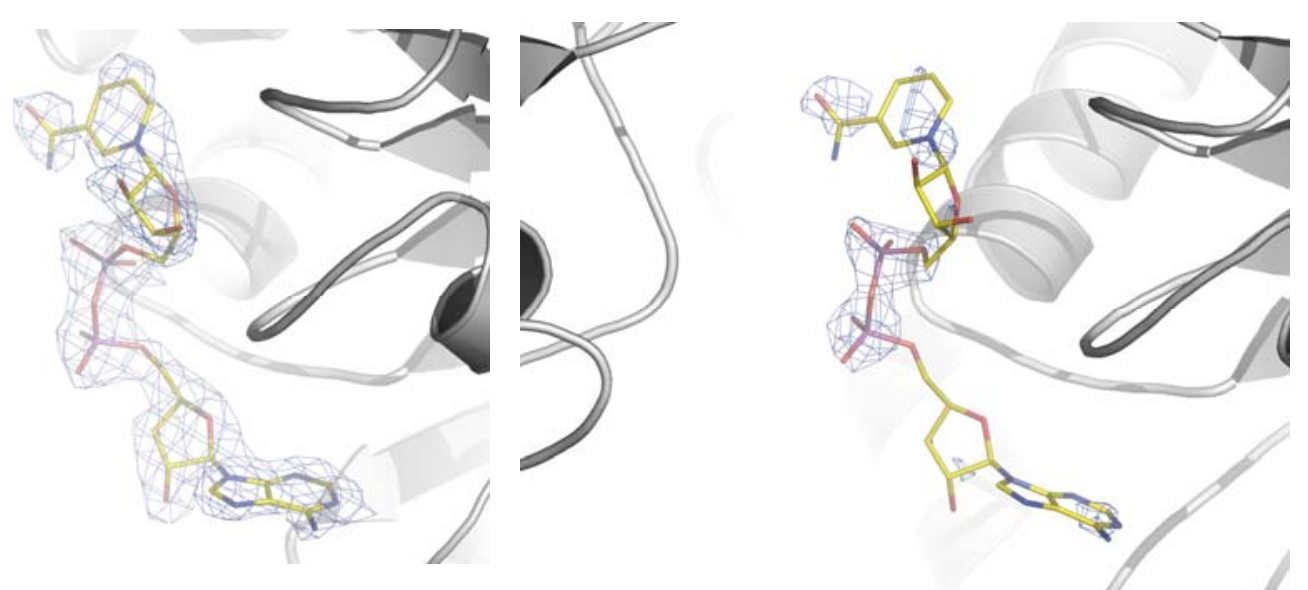

Figura 6- Mapas de densidade eletrônica $(2 \mathrm{~m}|\mathrm{Fo}|-\mathrm{D}|\mathrm{Fc}|)^{\S}$, contornados a $1,2 \delta$, na região do $\mathrm{NAD}^{+}$para os monômeros $\mathrm{D}$ (direita) e $\mathrm{B}$ (esquerda). No monômero $\mathrm{D}$ existe densidade contínua para a molécula de NAD, enquanto no monômero $B$ essa densidade é descontínua. Esse fato reflete a ocupação de 1 no monômero $D$ e de 0.5 no monômero $B$ (quando o mapa $(2 \mathrm{~m}|\mathrm{Fo}|-\mathrm{D}|\mathrm{Fc}|)$ é contornado a $0,75 \delta$ a densidade eletrônica para o $N A D^{+}$ no monômero B é contínua).

Esses resultados indicam que cada monômero tem particularidades estruturais e deve ser tratado independentemente durante o refinamento, ou seja, durante o refinamento não se utilizou restrições do tipo NCS.

Nesse ponto do refinamento, optou-se por verificar, um a um, todos os resíduos do tetrâmero, de forma a analisar quais deles encaixam-se adequadamente na densidade eletrônica. Nos casos onde a cadeia lateral dos aminoácidos não se encaixava na densidade eletrônica, utilizou-se o programa $\mathrm{O}$ [Jones et al., 1991] na busca de rotâmeros conformacionais preferenciais, que melhor se encaixassem na densidade eletrônica.

Após cada ciclo de manipulação o modelo foi minimizado por gradientes conjugados e os mapas $(2 m|F o|-D|F c|)$ e $(m|F o|-D|F c|)$ foram inspecionados de forma a se verificar se os rotâmeros alterados, de fato, levavam a uma melhora no mapa de densidade eletrônica.

\footnotetext{
$\S$ Os coeficientes m( figura de mérito) e D podem ser calculados segundo o método descrito por Read (1986)
} 
Após alguns ciclos de refinamento, os mapas de Fourier diferença (m|Fol $D|F c|)$ da região do sítio ativo do monômero $B$ revelaram uma densidade eletrônica relativa ao inibidor ligado covalentemente a $\mathrm{Cys}^{166}$ e estendendo-se em direção aos resíduos $\mathrm{Thr}^{199}, \mathrm{Thr}^{197}$.

Uma molécula do inibidor foi introduzida no modelo e seu conjunto de coordenadas refinadas através de minimização por gradientes conjugados.

A análise subseqüente dos mapas de Fourier diferença $(m|F o|-D|F c|)$ revelou que o inibidor, assim como o co-fator, também está presente nos monômeros C e D. Adicionalmente, o mapa diferença revelou que nos monômeros B e C o inibidor poderia ser encontrado em duas conformações alternativas $(50 \%$ para cada conformação).

Dessa forma, no monômero D o inibidor interage exclusivamente no sítio de ligação do fosfato orgânico (conformação Ps), enquanto nos monômeros B e C ele interage tanto no sítio de ligação do fosfato orgânico (conformação Ps) como inorgânico (conformação Pi) (Figura 7).

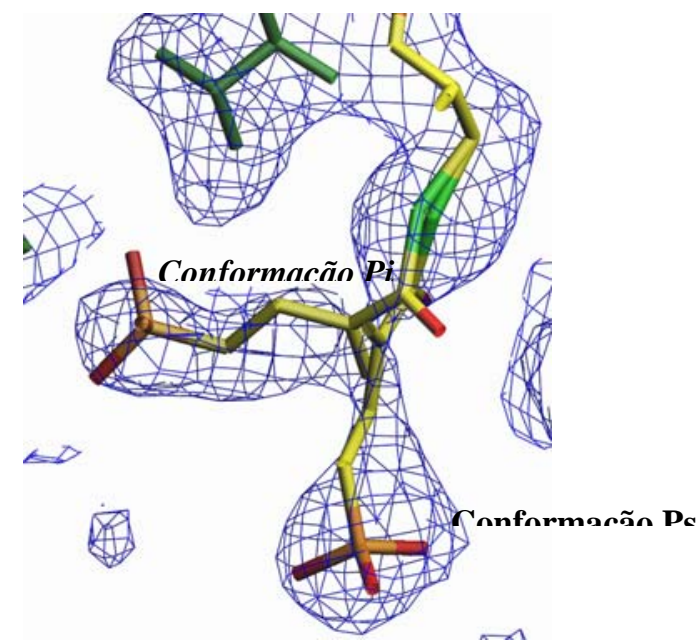

Figura 7- Mapa de densidade eletrônica $(2 \mathrm{~m}|\mathrm{Fo}|-\mathrm{D}|\mathrm{Fc}|)$, contornado a $0.7 \sigma$ no sítio ativo do monômero B. O inibidor (33) está presente em duas conformações alternativas denominadas conformação Ps (vertical) e conformação PI (horizontal).

Nos monômeros em que o inibidor se encontra em duas conformações, a ocupação do NAD foi refinada para $50 \%$. 
$\mathrm{Na}$ última etapa do refinamento, utilizou-se o programa ARP [Lamzin \& Wilson, 1993] para introduzir moléculas de águas no conjunto de dados. Esse procedimento permitiu incluir 695 moléculas de água no conjunto de dados.

$O$ modelo final apresenta $R_{\text {factor }}=0.20$ e $R_{\text {free }}=0.26$. Os resultados do refinamento estão resumidos na tabela 8 
Tabela 8- Estatísticas do modelo cristalográfico gGAPDH-33 após refinamento.

\section{Número de átomos no modelo}

proteína 1436

moléculas de água

695

inibidores

3 (monômeros B, C e D)

\begin{tabular}{ll}
\hline \hline Resolução & $20-2.5 \AA$ \\
\hline \hline Número de Reflexões utilizadas durante o refinamento & \\
$\quad$ Conjunto de trabalho & 45995 \\
Conjunto teste & 2455 \\
\hline \hline Índices residuais cristalográficos & 0.20 \\
$\mathrm{R}_{\text {factor }}$ & 0.26 \\
$\mathrm{R}_{\text {free,3\% }}$ & \\
\hline \hline Desvios quadráticos médios dos valores ideais de \\
geometria
\end{tabular}




\subsubsection{1- Qualidade da estrutura}

Durante todo o refinamento, o programa Procheck [Laskowski et al., 1992] foi utilizado para se acompanhar a estereoquímica do modelo.

$\mathrm{Na}$ estrutura final, mais de $99 \%$ dos resíduos encontram-se em regiões favoráveis do diagrama de Ramachandran. Exceção a Val ${ }^{255}$ dos 4 monômeros que se encontra em região desfavorável (Figura 8).

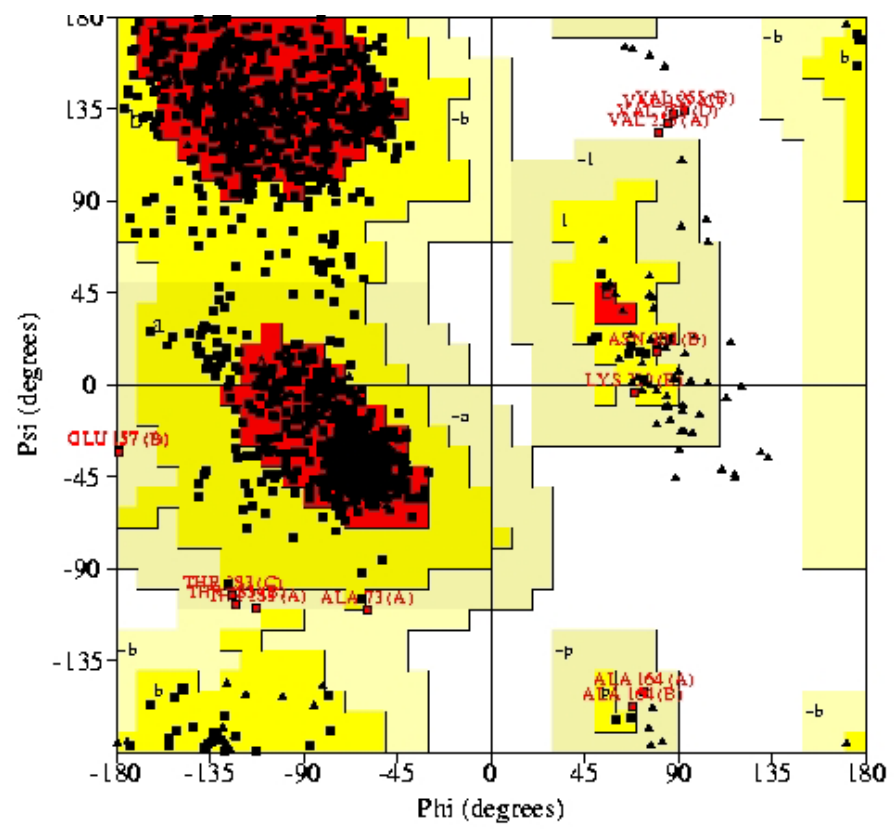

Figura 8- Diagrama de Ramachandran do complexo gGAPDH-33. O resíduo Val ${ }^{255}$ nos quatro monômeros encontra-se numa região não permitida do diagrama de Ramachandran. Essa conformação é conservada em todas as GAPDHs já descritas [Watson et. al. 1972; Skarzynski et al., 1987; Vellieux et al., 1993; Kim et al., 1995, Souza et al., 1998] e tem importância para o mecanismo catalítico da enzima. 
Esse resíduo está localizado numa alça entre duas folhas $\beta$ consecutivas e sua conformação desfavorável é comum a todas estruturas de GAPDH disponíveis na literatura [Watson et. al. 1972; Skarzynski et al., 1987; Vellieux et al., 1993; Kim et al., 1995, Souza et al., 1998]. Aparentemente, essa conformação é importante para o correto posicionamento da Cys ${ }^{166}$, e da nicotinamida do NAD durante o mecanismo catalítico da enzima.

\subsubsection{2 - Análise do complexo gGAPDH-33}

Uma vez que os inibidores irreversíveis possuem um aceptor de Michael, dois modos de reação com a cisteína seriam possíveis. No primeiro, o ataque do grupo tiol da cisteína à carbonila levaria a formação do complexo (gGAPDH-33) que mimetizaria a tio-enzima presente no mecanismo catalítico da enzima. Entretanto é possível que o grupo tiol da cisteína ataque o grupo metileno conjugado levando a uma adição do tipo 1,4 e, conseqüente, à formação de um complexo tioéter entre a enzima e o inibidor. Ambas as possibilidades estão representadas na figura 9.

A estrutura cristalográfica elimina qualquer dúvida sobre o mecanismo de inativação que esse inibidor apresenta (mecanismo A). 
A

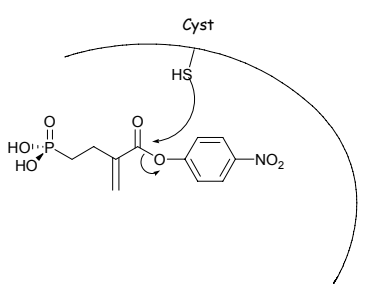

$\mathrm{Pi}$

B
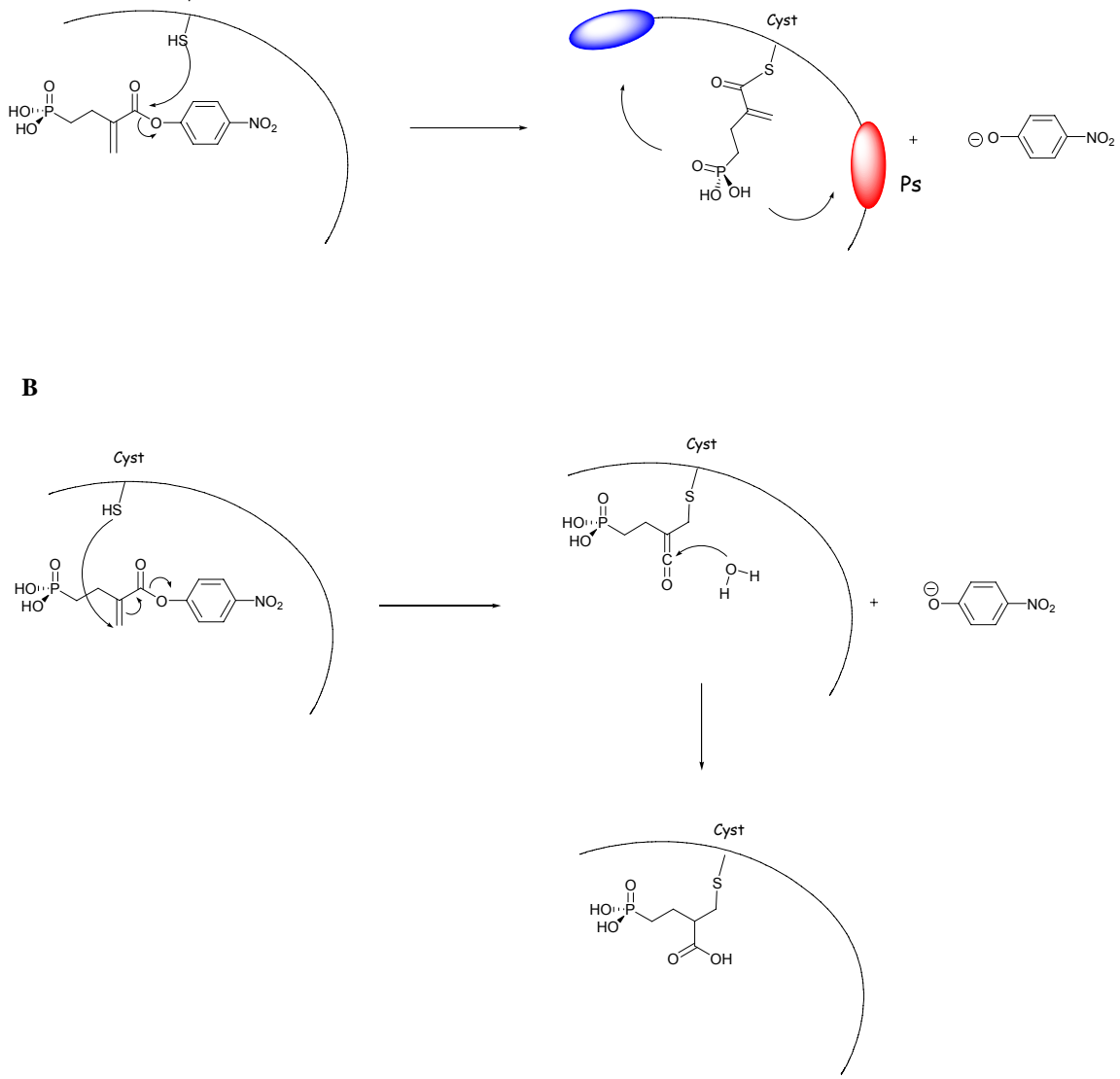

Figura 9- Mecanismos de inibição irreversível possíveis para o composto 33. A) Ataque nucleofílico da Cys $^{166}$ à carbonila do composto. B) Adição de Michael $(1,4)$ ao sistema etilênico conjugado. Figura gentilmente cedida pelo Dr. Sylvain Ladame, UPS, Toulouse, França.

Quando o inibidor se encontra na conformação $\mathrm{Pi}$, presente apenas nos monômeros $B$ e $C$, o seu grupo fosfato realiza ligações de hidrogênio com os resíduos $\operatorname{Thr}^{226}$ e $\operatorname{Arg}^{249}$. Nessa conformação o grupo fosfonato encontra-se a $3.35 \AA$ da posição previamente descrita para o sítio de fosfato em gGAPDH de $L$. mexicana [Kim et al, 1998] e 4.81Å da posição descrita em T. brucei [Vellieux, 1993] (Figura 10). 


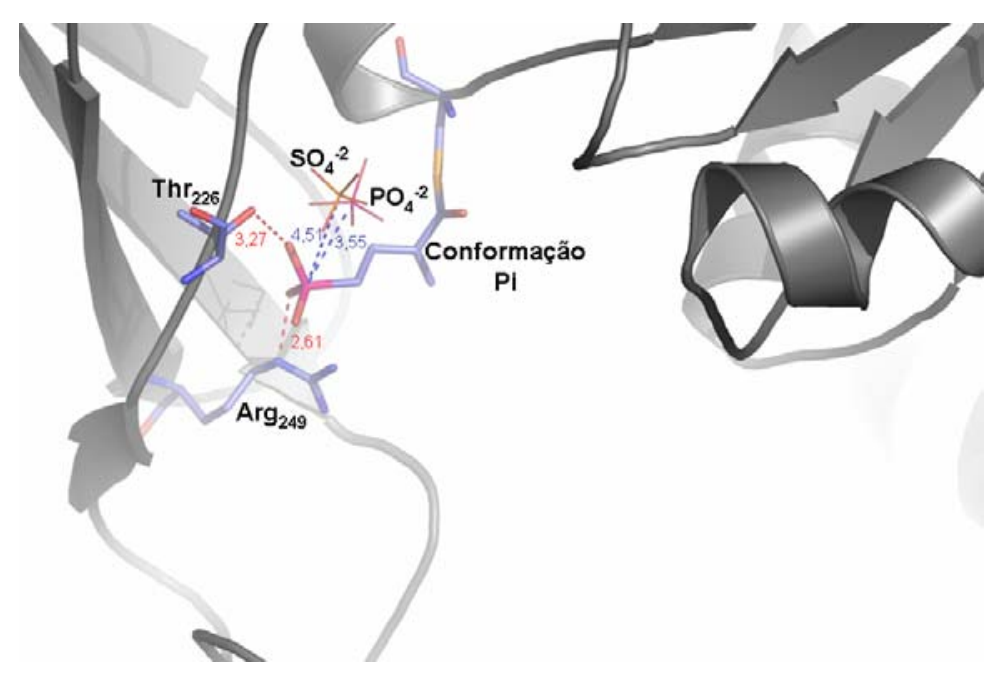

Figura 10- Perfil de interação do composto 33 no sítio $\mathrm{Pi}$. O grupo fosfonato encontra-se a $3.35 \AA$ da posição previamente descrita para o grupo $\mathrm{PO}_{4}^{-2} \mathrm{em} L$. mexicana e a $4.81 \AA$ da posição descrita para o grupo $\mathrm{SO}_{4}{ }^{-2} \mathrm{em} T$. brucei (linhas pontilhadas em azul). Além disso, o composto $\mathbf{3 3}$ faz ligações de $\mathrm{H}$ com os resíduos $\mathrm{Thr}^{226}$ e $\operatorname{Arg}^{249}$ (linhas pontilhadas em vermelho). A estrutura da proteína está representada de acordo com sua estrutura secundária, exceto pelos resíduos que fazem ligações de $\mathrm{H}$ com o inibidor. As posições dos grupos $\mathrm{SO}_{4}^{-2}$ e $\mathrm{PO}_{4}^{-2}$ foram obtida a partir da sobreposição das estruturas 1GYP e 1A7K na estrutura do complexo gGAPDH-33.

$\mathrm{Na}$ conformação Pi o grupo carbonila do inibidor está direcionado para o anel nicotinamida (carregado positivamente) do NAD ${ }^{+}$.

Yun e colaboradores [Yun et al, 2000] cristalizaram a enzima GAPDH de $E$. coli nas formas holo, apo e ligada ao intermediário hemicetal do ciclo catalítico da enzima. Nessa última forma, não há moléculas de $\mathrm{NAD}^{+}$no modelo. Entretanto levando em conta a posição do $\mathrm{NAD}^{+}$, obtida a partir da estrutura Holo, Yun e colaboradores propuseram que a carbonila do substrato (gliceraldeído-3-fosfato) deveria interagir com o nitrogênio positivamente carregado do $\mathrm{NAD}^{+}$, posicionando o substrato para a transferência do hidreto. Após a redução do $\mathrm{NAD}^{+}$, o substrato seria deslocado para o sítio de ligação Ps através de uma rotação na ligação C1-C2 do intermediário (Figura 11) 

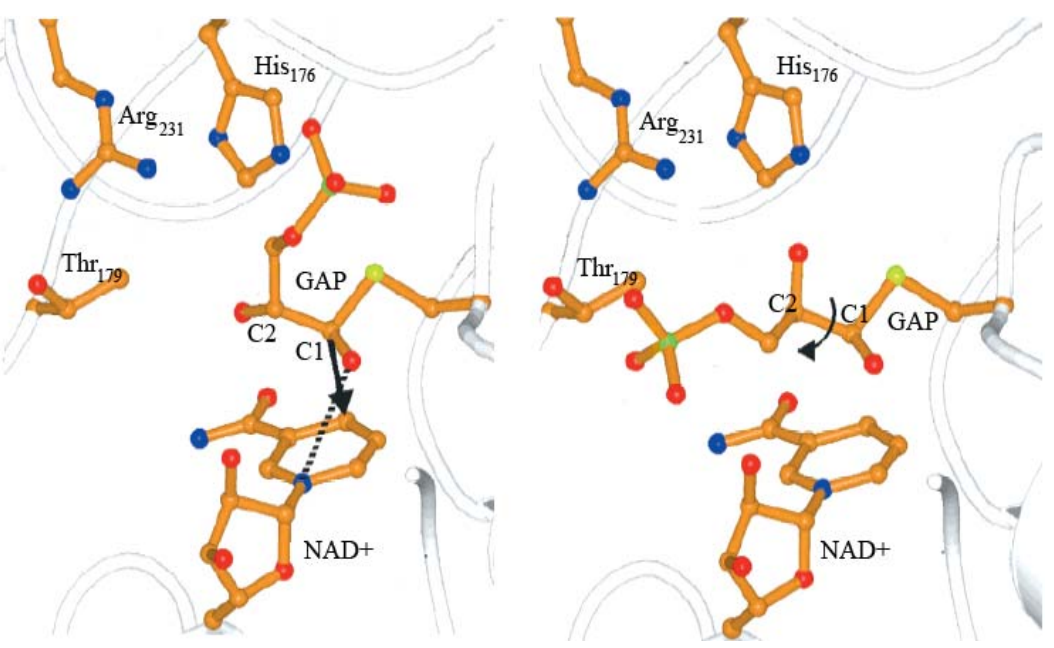

Figura 11- Modelo de interação do gliceraldeído 3-fosfato (GAP) no sítio ativo da GAPDH de E. coli. Segundo Yun e colaboradores [Yun et al, 2000], quando o GAP interage no sítio $\mathrm{Pi}$ (esquerda), a carbonila deveria interagir com o anel carregado positivamente do $\mathrm{NAD}^{+}$. Após redução do cofator o GAP deveria sofrer uma rotação entre os carbonos C1 e C2, a qual posicionaria o grupo fosfato no sítio Pi. Figura adaptada de Yun et al., 2000.

A estrutura cristalográfica do complexo gGAPDH-33 revela que a distância entre o oxigênio da carbonila e o $\mathrm{N}$ do anel nicotinamida é de $3.63 \AA$, portanto maior do que aquela esperada para uma interação iônica como aquela proposta por Yun e colaboradores [Yun et al., 2000]

Na conformação Ps, o grupo fosfonato faz ligações de hidrogênio com os resíduos $\mathrm{Thr}^{197}, \mathrm{Arg}^{249}$ e com uma hidroxila do anel ribose do NAD. Além disso, a carbonila faz ligação de hidrogênio com o resíduo His ${ }^{194}$. Nessa conformação o grupo fosfonato está localizado a $0.93 \AA$ da posição previamente descrita para o sítio de ligação de fosfato em $L$. mexicana \{Kim et al., 1998] e $0.70 \AA ̊$ da posição de sulfato descrita em T. brucei gGAPDH [Vellieux et al., 1993] (Figura 12).

Na conformação Ps a carbonila do inibidor aponta na direção contrária ao anel carregado da nicotinamida (Figura 12). Assim, o inibidor, na conformação Ps, também não deve realizar as interações iônicas mencionadas anteriormente. 


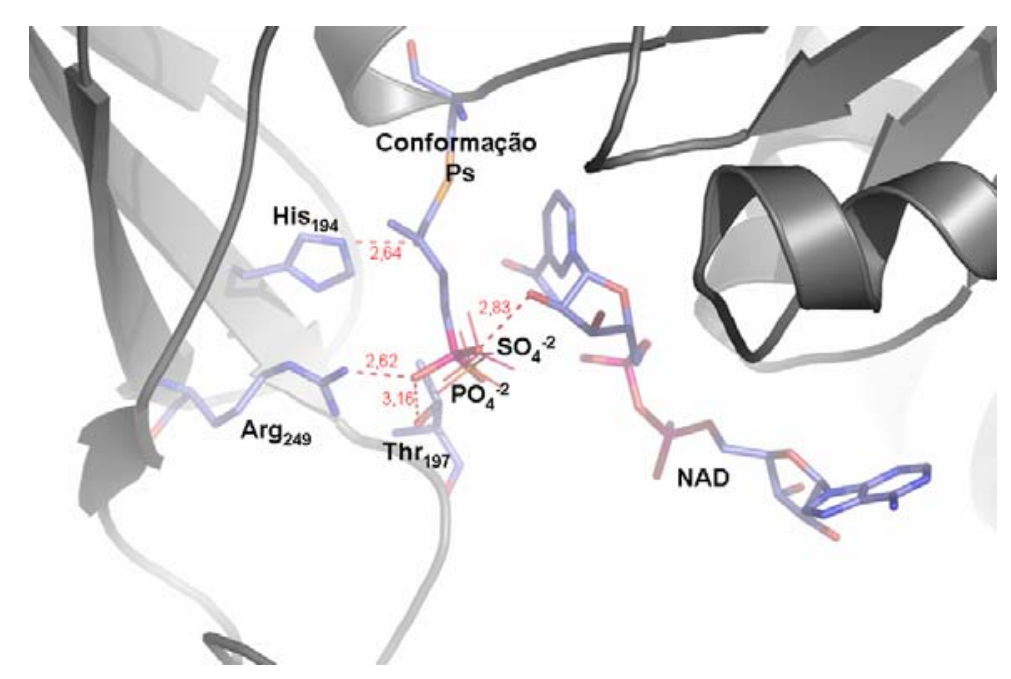

Figura 12- Perfil de interação do composto 33 no sítio Ps. O grupo fosfonato encontra-se a menos de $1,0 \AA$ da posição previamente descrita para os grupos $\mathrm{PO}_{4}^{-2} \mathrm{em} \mathrm{L}$. mexicana e $\mathrm{SO}_{4}{ }^{-2} \mathrm{em} \mathrm{T}$. brucei (não representado na figura). Nessa conformação, o composto 33 faz ligações de $\mathrm{H}$ com os resíduos $\mathrm{Arg}^{249}$ e $\mathrm{Thr}^{197}$ através do seu grupo fosfato, o qual também interage com uma hidroxila da ribose do NAD+ (linhas pontilhadas em vermelho). Além disso, a carbonila do composto 33 está orientada na direção do resíduo $\mathrm{His}^{194}$, o que pode favorecer uma interação do tipo ligação de $\mathrm{H}$ ou transferência de carga de acordo com o estado de protonação do resíduo.

O complexo gGAPDH-33 mimetiza a etapa posterior aquela descrita por Yun [Yun et al, 2000], entretanto segundo o mecanismo proposto por ele, o inibidor 33 deveria ser encontrado somente na conformação Ps. Outra contraposição aos resultados de Yun vem do fato que o deslocamento do grupo fosfato do sítio Pi para o sítio Ps, ocorre através de uma rotação na ligação SG-C1 do complexo e não na ligação C1-C2 (Figura 13).
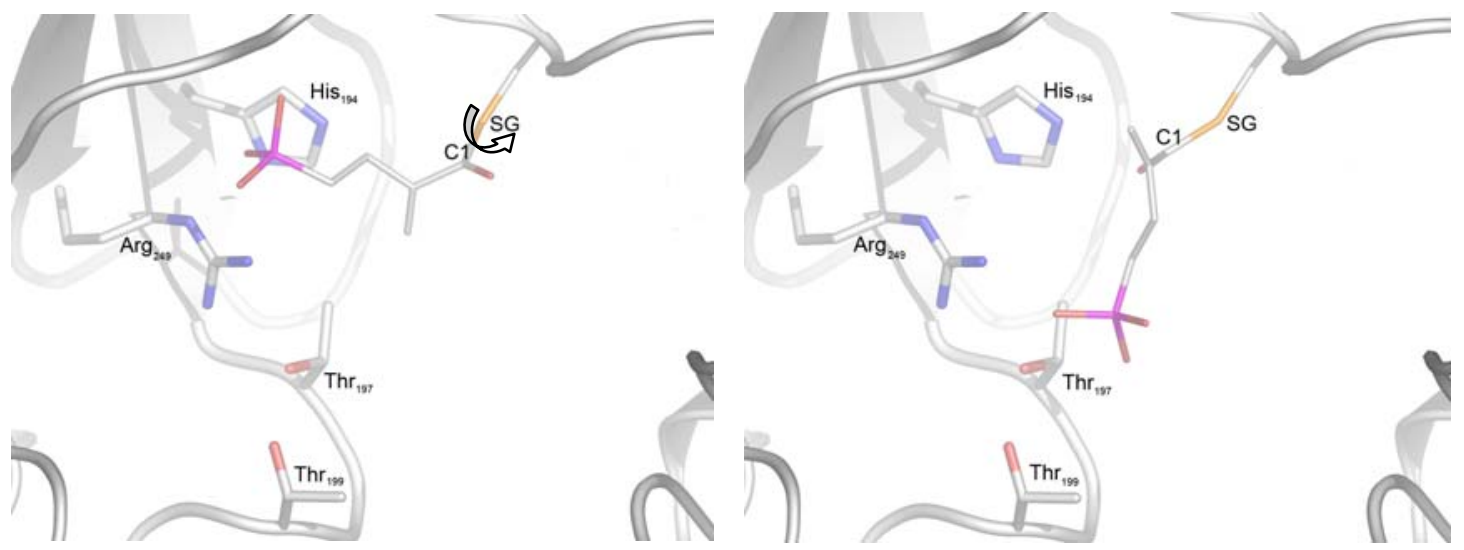

Figura 13- Mecanismo de interação do composto 33 no sítio ativo da gGAPDH de $T$. cruzi. Esse complexo mimetiza o intermediário tiocetal do mecanismo catalítico da enzima. Segundo a estrutura cristalográfica, o composto $\mathbf{3 3}$ deve interagir primeiramente no sítio de $\mathrm{Pi}$ (vide figura 10). Após a saída do cofator (não representado na figura) o composto sofre uma rotação na ligação SG-C1 que posiciona o grupo fosfato no sítio Ps (vide figura 12). Os 
resíduos em destaque na figura são equivalentes àqueles destacados por Yun e colaboradores na figura 11.

A comparação da estrutura cristalográfica do complexo gGAPDH-33 com a estruturas nativa [Souza et al, 1998] e em complexo com um inibidor de origem natural [Pavão, 2002] revela que as principais diferenças estão relacionadas a orientação do resíduo $\mathrm{Arg}^{249}$. Nas estruturas anteriores, onde não havia fosfato ou análogos de substrato no sítio ativo, o resíduo $\operatorname{Arg}^{249}$ aponta para o resíduo $\mathrm{Asp}^{210}$. No complexo gGAPDH-33 esse resíduo aponta para os resíduos $\operatorname{Thr}^{197}$ e $\operatorname{Thr}^{199}$ e faz ligações de hidrogênio com o grupo fosfato (tanto na conformação Ps quanto na conformação Pi). Outra diferença marcante desse complexo é a distância entre o $\mathrm{N} \varepsilon$ da $\mathrm{His}^{194}$ e $\mathrm{S} \delta$ da $\mathrm{Cys}^{166}$, que varia de $3.2 \AA \hat{A}$ na estrutura nativa a $3.7 \AA \hat{~ n a}$ estrutura da gGAPDH em complexo com chalepina [Pavão et al., 2002]. No

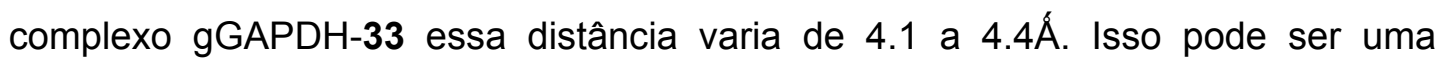
conseqüência da ligação do inibidor irreversível no sítio Pi.

Os demais resíduos do sítio ativo apresentam conformação praticamente idêntica àquela descrita anteriormente [Souza et al., 1998; Pavão et al., 2002], exceto pelos resíduos $\operatorname{Ser}^{224}$ a $\mathrm{Ala}^{229}$ que fazem parte de uma alça que está deslocada $0,55 \AA$ em direção ao sítio Pi. Comportamento semelhante foi descrito para a estrutura da gGAPDH de L. mexicana quando cristalizada em baixa concentração de $\left(\mathrm{NH}_{4}\right)_{2} \mathrm{SO}_{4}$ [Kim et al, 1998] e para a estrutura cristalográfica do intermediário hemicetal em GAPDH de E. coli [Yun et al., 2000].

\subsection{3- Refinamento do conjunto de dados gGAPDH-30}

O procedimento para o refinamento do conjunto de dados gGAPDH-30 segue aquele descrito para o conjunto de dados gGAPDH-33 com pequenas modificações, que serão destacadas a seguir. Entre elas destaca-se o fato de que 
todo o refinamento foi realizado, desde o início, sem imposição de restrições do tipo NCS.

O modelo inicial, obtido pelo programa AMoRe [Navaza, 1994], foi refinado, primeiramente, no espaço recíproco através de anelamento simulado. Os mapas de densidade eletrônica obtidos mostram claramente a presença do co-fator em todos os monômeros. Quatro moléculas de $\mathrm{NAD}^{+}$foram introduzidas manualmente no modelo e tiveram suas posições e fatores de temperatura refinados.

O modelo foi então refinado no espaço real, utilizando o programa O. Após vários ciclos de reconstrução da cadeia e minimização por gradientes conjugados, 441 moléculas de água foram introduzidas no modelo utilizando o programa ARP [Lamzin \& Wilson, 1993].

Nesse momento optou-se por remover as moléculas de água presentes no sítio ativo da enzima e calcular novos mapas de densidade eletrônica.

A análise do mapa $(2 \mathrm{~m}|\mathrm{Fo}|-\mathrm{D}|\mathrm{Fc}|)$ mostra densidade claramente definida para o inibidor 30 somente no monômero A (Figura 14).

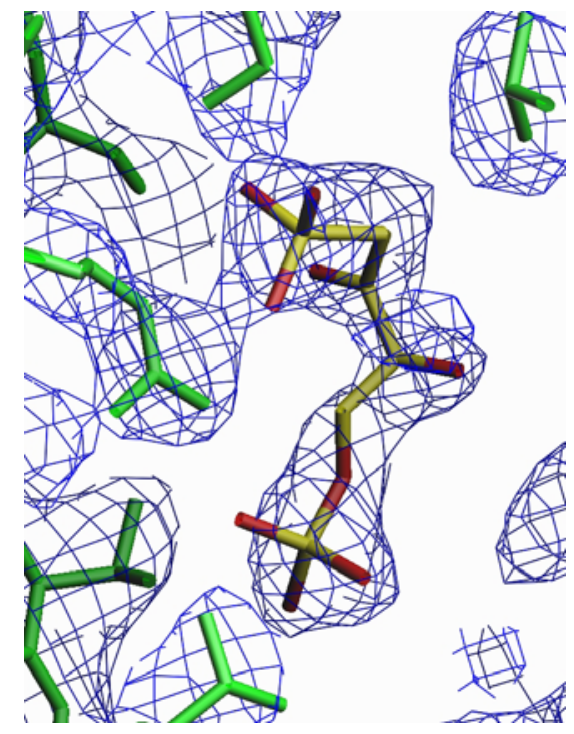

Figura 14- Mapa de densidade eletrônica $(2 \mathrm{~m}|\mathrm{Fo}|-\mathrm{D}|\mathrm{Fc}|)$ contornado a $0,8 \sigma$ no sítio ativo do complexo gGAPDH-30. Os resíduos da proteína estão representados em verde e os átomos do inibidor estão coloridos de acordo com tipo de átomo 
Uma molécula de inibidor foi então introduzida no modelo e o conjunto todo foi refinado até $R_{\text {factor }}=0.19$ e $R_{\text {free }}=0.26$. Os resultados finais do refinamento estão resumidos na tabela 9

Tabela 9- Estatísticas do modelo cristalográfico gGAPDH-30 após refinamento.

\section{Número de átomos no modelo}

proteína

moléculas de água

453

inibidores

1 (monômero A)

\section{Resolução}

$8.0-2.75 \AA$

\section{Número de Reflexões utilizadas durante o refinamento}

Conjunto de trabalho

Conjunto teste

\section{Índices residuais cristalográficos}

$\mathrm{R}_{\text {factor }}$

$\mathrm{R}_{\text {free }, 3 \%}$

0.26

\section{Desvios quadráticos médios dos valores ideais de} geometria

Comprimento de ligação

$$
0.0067 \AA
$$

Ângulos de ligação

\section{Fator de temperatura médio $\left(\AA^{2}\right)$}

Cadeia principal

Todos os átomos 


\subsubsection{1- Qualidade da estrutura}

Apesar da falta de restrições do tipo NCS, os mapas de densidade eletrônica calculados para o complexo gGAPDH-30 apresentam boa qualidade, exceto para os resíduos 65-74, 99-103 e 117-121 localizados numa alça flexível do monômero C, resíduos 99-102, também numa alça flexível, no monômero B e alguns resíduos nas porções $\mathrm{N}$ e $\mathrm{C}$ terminal. No geral, a estereoquímica do modelo é bastante satisfatória com mais de $99 \%$ dos resíduos nas regiões permitidas do gráfico de Ramachandran. Novamente, exceção deve ser feita ao resíduo $\mathrm{Val}^{255}$, por razões já descritas nas páginas 71 e 72.

\subsubsection{2- Análise do complexo gGAPDH-30}

A análise do complexo revela que o grupo fosfato está localizado no sítio de ligação do fosfato, onde ele faz ligações de hidrogênio com os resíduos $\mathrm{Thr}^{197}$, $\operatorname{Thr}^{199}$ e $\operatorname{Arg}^{249}$ (Figura 15). Essa localização pouco difere da posição previamente descrita para os sítios de ligação do sulfato e fosfato em gGAPDHs de T. brucei [Vellieux, 1993]e L. mexicana [Kim et al, 1998] (1.11 e 0.48A, respectivamente) (Figura 16). Situação bastante diferente pode ser descrita para o grupo fosfonato. 


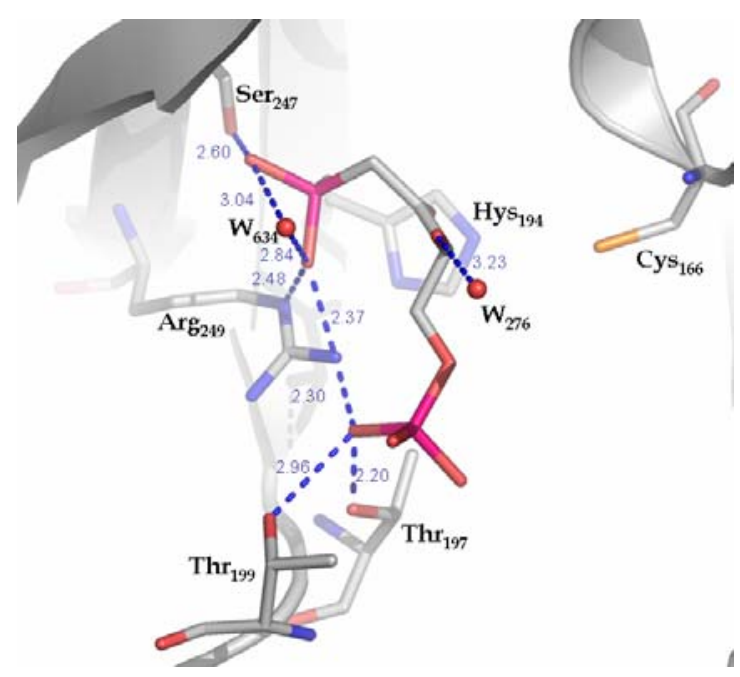

Figura 15- Perfil de interação do composto 30 no sítio ativo da enzima gGAPDH de T. cruzi. O grupo fosfato faz ligações de hidrogênio com os resíduos $\mathrm{Arg}^{249}$, $\mathrm{Thr}^{197}$ e $\mathrm{Thr}^{199}$ (linhas pontilhadas em azul). O grupo fosfonato faz ligações de hidrogênio com os resíduos $\mathrm{Arg}^{249}$, $\operatorname{Ser}^{247}$ (linhas pontilhadas em azul) e sua carbonila está orientada em direção ao resíduo $\mathrm{His}^{194}$. Duas ligações de hidrogênio adicionais são formadas com moléculas de água cristalográficas. A estrutura da proteína está representada de acordo com sua estrutura secundária, exceto pelos resíduos que fazem ligações de $\mathrm{H}$ com o inibidor e por outros resíduos importantes para o mecanismo catalítico.

A estrutura cristalográfica mostra o grupo fosfonato fazendo ligações de hidrogênio com os resíduos $\operatorname{Ser}^{247}$ e $\operatorname{Arg}^{249}$, num sítio localizado a $5.38 \AA$ e $4.06 \AA$ das posições previamente descritas para sítios de sulfato e fosfato em $T$. brucei [Vellieux et al., 1993] e L. mexicana [Kim et al., 1998] (Figura 17).

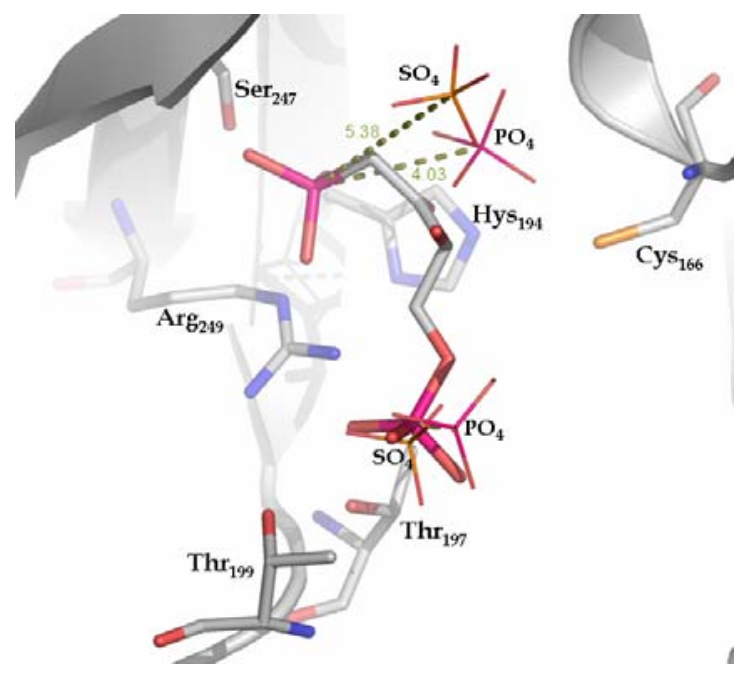

Figura 16- Comparação das posições cristalográficas dos grupos fosfonato e fosfato em relação as posições previamente descritas para os grupos $\mathrm{SO}_{4}^{-2}$ em $T$ brucei e $\mathrm{PO}_{4}^{-2} \mathrm{em}$ L. mexicana. Enquanto o grupo fosfato localiza-se a menos do que $1 \AA$ das posições previamente descritas (sítio Ps), o grupo fosfonato encontra-se entre 4 à $5 \AA$ das posições previamente descritas (vide linhas pontilhadas). As posições dos grupos $\mathrm{SO}_{4}^{-2} \mathrm{e} \mathrm{PO}_{4}^{-2}$ foram obtida a partir da sobreposição das estruturas $1 \mathrm{GYP}$ e $1 \mathrm{~A} 7 \mathrm{~K}$ na estrutura do complexo gGAPDH-30. 
Na verdade, a localização desse novo sítio é próxima aquela encontrada no complexo gGAPDH-33 (Figura 17)

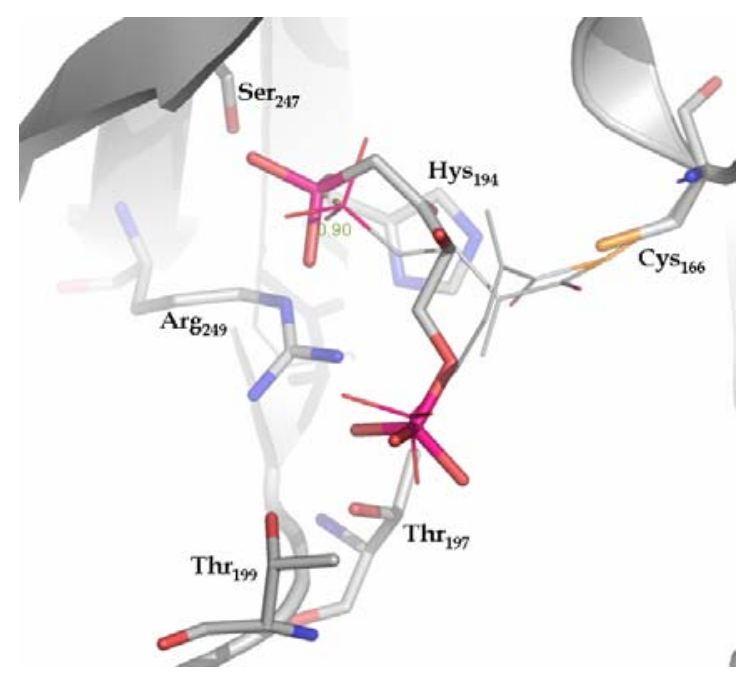

Figura 17- Comparação da localização dos grupos fosfato e fosfonato do complexo gGAPDH-30 com as posições dos grupos fosfonato no complexo gGAPDH-33. Existe uma boa concordância entre as posições dos grupos fosfato e fosfonato em ambas as estruturas (distância menor que $1 \AA$ ). A grande distância entre a localização do grupo fosfonato e as posições previamente descritas para $\mathrm{SO}_{4}{ }^{-2}$ e $\mathrm{PO}_{4}{ }^{-2}$ (vide figura 16), revela a grande plasticidade do sítio Pi quando comparado ao sítio Ps.

Chama a atenção o fato da hidroxila ligada ao carbono C2 não fazer, segundo esse modelo de ligação do inibidor, nenhuma interação com resíduos do sítio ativo da gGAPDH.

De fato, devido a baixa resolução dos dados de difração é difícil posicionar inequivocamente o inibidor dentro da densidade eletrônica e assim excluir a possibilidade do grupo fosfato estar localizado na posição do grupo fosfonato e vice-versa.

Numa tentativa de dirimir essa dúvida, o composto $\mathbf{3 0}$ foi modelado também segundo a hipótese de que o grupo fosfato estaria interagindo no sítio de ligação do grupo fosfonato e vice-versa (Figura 18). Entretanto, a menor complementaridade entre inibidor e densidade eletrônica sugere que o modelo de interação descrito acima (Figura 14) é correto. 


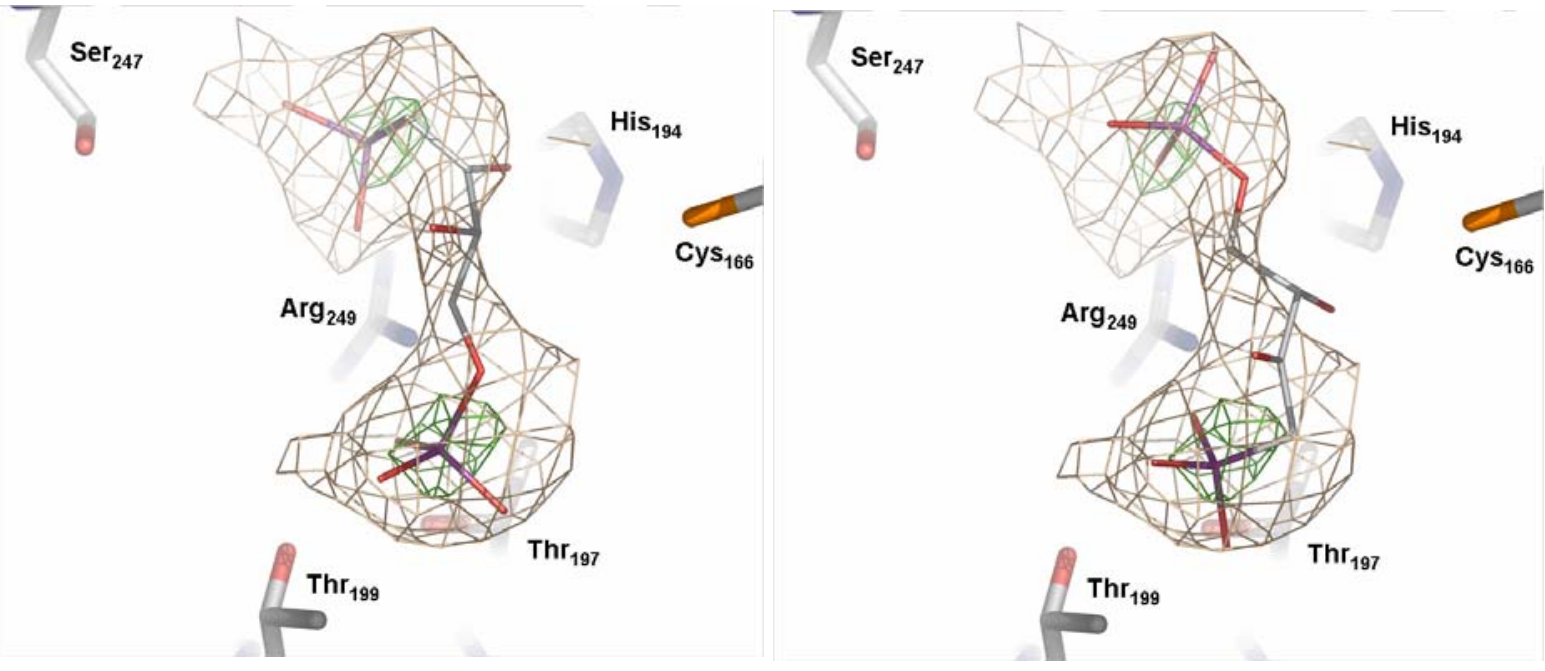

Figura 18- Mapas de densidade eletrônica ( $m|F o|-D|F c|)$ contornados a 1,2ס (marrom) e 6,0ठ (verde) no sítio ativo do complexo gGAPDH-30. Devido a baixa resolução dos dados cristalográficos, as orientações a esquerda e a direita do composto $\mathbf{3 0}$ foram testadas. À esquerda temos a conformação refinada final e à direita o resultado caso o inibidor fosse refinado na orientação invertida. O melhor encaixe da conformação à esquerda, na densidade eletrônica, nos levou a considerar essa orientação como correta.

Estudos de inibição enzimática das enzimas gGAPDH de T. brucei e T. cruzi revelaram um perfil de inibição bastante distinto para os análogos de 1,3-BPG (Tabela 10). 
Tabela 10- Resultados de inibição das enzimas gGAPDH $\left(\mathrm{IC}_{50}\right)$ de $T$. brucei e $T$. cruzi frente aos derivados de 1,3-BPG.

Estrutura
$(\mu \mathrm{M})$

Esse resultado é bastante surpreendente uma vez que essas enzimas têm mais de $95 \%$ de identidade. A ausência de estruturas cristalográficas da gGAPDH de $T$. brucei em complexo com análogos de 1,3-BPG torna impossível um estudo detalhado dos motivos estruturais responsáveis por esse comportamento.

Alternativamente, métodos de modelagem molecular foram utilizados na tentativa de melhor entender o diferente perfil de inibição dos compostos apresentados na tabela 10. Esse trabalho foi realizado com o Dr. Carlos H. T. P. 
Silva. Detalhes experimentais do protocolo de modelagem molecular podem ser encontrados no apêndice D.

Os resultados de modelagem sugerem que apesar da grande identidade seqüencial e estrutural entre as gGAPDHs de $T$ brucei e $T$. cruzi, os análogos de 1,3-BPG comportam-se de forma diferente quando minimizados dentro dos respectivos sítios ativos (Figura 19).

Os resultados de modelagem sugerem que todos os compostos da série interagem com os mesmos resíduos que $\mathbf{3 0}$. Todos os compostos apresentaram boa interação no sítio Ps e baixo rmsd entre eles, entretanto não foram encontradas interações fortes no sítio Pi. Acredita-se que o sítio Pi seja o primeiro local de interação do G3P [Yun et al, 2000; Castilho et al, 2003]. A falta de interações fortes nesse sítio pode estar relacionada com a baixa atividade inibitória dos compostos 26 a 30.

Essa hipótese é reforçada pelo comportamento dos inibidores dentro do sítio ativo da gGAPDH de T. brucei. Nesse caso os compostos 26 a 30 apresentam menor rmsd no sítio Pi e um conformação mais curvada. 


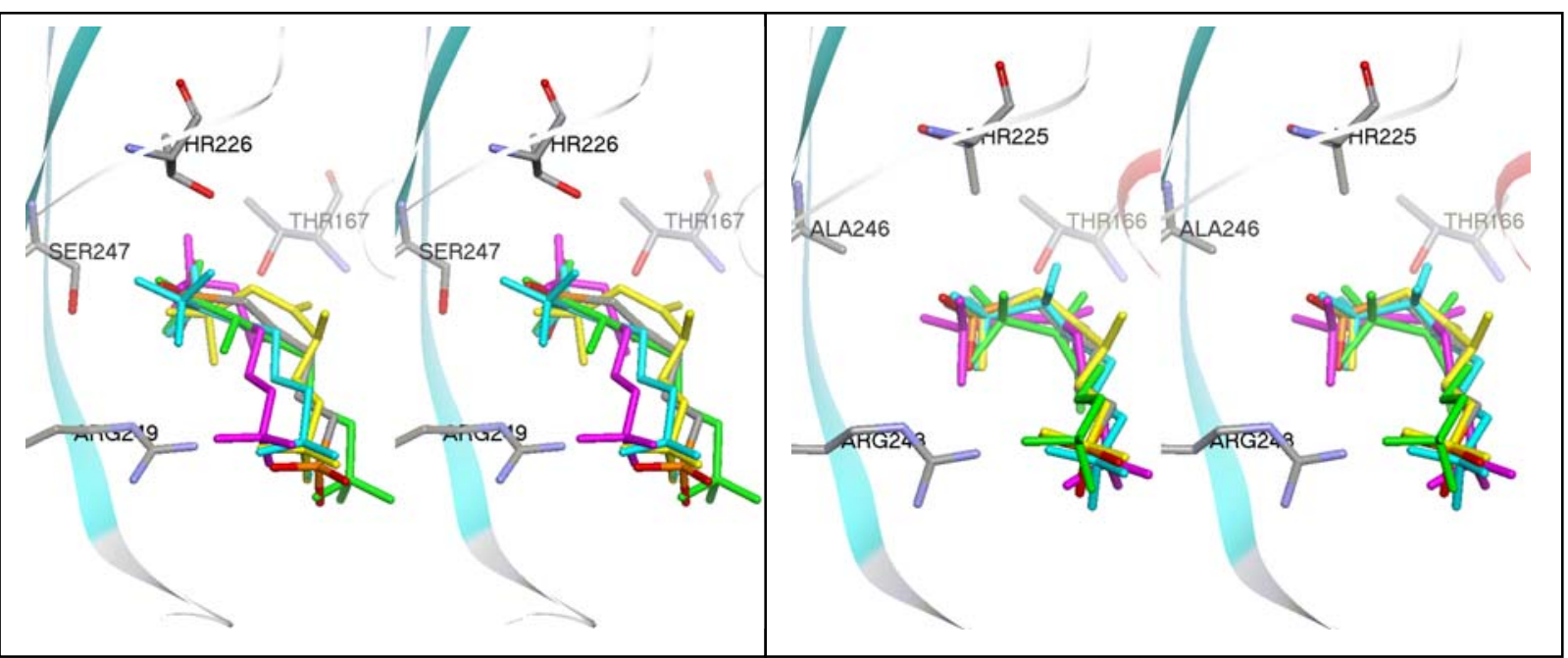

(a)

( b )

Figura 19- Comparação dos resultados de modelagem molecular para os compostos 26-30 no sítio ativo da gGAPDH de T. cruzi GAPDH (a) e T. brucei (b). As principais diferenças encontradas são; menor rmsd entre os inibidores quando no sítio ativo de $T$. brucei e uma conformação mais curvada em $T$. brucei do que em $T$. cruzi. Diferenças estruturais que podem estar relacionadas com esses resultados são; diferentes rotâmeros para o resíduo $\mathrm{Thr}^{226} / \mathrm{Thr}^{225}$ e substituição resíduo $\mathrm{Ser}^{247}$ por Ala ${ }^{246}$, conforme discutido na página 90 .

Esse fato se reflete no valor médio da distância entre os átomos de fósforo

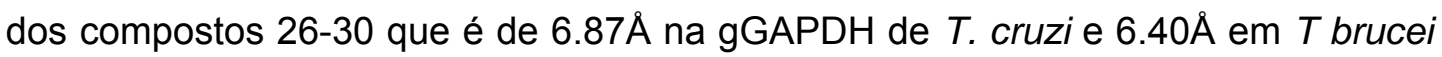
(Tabela 11). 
Tabela 11- Distância inter-fósforo após a simulação computacional no sítios ativos da gGAPDH de T. cruzi e de T. brucei (entre parênteses)

\begin{tabular}{cc}
\hline \hline Composto & D p-p, em A \\
\hline \hline $\mathbf{2 6}$ & $7.17(6.32)$ \\
$\mathbf{2 7}$ & $7.21(6.58)$ \\
$\mathbf{2 8}$ & $6.65(6.61)$ \\
$\mathbf{2 9}$ & $6.70(6.32)$ \\
$\mathbf{3 0}$ & $6.63(6.18)$ \\
\hline \hline
\end{tabular}

Apesar da grande conservação no sítio ativo das gGAPDHs de T. brucei e $T$. cruzi é possível identificar diferenças estruturais no sítio ativo dessas enzimas que podem estar relacionadas com os resultados de modelagem molecular; (a) substituição do resíduo $\operatorname{Ser}^{247}$ em T. cruzi gGAPDH por Ala ${ }^{246}$ em T. brucei; (b) rotâmeros diferentes para o resíduo $\mathrm{Thr}^{226} / \mathrm{Thr}^{225}$, $T$ cruzi e $T$ brucei respectivamente.

Na gGAPDH de $T$ cruzi os resíduos $\operatorname{Ser}^{247}$ e $\operatorname{Thr}^{226}$ competem com o resíduo $\operatorname{Arg}^{249}$ pelos grupos fosfonato dos inibidores, resultando numa interação menos eficiente dos inibidores com o resíduo $\operatorname{Arg}^{249}$ e possibilitando assim as conformações estendidas. Na gGAPDH de T. brucei, o resíduo $\operatorname{Arg}^{248}$ é o principal ponto de interação uma vez que o resíduo $\mathrm{Ala}^{246}$ não faz ligação de hidrogênio com o grupo fosfonato e o resíduo $\mathrm{Thr}^{225}$ não está orientado de forma a interagir com os receptores. Essas peculiaridades, possivelmente, resultam na conformação curvada encontrada nos estudos de modelagem. 
5- Referências bibliográficas

Arndt U. W., Haselgrove J. C., Faruqui A. R., Huxley H. E., (1977). "Design and Use of a Camera for Low-Angle X-ray Diffraction Experiments with Synchrotron Radiation". J. Phys. Sci. Instr. 10: 1035-1044

Aronov, A. M., Suresh, S., Buckner, F. A. S., Voorhis, W. C. V., Verlinde, C. J. M. J., Opperdoes, F. R., Hol, W. G. J., Gelb, M. H. (1999). "Strucuture-based design of submicromolar, biologically active inhibitor of Trypanosomatid glyceraldehide-3phosphate dehydrogenase" Proc. Nat. Acad. Sci. USA 96: 4273-4278

Bressi, J.C., Verlinde, C.L.M.J., Aronov, A.M., Le Shaw, M., Shin, S.S., Nguyen, L.N., Suresh, S., Buckner, F.S., Van Voorhis, W.C., Kuntz, I.D., Hol, W.G.J., and Gelb, M.H. (2001) J. Med. Chem. 44, 2080-2093

Corbier, C., Michels, S., Wonacott, A.J., and Branlant, G. (1994) Biochem. 33, 32603265.

Brunger, A.T. (1992) "Free-R-value - A novel statistical quantity for assessing the accuracy of crystal structures" Nature, 355(6359), 472-475

Brunger, A.T., Rice, L. M. (1997) "Crystallographic refinement by simulated annealing: Methods and Applications" Methods in Enzymology, 277, 243-269

Brunger, A.T.; Adams, P. D.; Clore, G. M.; Delano, W. L.; Gros, p.; GroseeKunstleve, R. W.; Jang, J.; Kuszewski, J.; Nilges, M.; Pannu, N. S.; Read, R. J.; Rice, L. M.; Simonson, T.; Warren, G. L. (1998).Crystallography \& NMR System: "A New Software Suite for Macromolecular Structure Determination.", Acta Cryst. D54:905-921.

Drenth, J., Principles of protein X-ray crystallography. 2.ed. New York, Chernow Editorial Services, inc 1995

Ducruix, A. \& Giegé, R. (1992). "Crystallization of Nucleic Acids and Proteins - A Practical Approach." Oxford University Press. 331p.

Duggleby, R.G. and Dennis, D.T. (1974) "Nicotinamide adenine dinucleotide-specific glyceraldehydes-3-phosphate dehydrogenase from Pisum-sativum - assay and steady-state kinetics" J. Biol. Chem. 249, 167-174.

French, G. S., Wilson, K. S. (1978) "On the treatment of negative intensity observations" Acta Cryst., A34, 517-525

Guimarães, B.G. (1998). "Estudos Estruturais e Cinéticos da Enzima Gliceraldeído3-Fosfato Desidrogenase de Trypanosoma cruzi e Mutantes D210L, D210LG213D."Tese de Doutorado. IFSC-USP, São Carlos-SP. 
Harrigan, P.J. and Trentham, D.R. (1973)"Kinetic studies of acylation of pig muscle D-glyceraldehyde 3-phosphate dehydrogenase by 1,3-diphosphoglycerate and of proton uptake and release in overall enzyme mechanism" Biochem. J. 135, 695-703.

Jones, T. A., Zou, J. Y., Cowan, S. W., Kjeldgaard, M (1991) "improved methods for building protein models in electron density maps and the location of errors in these models" Acta Cryst. , A47, 110-119

Kim, H., Feil, I.K., Verlinde, C.L.M., Petra, P.H, and Hol, W.G.J. (1995) "Crystal structure of glycosomal glyceraldehyde-3-phosphate dehydrogenase from Leishmania mexicana - implication for structure-based drug design and a new position for the inorganic phosphate binding-site" Biochem. 34, 14975-14986.

Kim, H., Hol, W. G. (1998) "Crystal structure of Leishmania mexicana glycosomal glyceraldehyde-3-phosphate dehydrogenase in a new crystal form confirms the putative physiological active site structure" J. Mol. Biol., 278, 5-11

Konnert, J. H., Hendrikson, W. A. (1980) "A restrained-parameter thermal-factor refinement procedure" Acta Cryst. A36, 344-349.

Kuriyan, J., Brünger, A. T., Karplus, M., Hendrikson W. A. (1989) "X-ray Refinement of Protein Structures by Simulated Annealing: Test of the Method on Myohemerythrin" Acta Cryst., A45, 396-409

Lamzin, V. S., Wilson K. S. (1993) "Automated refinement of protein models" Acta Cryst., D49, 129-147

Laskowski, R.A.; Mac Arthur, M.W.; Moss, D.S.; Thorton, J.M. (1992). Procheck versão 2.0 , Inglaterra.

Maignan S., Guilloteau JP., Zhou-Liu Q., Clement-Mella C., Mikol V. (1998) " Crystal Structures of the Catalytic Domain of HIV-1 Integrase Free and Complexed with its Metal Cofactor: High Level of Similarity of the Active Site with Other Viral Integrases" J. Mol. Biol. 282, 359-368

Moran, L. A., Scrimgower, K. G. (1994) "Biochemistry" Pearson Higher Education Navaza, J. (1994)."AMORE - An Automated Package for Molecular Replacement." Acta Cryst. A50: 157-163

Otwinowski, Z.; Minor, W., (1997) "Processing of X-Ray Diffraction Data Collected in Oscillation Mode", Methods in Enzymology, Vol.276: Macromolecular Crystallography. Part A, p. 307- 326, C.W. Carter, Jr. \& R.M. Sweet, Eds., Academic Press

Pavão F., Castilho M.S., Pupo M..T, Dias R.L.A., Correa A.G., Fernandes J.B., da Silva M.F.G.F., Mafezoli J., Vieira .PC., Oliva G. (2002) "Structure of Trypanosoma cruzi glycosomal glyceraldehyde-3-phosphate dehydrogenase 
complexed with chalepin, a natural product inhibitor, at 1.95 angstrom resolution." FEBS Lett. 520(1-3):13-17.

Polikarpov, I., Perles, L. A., de Oliveira, R. T., Oliva, G., Castellano, E. E., Garratt, R. C., and Craievich, A. (1998) "Set-up and experimental parameters of the protein crystallography beamline at the Brazilian National Synchroton laboratory" J. Synchrotron Radiat. 5, 72-76.

Read, R. J. (1986) "Improved Fourier coefficients for maps using phases from partial structures with errors" Acta Cryst., A42 140-149

Segal, H.L. and Boyer, P.D. (1953) "The role of sulphydryl groups in the activity of D-glyceraldehyde-3-phosphate dehydrogenase"J. Biol. Chem. 204, 265-281.

Skarzynski, T., Moody, P.C.E., and Wonacott, A.J. (1987) "Stucture of hologlyceraldehyde-3-phosphate dehydrogenase from Bacillus stearothermophilus at 1.8Å resolution"J. Mol. Biol. 193, 171-187.

Souza, D.H.F., Garrat, R.C., Araújo, A.P.U., Guimarães, B.G., Jesus, W.D.P., Michels, P.A.M., Hannaert, V. and Oliva, G. (1998). "Trypanosoma cruzi Glycosomal Glyceraldehyde-3-Phosphate Dehydrogenase: Structure, Catalytic Mechanism and Targeted Inhibitor Design.", FEBS Lett. 424: 131-135.

Vellieux, F.M.D., Hajdu, J., Verlinde, C.L.M.J., Groendijk, H., Read, R.J., Greenhough, T.J., Campbell, J.W., Kalk, K.H., Littlechild, J.A., Watson, H.C., and Hol, W.G.J. (1993) "Structure of glycosomal glyceraldehyde-3-phosphate dehydrogenase from Trypanosoma brucei determined from Laue data" Proc. Natl. Acad. Sci. USA 20, 2355-2359.

Watson, H.C., Duée, E. and Mercer, W.D. (1972) "Low resolution structure of glyceraldehyde-3-phosphate dehydrogenase"Nature New Biol. 240, 130.

Yun, M., Park, C.G., Kim, J.Y., and Park, H.W. (2000) "Structural analysis of glyceraldehyde-3-phosphate dehydrogenase from Escherichia coli: Direct evidence of substrate binding and cofactor-induced conformational changes"Biochem. 39, 10702-10710 


\section{Capítulo IV- Modelagem molecular de inibidores da enzima gGAPDH de T. cruzi.}

\section{1- Introdução}

A dificuldade para obtenção de co-cristais da enzima gGAPDH com seus inibidores constitui um entrave para o processo de planejamento racional de inibidores com base na estrutura tridimensional da enzima. Uma alternativa para contornar, pelo menos parcialmente, esse problema passa pela a utilização de métodos de modelagem molecular que possam fornecer modelos plausíveis de interação inibidorenzima, ou seja, que modelem a interação de uma pequena molécula (ligante) dentro 
do sítio ativo da enzima de interesse. Esse processo é geralmente definido como “docking" (acoplamento) e será assim denominado de agora em diante.

O problema do docking pode ser divido em duas etapas principais;

1-gerar todos os complexos possíveis

2- identificar dentre os complexos gerados aquele que corresponde a solução correta.

A fim de realizar essas etapas os programas utilizam diferentes funções de busca (etapa 1) e diferentes funções de pontuação (etapa 2).

Os programas de docking em geral consideram que a molécula do receptor é rígida, enquanto a molécula do ligante pode ter uma flexibilidade parcial [Morris et al., 1998, Kramer et al., 1999].

Outra questão importante é a limitação do espaço translacional a ser explorado e como o ligante pode explorar esse espaço de forma adequada.

Enquanto alguns programas de docking exploram toda a superfície da proteína, outros exploram apenas uma região pré-definida pelo usuário. Dentro do primeiro tipo encontram-se os programas destinados ao docking proteína-proteína [Gabb et al., 1997] e dentro do segundo tipo encontram-se os programas destinados ao docking ligante-proteína [Leach \& Kuntz, 1992; Morris et al., 1998; Kramer et al., 1999].

Uma vez geradas todas as conformações possíveis do inibidor dentro do sítio de interação, é necessário avaliar cada uma dessas conformações e determinar qual dentre elas é a correta. Para tanto se utilizam funções de pontuação que levam em conta as interações intermoleculares descritas por termos clássicos da mecânica molecular (ex, campo de força AMBER), funções de pontuação empíricas (derivadas estatisticamente a partir de um conjunto de complexos cristalográficos (ligante-enzima, proteína-proteína, antígeno-anticorpo)), etc. 
Os programas utilizados para realizar os estudos descritos nesse trabalho foram; Autodock [Morris et al., 1998] e FLO [McMartin \& Bohacek, 1997]. Ambos os programas utilizam métodos estocásticos para tentar posicionar o ligante/inibidor dentro do sítio ativo e fazem a avaliação dos resultados encontrados segundo uma função de pontuação baseada no campo de força AMBER.

O programa Autodock, em particular, tem uma função de pontuação modificada, de forma a predizer empiricamente a energia livre de interação entre o ligante/inibidor e a enzima. Outra particularidade na função de pontuação do programa Autodock é a presença de uma penalidade para o "congelamento" de uma ligação simples quando da formação do complexo.

O programa FLO, por sua vez, permite a minimização do ligante dentro do sítio ativo da enzima, levando-se em consideração certo grau de flexibilidade para os resíduos da proteína.

A escolha desses programas baseou-se em dois critérios;

1- Disponibilidade e acesso gratuito desses programas para uso acadêmico;

2- Relatos na literatura de que métodos de busca estocásticos conseguem prever a localização de ligantes/inibidores em posições próximas daquelas encontradas cristalograficamente [Morris et al., 1998, Diller \& Verlinde, 1999].

\section{2- Metodologia geral de docking}

A maior afinidade de um ligante pela enzima reflete sua alta complementaridade química e estérica. Portanto, dentro de cada série de inibidores escolheu-se o composto com maior atividade inibitória, ou seja, aquele que apresentaria maior complementaridade química e estérica pela enzima, para se realizar os estudos de 
docking. Essa estratégia foi adotada pois compostos menos ativos podem interagir de forma inespecífica com a enzima e esse comportamento refletiria num aumento do número de soluções incorretas.

Além disso, dada a semelhança estrutural dos compostos dentro de suas classes, pode-se supor que seus modos de ligação sejam bastante semelhantes e que se possa modelar o modo de ligação de toda a série de inibidores a partir do modo de ligação do composto mais ativo.

Nos estudos de docking com o programa Autodock optou-se pela função de busca baseada no algoritmo genético modificado (Lamarckiano) [Morris et al., 1998] utilizando os parâmetros descritos no apêndice B. O programa FLO, por sua vez, possui uma função de busca baseada no algoritmo de Monte Carlo e o único parâmetro que pode ser controlado pelo usuário é o número de vezes que o programa realiza o ciclo de gerar conformações pelo método de Monte Carlo, minimizar essas conformações e avaliar a pontuação das conformações resultantes. Em todos os experimentos realizados esse número foi igual a 200 .

Após análise das energias de interação das soluções encontradas pelos programas de docking, procedeu-se a análise visual dos resultados obtidos. O modelo de interação de melhor energia de interação com a enzima, e que não apresenta problemas de solvatação/dessolvatação, foi então selecionado e utilizado para modelar os demais compostos da sua série.

Como o programa FLO permite que a solução encontrada pela função de busca seja minimizada dentro do sitio de interação (considerando uma flexibilidade parcial dos resíduos da enzima), essa estratégia foi adotada tanto para os resultados obtidos com o programa FLO, como para os resultados obtidos com o programa Autodock. O Algoritmo de minimização apresenta um termo adicional que tenta otimizar a posição dos átomos do ligante em relação à superfície acessível ao solvente da enzima. $\mathrm{O}$ 
resultado desse protocolo é a otimização da geometria do inibidor para sua interação com a enzima.

Os estudos de modelagem utilizaram as coordenadas cristalográficas da enzima gGAPDH nativa (estrutura na sua forma Holo), em complexo com o inibidor de origem natural chalepina (estrutura na sua forma Apo) e em complexo com o inibidor 33, descrito no capítulo III (estrutura na forma Holo e com sítios Pi e Ps préorganizados). A utilização dessas três estruturas visou simular a flexibilidade da enzima, uma vez que cada uma das estruturas cristalográficas apresenta modificações estruturais associadas a etapas características do mecanismo catalítico da enzima. Nas três estruturas cristalográficas foram considerados todos os tautômeros do resíduo $\mathrm{His}^{194}$, bem como a possibilidade de rotação de 180 graus no plano do anel da histidina e os estados protonado e não protonado do resíduo Cys ${ }^{166}$. Esse resíduos participam do mecanismo catalítico da gGAPDH e seu estado de protonação/tautomerização não pode ser determinado experimentalmente a partir das estruturas cristalográficas disponíveis.

A combinação desses parâmetros forneceu 8 modelos (Figura 1) de enzima para cada uma das estruturas disponíveis, totalizando 24 condições diferentes nas quais os estudos de docking foram realizados. 
<smiles>Sc1c[nH]cn1</smiles><smiles>Sc1cnc[nH]1</smiles><smiles>Sc1cnc[nH]1</smiles><smiles>Sc1c[nH]cn1</smiles><smiles>[3H]CS</smiles><smiles>Sc1c[nH]cn1</smiles><smiles>[Z6]CS</smiles><smiles>Sc1cnc[nH]1</smiles><smiles>[Z6]CS</smiles><smiles>Sc1cnc[nH]1</smiles><smiles>[3H]CS</smiles>

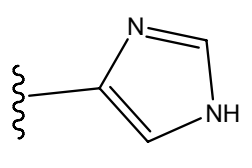<smiles>[3H]CS</smiles><smiles>[Z6]CS</smiles>

Figura 1- condições de protonoação da Cys ${ }^{166}$ e tautômeros da His ${ }^{194}$ utilizados nos estudos de docking. Conforme demonstrado acima, 8 condições diferentes de sítio ativo foram consideradas para cada uma das estruturas cristalográficas.

\section{3- Modelagem molecular de derivados cumarínicos.}

Conforme mencionado no capítulo II, item 3.4.1, uma série de derivados cumarínicos teve sua atividade inibitória frente a enzima gGAPDH de T. cruzi testada. A série de 3-piperonilcumarinas com anéis heterocíclicos na posição $R_{1}$ (vide tabela 1 do capítulo II) apresentou boa atividade inibitória e por essa razão foi selecionada para estudos de modelagem molecular

Outra razão para esse estudo vem do trabalho de Menezes e colaboradores com a chalepina e outras cumarinas de origem natural [Menezes et al., 2003]. Segundo os resultados desse trabalho, grupos volumosos (maiores do que 1,1-dimetilalila) na posição 3 deveriam diminuir a atividade inibitória de derivados cumarínicos contra a enzima gGAPDH. Entretanto, a atividade inibitória dos compostos 8 e 10, que possuem um grupo piperonil nessa posição, é semelhante aquela descrita para a chalepina (vide tabela 1 do capítulo II). 
Esse fato nos chamou atenção para uma questão levantada por Menezes e colaboradores; estariam estes derivados cumarínicos interagindo no mesmo sítio de ligação na enzima ?

A sobreposição estrutural dos derivados $\mathbf{8 ,} 9$ e $\mathbf{1 0}$ nas coordenadas cristalográficas da chalepina mostra que esses compostos não devem interagir no mesmo sítio de ligação que a chalepina* (figura 2).

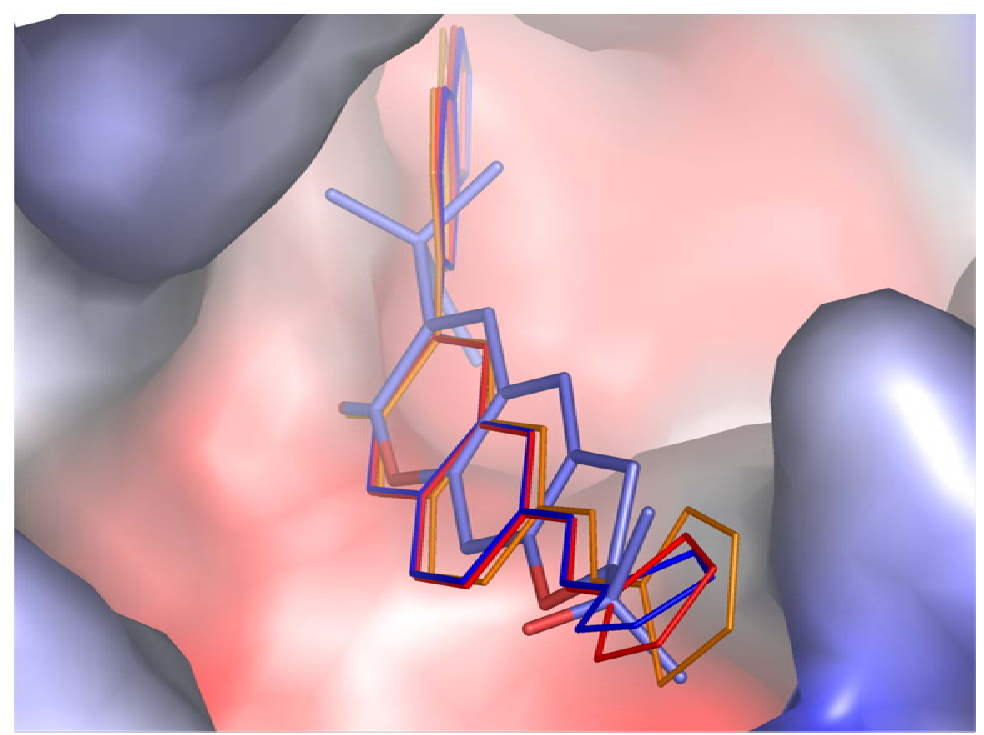

Figura 2- Sobreposição estrutural dos derivados cumarínicos 8, 9 e $10 \mathrm{com}$ relação a chalepina. A proteína está representada de acordo com sua superfície molecular, e colorida de acordo com o seu potencial eletrostático (vermelho negativo, azul positivo). Note que os grupos piperonilas dos derivados cumarínicos 8, 9, e 10 localizam-se muito próximo à superfície molecular da proteína. De fato ocorreria um choque estérico entre os átomos dos inibidores e da proteína se eles se ligassem dessa forma no sítio ativo da gGAPDH. Os inibidores estão representados da seguinte forma; chalepina - linhas grossas coloridas de acordo com o tipo de átomo, derivados cumarínicos 8 (vermelho), 9 (laranja) e 10 (azul) estão representados por linhas finas.

\footnotetext{
* A sobreposição estrutural foi realizada com o programa FLO. O algoritmo de sobreposição considera a conformação cristalográfica do alvo (chalepina) como conformação bioativa e tenta sobrepor as moléculas de inibidor sobre essa conformação, portanto além de uma simples sobreposição, átomo à átomo, é realizada também uma otimização da conformação dos inibidores, considerando-se como mínimo global a conformação bioativa.
} 
Esse resultado nos levou a utilizar métodos de modelagem molecular para tentar compreender o perfil de interação dos derivados heterocíclicos e explicar as diferenças de atividade encontradas para os compostos $8,9 \mathrm{e}^{\dagger} \mathbf{1 0}^{\dagger}$.

De acordo com a metodologia de docking descrita, o composto 10 foi escolhido como modelo para os estudos de docking.

Ao se analisar as soluções com melhor pontuação do programa Autodock constatou-se que na maioria dos casos havia problemas de solvatação bastante sérios ou baixa complementaridade estérica entre 10 e a enzima. Por outro lado, as soluções encontradas pelo programa FLO, quando se utilizou a estrutura do complexo gGAPDHchalepina [Pavão et al., 2002], apresentaram melhor perfil de interação. Na figura 3 está representado o melhor modelo de interação proposto para 10 em relação à superfície acessível ao solvente.
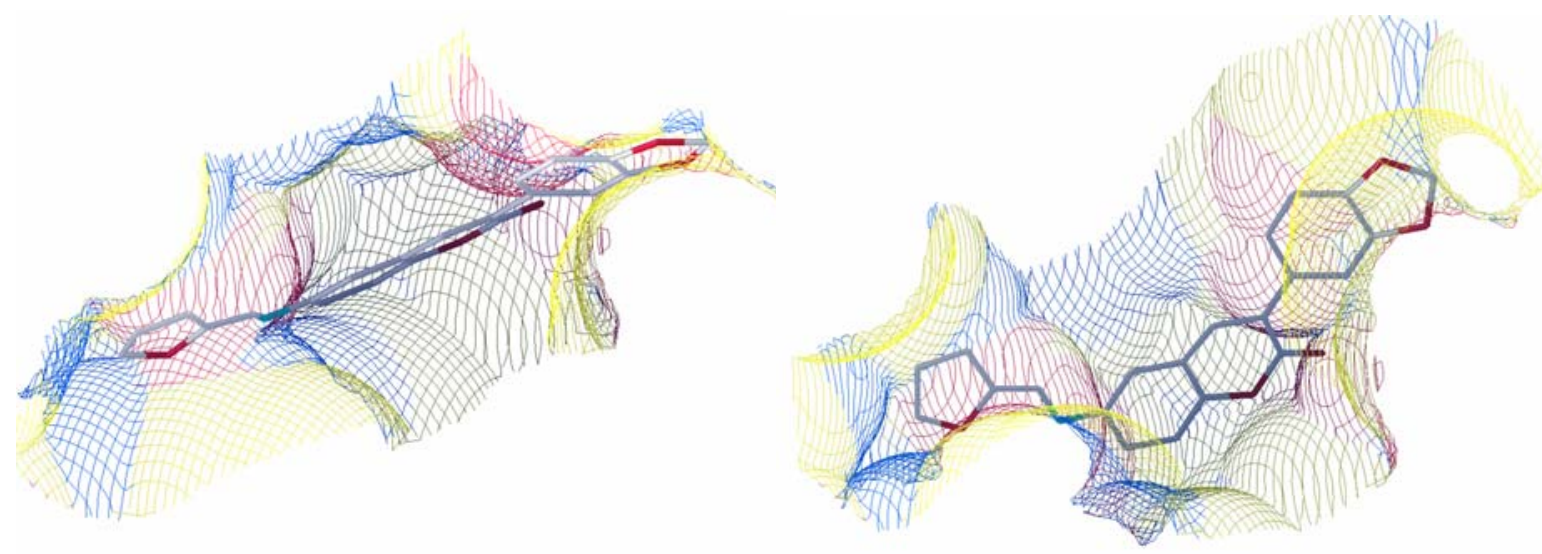

Figura 3- Modelo de interação de 10 em relação à superfície acessível ao solvente (SAS) da enzima gGAPDH. A figura mostra duas visões diferentes do ligante dentro do sítio ativo. $\mathrm{Na}$ figura da esquerda podemos perceber que o anel metilenodioxila encontra-se "enterrado" entre duas regiões hidrofóbicas (amarela) enquanto o anel furano encontra-se perto de uma região doadora de prótons (vermelha). O anel cumarínico encontra-se distante da SAS contribuindo muito pouco com a energia de interação desse modelo de interação $(30,7 \mathrm{KJ} / \mathrm{mol})$. O esquema de cores da SAS está discutido abaixo. Chama atenção o fato do anel cumarínico não se encontrar próximo a SAS, o que poderia acarretar em problemas de solvatação/dessolvatação. Entretanto essa região da proteína tem caráter hidrofóbico, o que minimizaria esse problema.

† Paralelamente aos estudos de modelagem molecular, tentou-se co-cristalizar esses compostos com a enzima gGAPDH, entretanto ainda não obtivemos sucesso nesses experimentos 
Durante a análise visual, a qualidade da solução encontrada pode ser avaliada através da complementaridade estérica e química que o composto apresenta em relação à superfície acessível ao solvente da proteína. Segundo essa representação, os átomos do composto deveriam se localizar próximos à superfície, e aqueles que realizam interações do tipo ligação de $\mathrm{H}$ deveriam estar localizados ligeiramente no interior da superfície acessível ao solvente.

O programa FLO fornece ainda uma outra ferramenta para auxiliar essa análise; a superfície acessível ao solvente é colorida de acordo com o tipo de interação favorável para um dado resíduo/átomo. Dessa forma, regiões hidrofóbicas (onde se devem encontrar interação do tipo Van der Waals entre o composto e a enzima) são coloridas de amarelo, regiões polares aceptoras de prótons (onde deveria se localizar um doador de prótons no inibidor) são coloridas de azul; regiões polares doadoras de prótons (onde deveria se localizar um aceptor de prótons no inibidor) são coloridas de vermelho.

Segundo esse modelo de interação, a atividade inibitória está relacionada com interações que os oxigênios dos grupos metilenodioxila e furano realizam com os resíduos $\operatorname{Ser}^{164}$, e, Thr $^{199}$ respectivamente.

Esse modo de interação pode ser uma conseqüência da baixa complementaridade entre o anel cumarínico e o sítio ativo da gGAPDH. A estrutura cristalográfica do complexo chalepina-gGAPDH revela que importantes interações entre a cumarina (chalepina) e o sítio ativo são mediadas por moléculas de águas [Pavão et al., 2002]. A figura 4 mostra o padrão de interação de 10 segundo o modelo de interação sugerido pelos programas de docking. 


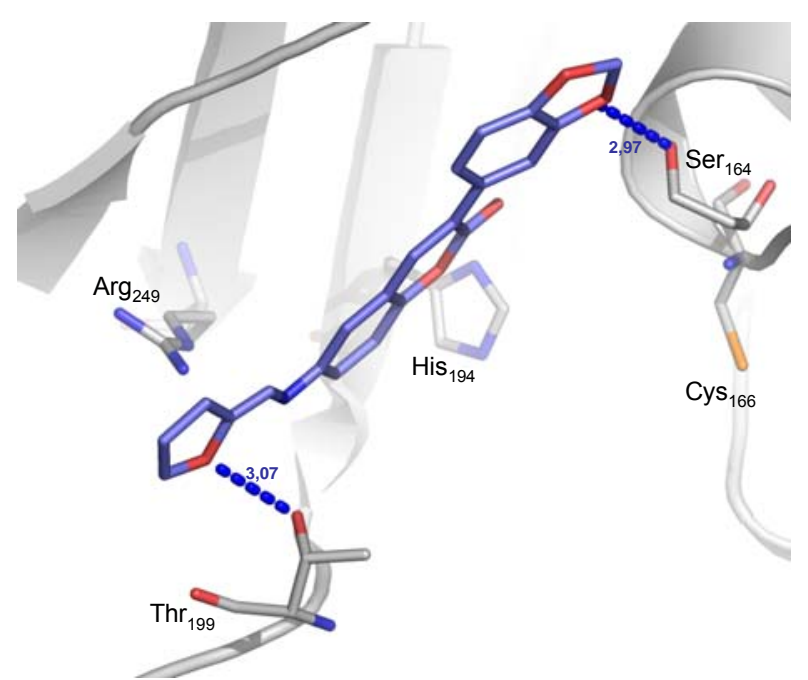

Figura 4- padrão de interação de $10 \mathrm{com}$ a enzima gGAPDH. Segundo o modelo de interação proposto pelo programa FLO. O composto 10 realiza ligações de $\mathrm{H}$ com os resíduos $\operatorname{Ser}^{164} \mathrm{e}$ $\mathrm{Thr}^{199}$. Os demais resíduos em destaque na figura são essenciais para o mecanismo catalítico da enzima. A enzima está representada de forma esquemática na forma de folhas $\beta$ e hélices $\alpha$.

A fim de avaliar os demais compostos da série segundo esse modelo de interação proposto, realizou-se a troca do hetero-átomo do anel na posição $R_{1}$ (substituição do oxigênio do anel furano por nitrogênio e enxofre) e os compostos 8 e 9 foram minimizados dentro do sitio ativo da enzima. A figura 5 mostra a sobreposição das soluções encontradas para os compostos 8, 9 e 10. 


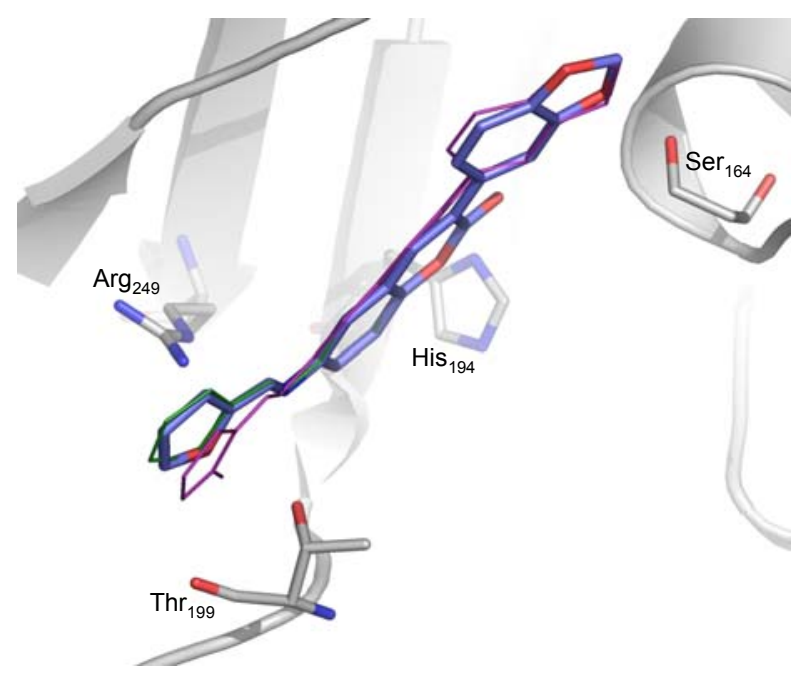

Figura 5- Sobreposição das soluções encontradas pelo programa FLO para os compostos 8, 9 e 10. A sobreposição dos compostos é quase perfeita, a não ser por um deslocamento mínimo na região dos heteroátomos. De fato isso ocorre de forma a favorecer ou não a formação da ligação de $\mathrm{H}$ com o resíduo $\mathrm{Thr}^{199}$. O composto 10 está representado de acordo com o tipo de átomo, 8 está representado em púrpura e $9 \mathrm{em}$ verde. A proteína está representada de forma esquemática na forma de folhas $\beta$ e hélices $\alpha$.

Observa-se um pequeno deslocamento entre os inibidores na região dos anéis heterocíclicos. Isso pode ser decorrente das diferentes orientações necessárias para que se forme uma ligação de hidrogênio entre o inibidor e a enzima. No caso do composto 9 não há formação da ligação de $\mathrm{H}$ entre o heteroátomo enxofre e o resíduo $\mathrm{Thr}^{199}$. Dessa forma o composto não fica preso dentro do sítio ativo o que deve influenciar negativamente sua interação com a enzima. Esse pode ser um fator importante para a menor atividade de 9 em relação ao demais bioisósteros da série.

Os compostos 8a e 11 não foram incluídos nesse estudo de modelagem, entretanto a análise visual do composto 11 revela que o heteroátomo do anel indol não está localizado na posição ideal para fazer ligação de hidrogênio com o resíduo $\mathrm{Thr}^{199}$. O composto $\mathbf{8 a}$, por sua vez, apresenta o heteroátomo na posição ideal para realizar esse tipo de interação, contudo sua atividade inibitória também é reduzida (quando comparada, por exemplo, ao composto 9). Nesse caso a explicação para sua menor 
atividade frente à gGAPDH pode estar relacionada com o caráter $\pi$-deficiente do seu anel heterocíclico. Esse caráter ( $\pi$-deficiente) deve desfavorecer uma interação do tipo transferência de carga entre o inibidor e o resíduo $\operatorname{Arg}^{249}$ (que estaria localizado na proximidade do anel piridina) e conseqüentemente influenciar negativamente a interação desse inibidor com a enzima.

\section{4- Modelagem de compostos bisfosfonados}

A caracterização do modo de interação entre os derivados bisfosfonados e a enzima gGAPDH é de grande importância para o planejamento de novos inbibidores. Até o presente momento não se conseguiu cristais de boa qualidade para estudos de difração de raios $X$, razão pela qual, recorreu-se mais uma vez aos estudos de modelagem molecular como forma de criar modelos de interação ligante-enzima que pudessem guiar o planejamento de novos derivados bisfosfonados.

O composto 22 apresenta dois átomos de fósforo separados por uma distância de $2,70 \AA \AA$, a qual é comparável à distância dos átomos de fósforo presentes na molécula de NAD (2,89Å). Por essa razão supôs-se inicialmente que o composto 22 poderia estar mimetizando os fosfatos do NAD e competindo com ele pelo seu sítio de ligação. Numa tentativa de corroborar essa hipótese o programa Catalyst foi utilizado para sobrepor o composto 22 nas coordenadas cristalográficas do NAD $\ddagger$ (Figura 6).

\footnotetext{
‡ Esse estudo foi realizado pelo professor Eric Oldfield na Universidade de Urbana Campaign e apenas os resultados finais desse estudo estão apresentados nesse trabalho. Os detalhes experimentais não serão apresentados.
} 


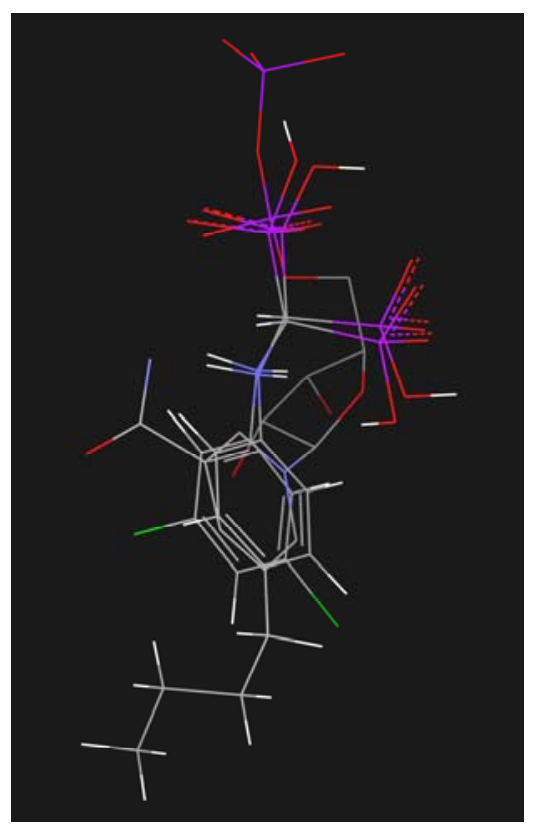

Figura 6- Sobreposição estrutural dos compostos 22 e de um possível derivado nas coordenadas cristalográficas do NAD da estrutura nativa de gGAPDH de $T$. cruzi. A figura mostra apenas a região de sobreposição dos compostos sobre NAD (apenas parte da molécula do NAD está representada). Figura gerada pelo prof. Oldfield utilizando o programa Catalyst.

Apesar do modelo de sobreposição com o NAD ser bastante razoável, esse tipo de estudo não leva em consideração fatores bastante importantes para o planejamento racional de inibidores, por exemplo, a estrutura tridimensional do receptor e as restrições estereoquímicas que ela impõe.

Numa tentativa de adicionar essa informação estrutural ao nosso modelo, utilizou-se o programa FLO para sobrepor o composto 22 nas coordenadas cristalográficas do NAD, encontrado no complexo gGAPDH-30 (descrito no capítulo III).

Os resultados encontrados assemelham-se àqueles encontrados pelo programa Catalyst, exceto por um deslocamento da cadeia alquílica do composto 22, que é resultado de choque estérico com resíduos da proteína (Figura 7).

Figura 7- Sobreposição estrutural do composto 22 sobre as coordenadas do NAD encontradas no complexo gGAPDH-30. À esquerda está representado o resultado obtido com a Cys ${ }^{166}$ protonada e à direita o resultado obtido com a Cys ${ }^{166}$ desprotonada. As moléculas de ligante 


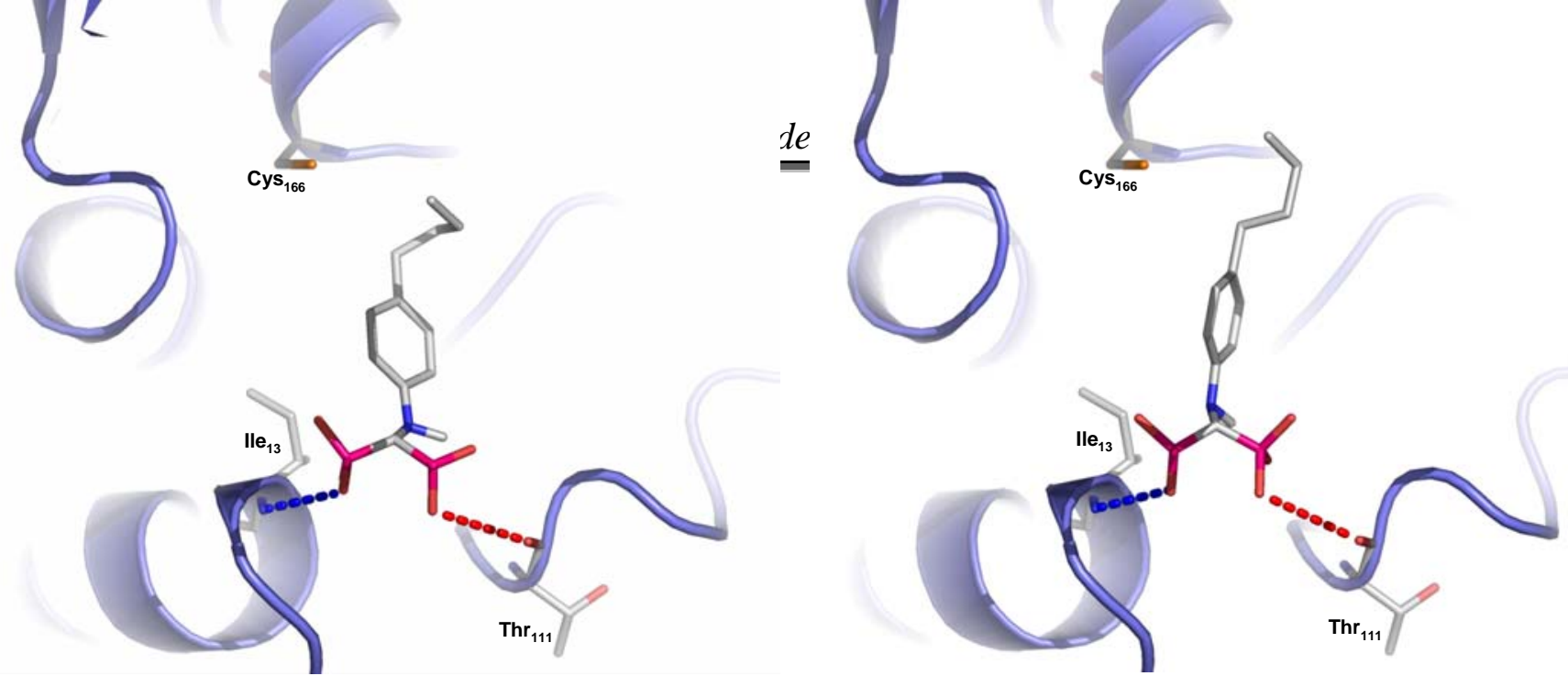

estão representadas por linhas grossas e a molécula de NAD está representada em linhas finas.

Entretanto a análise das interações que o composto 22 deveria fazer, se interagindo nessa posição, apresenta algumas características incomuns; (i) grupos apolares do composto amplamente expostos ao solvente, (ii) grupos fosfonatos em choques estéricos com a proteína, (iii) rede de ligações de $\mathrm{H}$ incompleta entre ligante e proteína (Figura 8).

A soma de todos estes fatores nos leva a crer que esse não é o modo de interação correto do composto 22. 


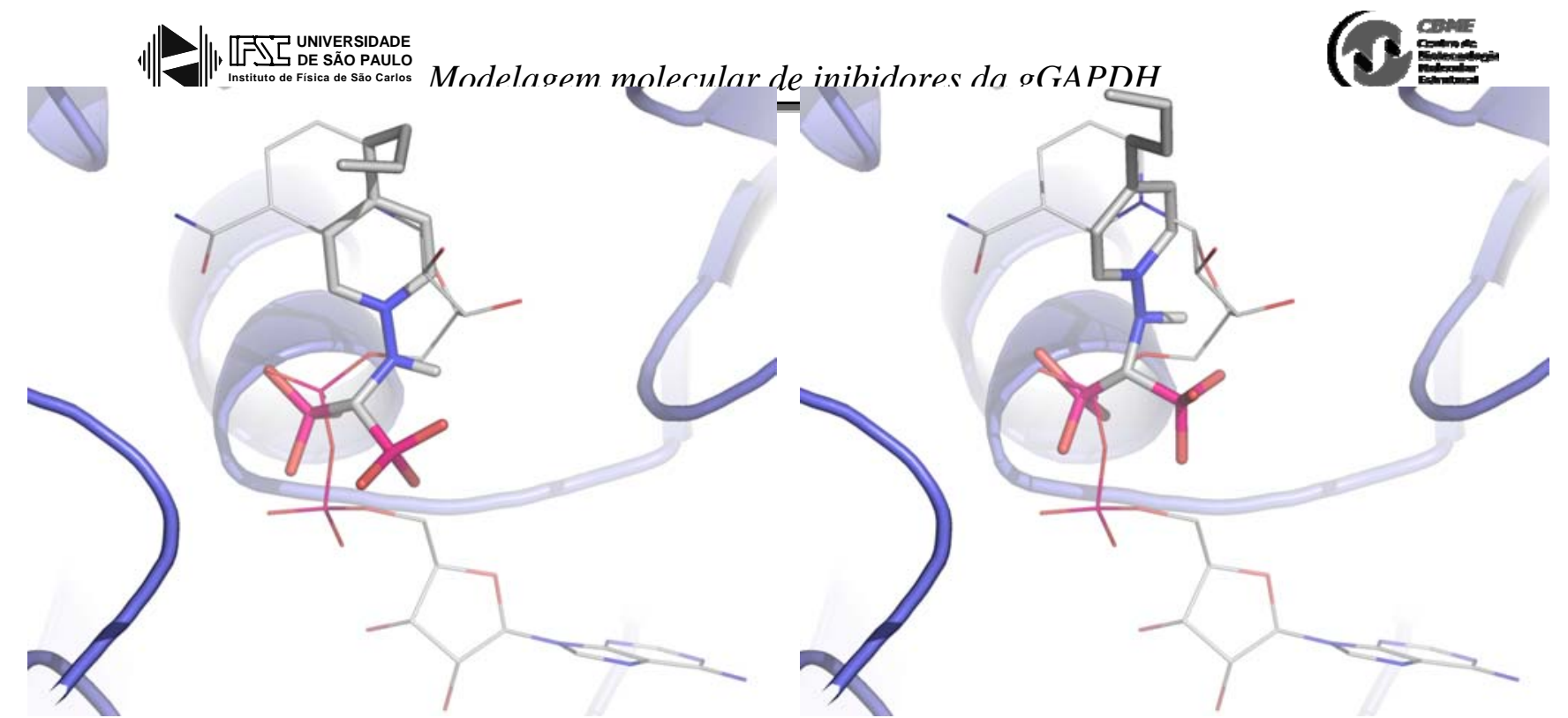

Figura 8- Perfil de interação molecular do composto 22 no sítio de ligação do NAD. Esquerda (resultado obtido com a Cys ${ }^{166}$ protonada). Segundo esse modelo de interação um dos grupos fosfonato apresentaria choque estérico com o resíduo $\mathrm{Thr}^{111}$. Direita (resultado obtido com a Cys ${ }^{166}$ desprotonada) o mesmo choque estérico ocorreria e, além disso, a cadeia alquílica está distante da SAS e exposta ao solvente.

Numa tentativa de encontrar um modelo de interação alternativo para o composto 22, os programa Autodock e FLO foram utilizados para realizar o docking do composto $22^{\S}$ no sítio ativo e no sítio do cofator da enzima gGAPDH. A estrutura cristalográfica utilizada nesses estudos foi aquela do complexo gGAPDH-30.

Os modelos de interação gerados pelos programas FLO e Autodock estão discutidos separadamente a seguir.

\footnotetext{
${ }^{\S}$ Os compostos 23 e 24 não haviam sido ensaiados quando dos estudos de modelagem molecular
} 


\section{1- Resultados de docking obtidos com o programa FLO}

As soluções encontradas pelo programa convergem para dois modos de interação, de acordo com os diferentes estados de protonação da Cys ${ }^{166}$.

\subsection{1- Resultados obtidos com Cys ${ }^{166}$ protonada}

A maioria das soluções apresenta os grupos fosfonato localizados no sítio de ligação do fosfato inorgânico $\left(\mathrm{Thr}^{226}, \mathrm{Arg}^{249}, \mathrm{Thr}^{167}\right)$ e a parte hidrofóbica estendendo-se em direção ao anel nicotinamida do NAD+. (Figura 9)

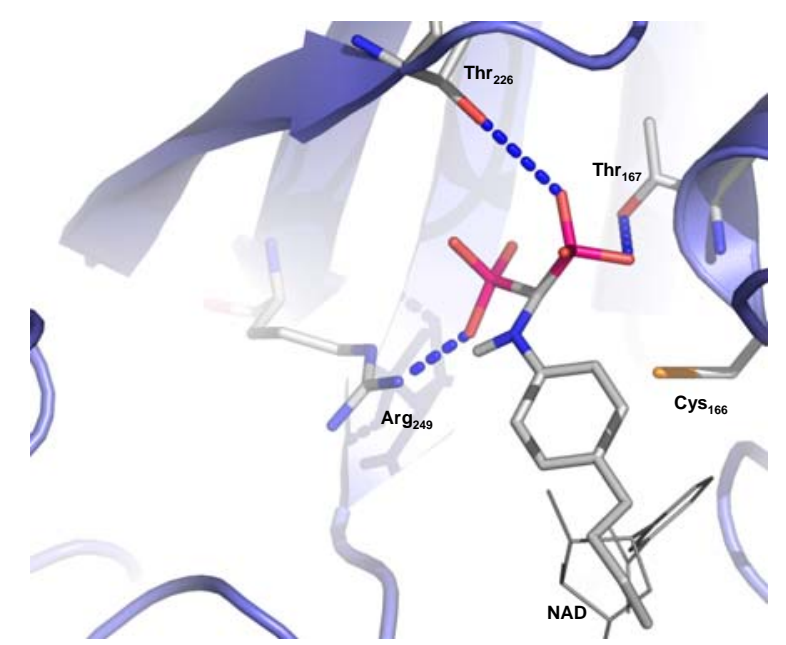

Figura 9- Perfil de interação molecular do composto 22. Os grupos fosfato localizam-se próximos ao sítio de fosfato inorgânico onde realizam ligações de $\mathrm{H}$ com os resíduos $\mathrm{Thr}^{167}$, $\mathrm{Thr}^{226}$ e $\mathrm{Arg}^{249}$. A cadeia alquílica estende-se em direção a Cys ${ }^{166}$ e ao anel nicotinamida do $\mathrm{NAD}^{+}$(representado em cinza - linhas finas).

Essa solução apresenta boa complementaridade estérica e química (fosfato localizados em regiões vermelhas - doadoras de prótons - e cadeia alquílica próxima a região amarela - apolar) com a SAS conforme demonstrado na figura 10 


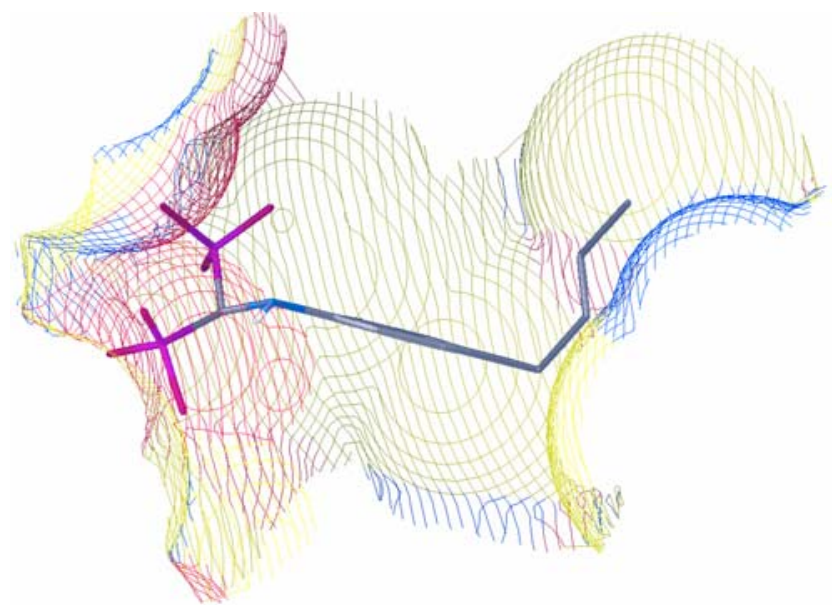

Figura 10- Modelo de interação de 22 em relação à superfície acessível ao solvente (SAS) da enzima gGAPDH. Pode-se perceber que os grupos fosfato do ligante encontram-se próximos de uma superfície vermelha (doadora de prótons), enquanto sua cadeia alquílica e o anel fenílico estão próximos a uma região hidrofóbica (superfície amarela).

\subsection{2- Resultados obtidos com Cys ${ }^{166}$ desprotonada}

As soluções mais uma vez posicionam os grupos fosfonatos na região do sítio de fosfato inorgânico, porém o anel fenílico e a cadeia alquílica da molécula estão orientados numa "direção" diferente daquela encontrada para a Cys ${ }^{166}$ desprotonada. Nesse caso a cadeia alquílica estende-se em direção ao resíduo Asp $^{210}$ (Figura 11). 

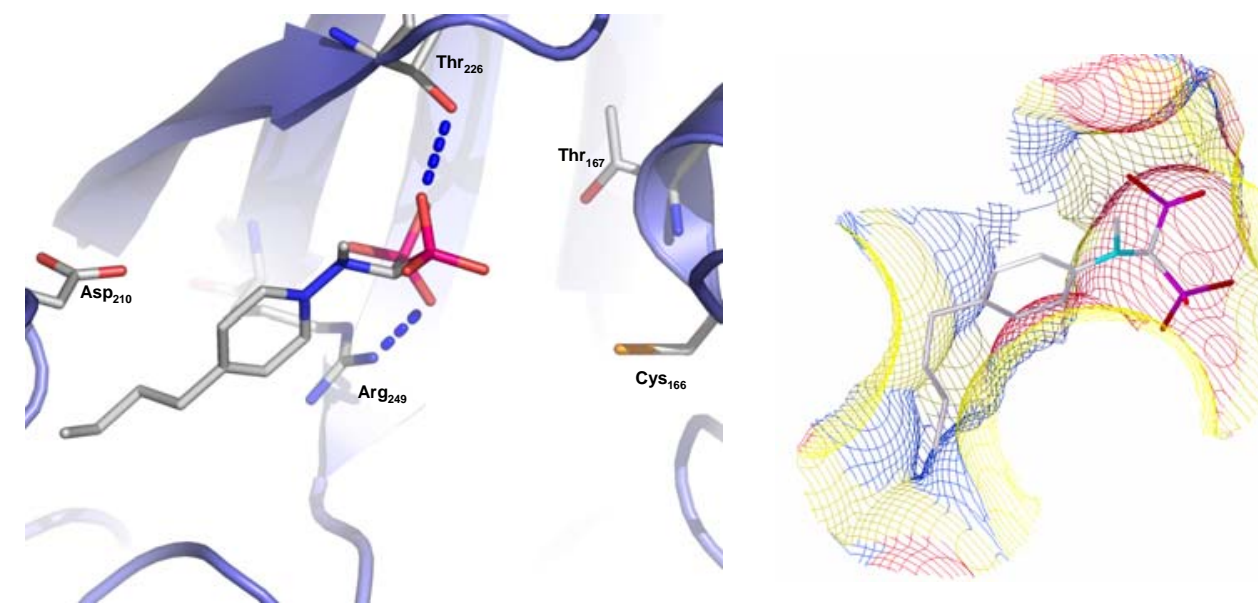

Figura 11- (esquerda) Perfil de interação molecular do composto 22. Os grupos fosfonato localizam-se próximos ao sítio de fosfato inorgânico onde realizam ligações de $\mathrm{H}$ com os resíduos $\mathrm{Thr}^{226}$ e $\mathrm{Arg}^{249}$. A cadeia alquílica por sua vez está próxima ao resíduo $\mathrm{Asp}_{210}$, porém não interage com ele. (direita) Modelo de interação de 22 em relação à superfície acessível ao solvente (SAS) da enzima gGAPDH. Nota-se que a complementaridade com a SAS também é bastante razoável.

\section{2- Resultados de dockig com o programa AUTODOCK}

A melhor solução encontrada pelo programa Autodock para Cys ${ }^{166}$ desprotonada (Figura 12) é idêntica àquela encontrada pelo programa FLO, nas mesmas condições.

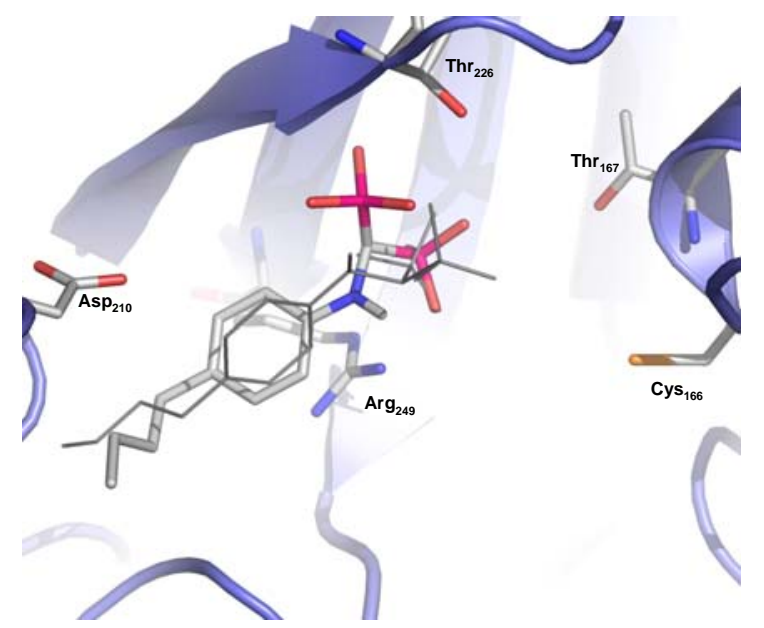

Figura 12- Sobreposição da solução encontrada pelo programa Autodock sobre a solução encontrada pelo programa FLO quando se considera a Cys ${ }^{166}$ desprotonada. O perfil de interação dessa solução é praticamente igual àquele descrito na figura 11 (ligação de hidrogênio com os resíduos $\operatorname{Thr}^{226}$ e $\mathrm{Arg}^{249}$ ) 
O consenso na solução encontrada por programas de docking que utilizam funções de busca e pontuação diferentes reforça a hipótese de que o modelo de interação do composto 22 pode ser aquele encontrado nos dockings realizados com a Cys $^{166}$ desprotonada.

Esse modelo de interação parece bastante razoável uma vez que nossos estudos cristalográficos, assim como muitos outros da literatura, mostram que o sítio do fosfato inorgânico é bastante flexível, o que Ihe possibilitaria acomodar os dois grupos fosfato de 22. Outro resultado que embasa essa hipótese é o encaixe dessa solução na superfície de interação molecular gerada pelo programa GRID [Goodford, 1985] para as cargas de prova $\mathrm{CH}_{3}$ e $\mathrm{PO}_{4}^{-2}$, (Figura 13).

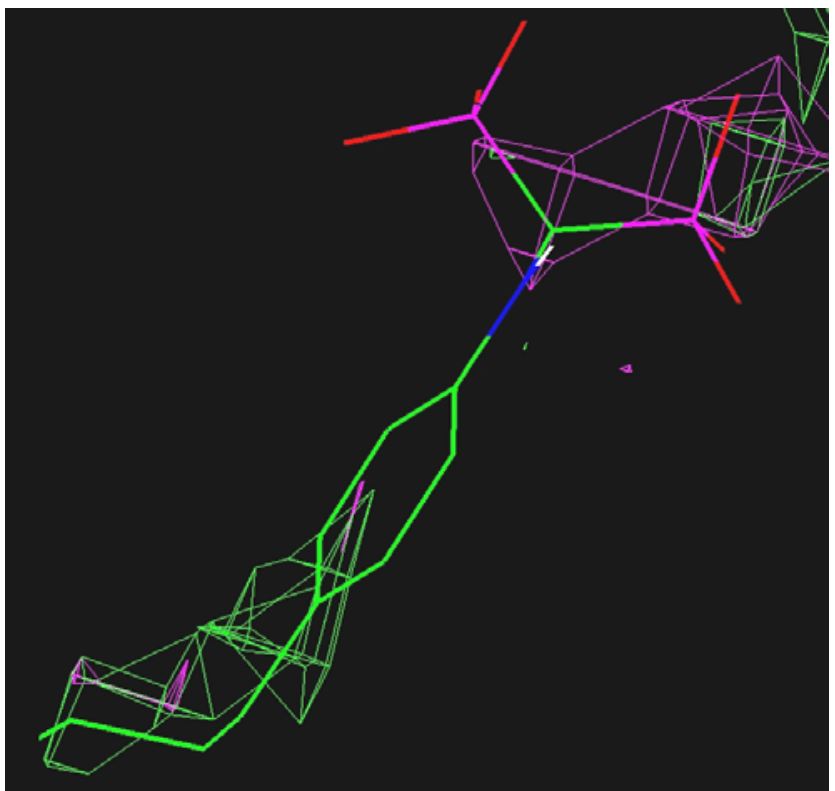

Figura 13- Sobreposição dos contornos de energia para $\mathrm{CH}_{3}(-3.0 \mathrm{Kcal} / \mathrm{mol})$ em verde e $\mathrm{PO}_{4}^{-2}(-12.0 \mathrm{Kcal} / \mathrm{mol})$ em rosa sobre a conformação do composto 22 gerada pelo programa Autodock 
Com base nesse modelo de interação, uma série de derivados foi proposta (Figura 14) e está sendo sintetizada pelo prof. Eric Oldfield<smiles>[R]C1Cc2ccc(NC(P(=O)(O)O)P(=O)(O)O)cc2C1</smiles><smiles>[R]C1COc2cc(NC(P(=O)(O)O)P(=O)(O)O)ccc2O1</smiles><smiles>[R17]CCC[N+](=O)[O-]</smiles>

Figura 14- Derivados bisfosfonados propostos para síntese com base no modelo de interação previsto pelos programas FLO e Autodock.

\section{5- Referências bibliográficas}

Diller, D. J.; Verlinde, C. L. M. J. (1999) "A critical evaluation of several global optimization algorithms for the purpose of molecular docking" J. Comp.Chem.. 20(16) 1740-1751

Gabb, H. A; Jackson, R. M; Sternberg M. J. E. (1997) "Modelling protein docking using shape complementarity, electrostatics, and biochemical information." J. Mol. Biol., 272:106-120, 1997.

Goodford, P. J. (1985) "A computational procedure for determining energetically favorable binding-sites on biologically important macromolecules", J. Med. Chem., 28(7), 849.857.

Kramer B.; Rarey M.; Lengauer T. (1999) "Evaluation of the FlexX incremental construction algorithm for protein-ligand docking" PROTEINS: Struct. Funct. Gen $37: 228\{241)$

Leah, A. R., Kuntz, I. D. (1992) "Conformational-analysis of flexible ligands in macromlecular receptor-sites", J. Comp. Chem., 13(6), 730-748

Mcmartin, C.; Bohacek, R. S. (1997) "QXP: Powerful, rapid computer algorithm for structure-based drug design" J. Comp. aided. Mol. Design, 11, 333-344 
Menezes, I. R. A., Lopes, J. C..D., Montanari, C. A., Oliva, G., Pavão, F., Castilho, M. S., Vieira, P. C., Pupo, M. T. (2003 )“3D QSAR studies on binding affinities of coumarin natural products for glycosomal GAPDH of Trypanosoma cruzi" J. Comp. Aided Mol. Design, 17, 277-290, 2003.

Morris G. M.; Goodsell D. S.; Halliday, R. S.; Huey, R.; Hart, W. E.; Belew, R. K.; Olson, A. J. (1998) "Automated Docking Using a Lamarckian Genetic Algorithm and an Empirical Binding Free Energy Function.” J. Comp. Chem. 19(14), 1639-1662

Pavão F., Castilho M.S., Pupo M.T, Dias R.L.A., Correa A.G., Fernandes J.B., da Silva M.F.G.F., Mafezoli J., Vieira .PC., Oliva G. (2002) "Structure of Trypanosoma cruzi glycosomal glyceraldehyde-3-phosphate dehydrogenase complexed with chalepin, a natural product inhibitor, at 1.95 angstrom resolution." FEBS Lett. 520(1-3), 13-17 


\section{Capítulo V- Clonagem,}

\section{expressão e purificação da enzima XPRT de L. major Friedling}

1- Introdução

Para se obter o clone de um gene torna-se necessário utilizar um vetor no qual o gene de interesse deve ser inserido. Os plasmídeos estão entre os vetores mais utilizados e, com base na presença ou ausência de região promotora, podem ser separados em dois grupos distintos: plasmídeos de clonagem propriamente ditos, utilizados para propagar o gene clonado, e plasmídeos de expressão que, além de propagar o gene, apresentam região 
promotora possibilitando a expressão da proteína recombinante em células hospedeiras apropriadas. Os passos gerais para a clonagem de um gene, usando um plasmídeo como vetor e uma bactéria como agente de propagação, estão descritos de maneira resumida a seguir e apresentados de forma esquemática na figura 1.

Após a seleção do gene de interesse (DNA doador), deve-se escolher o plasmídeo a ser utilizado, a fim de introduzi-lo na célula hospedeira, que pode ser, por exemplo, uma bactéria. O vetor escolhido pode apresentar sítios de clivagem complementares aos sítios encontrados no DNA doador. Endonucleases de restrição se ligam a seqüências específicas de bases (sítios de clivagem) e clivam o DNA por hidrólise da ligação fosfodiéster. As hidrólises dos dois DNAs devem ser feitas em experimentos separados, resultando na linearização do vetor e na separação do gene alvo do restante do DNA doador. No procedimento seguinte, o gene e o plasmídeo linearizados são ligados pela ação de uma enzima, a DNA-ligase. A nova molécula formada (DNA recombinante), é então introduzida em uma célula bacteriana previamente preparada, denominada célula competente. A multiplicação em série da bactéria transformada caracteriza a clonagem do gene [Howe, 1985; Stansfid, 1996, Watson et al., 1992]. 
A1

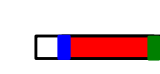

\section{A2}

Adição das enzimas de restrição

B1
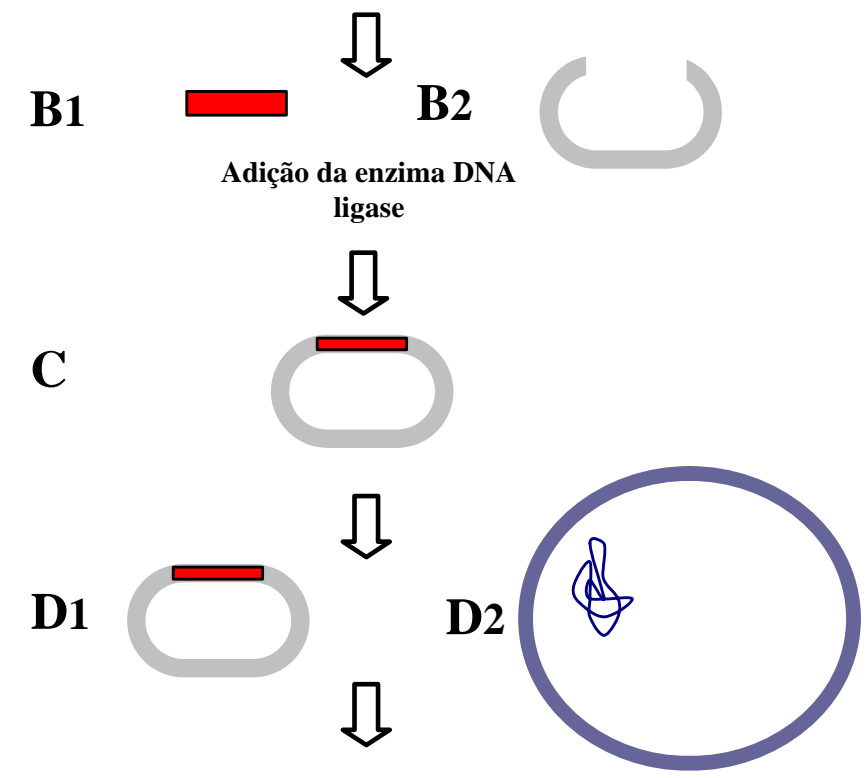

Experimento para a transformação das bactérias competentes

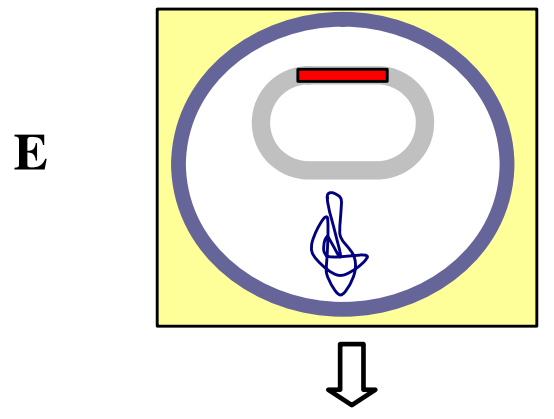

Experimento para a propagação das células transformadas

$\mathbf{F}$

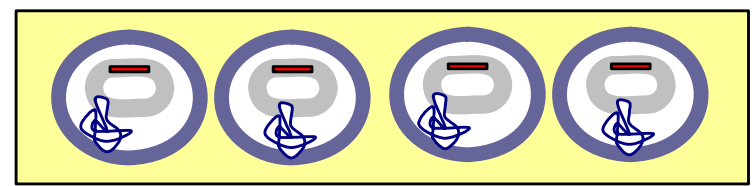

Figura 1- Representação esquemática de um experimento de clonagem em bactéria. A1- Fragmento de DNA com o gene de interesse destacado em vermelho e dois sítios de clivagem para enzimas de restrição distintas marcados em verde e azul. A2Plasmídeo vetor contendo sítios para clivagens iguais aos encontrados no DNA de interesse. B1-Gene alvo liberado pela ação das enzimas de restrição. B2Plasmídeo linearizado. C e D1- Plasmídeo recombinante gerado pela ação da enzima DNA-ligase. D2- Célula bacteriana competente. EBactéria transformada com o DNA recombinante isolada em meio de cultura seletivo (representado em amarelo). F- Clones obtidos após incubação em meio de cultura seletivo.

Qualquer estratégia elaborada para conseguir clones de um gene apresenta como dificuldade inicial a obtenção de muitas cópias do gene alvo. Na prática, a amplificação do gene por PCR é a metodologia utilizada para superar essa dificuldade. A amplificação pode ser feita a partir do DNA genômico ou biblioteca gênica do organismo de interesse. Na amplificação são utilizados pequenos 
fragmentos sintéticos de DNA, denominados oligodesoxirribonucleotídeos (oligonucleotídeos), que hibridizam com as extremidades do gene alvo, possibilitando sua amplificação pela ação de uma enzima DNA-polimerase. Posteriormente a amplificação, o gene obtido em grande quantidade pode ser purificado e utilizado nos passos subseqüentes da clonagem.

\section{2- Amplificação do gene xprt de Leishmania major}

Numa primeira etapa, utilizou-se como sonda a seqüência de xprt de $L$. donovani, recentemente publicada, para identificar no genoma de L. major (http://www.ebi.ac.uk/parasites/leish.html) a seqüência de bases que codifica a enzima XPRT nesse organismo. Uma vez identificada essa seqüência, o DNA genômico de L. major foi submetido à amplificação por PCR.

$\mathrm{Na}$ amplificação utilizaram-se dois oligonucleotídeos complementares as regiões terminais do gene xprt de $L$. major. Os oligonucleotídeos foram sintetizados por uma empresa especializada e, de acordo como a representação esquemática na figura 2, apresentam sítios para a clivagem com as enzimas de restrição Nde I e Xho I. Conforme será apresentado no item que trata da clonagem do gene xprt no vetor de expressão pET29a(+), os sítios de clivagem são importantes para a obtenção da proteína na forma nativa. 


\section{5' TAG CTA CAT ATG CTA CCA ACC CAC ATG 3' $\uparrow$ Nde I $\uparrow$ \\ 5'TCT CGA GTC AGA GCT TGG CAG GAT AAC GGG 3' Oligonucleotídeo 2 $\uparrow$ Xho I}

Figura z- sequencıa ae pases aos olıgonucıeotıaeos utוlızaaos para a ampııtıcaçao do gene xprt por PCR. Em destaque os sítios de ligação das enzimas de restrição Nde I e Xho I utilizadas na clonagem do gene xprt.

A solução para a reação de PCR e o protocolo utilizado durante a amplificação estão apresentados nas tabelas 1 e 2 respectivamente.

Tabela 1- Reagentes utilizados na amplificação do gene xprt de L. major por PCR.

\begin{tabular}{lcc}
\hline \hline Reagente & Volume $(\mu l)$ & Concentração \\
\hline \hline Tampão 10x PCR & 5 & \\
$\mathrm{Mg} \mathrm{Cl}_{2}$ & 1,5 & $50 \mathrm{mM}$ \\
dNTPs & 1 & $10 \mathrm{nM}$ \\
Oligonucleotídeo 1 & 1,25 & $100 \mathrm{pM}$ \\
Oligonucleotídeo 2 & 1,25 & $100 \mathrm{pM}$ \\
$\mathrm{H}_{2} \mathrm{O}$ & 36,5 & $5 \mathrm{U} / \mu \mathrm{l}$ \\
Taq DNA. Pol. & 0,5 & $160 \mathrm{ng} / \mu \mathrm{l}$ \\
DNA genômico & 1 & \\
& Final 50 & \\
\hline \hline
\end{tabular}

Tabela 2- Protocolo da reação de PCR utilizado na amplificação do gene xprt de $L$. major

\begin{tabular}{ccc}
\hline \hline Temperatura $\left({ }^{\circ} \mathrm{C}\right)$ & Número de ciclos & Tempo de duração (segundos) \\
\hline \hline 94 & 1 & 180 \\
94 & 30 & 45 \\
55 & 30 & 30 \\
72 & 30 & 90 \\
72 & 1 & 600 \\
4 & Indeterminado & Indeterminado \\
\hline \hline
\end{tabular}

Após a reação de amplificação, $5 \mu \mathrm{l}$ do produto final $(50 \mu \mathrm{l})$ foram analisados em gel-eletroforese (1\% Agarose/1X TAE, pH8.3). Esse experimento permitiu comprovar o sucesso da amplificação (Figura 3). 


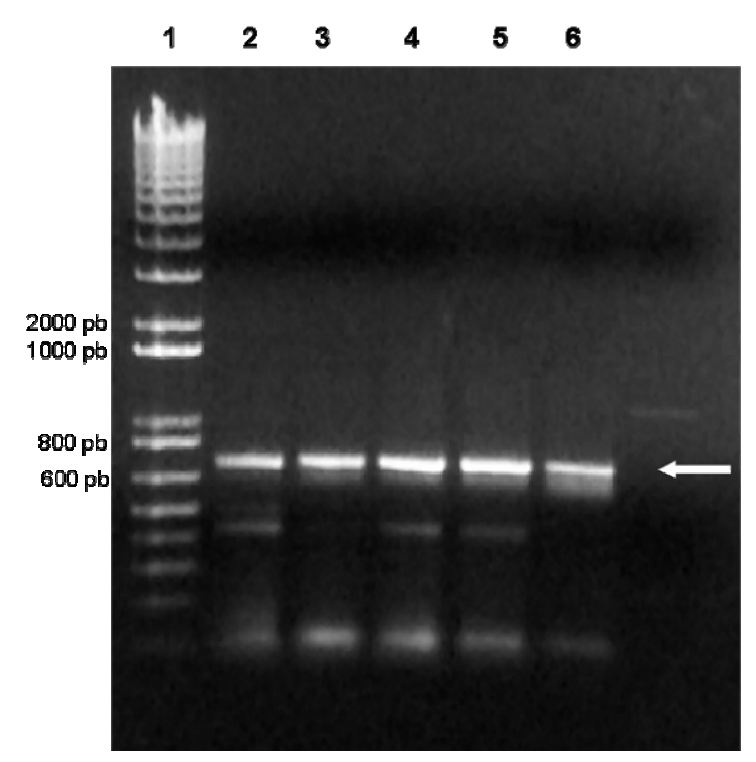

Figura 3- Gel de agarose comprovando a amplificação do gene xprt de L. major por PCR. Canaleta 1; padrão 1kb, canaletas de 2 a 6 produto de amplificação por PCR. A seta indica que o produto de PCR apresenta o peso esperado de 700pb.

\section{3- Clonagem do Gene xprt purificado no Vetor de Clonagem pGEM-T}

A clonagem de um gene no vetor pGEM-T utiliza resíduos de adenina adicionados pela Taq DNA polimerase às extremidades do gene durante a amplificação por PCR. As adeninas são ligadas aos resíduos de timina não pareados existentes no sítio de clonagem do vetor. Assim sendo, a clonagem de genes no vetor pGEM-T independe da existência de sítios de restrição no fragmento de PCR [PROMEGA pGEM-T system manual, 2001].

O plasmídeo recombinante pGEM-T/xprt, obtido através da inserção do gene xprt no vetor de clonagem pGEM-T, apresenta tamanho maior que o plasmídeo original (Figura 4), o que é indicativo da presença do inserto no plasmídeo. Os reagentes da solução de ligação são apresentados na tabela 3. As condições experimentais foram: 24 horas a $4^{\circ} \mathrm{C}$ em repouso. 
Tabela 3- Reagentes utilizados na ligação do gene xprt de L. major ao vetor pGEM-T.

\begin{tabular}{lcc}
\hline \hline Reagente & Volume $(\mu l)$ & Concentração \\
\hline \hline pGEM-T & 2 & $50 \mathrm{ng} / \mu \mathrm{l}$ \\
Gene xprt (purificado) & 5 & $200 \mathrm{ng} / \mu \mathrm{l}$ \\
T4 DNA-ligase 5x & 2 & $1 \mathrm{U} / \mu \mathrm{l}$ \\
Tampão (2x ligase) & 1 &
\end{tabular}

Final 10

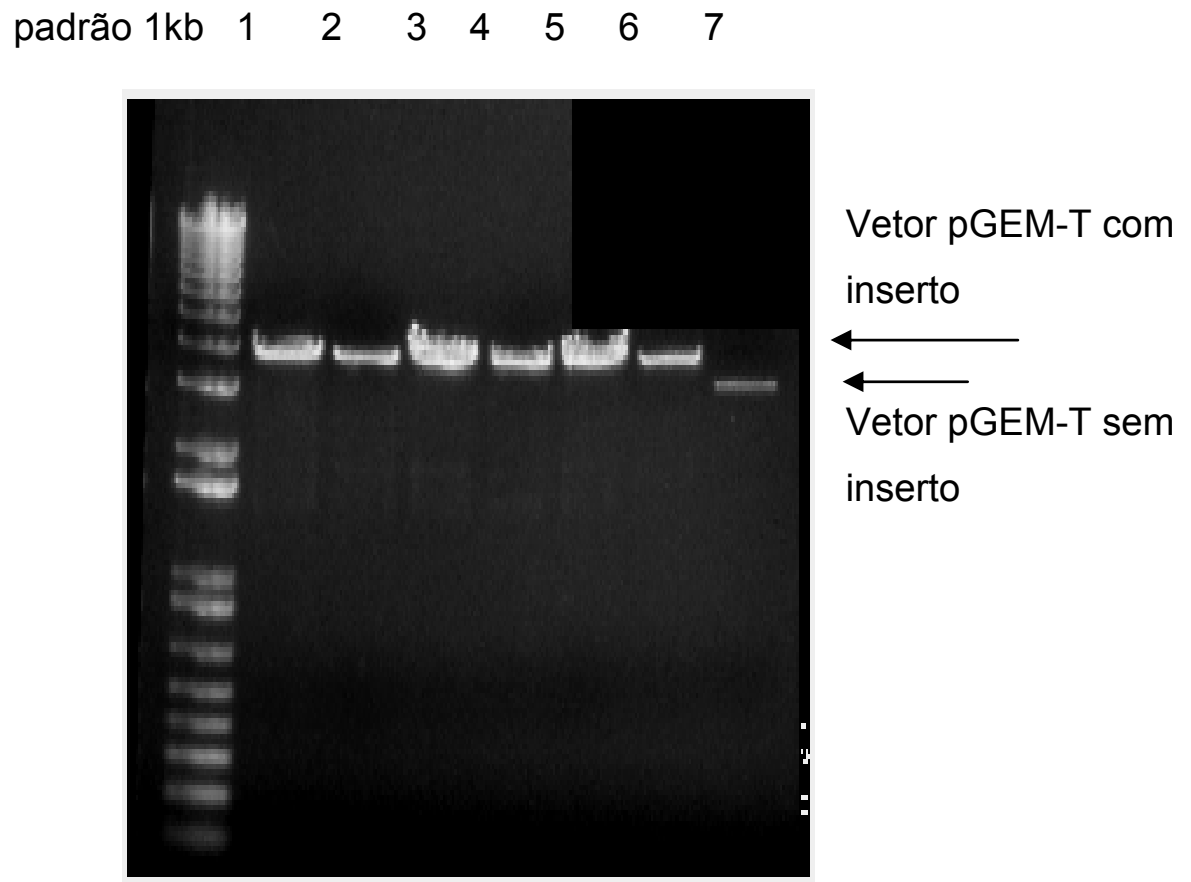

Figura 4- Gel de agarose 1\%. Canaleta 1 marcador de peso molecular; Canaleta 7 vetor sem inserto linearizado. Canaletas de 2 a 6, clones provenientes da ligação inserto com o vetor pGEM-T. O aumento de altura em relação ao vetor sem inserto é indicativo da presença do inserto.

A seguir, realizou-se o seqüenciamento das bases do inserto de forma a verificar a presença de mutações e seu alinhamento com as bases complementares. A seqüência de bases obtida, quando alinhada com a seqüência do gene xprt de L. major Friedling, depositada no GenBank, mostra uma identidade de $98 \%$ (Figura 5), enquanto a seqüência protéica apresenta identidade de $100 \%$ 
Leishmania major chromosome 21 clone L9365 strain Friedlin, complete sequence

Length $=30098$

Score $=1324$ bits $(668)$, Expect $=0.0$

Identities $=710 / 720(98 \%)$, Gaps $=3 / 720(0 \%)$

Strand $=$ Plus / Minus

Query: 29 atgctaccaaaccacagttgccagggcttcgtgcatgctccagggcagggtcttcgtgga 88

||||||||||||||||| | |||||||||||||||||||||||||||||

sbjct: 21870 atgctaccaaaccacagttgtaaaggcttcgtggatgc-ccagggcagggtcttcgtgga 21812

Query: 89 tggccgcgagtaccccatggcgtctggcattgtcgccacggaggacgtgattcaggcgaa 148

|||||||||||||||||||||||||||||||||||||||||||||||||||||||

Sbjct: 21811 tggccgcgagtaccccatggcgtctggcattgtcgccacggaggacgtgattcaggcgaa 21752

Query: 149 catcaaggccatggcgaacacaatcgcgaaggactacaagtcgctcagccaccgcgacgt 208

Sbjct: 21751 catcaaggccatggcgaacacaatcgcgaaggactacaagtcgctcagccaccgcgacgt 21692

Query: 209 tcgtctgtcacccggcacggcggccaccgcagaggcggcggaggcgccgatcagctacga 268

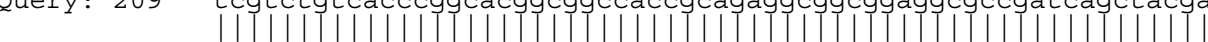

sbjct: 21691 tcgtctgtcacccggcacggcggccaccgcagaggcggcggaggcgccgatcagctacga 21632

Query: 269 caacccgcttatcataatctccgtgctcaagggcagctacatcttcacatccgacttcat 328

||||||||||||||||||||||||||||||||||||||||||||||||||||||||||||

Sbjct: 21631 caacccgcttatcataatctccgtgctcaagggcagctacatctcacatccgacttcat 21572

Query: 329 ccgctacctcggcgactgcggcctgccgcacgttgtcgactttgtgcgcttggcctcgta 388 ||||||||||||||||||||||||||||||||||||||||||||||||||||||

sbjct: 21571 ccgctacctcggcgactgcggcetgccgcacgttgtcgactttgtgcgcttggcetcgta 21512

Query: 389 caattcggatacaacgagcaccggtcagatctcgatgctggcgggtctcaggttcgagaa 448

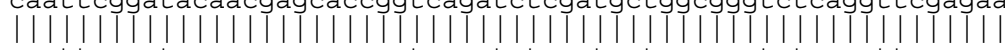

Sbjct: 21511 caattcggatacaacgagcaccggtcagatctcgatgctggcgggtctcaggttcgagaa 21452

Query: 449 tctacgcggcaagcatgtactgatcatcgaggatgtgtgcgactccgggcgcacgctgtg 508 ||||||||||||||||||||||||||||||||||||||||||||||||

Sbjct: 21451 tctacgcggcaagcatgtgctgatcgtcgaggatgtgtgcgactccgggcgcacgctgcg 21392

Query: 509 cttcctgcgtgattacatcatggagaagtttcagcccaagagcgtcaagacgctcgtgat 568

||||||||||||||||||||||||||||||||||||||||||||||||||||||

sbjct: 21391 cttcctgcgtgattacatcatggagaagtttcagcccaagagcgtcaagacgctcgtgat 21332

Query: 569 ggtgaacaaagagcaggcggcgcgcaagttggacttcgatccagagtacttctgccttgc 628

TT|T|||||||T||T|T|||T|||T||T|||||T|||||T|T|||||||||||T||

sbjct: 21331 ggtgaacaaagagcaggcggcgcgcaagttggacttcgatccagagtacttctgccttgc 21272

Query: 629 tggcccaaacaagtacattgtcggatacgggttcgaggtgaacgatcgctaccgtgactt 688

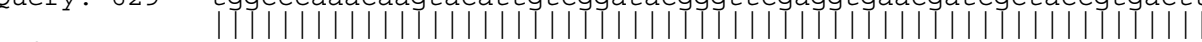

Sbjct: 21271 tggcccaaacaagtacattgtcggatacgggttcgaggtgaacgatcgctaccgtgactt 21212

Query: 689 gcgtcacatcttcatcctgcgggacggggaggcccacccgttatccctgccaagctctga 748

|||||||||||||||||||||||||||||||||||||||||||||||||||||

sbjct: 21211 gcgtcacatcttcatcctgcgggacggggagg-ccacccgttat-cctgccaagctctga 21154

Figura 5- Alinhamento da seqüência do gene xprt de L. major depositada no genebank com a seqüência clonada no vetor pGEM-T. A alta identidade seqüencial entre essas duas seqüências confirma que o inserto presente no vetor pGEM-T corresponde ao gene xprt de L. major. 


\section{4- Extração do DNA Recombinante pGEM-T/xprt e Purificação do Gene XPRT}

Conforme descrito na sessão 2.1 , vetores de clonagem são utilizados para propagar o gene de interesse, porém, não possibilitam a expressão da proteína alvo. Uma vez que existe a intenção de expressar o produto gênico, torna-se necessário: a)- Extrair o vetor de clonagem. b)- Clivar com enzimas de restrição. c)Purificar o gene de interesse. d) Introduzir o gene de interesse em vetor de expressão.

O fluxograma da figura 6 apresenta os passos realizados na extração e purificação do DNA recombinante pGEM-T/xprt a partir de bactérias Escherichia coli DH5 $\alpha$ transformadas. Nessa purificação foi utilizado o Kit Gibco BRL Concert Rapid Plasmid Miniprep System.

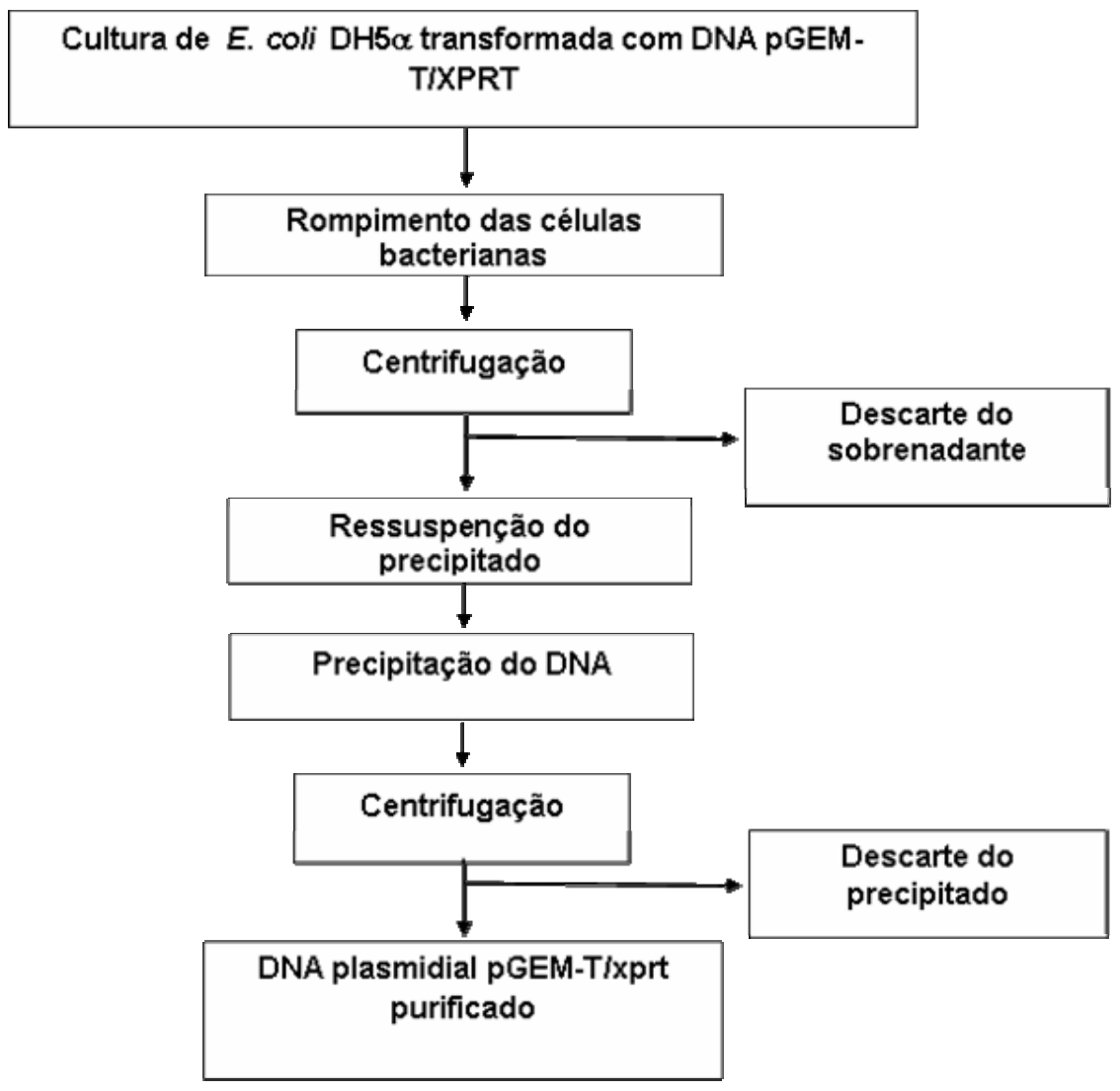

Figura 6- Fluxograma das etapas da extração e purificação do DNA recombinante pGEMT/xprt. 
O DNA recombinante purificado segundo o fluxograma da figura 6 , foi utilizado para a clivagem com as enzimas de restrição Nde I e Xho I e posterior clonagem do vetor de expressão pET29a(+) [Novagem pET-29A manual system].

\section{5- Clivagem do DNA recombinante pGEM-T/xprt e do Vetor pET29a(+) com as Enzimas de Restrição Nde I e Xho I}

Conforme será apresentado no item 8, a clonagem do gene XPRT no vetor de expressão pET29a(+) depende da existência de extremidades coesivas complementares entre o DNA do vetor e do gene. Por essa razão o plasmídeo pGEM-T/xprt foi clivado com as enzimas de Nde I e Xho I. Os reagentes utilizados na clivagem são apresentados na tabela 4 . As condições experimentais foram: 4 horas em repouso a $18^{\circ} \mathrm{C}$.

Tabela 4- Reagentes utilizados na clivagem do vetor recombinante (pGEM-T/xprt).

\begin{tabular}{ccc}
\hline \hline Reagente & Volume $(\mu \mathrm{l})$ & Concentraçăo \\
\hline \hline DNA pGEM-T/ xprt & 12 & \\
Tampão 2x REact 2 & 16 & \\
$($ GIBCO) & & $5 \mathrm{ng} / / \mu \mathrm{l} / / \mu \mathrm{l}$ \\
Nde I & 2 & $10 \mathrm{U} / / \mu \mathrm{l}$ \\
Xho I & 2 & \\
$\mathrm{H}_{2} \mathrm{O}$ & 18 &
\end{tabular}

Final 40

A seguir o vetor $\mathrm{pET} 29 \mathrm{a}(+)$ foi linearizado com as mesmas enzimas de restrição. Nesse experimento foi utilizado uma solução composta pelos reagentes

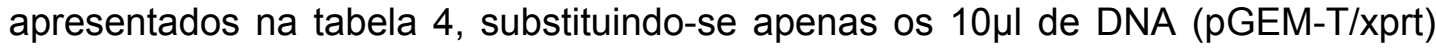
por $10 \mu \mathrm{l}$ de do vetor pET29(a)+. As condições experimentais foram: 4 horas em repouso a $37^{\circ} \mathrm{C}$. 
Os produtos de digestão foram então purificados segundo o protocolo do kit Gibco BRL - Concert Rapid Gel Extraction System.

\section{6- Clonagem do Gene xprt no Vetor de Expressão pET29a(+)}

Nessa etapa, o gene xprt e o vetor pET29(a)+ apresentavam extremidades coesivas complementares provenientes dos experimentos descritos no item 7 . Dessa forma, o DNA recombinante $\mathrm{pET} 29(\mathrm{a})+/ \mathrm{xp}$ rt pode ser obtido a partir da reação de ligação cujos reagentes são apresentados na tabela 5. As condições experimentais utilizadas foram: 24 horas em repouso a $4^{\circ} \mathrm{C}$.

Tabela 5- Reagentes utilizados na ligação do gene xprt de L. major ao vetor pET29a $(+)$

\begin{tabular}{lcc}
\hline \hline Reagente & Volume $(\mu \mathrm{l})$ & Concentração \\
\hline \hline pET29a(+) (Nde I -Xho I) & 2 & $100 \mathrm{ng} / / \mu \mathrm{l}$ \\
Gene xprt (Nde I-Xho I) & 5 & $100 \mathrm{ng} / / \mu \mathrm{l}$ \\
Tampão T4 DNA-ligase 5x & 2 & $1 \mathrm{U} / / \mu \mathrm{l}$ \\
T4 DNA-ligase & 1 & \\
& Final 10 & \\
\hline \hline
\end{tabular}

7- Inserção do DNA Recombinante pET29a(+)/xprt em bactérias Escherichia coli BL21 (DE3)

A mistura de ligação (tabela 5) contendo o DNA recombinante pET29a $(+) / x p r t$ foi utilizada para a transformação de bactérias competentes $E$. coli BL21(DE3). A metodologia para a transformação das bactérias, utilizadas neste experimento, baseia-se no choque térmico [Ausubel, 1995]. Células de E. coli BL21(DE3) competentes foram colocadas em contato com $10 \mu$ da reação de 
ligação apresentada na tabela 5. A solução contendo células competentes e mistura de ligação foi submetida a choque térmico.

\section{8- Seleção das Bactérias Escherichia coli BL21 (DE3) Transformadas com o DNA Recombinante pET29a(+)/xprt}

As bactérias transformadas foram selecionadas após plaqueamento em meio de cultura LB sólido contendo o antibiótico canamicina a $30 \mu \mathrm{g} / \mathrm{ml}$. A cultura foi mantida em repouso por 12 horas a $37^{\circ} \mathrm{C}$. Para confirmar a presença do inserto (gene xprt) no plasmídeo pET29a(+), 7 colônias foram selecionadas e crescidas em meio de cultura LB líquido contendo o antibiótico canamicina a $30 \mu \mathrm{g} / \mathrm{ml}$. As condições experimentais foram: 12 horas a $37^{\circ} \mathrm{C}$ sob agitação. O DNA plasmidial foi extraído pelo método de lise alcalina das células [Ausubel, 1995]. Os plasmídeos recombinantes $\mathrm{pET} 29 \mathrm{a}(+) / \mathrm{xprt}$ foram submetidos à clivagem com as enzimas de restrição Nde I e Xho I. A análise da clivagem em gel-eletroforese (1\%Agarose/1X TAE, pH8.3) confirmou a presença de inserto com o tamanho esperado (aproximadamente 700 pares de bases) em 6 dos 7 clones obtidos (Figura 7). Alíquotas de $1 \mathrm{ml}$ das diferentes culturas bacterianas contendo os clones, foram suplementadas com $20 \%$ de glicerol e congeladas a $-80^{\circ} \mathrm{C}$ para serem utilizadas nas próximas etapas do projeto. 


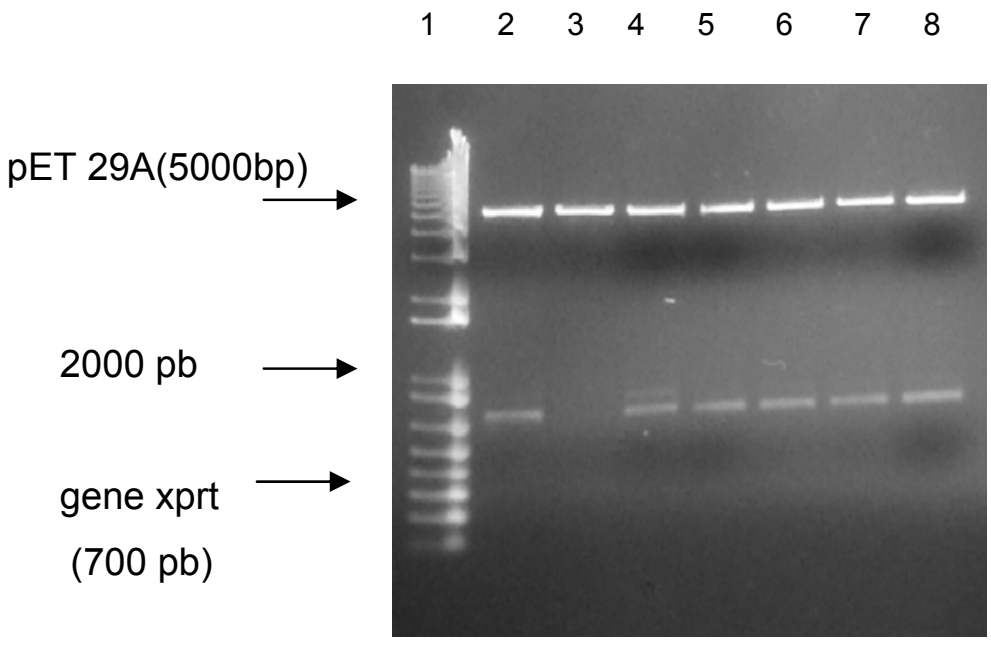

Figura 7- Gel de agarose 1\% mostrando a digestão do vetor pET29a com as enzimas de restrição Nde I e Xho I em diversos clones. Canaleta 1 padrão de peso molecular $1 \mathrm{~Kb}$; Canaletas de 2 à 8 digestão de clones provenientes da ligação do inserto no vetor. Exceto pela canaleta 3 pode-se ver claramente duas bandas, uma delas ao redor de 5000bp correspondente ao vetor e outra perto de 700bp, cujo peso é aproximadamente aquele esperado para o gene xprt

\section{9- Expressão e purificação da proteína XPRT}

Conforme apresentado anteriormente, foram obtidos 6 clones da bactéria BL21 (DE3) contendo o plasmídeo recombinante pET29a(+)/xprt. Todos esses clones foram testados quanto à produção da enzima XPRT na sua forma solúvel.

As colônias isoladas, relativas a cada um dos clones, foram cultivadas à $37^{\circ} \mathrm{C}$, em meio LB com canamicina $(30 \mathrm{mg} / \mathrm{ml})$, até densidade ótica de 0,8 a $600 \mathrm{nM}$. Então, adicionou-se IPTG para uma concentração final de 1mM IPTG e manteve-se a temperatura de $37^{\circ} \mathrm{C}$ por 4 horas. Após esse período, as culturas foram centrifugadas, o sobrenadante foi descartado e as células ressuspendidas em tampão TRIS-HCl 100mM pH 7.5 contendo $1 \mathrm{mM}$ de leupeptin, $1 \mathrm{mM}$ de PMSF e $10 \mathrm{mM}$ de $\mathrm{MgCl}^{+2}$ (tampão B).

As células foram rompidas para a análise dos níveis de XPRT expressa na forma solúvel. A figura 8 mostra os níveis de expressão da enzima XPRT em 4 clones. 


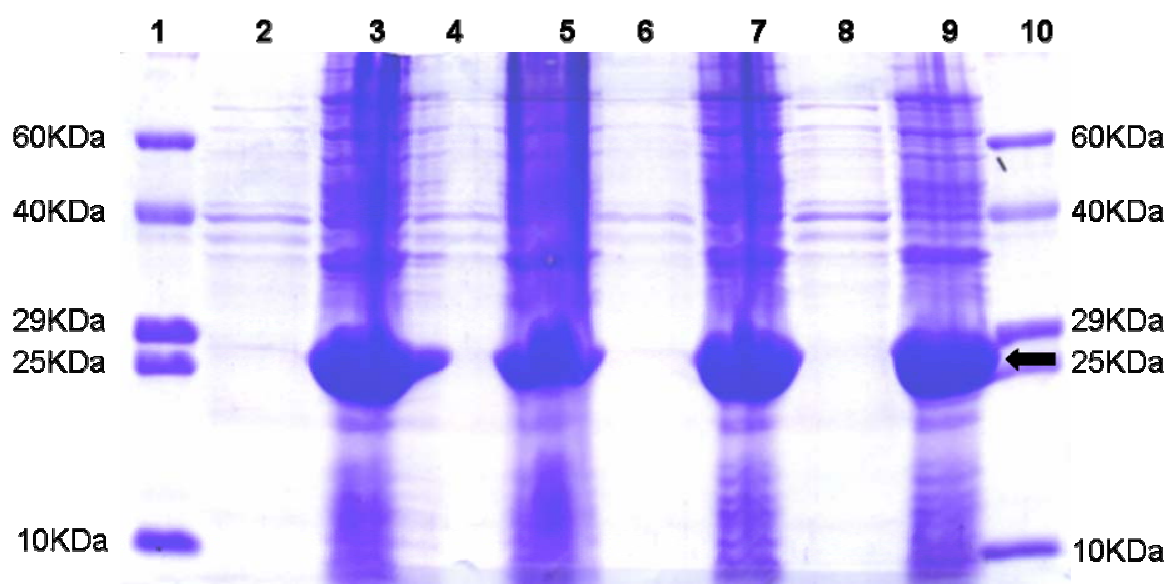

Figura 8- Gel SDS-PAGE mostrando a expressão gênica da enzima XPRT à $37^{\circ} \mathrm{C}$ (4 horas) e utilizando $1 \mathrm{mM}$ de IPTG. Após lise por sonicação e separação por centrifugação $(25.000 \mathrm{~g}$ por 15 minutos), aplicou-se $10 \mu \mathrm{L}$ do sobrenadante e do precipitado em gel de poliacrilamida 15\%. Canaleta 1, padrão de peso molecular; Canaleta 2, sobrenadante do clone 1; Canaleta 3 precipitado do clone 1; Canaleta 4, sobrenadante do clone 2; Canaleta 5 precipitado do clone 2; Canaleta 6, sobrenadante do clone 3; Canaleta 7 precipitado do clone 3; Canaleta 8, sobrenadante do clone 4; Canaleta 9 precipitado do clone 4; Canaleta 10, padrão de peso molecular. A seta indica a banda relativa a XPRT.

O resultado obtido para todos os clones foi praticamente o mesmo; superexpressão da proteína de interesse na forma não solúvel ${ }^{*}$.

Esse comportamento pode ter sido causado por condições muito drásticas de indução, seja pela temperatura elevada ou por quantidade excessiva de IPTG. Esse resultado pode estar relacionado também ao processo de lise das bactérias.

Por essa razão, vários processos de lise foram testados (congelamento/descongelamento, sonicação, etc). Entretanto, não houve melhora significativa no perfil de expressão da XPRT na forma solúvel (dados não apresentados).

* Os experimentos subseqüentes foram realizados apenas com 4 clones, escolhidos aleatoriamente, porém por razões de objetividade, os resultados apresentados referem-se apenas a um clone. 
A seguir, decidiu-se reduzir a temperatura na qual a indução foi realizada e procurar otimizar a quantidade de IPTG necessária para super-expressão da enzima XPRT na sua forma solúvel.

De acordo com o novo protocolo de indução, após o fermentado atingir a densidade ótica de $0,8(600 \mathrm{nM})$, a temperatura dos agitadores foi reduzida para $20^{\circ} \mathrm{C}$ e adicionaram-se quantidades decrescentes de IPTG em cada um dos experimentos. O tempo de indução nesse experimento foi de 12 horas. Os resultados apresentados na figura 48 mostram que o uso de apenas $0,05 \mathrm{mM}$ de IPTG, apesar de ainda apresentar uma parcela de enzima insolúvel, produz uma quantidade considerável de XPRT na sua forma solúvel (canaleta 9 da figura 9).

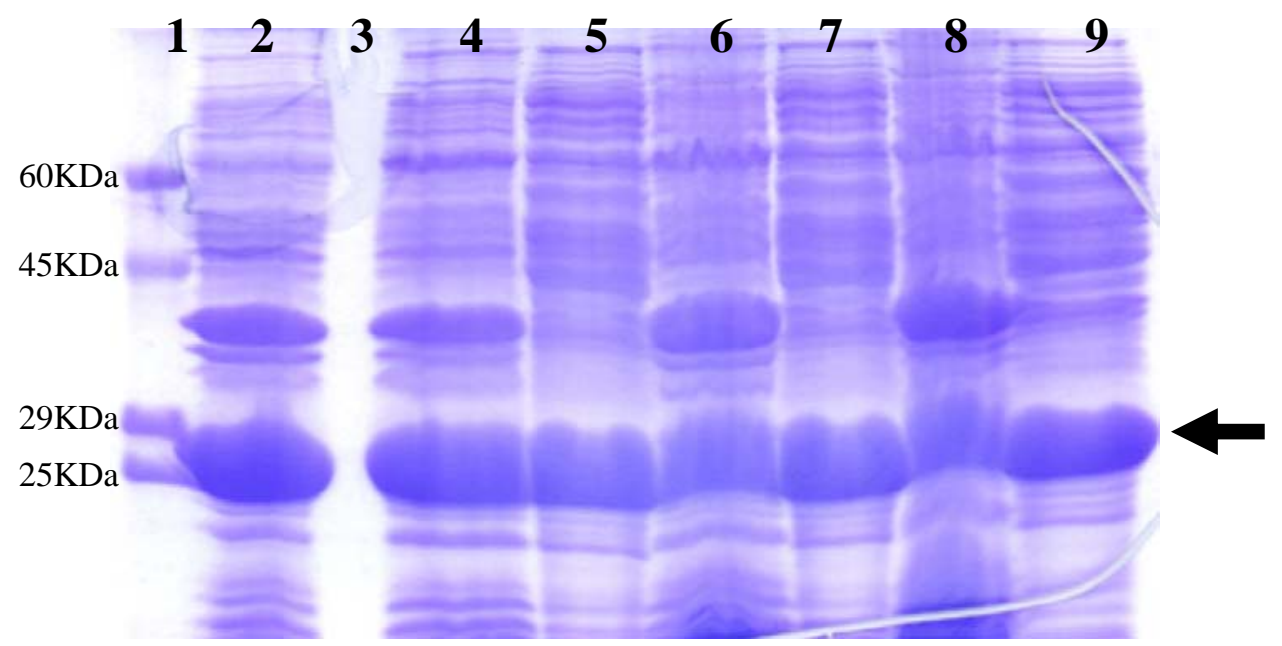

Figura 9- Gel SDS-PAGE mostrando a expressão gênica da enzima XPRT quando realizado a $20^{\circ} \mathrm{C}$ (12 horas) e variando-se decrescentemente da esquerda para a direita a quantidade de IPTG (1mM, 0,2mM, 0,1mM e 0,05mM). Após lise por sonicação e separação por centrifugação $(25.000 \mathrm{~g}$ por 15 minutos), aplicou-se $10 \mu \mathrm{L}$ do sobrenadante e do precipitado em gel de poliacrilamida $15 \%$. Canaleta 1, padrão de peso molecular; Canaleta 2, precipitado do clone 1; Canaleta 3 não foi aplicada amostra; Canaleta 4, precipitado do clone 2; Canaleta 5 sobrenadante do clone 2; Canaleta 6, precipitado do clone 3; Canaleta 7 sobrenadante do clone 3; Canaleta 8, precipitado do clone 4; Canaleta 9 sobrenadante do clone 4. A seta indica a banda relativa a XPRT.

Um fator que poderia ser responsabilizado pela baixa solubilidade da enzima seria o seu enovelamento incompleto ou errôneo. Como o mecanismo catalítico das PRTases exige da presença de íons magnésio [Vos et al, 1998], supomos que a 
presença desse íon no meio reacional pudesse estar envolvido no enovelamento da XPRT. Por isto se adicionou à condição otimizada de expressão $5 \mathrm{mM}$ de $\mathrm{MgCl}_{2}$. Não houve mudança considerável no perfil de expressão, porém devido a maior estabilidade de outras PRTases na presença de íons magnésio optamos por mantêlo na condição de expressão otimizada.

O protocolo para expressão da enzima XPRT recombinante em larga escala está resumido na figura 10

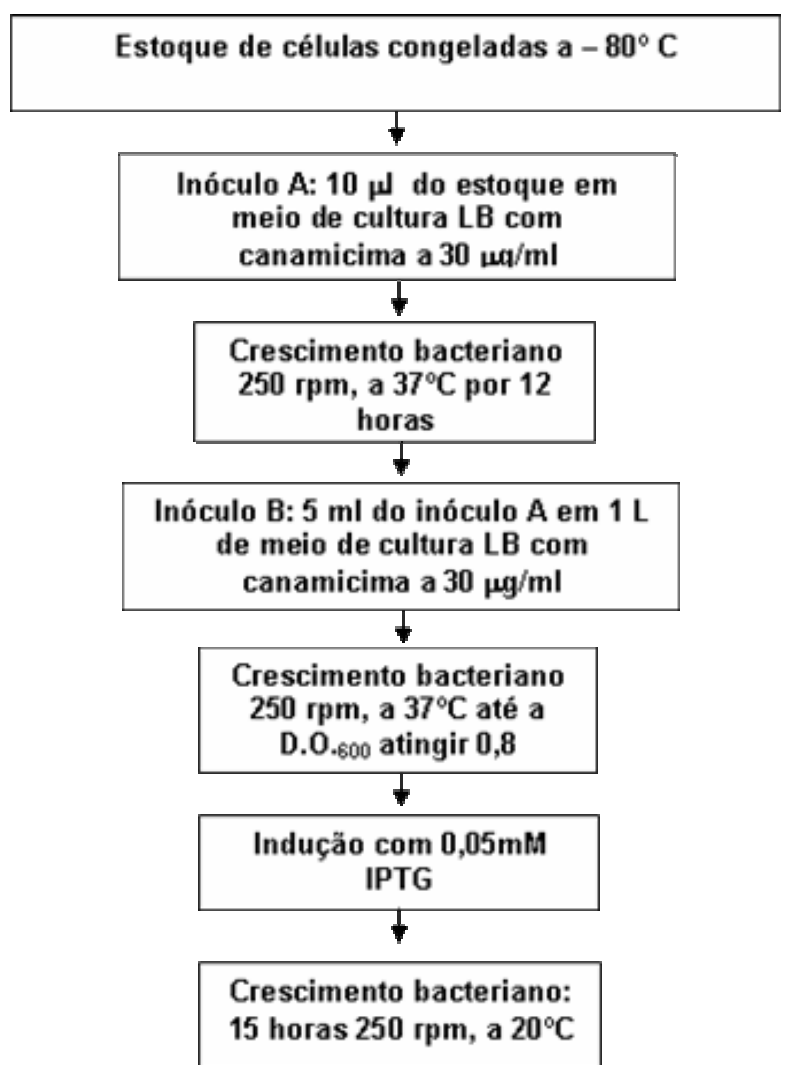

Figura 10- Fluxograma do protocolo estabelecido para expressar a enzima XPRT recombinante em grande escala. 


\section{0- Purificação da XPRT de L. major}

\section{1- Introdução}

Um procedimento típico para a purificação de proteínas inicia-se com o rompimento das células. A partir desse momento, segue-se uma série de fracionamentos em que cada etapa explora características físico-químicas peculiares a cada proteína.

Existem algumas estratégias bastante eficazes para purificação de proteínas, como por exemplo;

1- Preciptação da proteína com sulfato de amônio, seguida de separação por interação hidrofóbica e, finalmente, separação por troca iônica

2- Separação inicial em colunas de troca iônica seguida por colunas de interação hidrofóbica.

3- Separação em colunas de afinidade

A purificação da XPRT seguiu o seguinte procedimento: Após indução com $0,005 \mathrm{mM}$ de IPTG por 15 horas, à $20^{\circ} \mathrm{C}$, as células provenientes de 1 litro de cultura foram separadas do meio através de centrifugação a $25.000 \mathrm{~g}$ por 15 minutos a $4^{\circ} \mathrm{C}$.

As 9,8 gramas de células obtidas (média por preparação) foram ressuspendidas em $30 \mathrm{ml}$ de tampão $B$ e rompidas por sonicação durante 15 minutos utilizando intervalos regulares de 1 minuto de sonicação por 1 minuto de descanso e mantendo-se as células durante todo o tempo em banho de gelo. A fração solúvel foi recuperada através de centrifugação a 25.000 g por 15 minutos a $4^{\circ} \mathrm{C}$.

De posse de enzima solúvel em quantidades razoáveis, iniciaram-se as tentativas de padronização da purificação da enzima XPRT. 
Primeiramente optou-se por seguir a primeira estratégia mencionada e testou-se a concentração de sulfato de amônia necessária para preciptar a enzima XPRT.

\section{2- Precipitação com sulfato de amônio}

A figura 11 mostra o perfil de solubilidade da enzima XPRT em diferentes concentrações de $\left(\mathrm{NH}_{4}\right)_{2} \mathrm{SO}_{4}$. A enzima precipita desde $35 \%$ até $60 \%$ de $\left(\mathrm{NH}_{4}\right)_{2} \mathrm{SO}_{4}$ entretanto o máximo de precipitação ocorre em $50 \%$ de $\left(\mathrm{NH}_{4}\right)_{2} \mathrm{SO}_{4}$.

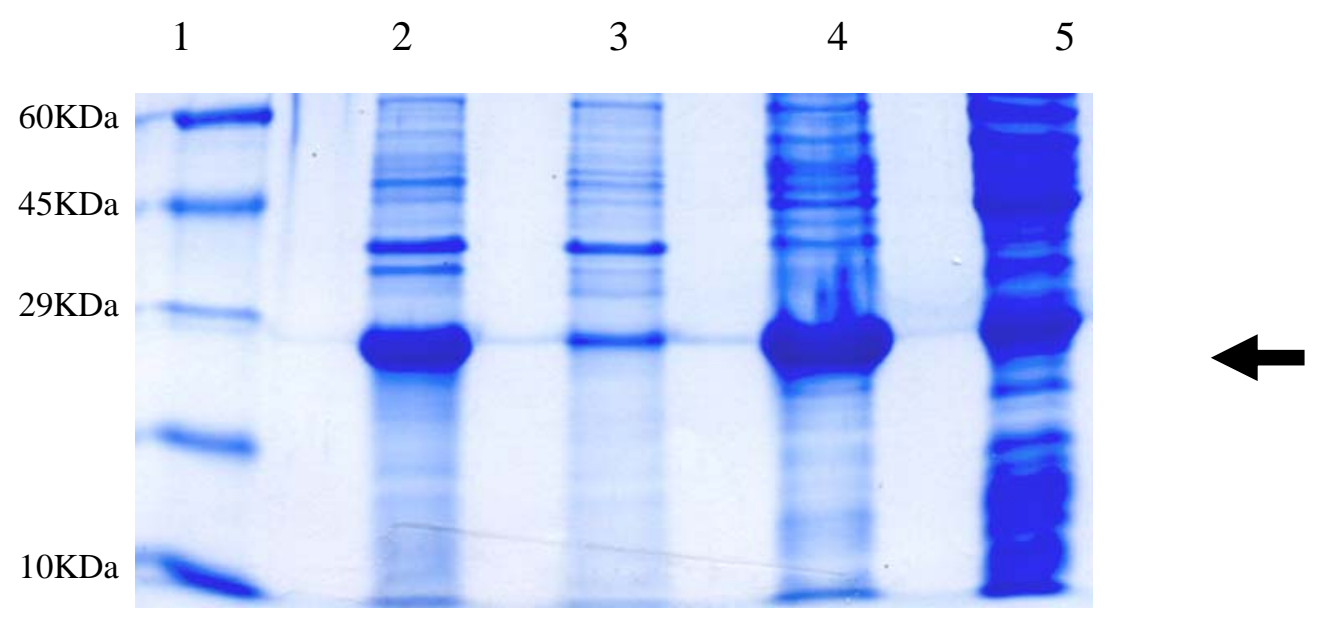

Figura 11- Gel SDS-PAGE mostrando a solubilidade da enzima XPRT em concentrações crescentes de sulfato de amônio. Canaleta 1, padrão de peso molecular; Canaleta 2, sobrenadante da lise por sonicação; Canaleta 3, precipitado de uma solução 40\% (M/V) de sulfato de amônio; Canaleta 4, precipitado de uma solução $50 \%$ (M/V) de sulfato de amônio; Canaleta 6 sobrenadante de uma solução $60 \%(\mathrm{M} / \mathrm{V})$ de sulfato de amônio. A seta indica a banda relativa a enzima XPRT

\section{3- Purificação cromatográfica da enzima XPRT de $L$ major}

Num segundo momento procurou-se estabelecer um protocolo cromatográfico para refinar a purificação da enzima XPRT. Após testar diversas resinas disponíveis no laboratório constatou-se que seria possível utilizar a resina de interação hidrofóbica (phenyl sepharose) e a seguir uma coluna de troca aniônica ( $Q$ sepharose). Quando da utilização da resina $Q$ sepharose a enzima 
XPRT é eluída antes do gradiente $0 \rightarrow 1 \mathrm{M}$ de $\mathrm{NaCl}$. $O$ perfil de purificação conseguido em cada etapa do protocolo de purificação está representado na figura 12 e na tabela 6

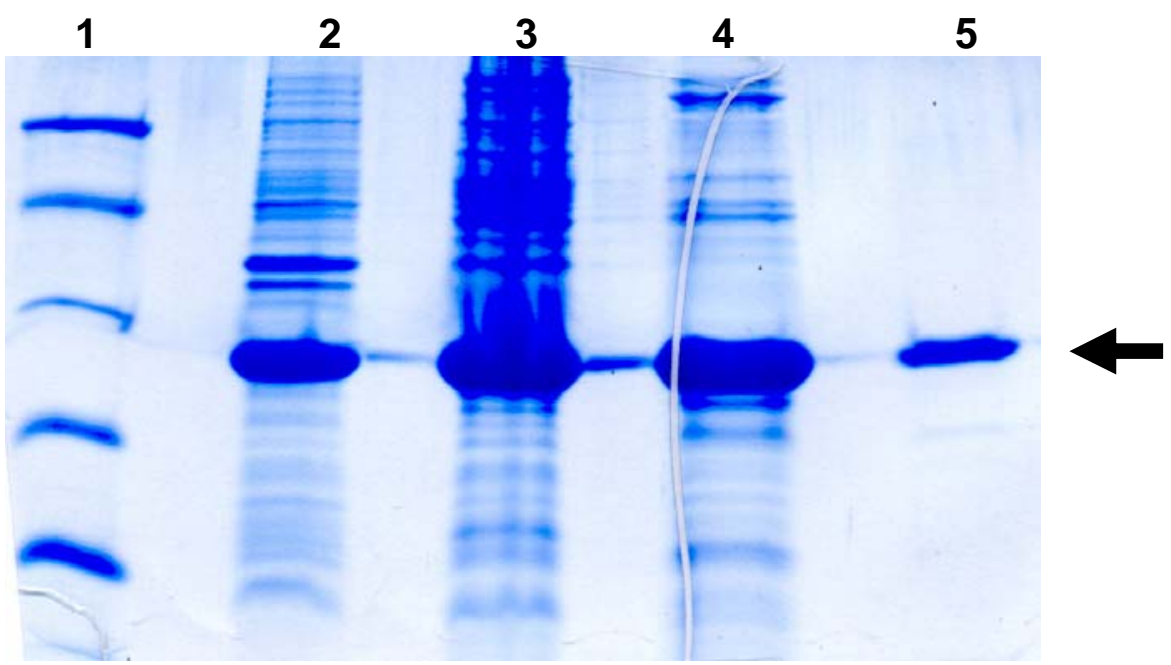

Figura 12- Gel SDS-PAGE mostrando o perfil de purificação da enzima XPRT. Canaleta 1, padrão de peso molecular; Canaleta 2, sobrenadante da lise por sonicação; Canaleta 3 , precipitado de uma solução $50 \%(\mathrm{M} / \mathrm{V})$ de sulfato de amônio; Canaleta 4, frações reunidas da eluição da proteína em uma coluna phenyl sepharose com fluxo reverso $1 \rightarrow 0 \mathrm{M}$ de $(\mathrm{NH} 4)_{2} \mathrm{SO}_{4}$ (a enzima XPRT elui em $0,7 \mathrm{M}$ de $(\mathrm{NH} 4)_{2} \mathrm{SO}_{4}$ ); Canaleta 5 , eluição da solução de proteína em uma coluna $Q$ sepharose. A enzima elui antes do gradiente $0 \rightarrow 1 \mathrm{M}$ de $\mathrm{NaCl}$.

Tabela 6- Perfil de purificação de enzima XPRT de L. major

\begin{tabular}{cccc}
\hline $\begin{array}{c}\text { Etapa da } \\
\text { purificação }\end{array}$ & $\begin{array}{c}\text { Proteína total } \\
(\mathbf{m g} / \mathbf{m l})\end{array}$ & $\begin{array}{c}\text { Atividade } \\
\text { específica (U) }\end{array}$ & $\begin{array}{c}\text { Fator de } \\
\text { Purificação } \\
\text { (vezes) }\end{array}$ \\
\hline \hline Lisado & 217,8 & $8,01.10^{-4}$ & 0 \\
Preciptação & 138,5 & $1,2.10^{-3}$ & 1,4 \\
com (NH4) ${ }_{2} \mathrm{SO}_{4}$ & 51,0 & $1,9.10^{-3}$ & 1,5 \\
Phenyl & & & \\
sepharose & 15,5 & $3,6.10^{-3}$ & 4,5 \\
Q sepharose & & & \\
\hline \hline
\end{tabular}




\section{1-Caracterização da enzima XPRT de L. major}

Segundo cálculos teóricos, o pl da enzima XPRT seria de 6,49 ( PROT PARAM, http:///www.expasy.ch), a determinação do ponto isoelétrico utilizando o sistema FAST da Pharmacia indica que o pl real da enzima está bastante próximo aquele predito teoricamente, aproximadamente 6,5 (Figura 13).

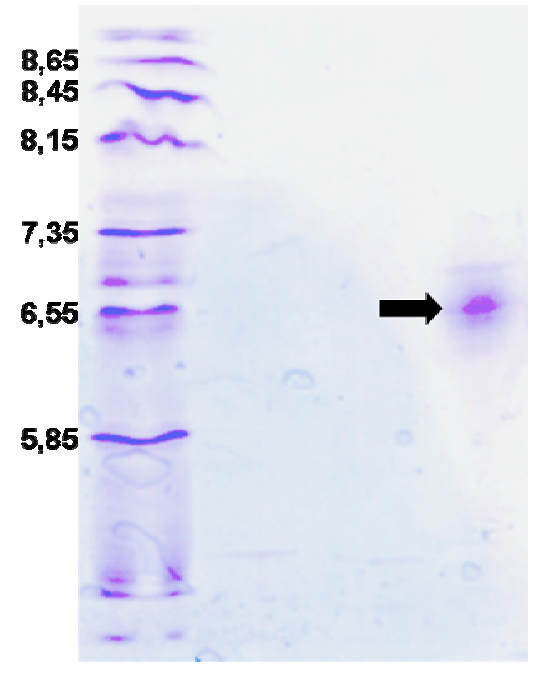

Figura 13- Gel de focalização isoelétrica da enzima XPRT. A esquerda temos os padrões de $\mathrm{pH}(3-9)$ e a direita a enzima XPRT. A posição da enzima XPRT, indicada pela seta, é compatível com o pH 6,5

A partir dessa informação iniciou-se a caracterização cinética da enzima XPRT

\section{1- Caracterização cinética da enzima XPRT de L. major}

Os experimentos de caracterização cinética da enzima XPRT foram realizados através de um protocolo espectrofotométrico descrito por Jardim e colaboradores [Jardim et al., 1999]. Esse protocolo mede a conversão da base purínica no respectivo nucleosídeo monosfosfato, por exemplo, conversão de xantina em xantosina monofosfato. Dessa forma, a grandeza analisada é a quantidade de nucleosídeo monofosfato formado. Essa medida foi realizada em 
254nM para xantosina monofosfato, em 250nM para hipoxantosina monofosfato e em 243nM para guanosina monofosfato.

Afim de seguir o protocolo descrito acima, algumas informações a cerca da enzima são necessárias; o coeficiente de extinção molar calculado utilizando a base da dados BRENDA (www.brenda.uni-koeln.de) [Schomburg et al, 2002] e a concentração molar estimada através da absorção em 280 nM.

Antes de se iniciar os experimentos para determinação das constantes de afinidade frente aos possíveis substratos, é importante determinar o $\mathrm{pH}$ ótimo da enzima em estudo. Esse estudo foi realizado medindo-se a atividade da enzima em diferentes pHs $(7,0-9,5)$. Verificou-se que a atividade ótima da enzima está bastante próxima de $\mathrm{pH} 8,0$ (Figura 14). Por esse motivo, os testes cinéticos foram realizados em pH 7,8 (tampão HEPES 50mM)

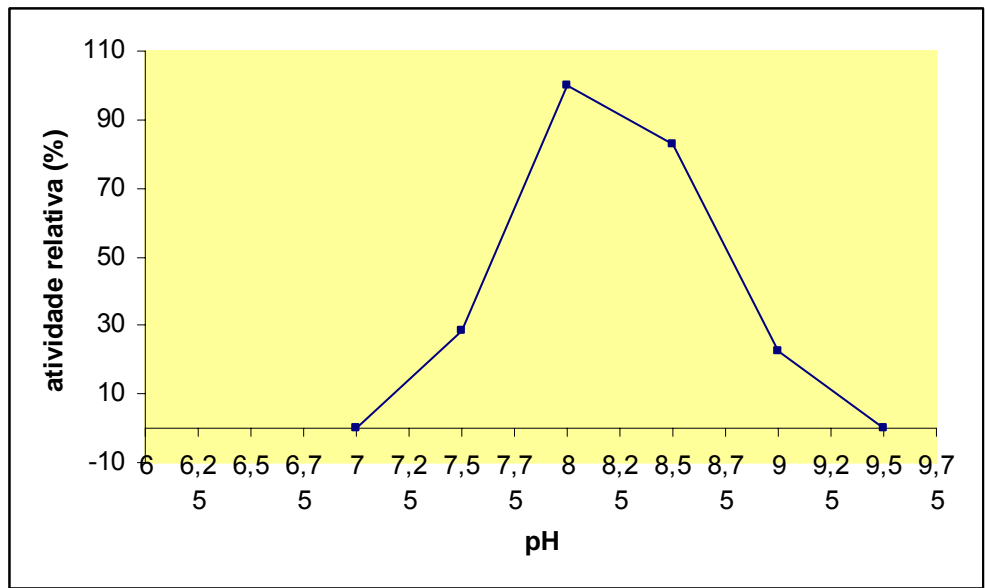

Figura 14- Efeito do $\mathrm{pH}$ sobre a atividade da enzima XPRT de L. major. As medidas foram realizadas em tampão HEPES $50 \mathrm{mM}$ na presença de $100 \mu \mathrm{M}$ de xantina, $1 \mathrm{mM}$ PRPP e $5 \mathrm{mM}$ $\mathrm{Mg}^{+2}$ e a $25^{\circ} \mathrm{C}$.

As medidas de cinética enzimática foram realizadas com enzima na concentração final de 4nM. O meio reacional contém 1mM PRPP, $5 \mathrm{mM} \mathrm{Mg}^{+2} \mathrm{e}$ concentrações diferentes de substrato (xantina, hipoxantina e guanina) conforme descrito a seguir.

Foram realizadas pelo menos 3 medições para determinação da velocidade em cada uma das concentrações do substrato estudadas. O coeficiente angular das 
curvas foi determinado por regressão linear e a média desses valores foi utilizada para obtenção dos valores de $K_{\mathrm{m}}$ e $V_{\max }^{\dagger}$.

A seguir, temos representadas as curvas relativas a xantina (substrato principal) (Figura 15), hipoxantina e guanina (substratos alternativos) (Figuras 16 e 17). No eixo horizontal temos representado as diversas concentrações utilizadas para se determinar o $\mathrm{km}$ de cada um dos substratos e no eixo vertical a velocidade de formação do produto.

A XPRT exibe uma seletividade da ordem de 7 vezes para o seu substrato principal em relação a hipoxantina e de cerca de 65 vezes em relação a guanina.

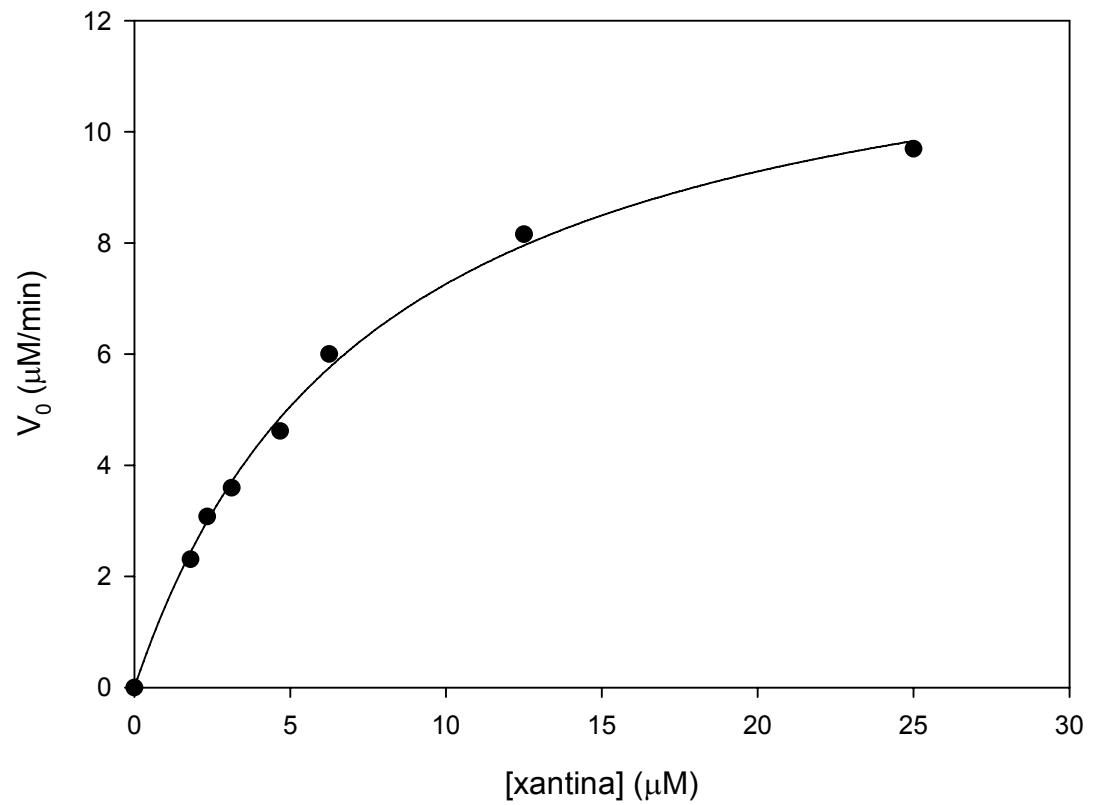

Figura 15- Gráfico de Michaelis-Menten mostrando os valores de $\mathrm{V}_{\max }(12,88 \pm 0,38 \mu \mathrm{M} / \mathrm{min})$ e $K_{\mathrm{m}}(7,73 \pm 0,51 \mu \mathrm{M})$ para xantina. As concentrações de xantina utilizadas foram $1,8 \mu \mathrm{M}$, $2,34 \mu \mathrm{M}, 3,125 \mu \mathrm{M}, 4,68 \mu \mathrm{M}, 6,25 \mu \mathrm{M} 12,5 \mu \mathrm{M}$ e $25 \mu \mathrm{M}$. A regressão não linear apresenta um $\mathrm{R}^{2}$ de 0,997

\footnotetext{
${ }^{\dagger} \mathrm{O}$ cálculo do valor de $\mathrm{km}$ e $\mathrm{V}_{\max }$ foram realizados através de regressão não linear utilizando o programa Sigmaplot [Charland, 1995]
} 


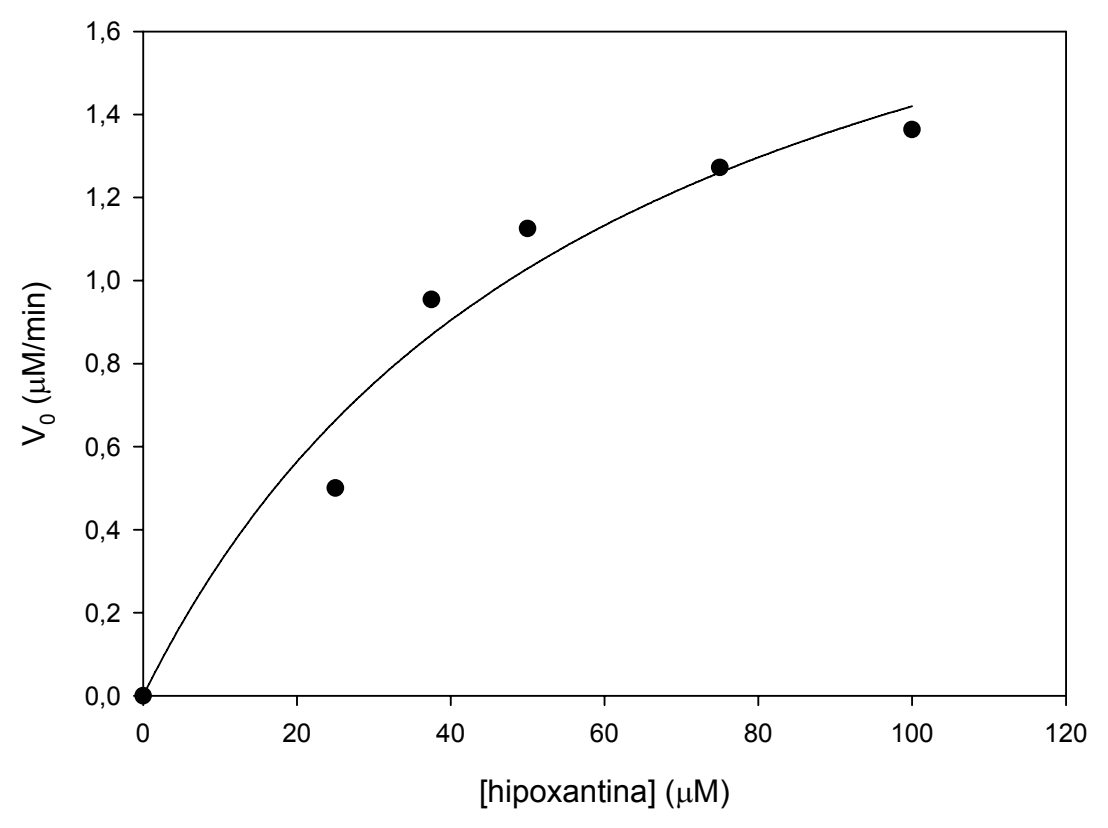

Figura 16- Gráfico de Michaelis-Menten mostrando os valores de $\mathrm{V}_{\max }(2,29 \pm 0,48 \mu \mathrm{M} / \mathrm{min})$ e $K_{\mathrm{m}}(61,33 \pm 25,94 \mu \mathrm{M})$ para hipoxantina. As concentrações de hipoxantina utilizadas foram $25 \mu \mathrm{M}, 37,5 \mu \mathrm{M}$, $50 \mu \mathrm{M}, 75 \mu \mathrm{M}$, e $100 \mu \mathrm{M}$. A regressão não linear apresenta um $R^{2}$ de 0,954

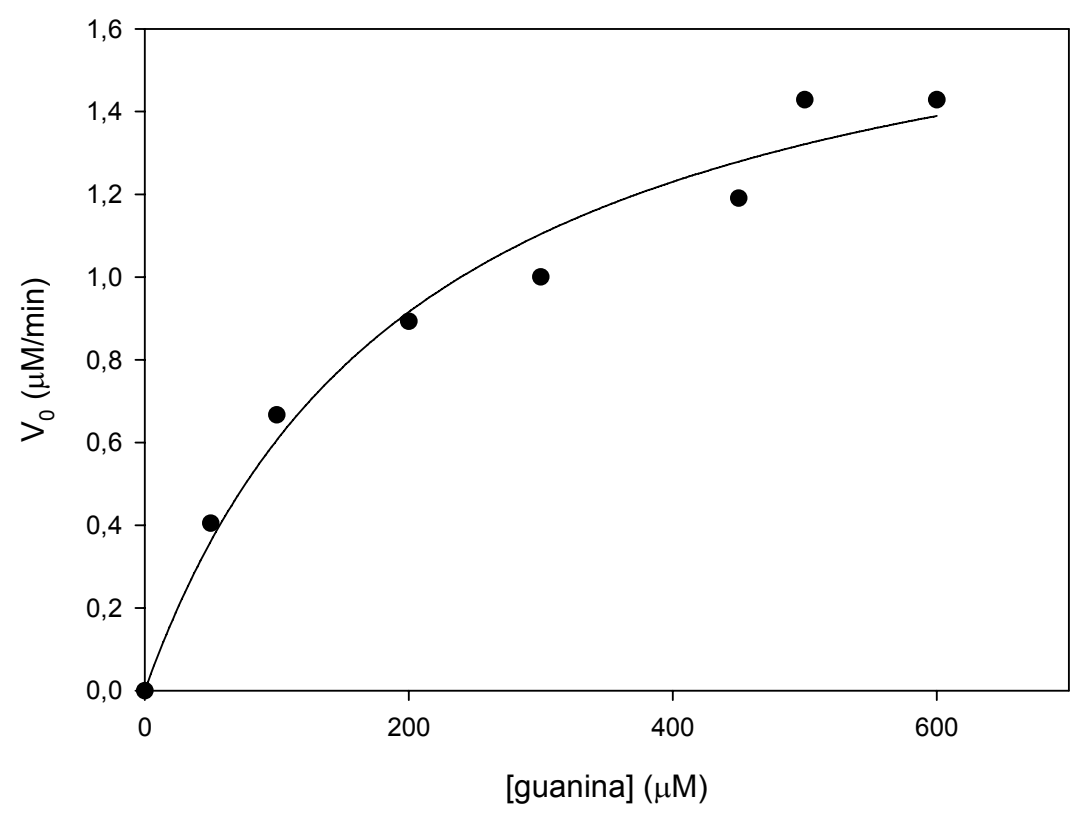

Figura 17- Gráfico de Michaelis-Menten mostrando os valores de $V_{\max }(1,87 \pm 0,16 \mu \mathrm{M} / \mathrm{min})$ e $K_{\mathrm{m}}(209,63 \pm 48,63 \mu \mathrm{M})$ para guanina. As concentrações de guanina utilizadas foram $50 \mu \mathrm{M}$, $100 \mu \mathrm{M}, 200 \mu \mathrm{M}, 300 \mu \mathrm{M}, 450 \mu \mathrm{M}, 500 \mu \mathrm{M}$, e $600 \mu \mathrm{M}$ A regressão não linear apresenta um $R^{2}$ de 0,975 
A afinidade da XPRT de L. major por xantina $(5,8 \mu \mathrm{M})$ é bastante semelhante àquela encontrada na enzima de $L$. donovani $(7,1 \pm 2.3 \mu \mathrm{M})$, por outro lado a afinidade por hipoxantina é muito maior $(41,7 \mu \mathrm{M}$ em L. major contra $448 \mu \mathrm{M}$ em $L$. donovani). Esse resultado sugere que a XPRT de L. major pode utilizar a hipoxantina como substrato alternativo com maior eficiência que $L$. donovani na via de recuperação de purino-nucleotídeos.

Jardim e colaboradores relatam ainda que a enzima XPRT de $L$. donovani tem um $K_{\mathrm{m}}$ para guanina superior a $100 \mu \mathrm{M}$, a enzima XPRT de $L$. major apresenta um $\mathrm{km}$ de $385,9 \mu \mathrm{M}$ o que demonstra que ambas as enzimas tem afinidade semelhante por esse substrato alternativo.

\section{4- Referência bibliográficas}

Ausubel, F. M., Brent, R., Kingston, R. E. (1995) "Short protocols in molecular biology" 2.ed. New York, Wiley.

Charland, M. B. (1995) "SigmaPlot for Scientists". Wm. C. Brown Communications

Howe, C. (1985) "Gene cloning and manipulation" Cambridge, Cambridge University Press.

Jardim, A., Bergeson, S. E., Shih, S., Carter, N., Lucas, R. W. Merlin, G., Myleri, P. J., Stuarti, K. Ullman, B. (1999) "Xanthine Phosphoribosyltransferase from Leishmania donovani:Molecular cloning, biochemical charactherization and genetic analysis" J. Biol. Chem., 274(48), 34403-34410

pGEM-t PROMEGA sysyem manual

(www.promega.com/pnotes/55/5265g/5265g_core.pdf) (Fevereiro 2004)

pET NOVAGEM System Manual

(www.fhcrc.org/labs/hahn/methods/biochem_meth/pet.pdf) (Março 2001).

Schomburg I, Chang AJ, Hofmann O, Ebeling C, Ehrentreich F, Schomburg D (2002) "BRENDA: a resource for enzyme data and metabolic information" Trends in biochem. Sci., 27 (1): 54-56

Stansfid, W. D. (1996) "Molecular and cell biology" New York, McGraw Hill.

Watson, J. D., Gilman, M., Witkowski, J., Zoller, M. (1992) "Recombinant DNA" New York, Scientific American Books, p.626, 1992. 


\section{Capítulo VI- Conclusões}

O planejamento racional de fármacos é um processo cíclico (vide figura 1, capítulo I) para o qual novas informações estruturais (resolução da estrutura cristalográfica em complexo com inibidores), cinéticas (dados de inibição enzimática) e de modelagem molecular (criação de modelos de interação ligante-macromolécula) contribuem decisivamente.

Nesse trabalho, foram estudadas duas enzimas (gGAPDH e XPRT) que se encontram em etapas bastante distintas no que se refere a sua utilização para o planejamento de fármacos contra tripanosomatídeos.

Primeiramente vamos tratar da enzima gGAPDH de T. cruzi. O mecanismo catalítico dessa enzima foi estudado em grande detalhe, uma vez que esse conhecimento pode ser convertido em informações úteis para o planejamento de inibidores mais potentes e seletivos. 
A fim de cumprir esse propósito, inibidores irreversíveis da enzima gGAPDH foram sintetizados pelo prof. Jack Périé da Univerdade Paul Sabatier, Toulouse, França e estudos de co-cristalização desses compostos $(\mathbf{3 1}, \mathbf{3 2}, \mathbf{3 3}, \mathbf{3 4})$ com a enzima gGAPDH foram realizados em nosso laboratório. O complexo gGAPDH-33 forneceu informações inéditas a respeito do mecanismo catalítico da enzima.

Embora o composto 33 não seja equivalente ao G3P (as diferenças consistem na ausência de uma hidroxila e na substituição de um átomo de oxigênio por um átomo de carbono) a sua similaridade, particularmente em relação ao tamanho da cadeia, é suficientemente boa para utilizá-lo para descrever o que deve acontecer com o intermediário tioester durante o processo de catálise.

O análogo do intermediário tioéster, encontrado na presença do $\mathrm{NAD}^{+}$fornece evidência experimental do mecanismo flip-flop proposto anteriormente [Corbier et al., 1994], uma vez que o inibidor pode interagir tanto no sítio Pi quanto no sítio Ps (monômeros B e C).

Além disso, essa estrutura cristalográfica do complexo gGAPDH-33 sugere que a isomerização do intermediário tioéster deve ocorrer durante a saída do cofator, em contraposição ao proposto por outros autores [Skarzynski et al, 1987; Corbier et al, 1994]. Essa hipótese está baseada na ocupação parcial que o NAD+ apresenta nos monômeros B e C (inibidor em duas conformações alternativas) e a ocupação total do cofator no monômero D (inibidor na conformação Ps). Esse resultado sugere que a presença do cofator, durante a catálise, está relacionada com a presença do intermediário tioéster na conformação Ps. Nessa conformação, o NAD faz ligação de hidrogênio (com o fosfato) e está a uma distância favorável para realizar interações do tipo Van Der Walls com o inibidor. Essas interações contribuem para estabilização do $\mathrm{NAD}^{+}$e seu papel no mecanismo catalítico da gGAPDH.

A luz dos resultados obtidos, o mecanismo catalítico da gGAPDH poderia ser resumido da seguinte forma: 
i- $\quad$ GAP liga-se o sítio $\mathrm{Pi}$ posicionando a carbonila para interagir com o anel carregado positivamente do anel nicotinamida $\left(\mathrm{NAD}^{+}\right)$

ii- $\quad$ Transferência do hidreto para o cofator leva a perda das interações e saída do cofator na forma reduzida.

iii- $\quad$ O intermediário tioacil sofre isomerização e passa a interagir no sítio Ps. Uma nova molécula de $\mathrm{NAD}^{+}$entra no sítio do cofator, sendo agora estabilizada através de ligação de hidrogênio e interações do tipo Van Der Walls.

Essas conclusões foram publicadas no periódico Biochemistry (apêndice C)

Essa informação auxiliou no planejamento de inibidores reversíveis da gGAPDH (26, 27, 28, 29, 30). Entretanto, esses compostos apresentaram um comportamento inesperado frente à enzima gGAPDH de $T$. cruzi e $T$. brucei (vide tabela 10, capítulo III), o qual somente pode ser entendido através de estudos de modelagem molecular realizados a partir do complexo gGAPDH-30.

Os resultados de modelagem molecular sugerem que na gGAPDH de T. brucei os inibidores adotam uma conformação mais curvada do que aquela observada na gGAPDH de T. cruzi (vide figura 20, capítulo III). Nessa situação o efeito eletrostático dos grupos fosfonato tornar-se-ia mais significante na enzima de T. brucei. A maior atividade inibitória dos compostos 27 e 28 contra gGAPDH de $T$. brucei seria explicada, portanto, pelo caráter mais ácido dos seus grupos fosfonato.

Ainda segundo os dados de modelagem, a menor atividade inibitória dessa série de inibidores frente à gGAPDH de $T$. cruzi pode ser uma conseqüência das interações eletrostáticas reduzidas com o resíduo $\operatorname{Arg}^{249}$.

Apesar da contribuição fundamental desses estudos no entendimento do mecanismo catalítico da enzima e do perfil de interação com a enzima gGAPDH, a aplicação total do conhecimento gerado para o desenho de novos inibidores ainda não se concretizou. Até o presente momento essa série de inibidores apresenta baixa afinidade pela gGAPDH (o melhor inibidor -29- apresenta uma $\mathrm{IC}_{50}$ de $700 \mu \mathrm{M}$ ). 
Situação bastante diferente foi observada para os inibidores de origem natural (flavonóides e ácido anacárdico). Esses compostos apresentam valores de inibição cerca de 10 vezes melhor do que os derivados de 1,3-BPG, entretanto a sua cocristalização com a enzima gGAPDH não obteve sucesso. Esse resultado pode ser devido à baixa solubilidade dos inibidores nas soluções de cristalização utilizadas. Na verdade, muitos dos compostos de origem natural são solúveis apenas em DMSO. Esse fato exige que esse solvente seja incorporado à condição de cristalização, contudo Pavão [Pavão, 2001] demonstrou que a gGAPDH na presença de DMSO não forma cristais adequados para os experimentos de difração de raios X. Por essa razão, acreditamos que a obtenção de sais dos inibidores testados contra a gGAPDH seja uma boa estratégia para se facilitar a etapa de co-cristalização da enzima com os inibidores outrora solúveis apenas em DMSO.

O mesmo tipo de problema afeta os derivados cumarínicos e de nucleosídeo. No caso dos primeiros, a encontrada foi a utilização de modelagem molecular para criação de modelos de interação que pudessem guiar o planejamento de novos derivados e a racionalização das relações estrutura atividade encontradas.

Como apresentado no capítulo IV, o modelo de interação das 3-piperonil cumarinas sugere que apenas os grupos na posição 3 (piperonil) e 7 (heterocíclos) fazem interações significativas com a enzima, enquanto o anel cumarínico localiza-se exposto ao solvente. A rigidez imposta por esse anel, aparentemente, é responsável pela baixa complementaridade estérica que essa série de derivados apresenta. Essa hipótese é reforçada pelo padrão de interação da chalepina no sítio ativo da gGAPDH [Pavão, 2001], no qual praticamente todas as interações são realizadas via moléculas de água.

Esse motivo, aliado ao fato de derivados cumarínicos terem sido intensivamente estudados por Pupo e colaboradores [Pupo, comunicação pessoal] e Correa e colaboradores [Correa, comunicação pessoal] sem conseguir moléculas com valores de $\mathrm{IC}_{50}$ de ordem nanomolar, nos levam a acreditar que o anel cumarínico não 
seja a melhor estrutura de partida para o planejamento de inibidores de gGAPDH de $T$. cruzi.

Por outro lado, derivados de ácido anacárdico parecem possuir as características essenciais para serem considerados bons compostos protótipo. Por exemplo, esses compostos apresentam uma estrutura química extremamente simples, pontos de modificação molecular ainda não otimizados (padrão de substituição no anel, comprimento da cadeia lateral, etc.), etc.

Estudos preliminares de modelagem molecular já estão sendo realizados com o objetivo de priorizar e racionalizar os estudos que serão realizados a seguir. Um breve resumo dos resultados obtidos será apresentado no capítulo VII.

No que se refere à enzima XPRT, o gene foi clonado e superexpresso em $E$. coli conforme protocolo descrito no capítulo $\mathrm{V}$. A seguir a proteína foi purificada e caracterizada cineticamente. Embora a afinidade da enzima frente xantina e guanina sejam semelhantes àquela encontrada para XPRT de L. donovani, o mesmo não ocorre com hipoxantina, uma vez que a XPRT de L. major apresenta afinidade cerca de 10 vezes maior que a XPRT de $L$ donovani.

Dada a grande identidade seqüencial entre essas duas enzimas (90\%), e a grande conservação do sítio de ligação de PRPP e de ligação da base, somente a comparação das estruturas cristalográficas de ambas as enzimas poderá fornecer a explicação definitiva para esse comportamento.

O trabalho realizado até o presente momento fornece a base para os estudos de cristalização da enzima XPRT de L. major, entretanto esses estudos não foram ainda iniciados porque a enzima precipita quando em concentrações superiores a $5 \mathrm{mg} / \mathrm{mL}$.

Estudos preliminares indicam que a presença de xantosina monofosfato estabiliza a enzima e pode ser útil para contornar o problema mencionado acima. Como alternativa imediata para tentar compreender estruturalmente a razão para essa diferença de afinidade, optou-se por gerar um modelo tridimensional da enzima XPRT 
através da técnica de modelagem por homologia. Os resultados preliminares desse trabalho serão apresentados no capítulo VII.

\section{Referências}

Pavão, F. (2001) "Estudos cristalográficos e planejamento racional de inibidores específicos da enzima gliceraldeído-3-fosfato desidrogenase glicossomal (gGAPDH) de Trypanosoma cruzi" Tese de doutorado IQSC, 115p 


\section{Capítulo VII- Perspectivas}

O projeto de planejamento racional de fármacos contra tripanosomatídeos pertence a uma das principais linhas de pesquisa do laboratório e por essa razão a busca e otimização de inibidores da enzima gGAPDH de T. cruzi continua sendo um dos principais objetivos a ser perseguido.

Com esse propósito, estudos de co-cristalização da enzima na presença de inibidores, quer de origem natural, quer de origem sintética, tem sido realizados rotineiramente em nosso laboratório.

Em colaboração com o doutorando Rafael V. C. Guido (doutorando IFSC, área Física biomolecular, N $N^{0}$ FAPESP 02/12680-1), novas condições de cristalização tem 
sido estudadas e cristais da enzima na presença de diversos inibidores foram recentemente obtidos (Figura 1)

Figura 1- (esquerda) cristais de gGAPDH na presença de 79A obtidos em pH 7.5, 0,1M de
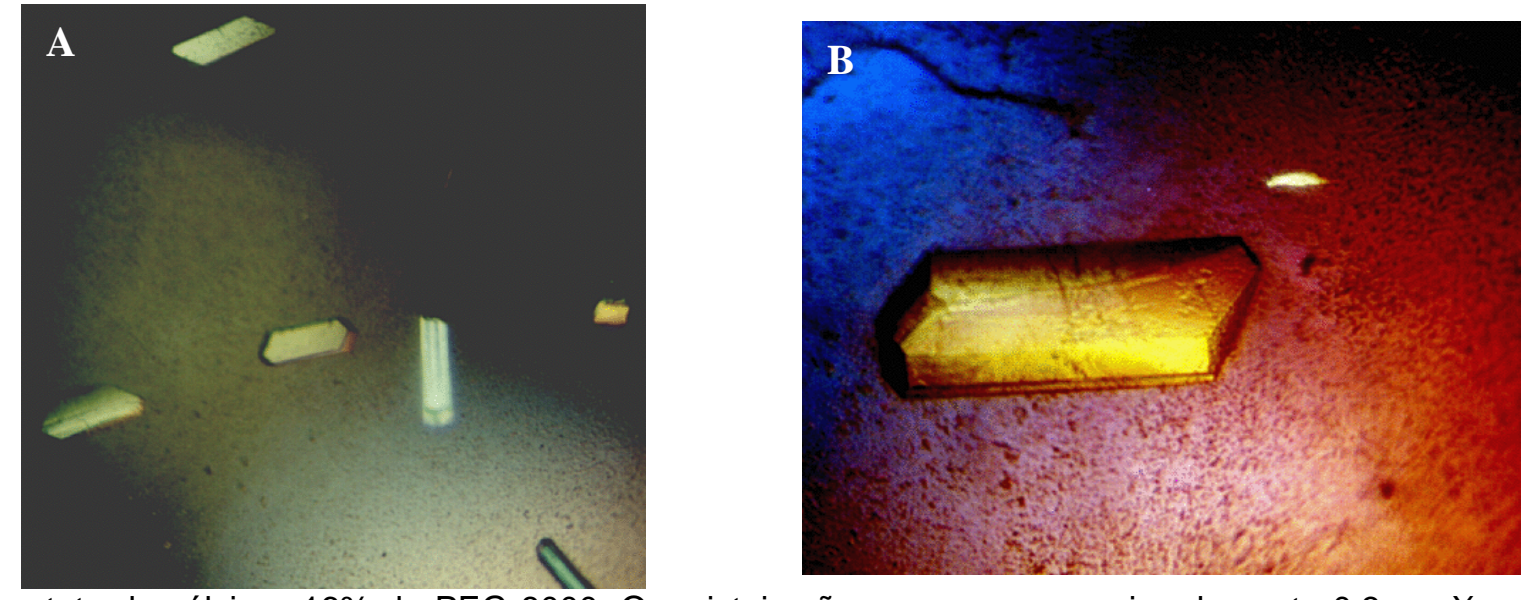

acetato de cálcio e $16 \%$ de PEG 8000 . Os cristais são pequenos, aproximadamente $0,3 \mathrm{~mm} \times$ $0,2 \mathrm{~mm} \times 0,2 \mathrm{~mm}$, e difratam a baixa resolução. (direita) cristal de gGAPDH obtido na presença de 79A em pH 7.5, 0,05M de acetato de cálcio e 16\% de PEG 8000. Os cristais obtidos apresentam dimensões maiores $(0,8 \mathrm{~mm} \times 0,4 \mathrm{~mm} \times 0,3 \mathrm{~mm})$

Dados de difração de raios $X$ de vários cristais de potenciais complexos foram coletados e tiveram suas estruturas resolvidas, porém em todas as estruturas refinadas até o presente momento não foi possível identificar moléculas de inibidores nos mapas de densidade eletrônica (2m|Fo| - D|Fc| ou m|Fo| - D|Fc|).

Esses resultados nos levaram a explorar outras técnicas de cristalização (soaking, macroseeding) na tentativa de obter cristais da enzima em complexo com os inibidores disponíveis. Esses estudos estão em andamento e serão concluídos por Guido.

Outra vertente que vem sendo intensamente explorada nesse projeto é a utilização de modelagem molecular (docking) para criação de modelos de interação ligante-macromolécula que possam guiar o processo de planejamento de novos derivados. Um exemplo bastante interessante da aplicação dessa metodologia pode 
ser encontrado no planejamento do composto 6, o qual foi desenvolvido em colaboração com Guido.

Segundo o modelo de interação proposto pelo programa FLO, a cadeia lateral do ácido anacárdico hidrogenado estende-se do resíduo $\operatorname{Arg}^{249}$ em direção ao sítio de ligação do cofator (Figura 2).

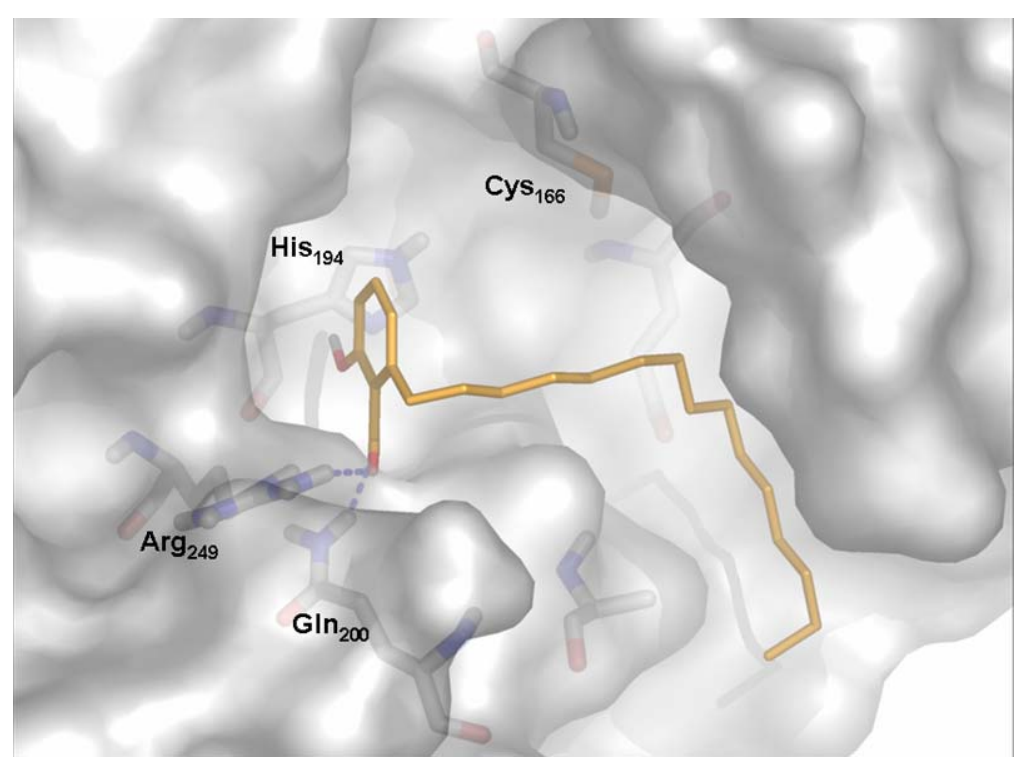

Figura 2- Modelo de interação do ácido anacárdico hidrogenado no sítio ativo da enzima gGAPDH de T. cruzi. Segundo o modelo proposto, o grupo ácido deve interagir com os resíduos $\operatorname{Arg}^{249}$ e $\mathrm{Gln}^{200}$ enquanto sua cadeia alifática estende-se em direção ao sítio de ligação do cofator (não representado na figura). A gGAPDH está representada através de sua superfície molecular e o inibidor está colorido de acordo com o tipo de átomo. Os resíduos que interagem com o inibidor ou são importantes para o mecanismo catalítico estão em destaque. 
A análise da superfície acessível ao solvente (para maiores detalhes vide figura 3 do capítulo IV e a discussão realizada nas páginas 105 e 106) indica que uma cadeia lateral de 8 carbonos contendo um grupo polar na extremidade poderia realizar interações polares com o resíduo $\operatorname{Arg}^{12}$ (Figura 3). Os resultados de modelagem molecular motivaram a síntese do composto 6, o qual apresenta $\mathrm{IC}_{50}$ de $4 \mu \mathrm{M}$ contra $28 \mu \mathrm{M}$ do ácido anacárdico hidrogenado.

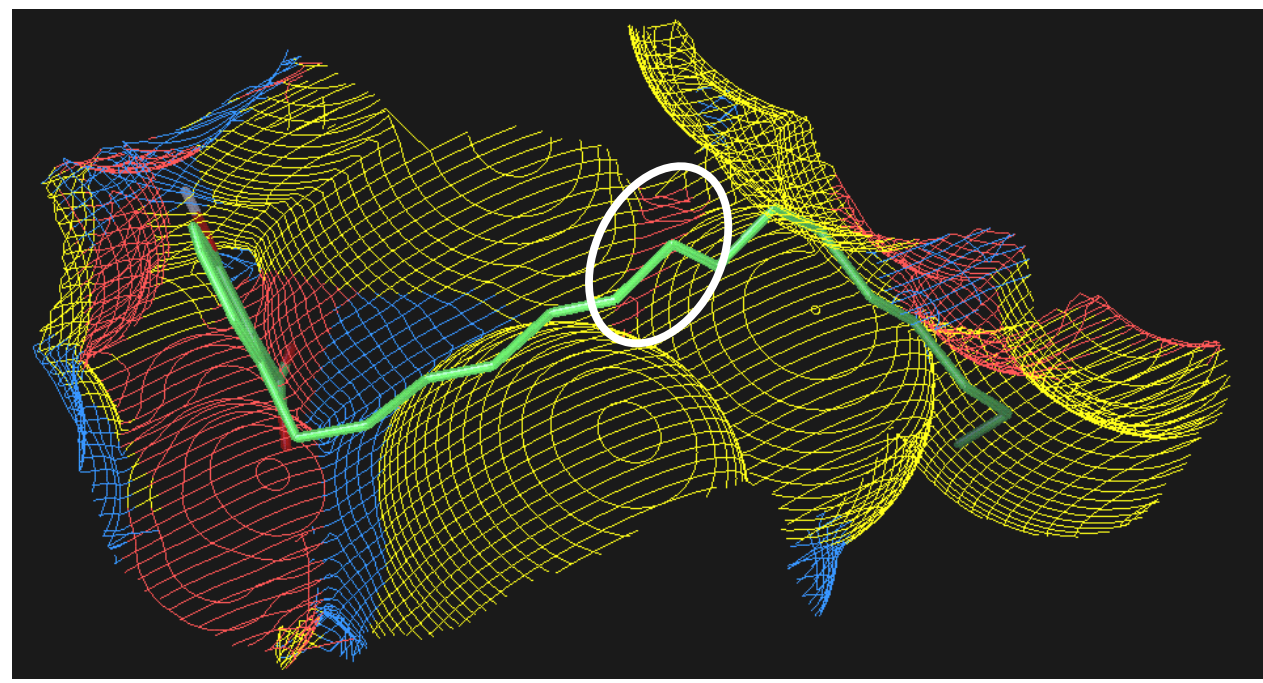

Figura 3- Modelo de interação do composto 6 no sítio ativo da enzima gGAPDH de T. cruzi com relação a SAS. Segundo o modelo proposto, um grupo polar na extremidade da cadeia lateral de 8 carbonos deve interagir com o resíduo $\operatorname{Arg}^{12}$ (não apresentado na figura) cuja SAS está destacada na figura.

Esse resultado ilustra a maneira como as técnicas de modelagem molecular têm auxiliado no planejamento de novos derivados. Cabe ressaltar, entretanto, que essa metodologia é qualitativa. O estudo das relações estrutura-atividade de forma quantitativa (QSAR) é uma forma de suprir essa lacuna no processo de planejamento racional e acelerar a otimização dos inibidores já identificados.

Com esse propósito, o Dr Adriano Andricopulo (Jovem Pesquisador do IFSC, NO FAPESP 02/03144-9) tem sido de inestimável valia na implementação dessa ferramenta e na implementação de novos protocolos para os ensaios cinéticos da 
enzima gGAPDH. Os resultados assim obtidos são muito mais reprodutíveis e confiáveis, tornando cada vez mais sólida a base sobre a qual esse projeto se fundamenta.

Com relação a enzima XPRT de L. major, espera-se iniciar em breve os estudos de cristalização e busca por inibidores (projeto de doutorado da aluna Elisandra M. Rodrigues). Estudos preliminares realizados em colaboração com o doutorando Marcio Silva ( $\mathrm{N}^{0}$ FAPESP 00/14709-1) identificaram uma série de compostos de origem natural que inibem a APRT e HGPRT de $L$ tarentolae, assim como a XPRT de L. major (Tabela 1). Tão logo os estudos de cristalização sejam iniciados, os estudos de co-cristalização da XPRT na presença desses e de outros inibidores que venham a ser identificados também serão realizados.

Tabela 1- Resultados de inibição enzimática de compostos testados contra APRT e HGPRT de L. tarentolae e XPRT de L. major.

$\begin{gathered}\text { IC } 50 \text { para APRT } \\ (\mu \mathrm{M})\end{gathered}$
$\begin{aligned} & \mathrm{IC}_{50} \text { para HGPRT } \\ & (\mu \mathrm{M})\end{aligned}$


Nesse ínterim, decidiu-se criar um modelo tridimensional da enzima XPRT através de modelagem por homologia. Apesar da baixa identidade seqüencial $(38 \%)$ entre a XPRT de L. major e a HGPRT de T. cruzi ( considerada como molécula modelo (Figura 4), as PRTases do tipo I, na qual a XPRT se encaixa, apresentam uma grande conservação estrutural [Guddat et al., 2002].
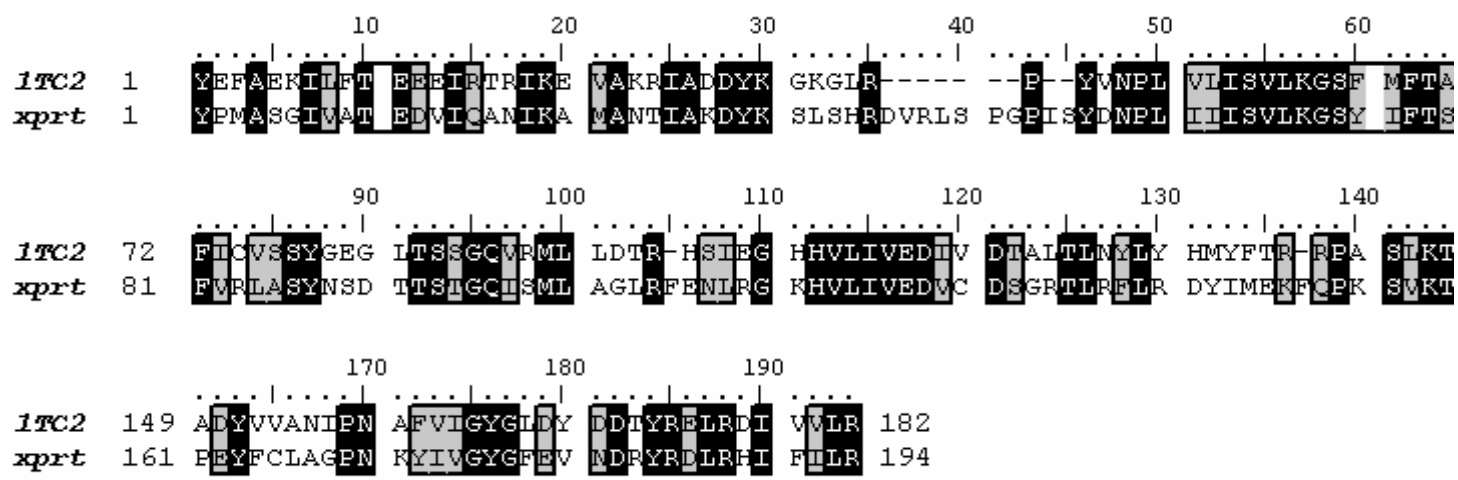

Figura 4- Alinhamento seqüencial entre XPRT de L. major (xprt) e HGPRT de T. cruzi (1TC2) utilizado pelo programa MODELLER 6.0. Em negrito temos os resíduos conservados e em cinza as mutações conservativas entre as seqüências.

Por essa razão acredita-se que o modelo gerado por homologia poderá ser útil para melhor entender o perfil de afinidade da XPRT frente aos seus substratos.

Assim que o modelo for finalizado ele será utilizado para tentar explicar o diferente perfil de afinidade da XPRT frente aos seus substratos e para criação de um modelo de interação entre a XPRT e seus inibidores. Além disso, o modelo poderá ser útil para resolução da estrutura cristalográfica da enzima através da técnica de substituição molecular.

\section{Referências}

Guddat L.W., Vos S., Martin J.L., Keough D.T., De Jersey J., (2002) "Crystal structures of free, IMP-, and GMP-bound Escherichia coli hypoxanthine phosphoribosyltransferase" PROTEIN SCIENCE 11 (7), 1626-1638 


\section{Apêndice A}

\section{ALgumAs DEFINIÇÕES IMPORTANTES EM CRISTALOGRAFIA, UTILIZADAS NESTE TRABALHO}

Intensidade, l(hkl):

$$
\mathrm{I}(\mathrm{hkl})=\frac{\mathrm{e}^{4}}{\mathrm{~m}^{2} \mathrm{c}^{4} \mathrm{r}^{2}} \mathrm{I}_{\mathrm{o}} \lambda^{3} \mathrm{LPA} \frac{\mathrm{V}_{\mathrm{x}}}{\mathrm{V}_{\text {cela }}^{2}}|\mathrm{~F}(\mathrm{hkl})|^{2}
$$

onde:

$V_{x}$ - Volume do cristal atingido pela radiação, $V_{\text {cela }}$ - Volume da cela unitária, $I_{o}$ - Intensidade do feixe incidente, L - Fator de Lorentz, P - Fator de Polarização, A - Fator de Absorção, F(hkl) - Fator de estrutura, $\lambda$ Comprimento de onda da radiação incidente, e - Carga do elétron, $m$ - Massa do elétron, c - Velocidade da luz, r - Distância cristal-detector. 
Fator de estrutura, $F(h k l)$ :

$\mathbf{F}(\mathrm{hkl})=\sum_{\mathrm{j}=1}^{\mathrm{N}} \mathrm{f}_{\mathrm{j}} \exp \left[2 \pi i\left(\mathrm{hx}_{\mathrm{j}}+\mathrm{ky}_{\mathrm{j}}+\mathrm{lz}_{\mathrm{j}}\right)\right] \exp \left[-\mathrm{Bsen}^{2} \frac{\theta}{\lambda^{2}}\right]=|\mathrm{F}(\mathrm{hkl})|^{2}[\exp i \alpha(\mathrm{hkl})]$ onde:

$\mathrm{N}$ - Número de átomos na cela unitária, $\mathrm{f}$ - Fator de espalhamento atômico, xyz - Coordenadas fracionárias no espaço real, hkl - Índices de Miller (espaço recíproco), B - Fator de temperatura atômico, $\theta$ - Ângulo de Bragg, $\lambda$ - Comprimento de onda da radiação incidente, $a(h k l)$ - Fase do Fator de estrutura.

\section{Função de Patterson, $P(u v w)$ :}

$$
\mathrm{P}(\mathrm{uvw})=\frac{1}{\mathrm{~V}} \sum_{\mathrm{l} \mathrm{kl} l}|\mathrm{~F}(\mathrm{hkl})|^{2} \exp [-2 \pi i(\mathrm{hu}+\mathrm{kv}+\mathrm{lw})]
$$

onde:

V - Volume da cela unitária, uvw - Coordenadas no espaço (cela) de Patterson, hkl - Índices de Miller (espaço recíproco), F(hkl) - Fator de estrutura.

Fator de estrutura calculado a partir do modelo, $F_{\text {calc }}(h k l)^{*}$ :

$$
\mathbf{F}_{\text {calc }}(\mathrm{hkl})=\sum_{\mathrm{j}=1}^{\mathrm{N}} \mathrm{f}_{\mathrm{j}}^{\mathrm{o}} \exp \left[2 \pi i\left(\mathrm{hx}_{\mathrm{j}}+\mathrm{ky}_{\mathrm{j}}+\mathrm{lz}_{\mathrm{j}}\right)\right] \exp \left[-\mathrm{Bsen}^{2} \frac{\theta}{\lambda^{2}}\right]
$$

onde:

$\mathrm{N}$ - Número de átomos na cela unitária, $f^{\circ}$ - Fator de espalhamento atômico não-anômalo, xyz - Coordenadas fracionárias no espaço real, hkl - Índices de Miller (espaço reciproco), B - Fator de temperatura atômico, $\theta$ - Ângulo de Bragg, $\lambda$ - Comprimento de onda da radiação incidente.

\footnotetext{
${ }^{*}$ No texto da tese $\mathrm{F}_{\text {calc }}$ está representado apenas por $\mathrm{F}_{\mathrm{c}}$ e $\mathrm{F}_{\mathrm{obs}}$ por $\mathrm{F}_{\mathrm{o}}$
} 
Densidade eletrônica, $\rho(x y z)$ :

$$
\rho(\mathrm{xyz})=\frac{1}{\mathrm{~V}} \sum_{\mathrm{hkl}}|\mathrm{F}(\mathrm{hkl})| \exp [-2 \pi i(\mathrm{hx}+\mathrm{ky}+\mathrm{lz})+i \alpha(\mathrm{hkl})]
$$

onde:

$V$ - Volume da cela unitária, $F(h k l)$ - Fator de estrutura, $x y z$ - Coordenadas fracionárias no espaço real, hkl - Índices de Miller (espaço recíproco), $\alpha(\mathrm{hkl})$ Fase do Fator de estrutura.

Fator-R, R:

$$
\mathrm{R}=\frac{\sum_{\mathrm{l} k \mathrm{kl}}\left|\mathrm{F}_{\mathrm{obs}}\right|-\left|\mathrm{F}_{\text {calc }}\right|}{\sum_{\mathrm{likl} \mid}\left|\mathrm{F}_{\mathrm{obs}}\right|}
$$

onde:

$F_{\text {obs }}$ - Fator de estrutura observado, $F_{\text {calc }}$ - Fator de estrutura calculado.

Fator $\mathbf{R}_{\text {free }}, \mathbf{R}_{\text {free }}$ :

$$
R_{T}^{\text {free }}=\frac{\sum_{\text {likl } l \subset T}|| F_{\text {obs }}|-| F_{\text {calc }}||}{\sum_{\text {hkl } l=T}\left|F_{\text {obs }}\right|}
$$

onde:

$F_{\text {obs }}$ - Fator de estrutura observado, $F_{\text {calc }}$ - Fator de estrutura calculado, hkl $\subset T$ representa todas as reflexões únicas pertencentes ao conjunto de teste T. 


\section{Apêndice B}

Parâmetros do algoritmo genético Lamarckiano utilizado nos experimentos de docking. Programa Autodock 3.05

\begin{tabular}{|c|c|c|}
\hline variável & $\begin{array}{c}\text { Valor } \\
\text { utilizado }\end{array}$ & parâmetro \\
\hline Ga_pop_size & 100 & $\begin{array}{l}\text { Número de indivíduos na } \\
\text { população }\end{array}$ \\
\hline Ga_num_evals & 2500000 & $\begin{array}{l}\text { Número máximo } \\
\text { avaliacões de energia }\end{array}$ \\
\hline Ga_num_generations & 270000 & $\begin{array}{l}\text { Número máximo de } \\
\text { gerações }\end{array}$ \\
\hline Ga_elitism & 1 & $\begin{array}{l}\text { Número de indivíduos que } \\
\text { sobrevivem }\end{array}$ \\
\hline Ga_mutation_rate & 0,02 & Taxa de mutação \\
\hline Ga_crossover_rate & 0.8 & Taxa de cross-over \\
\hline Ga_window_size & 10 & $\begin{array}{l}\text { Número de gerações para se } \\
\text { escolher o pior indivíduo }\end{array}$ \\
\hline Ga_cauchy_alpha & 0 & $\begin{array}{l}\text { Distribuição de Cauchy } \\
\text { média para mutação de um } \\
\text { gene }\end{array}$ \\
\hline Ga_cauchy_beta & 1 & $\begin{array}{l}\text { Variação da distribuição de } \\
\text { Cauchy para mutação de um } \\
\text { gene }\end{array}$ \\
\hline Sw_max_its & 300 & $\begin{array}{l}\text { Número de interações Solis } \\
\& \text { Wets durante a busca local }\end{array}$ \\
\hline Sw_max_succ & 4 & $\begin{array}{l}\text { Número de sucessos } \\
\text { consecutivos antes de mudar } \\
\text { o rho }\end{array}$ \\
\hline Sw_max_fail & 4 & $\begin{array}{l}\text { Número de fracassos } \\
\text { consecutivos antes de mudar } \\
\text { o rho }\end{array}$ \\
\hline Sw_rho & 1 & $\begin{array}{l}\text { Tamanho do espaço para ser } \\
\text { amostrado }\end{array}$ \\
\hline Ls_search_freq & 0,06 & $\begin{array}{l}\text { Probabilidade de se realizar } \\
\text { busca local para um } \\
\text { individuo }\end{array}$ \\
\hline
\end{tabular}




\section{Apêndice C}




\title{
Evidence for the Two Phosphate Binding Sites of an Analogue of the Thioacyl Intermediate for the Trypanosoma cruzi Glyceraldehyde-3-phosphate Dehydrogenase-Catalyzed Reaction, from Its Crystal Structure ${ }^{\dagger}$
}

\author{
Marcelo S. Castilho, Fernando Pavão, and Glaucius Oliva ${ }^{\ddagger}$ \\ Instituto de Física de São Carlos, USP, P.O. Box 369, 13560-970 São Carlos, SP, Brazil
}

Sylvain Ladame, Michèle Willson, ${ }^{\ddagger}$ and Jacques Périé ${ }^{*}+$

Laboratoire de Synthèse et de Physico Chimie de Molécules d'Intérêt Biologique UMR-CNRS 5068, Groupe de Chimie Organique Biologique, Université Paul Sabatier, 118, route de Narbonne, 31062 Toulouse Cedex, France

Received October 3, 2002; Revised Manuscript Received March 31, 2003

\begin{abstract}
Glyceraldehyde-3-phosphate dehydrogenase (GAPDH) catalyzes the reversible oxidative phosphorylation of D-glyceraldehyde 3-phosphate (GAP) into D-glycerate 1,3-bisphosphate (1,3-diPG) in the presence of $\mathrm{NAD}^{+}$and inorganic phosphate $\left(\mathrm{P}_{\mathrm{i}}\right)$. Within the active site, two anion-binding sites were ascribed to the binding of the $\mathrm{C} 3$ phosphate of GAP $\left(\mathbf{P}_{\mathrm{s}}\right)$ and to the binding of the attacking phosphate ion $\left(\mathbf{P}_{\mathrm{i}}\right)$. The role played by these two sites in the catalytic mechanism in connection with the functional role of coenzyme exchange (NADH- $\mathrm{NAD}^{+}$shuttle) has been investigated by several studies leading to the C3 phosphate flipping model proposed by Skarzynski et al. [Skarzynski, T., Moody, P. C., and Wonacott A. J. (1987) J. Mol. Biol. 193, 171-187]. This model has not yet received direct confirmation. To gain further insight into the role of both sites, we synthesized irreversible inhibitors which form with the essential cysteine residue a thioacyl enzyme analogue of the catalytic intermediate. Here we report the refined glycosomal Trypanosoma cruzi GAPDH in complex with a covalently bound GAP analogue at an improved resolution of $2.0-2.5 \AA$. For this holo-thioacyl enzyme complex, a flip-flop movement is clearly characterized, the change from the $P_{i}$ to the $P_{s}$ binding site being correlated with the coenzyme exchange step: the weaker interaction of the intermediate when bound at the $P_{s}$ site with the cofactor allows its release and also the binding of the inorganic phosphate for the next catalytic step. This result gives strong experimental support for the generally accepted flip-flop model of the catalytic mechanism in GAPDH.
\end{abstract}

Glyceraldehyde-3-phosphate dehydrogenase (GAPDH), the sixth enzyme in the glycolytic pathway, has been widely studied for its central role in energy production in both prokaryotes and eukaryotes. Additionally, intense research over the past decade has provided new insights into the functional diversity of mammalian GAPDH, more precisely its involvement in membrane transport, nuclear RNA externalization, transcriptional control of gene expression, and DNA replication and repair ( $I)$. More recently, it was shown that GAPDH plays important roles in apoptosis (2), in neuronal disorders $(3-5)$, and in certain types of cancer (6). Despite the involvement of GAPDH in such a variety of biological functions, this enzyme has an essential role in the control of glycolytic metabolite flux (7). So, GAPDH has been identified as a suitable target for the development of inhibitors of glycolysis in parasites of the Trypanosomatidae family (8). More specifically, Trypanosoma cruzi, the causative agent of Chagas disease in South-America, is

${ }^{\dagger}$ This work was done within the Comite Français d'Evaluation de la Coopération Universitaire avec le Brésil (COFECUB) program (Contract $294 \mathrm{H} 99$ ) which is fully acknowledged.

* To whom correspondence should be addressed. E-mail: perie $(a)$ cict.fr. Fax: (33) 561556011 .

\$Main authors highly dependent on glycolysis in infectious stages in mammals (9). From the mechanistic and structural results described here, a family of irreversible inhibitors is proposed as a set of lead compounds for the development of news drugs against Chagas disease.

GAPDH catalyzes the oxidative phosphorylation of glyceraldehyde 3-phosphate (GAP) ${ }^{1}$ into 1,3-bisphospho-Dglyceric acid (1,3-diPG) with the involvement of inorganic phosphate $\left(\mathrm{P}_{\mathrm{i}}\right)$ and nicotinamide adenosine dinucleotide $\left(\mathrm{NAD}^{+}\right)$. Its dehydrogenase activity depends on the $\left[\mathrm{NAD}^{+}\right] /$ [NADH] ratio, which needs to be kept constant in the cell. The reaction mechanism has been intensively investigated $(10-12)$ and the multistep catalytic process, proposed in 1976 (13), can be decomposed as follows: (i) an oxidoreduction reaction, corresponding to the nucleophilic attack of an activated cysteine on the carbonyl group of GAP, followed by a hydride transfer from the generated thiohe-

'Abbreviations: gGAPDH, glycosomal D-glyceraldehyde-3-phosphate dehydrogenase (EC 1.2.1.12); GAP, glyceraldehyde 3-phosphate; $P_{i}$, inorganic phosphate; $P_{s}$, phosphate group of the substrate glyceraldehyde 3-phosphate; 1,3-diPG, 1,3-bisphosphoglycerate; NADH, nicotinamide adenine dinucleotide (reduced form) $\mathrm{NAD}^{+}$, icotinamide adenine dinucleotide (oxidized form); EDTA, ethylenediaminetinamide acid- NMR, nucle (oxidized form), EDTA, ethy nediaminetetraacetic acid; NMR, nuclear magnetic resonance; MS, mass spectra; FTIR,
Fourier transform infrared; DTT, dithiothreitol. 
miacetal to $\mathrm{NAD}^{+}$, leading to the formation of a thioacyl enzyme, and (ii) a phosphorylation of the resulting thioester through the nucleophilic attack of inorganic phosphate on the carbonyl of the thioacyl group which leads to the formation of 1,3-diPG, which is subsequently released from the active site.

The three-dimensional structures of GAPDHs from several organisms have been crystallographically determined (1422,41 ). A common feature of these structures is the presence of two highly conserved cationic sites which were identified in the GAPDH active site and are able to bind two sulfate or phosphate ions in each monomer. On the basis of modeling studies, these cationic sites were assumed to be the two phosphate binding sites; $P_{s}$ is the $C 3$ phosphate of GAP and $P_{i}$ the inorganic phosphate. Although they were initially considered as specific interaction sites of each substrate, Skarzynski et al. (16) later established a more complex mechanism involving the possible transfer of the $\mathrm{C} 3$ phosphate of GAP from one site to the other during the sequence of catalytic events. From these earlier studies, it was proposed that the $\mathrm{C} 3$ phosphate of GAP should initially interact with the $P_{i}$ site during the steps leading to the formation of the acyl enzyme intermediate. The coenzyme exchange step is thought to result from a conformational isomerization of the thioacyl enzyme intermediate of the $\mathrm{C} 3$ phosphate of GAP from the $P_{i}$ to the $P_{s}$ site. The now free $P_{i}$ site could then bind inorganic phosphate, and the phosphorylation on $\mathrm{C}_{1}$ could then proceed by nucleophilic attack. Although Corbier et al. (23) have shown, by site-directed mutagenesis and kinetic studies, that the $\mathrm{C} 3$ phosphate of GAP first interacts at the $P_{i}$ site, flipping toward the $P_{s}$ site has never been demonstrated. Moreover, recent studies have suggested that this GAP phosphoryl group could also interact with a third cationic site, slightly different from the $P_{i}$ site and called the "new $\mathrm{P}_{\mathrm{i}}$ site" (20). Finally, more recent results of Yun et al. (24) obtained with the hemiacetal intermediate of Escherichia coli GAPDH are also in accordance with the flip-flop model. However, they do not provide direct evidence of this process. To shed some light on these mechanistic aspects, we thought that it would be helpful to mimic as closely as possible the acyl enzyme intermediate. Indeed, the three-dimensional structure of the enzymesubstrate-cofactor ternary complex could reveal the detailed binding modes of the substrate, allowing the evaluation of (1) the contribution made by phosphate binding sites and (2) the functional role of coenzyme exchange in the catalytic process. The formation of a thioacyl enzyme analogue could be obtained through the reaction between the active site cysteine residue and an activated carbonyl group of a GAP analogue, leading to an irreversibly bound and therefore stable complex. The previously described irreversible GAP$\mathrm{DH}$ inhibitors that are covalently bound at the active cysteine residue $(25-30)$ are not good representatives of the thioacyl enzyme intermediate

We report here the synthesis of ( $p$-nitrophenoxycarboxyl)propyl dihydroxyphosphonates, as GAP analogues, and their inactivation effects on glycosomal $T$. cruzi GAPDH (gGAP. $\mathrm{DH}$ ), in the search for compounds that covalently bind to the cysteine residue of the enzyme to produce a thioester complex. We also present the crystal structure of the holothioacyl enzyme complex of $T$. cruzi GAPDH with one member of this family of compounds, which reveals that the phosphoryl group of the molecule interacts with both $\mathrm{P}_{\mathrm{i}}$ and $P_{s}$ sites. Comparison of this complex with the holoenzyme from $T$. cruzi shows that a conformational change of the protein is induced upon inhibitor binding. Detailed analysis of interactions between the substrate analogue, cofactor, and protein provides strong experimental support for the generally accepted catalytic mechanism

\section{MATERIALS AND METHODS}

Synthesis of Inhibitors. All chemical reagents were purchased form either Aldrich or Lancaster Co. The pure compounds were identified by spectrometric analysis on an apparatus of the Institute at Molecular Chemistry Paul Sabatier (ICMPS-IR1744). IR spectra were recorded on a Perkin-Elmer FTIR 1610 spectrometer; ${ }^{1} \mathrm{H},{ }^{13} \mathrm{C}$, and ${ }^{31} \mathrm{P}$ NMR spectra were recorded on Bruker 250 and $200 \mathrm{MHz}$ FT apparatus, and mass spectra were determined on a Nemag R10-10 spectrometer. Elemental analysis was performed at the INP-ENSCT on an Eager 200 apparatus.

Synthesis of Carboxylic Acids. 4-(Diethoxyphosphoryl)butanoic acid 1a and 4-(diethoxyphosphoryl)-2-butenoic acid 2a were prepared by saponification of their corresponding ethyl esters and then isolated in their acidic form (Supporting Information). 2-[2-(Diethoxyphosphoryl)ethyl] acrylic acid 3a was prepared by condensation of the carbanion of diethylmethyl phosphonate on 3-bromo-2-(bromoethyl)propanoic acid via a double addition-elimination reaction. To a solution of diethylmethyl phosphonate $(1.47 \mathrm{~g}, 9.7 \mathrm{mmol})$ in anhydrous THF $(20 \mathrm{~mL})$ was slowly added $7.3 \mathrm{~mL}$ of $n$-BuLi $(11.6 \mathrm{mmol})$ at $-78^{\circ} \mathrm{C}$. After being stirred for 15 min at $-78^{\circ} \mathrm{C}$, this solution was added, via a cannula, to a solution of 3-bromo-2-(bromoethyl)propanoic acid (1.18 g, $4.8 \mathrm{mmol})$ and $n$-BuLi $(3.4 \mathrm{~mL}, 5.3 \mathrm{mmol})$ in anhydrous THF $(15 \mathrm{~mL})$ at $-78^{\circ} \mathrm{C}$. After being stirred for $1 \mathrm{~h}$ at -78 ${ }^{\circ} \mathrm{C}$ and overnight at room temperature, the mixture was neutralized with an aqueous solution saturated with $\mathrm{NH}_{4} \mathrm{Cl}$ and then acidified to $\mathrm{pH} 4$ with a $1 \mathrm{M} \mathrm{HCl}$ solution. The aqueous layer was subsequently extracted with $\mathrm{CH}_{2} \mathrm{Cl}_{2}$ (3 $\times 50 \mathrm{~mL}$ ), and the organic layer was dried with $\mathrm{MgSO}_{4}$, filtered, and evaporated. After purification by flash chromatography $\left(95: 5 \mathrm{CH}_{2} \mathrm{Cl}_{2} / \mathrm{MeOH}\right.$, and then $\left.90: 10\right)$, compound 3a was obtained as a pure colorless oil $(0.71 \mathrm{~g}, 58 \%)$ : ${ }^{1} \mathrm{H}$ NMR $\left(250 \mathrm{MHz}, \mathrm{CDCl}_{3}\right) \delta 1.2(\mathrm{~m}, 6 \mathrm{H}), 1.8-2.0(\mathrm{~m}, 2 \mathrm{H})$, $2.4-2.5(\mathrm{~m}, 2 \mathrm{H}), 3.9-4.0(\mathrm{~m}, 4 \mathrm{H}), 5.5(\mathrm{~s}, 1 \mathrm{H}), 6.1(\mathrm{~s}, 1 \mathrm{H})$, $11.4(\mathrm{~s}, 1 \mathrm{H}) ;{ }^{13} \mathrm{C} \mathrm{NMR}\left(62.9 \mathrm{MHz}, \mathrm{CDCl}_{3}\right) \delta 16.2\left(\mathrm{~d}, J_{\mathrm{C}-\mathrm{P}}\right.$ $=6.2 \mathrm{~Hz}), 24.4\left(\mathrm{~d}, J_{\mathrm{C}-\mathrm{P}}=140.8 \mathrm{~Hz}\right), 25.1\left(\mathrm{~d}, J_{\mathrm{C}-\mathrm{P}}=3.9\right.$ $\mathrm{Hz}), 61.9\left(\mathrm{~d}, J_{\mathrm{C}-\mathrm{P}}=6.5 \mathrm{~Hz}\right), 126.1,139.5\left(\mathrm{~d}, J_{\mathrm{C}-\mathrm{P}}=17.5\right.$ $\mathrm{Hz}), 169.0$; MS (DCI, $\left.\mathrm{NH}_{3}\right) m / z 237\left(\mathrm{MH}^{+}\right), 254\left(\mathrm{MNH}_{4}{ }^{+}\right)$.

Synthesis of p-Nitrophenyl Esters. They were prepared from the corresponding carboxylic acids by addition of $p$-nitrophenate anion on the nonisolated acyl chloride intermediate (1) and $\mathbf{2 b}$ in the Supporting Information). For compound $\mathbf{3 b}$, to a solution of carboxylic acid $(10 \mathrm{mmol})$ in anhydrous $\mathrm{CH}_{2} \mathrm{Cl}_{2}(20 \mathrm{~mL})$ was added thionyl chloride (1.1 $\mathrm{mL}, 15 \mathrm{mmol}$ ). After the mixture had been stirred overnight at room temperature, the volatile components were evaporated off, leading to the pure expected acid chloride evidenced by IR spectroscopy $\left(v_{\mathrm{C}=\mathrm{O}}=1747 \mathrm{~cm}^{-1}\right)$. The oily residue was then dissolved in anhydrous $\mathrm{CH}_{2} \mathrm{Cl}_{2}(20 \mathrm{~mL})$, and a solution of $p$-nitrophenol $(1.26 \mathrm{~g}, 9.1 \mathrm{mmol})$ and anhydrous triethylamine $(1.55 \mathrm{~mL}, 11.2 \mathrm{mmol})$ in $\mathrm{CH}_{2} \mathrm{Cl}_{2}$ 
$(20 \mathrm{~mL})$ was slowly added at $0{ }^{\circ} \mathrm{C}$. After the mixture had been stirred for $3 \mathrm{~h}$ at room temperature, the triethylammonium salts were filtered off, and the organic layer was washed with an aqueous solution saturated with $\mathrm{NaCl}(50 \mathrm{~mL})$, dried with $\mathrm{MgSO}_{4}$, filtered, and evaporated. $p$-Nitrophenyl ester 3b was thus obtained as a pale yellow oil ( $98 \%$ yield).

3-( $p$-Nitrophenoxycarboxyl)-3-ethylene propyl diethylphosphonate 3b: 'H NMR (250 MHz, $\left.\mathrm{CDCl}_{3}\right) \delta 1.3\left(\mathrm{t}, 6 \mathrm{H}, J_{\mathrm{H}-\mathrm{p}}\right.$ $=7.1 \mathrm{~Hz}), 1.9-2.0(\mathrm{~m}, 2 \mathrm{H}), 2.6-2.7(\mathrm{~m}, 2 \mathrm{H}), 4.0-4.1(\mathrm{~m}$, $4 \mathrm{H}), 5.8(\mathrm{~s}, 1 \mathrm{H}), 6.4(\mathrm{~s}, 1 \mathrm{H}), 7.2\left(\mathrm{~d}, 2 \mathrm{H}, J_{\mathrm{H}-\mathrm{H}}=9.1 \mathrm{~Hz}\right)$, $8.2\left(\mathrm{~d}, 2 \mathrm{H}, J_{\mathrm{H}-\mathrm{H}}=9.1 \mathrm{~Hz}\right) ;{ }^{13} \mathrm{C} \mathrm{NMR}\left(62.9 \mathrm{MHz}, \mathrm{CDCl}_{3}\right)$ $\delta 16.4\left(\mathrm{~d}, J_{\mathrm{C}-\mathrm{p}}=6.1 \mathrm{~Hz}\right), 24.5\left(\mathrm{~d}, J_{\mathrm{C}-\mathrm{p}}=141.6 \mathrm{~Hz}\right), 25.4$ $\left(\mathrm{d}, J_{\mathrm{C}-\mathrm{P}}=3.8 \mathrm{~Hz}\right), 61.6\left(\mathrm{~d}, J_{\mathrm{C}-\mathrm{P}}=6.5 \mathrm{~Hz}\right), 122.5,125.2$, $128.7,138.2\left(\mathrm{~d}, J_{\mathrm{C}-\mathrm{P}}=16.7 \mathrm{~Hz}\right), 145.3,155.4,163.9 ;{ }^{31} \mathrm{P}$ NMR $\left(81 \mathrm{MHz}, \mathrm{CDCl}_{3}\right) \delta 30.3 ; \mathrm{MS}\left(\mathrm{DCI}, \mathrm{NH}_{3}\right) \mathrm{m} / \mathrm{z} 358$ $\left(\mathrm{MH}^{+}\right), 375\left(\mathrm{MNH}_{4}{ }^{+}\right)$.

Synthesis of Dihydroxyphosphonates. They were prepared by following a classical procedure using bromotrimethylsilane (1c and $\mathbf{1 b}$ in the Supporting Information). For 3c, bromotrimethylsilane $(2.1 \mathrm{~mL}, 15.4 \mathrm{mmol})$ was added to diethyl phosphonate $3 \mathbf{b}$ (3.9 mmol) stored under an argon atmosphere. After the mixture had been stirred for $6 \mathrm{~h}$ at room temperature, all volatile components were removed by evaporation, and the oily residue was dissolved in $\mathrm{Et}_{2} \mathrm{O}$ (15 $\mathrm{mL})$ and extracted with water $(30 \mathrm{~mL}) .3 \mathrm{c}$ was obtained pure as a white or pale yellow powder ( $95 \%$ yield) after the aqueous solution had been freeze-dried.

3-( $p$-Nitrophenoxycarboxyl)-3-ethylene propyl dihydroxyphosphonate 3c: ${ }^{1} \mathrm{H}$ NMR $\left(250 \mathrm{MHz}, \mathrm{D}_{2} \mathrm{O}\right) \delta 2.0-2.1(\mathrm{~m}$, $2 \mathrm{H}), 2.6-2.7(\mathrm{~m}, 2 \mathrm{H}), 6.0(\mathrm{~s}, 1 \mathrm{H}), 6.5(\mathrm{~s}, 1 \mathrm{H}), 7.4(\mathrm{~d}, 2 \mathrm{H}$, $\left.J_{\mathrm{H}-\mathrm{H}}=9.1 \mathrm{~Hz}\right), 8.3\left(\mathrm{~d}, 2 \mathrm{H}, J_{\mathrm{H}-\mathrm{H}}=9.1 \mathrm{~Hz}\right) ;{ }^{3} \mathrm{C}$ NMR $(62.9$ $\left.\mathrm{MHz}, \mathrm{D}_{2} \mathrm{O}\right) \delta 27.4\left(\mathrm{~d}, J_{\mathrm{C}-\mathrm{P}}=3.4 \mathrm{~Hz}\right), 27.9\left(\mathrm{~d}, J_{\mathrm{C}-\mathrm{P}}=135.5\right.$ $\mathrm{Hz}), 125.4,128.1,132.3,140.3\left(\mathrm{~d}, J_{\mathrm{C}-\mathrm{p}}=16.1 \mathrm{~Hz}\right), 148.0$, $157.9,169.0 ;{ }^{31} \mathrm{P}$ NMR $\left(81 \mathrm{MHz}, \mathrm{D}_{2} \mathrm{O}\right) \delta 30.6$. Anal. Calcd for $\mathrm{C}_{11} \mathrm{H}_{12} \mathrm{NO}_{7} \mathrm{P}(301)$ : $\mathrm{C}, 43.87 ; \mathrm{H}, 4.02 ; \mathrm{N}, 4.65$. Found: $\mathrm{C}, 44.01 ; \mathrm{H}, 3.86 ; \mathrm{N}, 4.72$.

Enzyme Inhibition Assays. Assay reactions (total volume of $1.0 \mathrm{~mL}$ ) were carried out at $25^{\circ} \mathrm{C}$ in a $100 \mathrm{mM}$ triethanolamine, $\mathrm{HCl}$ buffer $(\mathrm{pH} 7.5, I=0.15)$ containing 1 $\mathrm{mM}$ EDTA, $0.1 \mathrm{M} \mathrm{KCl}, 10 \mathrm{mM} \mathrm{K}_{2} \mathrm{HPO}_{4}, 2 \mathrm{mM} \mathrm{NAD}{ }^{+}$, $0.8 \mathrm{mM}$ GAP, $20 \mu \mathrm{L}$ of a glyceraldehyde-3-phosphate dehydrogenase-containing solution, and variable concentrations of the inhibitor. The remaining GAPDH activity was determined by following at $340 \mathrm{~nm}$ the formation kinetics of $\mathrm{NADH}$ resulting from the reduction of $\mathrm{NAD}^{+}$by the enzyme. In all cases, the rates are expressed in micromoles of product formed per minute. One enzyme unit is defined as the amount of enzyme necessary for the formation of 1 $\mu \mathrm{mol}$ of 1,3-diPG/min.

For irreversible inhibitors, the inactivation kinetics were established by using saturating conditions of substrates and cofactor, after incubation of the enzyme with at least five different concentrations of inhibitor $(5,15,25,50$, and 75 $\mu \mathrm{M})$. Experiments were carried out in triplicate, and individual initial rates were kept only when they corresponded to values obtained with correlation coefficients equal to or better than 0.998 . The percentage of remaining activity was determined with respect to a reference, the enzyme incubated without inhibitor during the same period of time.

Preparation and Purification of Glycosomal T. cruz GAPDH. Recombinant T. cruzi gGAPDH was prepared and purified according to the previously reported procedure (22)

\begin{tabular}{ll}
\hline Table 1: Collection and Processing Statistics \\
\hline oscillation angle & $1.0^{\circ}$ \\
total no. of frames & 134 \\
total no. of collected reflections & 134297 \\
no. of unique reflections & 48450 \\
resolution range & $20.0-2.5 \AA$ \\
overall completeness & $99.0 \%(97.5 \%)^{a}$ \\
overall $R_{\text {merge }}$ & $11.3 \%(43.8 \%)^{a}$ \\
$I / \sigma l$ & $9.7(2.6)^{a}$ \\
redundancy & $2.8(2.5)^{a}$ \\
\hline${ }^{a}$ The values in parentheses correspond to the last resolution shell
\end{tabular}

${ }^{a}$ The values in parentheses correspond to the last resolution shell $(2.56-2.5 \AA)$.

with minor modifications. No DTT was used in the purification buffer since it can react with the inhibitors.

Cocrystallization Assays. Cocrystallization assays were carried out using a protein solution at $10 \mathrm{mg} / \mathrm{mL}$ and $\mathrm{NAD}^{+}$ at a saturating concentration, preincubated with $2.0 \mathrm{mM}$ inhibitor. Crystals of the gGAPDH-3-( $p$-nitrophenoxycarboxyl)-3-ethylene propyl dihydroxyphosphonate (3c) complex were grown at $18^{\circ} \mathrm{C}$ by hanging drop vapor diffusion, against a reservoir solution of $0.1 \mathrm{M}$ sodium cacodylate

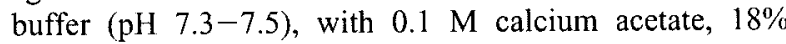
polyethylene glycol $8000,1.0 \mathrm{mM}$ EDTA, and $1.0 \mathrm{mM}$ sodium azide. The hanging drops were set up with equal volumes $(5+5 \mu \mathrm{L})$ of gGAPDH solution and reservoir buffer. Small flat crystals appeared within 2 weeks.

Data Collection and Processing. A single crystal of the gGAPDH-3c complex was flash-cooled to $100 \mathrm{~K}$ in an Oxford Cryostream Cooler. The cryoprotectant solution that was used consisted of $20 \%$ polyethylene glycol 400 added to the reservoir solution described above. Monochromatic $X$-ray data collection was performed in the Brazilian National Synchrotron Light Laboratory (LNLS) (31), using an incident wavelength of $1.54 \AA$. Diffraction spots were recorded on a MAR345 image plate, using the rotation method (32). Data indexing and scaling were carried out with DENZO and SCALEPACK, respectively (33). Data collection and processing statistics are summarized in Table 1 . The collected crystal belonged to space group $P 2_{1}$ with the following unit cell parameters: $a=81.46 \AA, b=85.26 \AA, c=105.15 \AA$, and $\beta=95.61^{\circ}$. The analysis of crystal contents reveals one tetramer per asymmetric unit and a $V_{\mathrm{m}}$ value of $2.21 \AA^{3 / \mathrm{Da}}$

Structure Determination and Refinement. The structure was determined by molecular replacement, using AMoRe (34). The native tetrameric gGAPDH structure (22) without cofactor and water molecules was used as a search model. Further refinement was performed using the CNS programs (35) with torsional molecular dynamics and maximum likelihood functions, and the addition of water molecules was conducted with ARP (36). Manual rebuilding of the macromolecular model and graphic visualization were performed using $O(37)$. The crystallographic $R_{\text {factor }}$ and $R_{\text {frec }}$ values, as well as the stereochemical quality of the model, were constantly monitored during the course of the refinement with PROCHECK (38). AMoRe provided a clear solution with one tetramer in the asymmetric unit, with a correlation factor of 0.67 and an $R_{\text {factor }}$ of 0.33 . The rotated and translated model was refined with a simulated annealing protocol using noncrystallographic symmetry (NCS) restraints. This refinement produced an $R_{\text {factor }}$ of 0.33 and an $R_{\text {free }}$ of 0.34 . Visual analysis of $F_{\mathrm{o}}-F_{\mathrm{c}}$ and $2 F_{\mathrm{o}}-F_{\mathrm{c}}$ maps revealed clear electron density for the NAD cofactor only in monomer $\mathrm{D}$. 

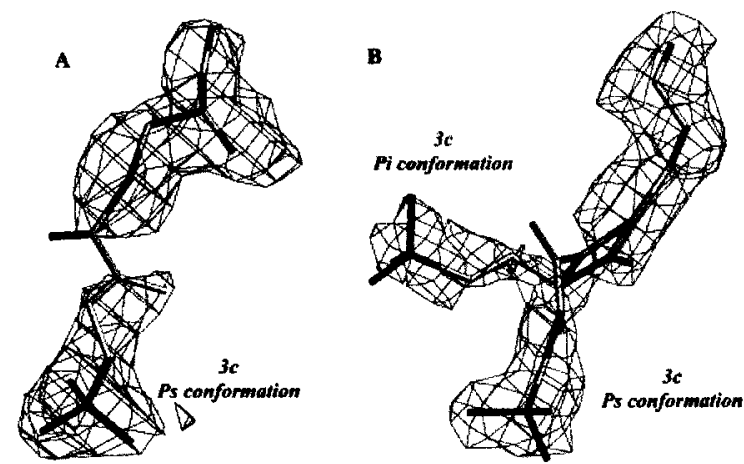

FIGURE 1: $2 F_{0}-F_{\mathrm{c}}$ map contoured at $0.8 \delta$ in the active site of monomer $\mathrm{D}$, represented in panel $\mathrm{A}\left(\mathrm{P}_{\mathrm{s}}\right.$ conformation), and monomer $\mathrm{B}$, represented in panel $\mathrm{B}\left(\mathrm{P}_{\mathrm{s}}\right.$ and $\mathrm{P}_{\mathrm{i}}$ alternate conformations). The continuous electron density from Cys 166 to $3 \mathrm{c}$ supports its covalent binding in both conformations, as discussed above. Atoms are colored according to the following code: $\mathrm{C}$ atoms in light purple, $\mathrm{N}$ atoms in blue, $\mathrm{S}$ atoms in orange, $\mathrm{P}$ atoms in pink, and $O$ atoms in red. This figure was created in $O(37)$.

This molecule was included, and a new refinement cycle was performed, without NCS restraints. $R_{\text {factor }}$ decreased to 0.23 and $R_{\text {free }}$ to 0.29 . After several cycles of manual rebuilding with $\mathrm{O}$ and minimization steps, unequivocal density for the inhibitor could be clearly identified in the active site of monomer D (Figure 1A). One molecule of 3c was manually built into this density, and water molecules were automatically added to the model using the program ARP. The refinement cycles resulted in an $R_{\text {factor }}$ of 0.20 and an $R_{\text {free }}$ of 0.27 . Careful analysis of the electron density maps indicated that subunits $B$ and $C$ could also have both NAD and inhibitor bound, possibly with lower occupancies. Therefore, NAD and the inhibitor were added to the atomic model, in the same conformation that was found in monome $\mathrm{D}$, and the subsequent refinement cycle included their occupancies as parameters, which converged to approximately $50 \%$. At this point, a difference Fourier map showed density close to Cys 166 in monomers $\mathrm{B}$ and $\mathrm{C}$, in which the inhibitor 3c could be fitted, in an alternative conformation (Figure 1B). As the previous refinement had shown halfoccupancy for the first conformation, an identical value $(50 \%)$ was assigned to the occupancy of the second conformation.

In the first conformation, the phosphonate moiety is located at the $\mathrm{P}_{\mathrm{s}}$ binding site, and in the second conformation, it occupies the $P_{i}$ binding site. The final cycles of refinement included as the atomic model the four protein subunits (named A-D), one NAD molecule and one inhibitor $3 \mathrm{c}$ in the $P_{s}$ conformation in subunit $D$, one NAD molecule and two alternative conformers of $\mathbf{3 c}$ in subunits $\mathrm{B}$ and $\mathrm{C}$, and a total of 695 water molecules. All amino acid side chains which did not exhibit any electron density in the final maps were assigned zero occupancies. The final crystallographic results are summarized in Table 2 .

\section{RESULTS}

Design and Synthesis of GAPDH Inhibitors. It was previously shown that GAPDH is a good target for the design of irreversible inhibitors since its mechanism involves the formation of a covalent intermediate between the enzymc and the substrate GAP. Following the strategy of targeting

\begin{tabular}{ll}
\hline Table 2: Final Refinement Statistics \\
\hline $\begin{array}{l}\text { resolution range } \\
\text { no. of amino acid residues }\end{array}$ & $20.0-2.5 \AA$ \\
$\quad$ per monomer & \\
no. of water molecules & 695 \\
$\quad$ in the asymmetric unit & \\
no. of inhibitor molecules & three (one in monomer B with two \\
& alternative conformations, one in \\
& monomer C with two alternative \\
& conformations, and one in monomer \\
& D in only one conformation) \\
$R_{\text {factor }}$ & 0.20 \\
$R_{\text {frec, } 3 \%}$ & 0.26 \\
rms deviation for bonds & $0.0063 \AA$ \\
rms deviation for angles & $1.22^{\circ}$ \\
\hline
\end{tabular}

the cysteine residue of the GAPDH active site involved in this covalent bonding, a few compounds bearing a reactive electrophilic site such as an epoxide or an $\alpha$-enal werc synthesized and proved to be potent GAPDH irreversible inhibitors (29). Since all these inhibitors bind to this cysteine residue through the formation of a thioether or an unstable thiohemiacetal linkage, we decided to design stable GAP analogues by replacing the aldehyde group in the inhibitor with an activated ester. We describe here the synthesis of three phosphonates, which are much less sensitive to hydrolysis than their phosphate analogues. The compounds were designed to bear a $p$-nitrophenol ester group, chosen to react with the active site cysteine to form a thioacyl enzyme, analogous to that formed during the catalytic mechanism. In this reaction, the $p$-nitrophenate group is released and can be easily monitored by its typical absorption at $410 \mathrm{~nm}$. Schemes depicting the syntheses of compounds $1 c, 2 c$, and $\mathbf{3 c}$ are given in the Supporting Information. These $p$-nitrophenyl esters were synthesized from the corresponding carboxylic acids via the formation of an acyl chloride intermediate. The phosphoric ethoxy ester protecting groups were removed in the last step by hydrolysis of instable trimethylsilyl phosphoric ester intermediates.

Irreversible Inhibition of GAPDH. The three $p$-nitrophenol esters $\mathbf{1 c}-\mathbf{3 c}$, which are GAP analogues, give a timedependent inactivation of $T$. cruzi gGAPDH. The saturated derivative 1c proved to be too unstable to allow the determination of the corresponding inhibition constants. Consequently, we focused our study on compounds $2 \mathrm{c}$ and $3 c$, which are much more stable because of the presence of a conjugated unsaturated group. Inactivation of $T$. cruzi gGAPDH by compound $\mathbf{3 c}$ follows pseudo-first-order kinetics. This irreversible effect was confirmed by the fact that no enzymatic activity was recovered after dilution of the enzyme/inhibitor mixture obtained after the incubation time. The plot of the reciprocal of the inactivation half-life versus inhibitor concentration results in a straight line passing through the origin, the slope of which corresponds to the $k_{\text {second }}$ value. T. cruzi gGAPDH was inactivated by compound $3 \mathrm{c} 6$ times faster than with compound $2 \mathrm{c}$ since the $k_{\text {sccond }}$ values are 7000 and $1200 \mathrm{M}^{-1} \mathrm{~min}^{-1}$, respectively. The kinetic equation describing this pathway under steady state conditions is expressed according to the classical kinetic expression (39).

Interaction Mode. Since these irreversible inhibitors bear Michael acceptor, two different ways of inactivation were possible. In the first (Scheme 1A), addition of the thiol of 
Scheme 1: Two Possible Inactivation Paths of GAPDH by Inhibitor $\mathbf{3} \mathbf{c}^{a}$
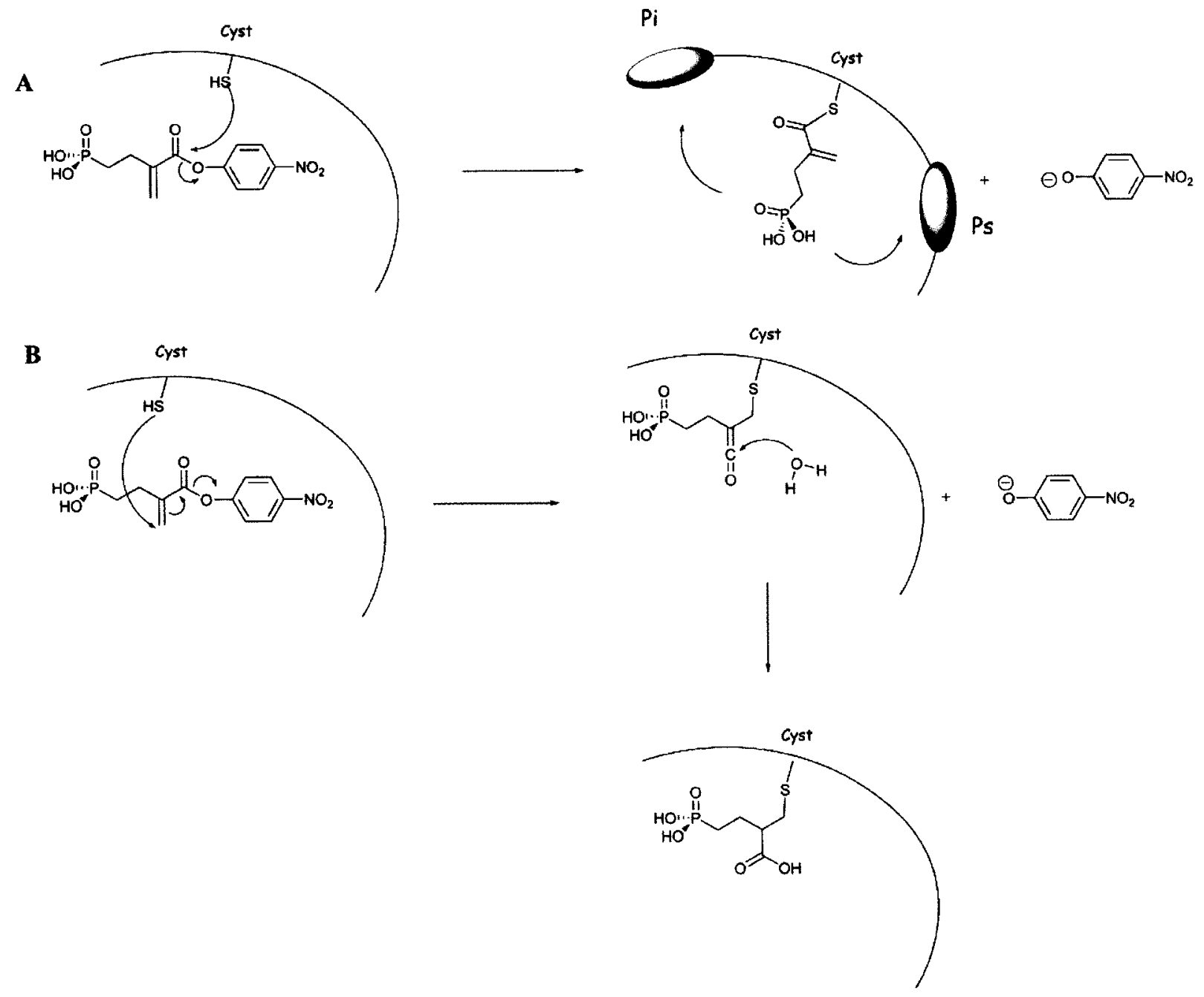

(A) Nucleophilic attack on the carbonyl group and (B) 1,4-nucleophilic addition.

the cysteine residue on the carbonyl group could lead to the expected thioacyl enzyme that mimics the covalent intermediate formed with GAP. In a second (Scheme 1B), a 1,4addition on the conjugated ethylenic system could lead to an enzyme-inhibitor covalent complex through the formation of a thioether bond. This configuration would not only enable the analysis of the specific interactions between $T$. cruzi gGAPDH and this series of inhibitors but also provide complementary information about the GAPDH reaction mechanism. To elucidate this question, X-ray analysis of the complex was undertaken.

Quality of the Structure. The structure has good stereochemistry indicators, with more than $99 \%$ of the residues showing main chain torsional angles in the allowed regions of the Ramachandran plot (40). Only Val255 is in an unfavorable region, though conserved in all other available GAPDH structures $(14,16,17,20,22)$. This residue is in a loop between two consecutive $\beta$-strands, in a conformation considered to be important for maintaining the correct positioning of the active residue Cys 166 with respect to the nicotinamide ring of the $\mathrm{NAD}^{+}$cofactor during catalysis. The average temperature factor values for the main chain atoms and all atoms of the 359 residues from each monomer are as follows: 25.11 and $24.65 \AA^{2}$ for monomer $A, 31.07$ and $30.53 \AA^{2}$ for monomer $\mathrm{B}, 42.74$ and $42.50 \AA^{2}$ for monomer $\mathrm{C}$, and 23.70 and $23.22 \AA^{2}$ for monomer $\mathrm{D}$, respectively. The higher $B$-factor in monomer $C$ reflects its higher mobility in the crystal lattice. Indeed, careful analysis of the crystal contacts of each of the four monomers in the a.u. indicates that subunit $\mathrm{A}$ has four neighboring monomers, subunit $B$ has six neighboring monomers, subunit $D$ has four neighboring monomers, and finally subunit $\mathrm{C}$ has only one neighboring monomer in the lattice, and this contact is made through the catalytic domain that forms the core of the tetrameric particle which is conformationally conserved in all four subunits.

Interactions of Compound $3 c$ with the Protein. The inhibitor is clearly bound to Cys 166 and forms a thioester resulting from the nucleophilic attack of the thiol on the activated ester carbonyl group. The inhibitor is found in two alternative conformations (Figure 1B), hereafter named the " $\mathrm{P}_{\mathrm{s}}$ conformation", present in monomers $\mathrm{B}-\mathrm{D}$, and the " $\mathrm{P}_{\mathrm{i}}$ conformation", present only in monomers B and C. In the $\mathrm{P}_{\mathrm{i}}$ conformation, the $3 \mathrm{c}$ phosphoryl group hydrogen bonds to residues Thr226 and Arg249 and its phosphorus atom is $3.35 \AA$ from the previous position described for the phosphate 


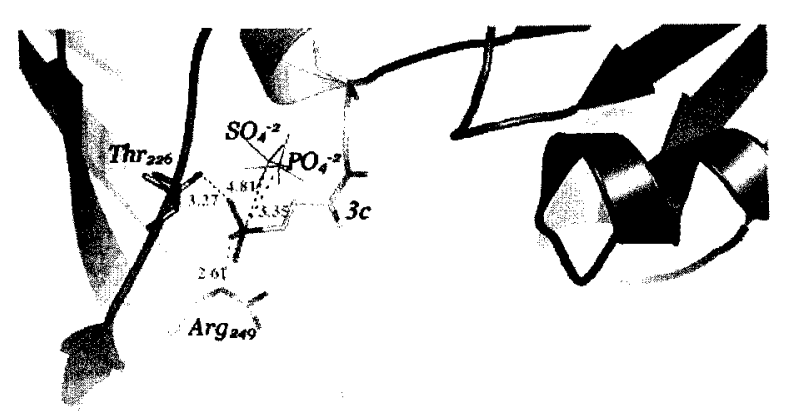

$\mathbf{A}$

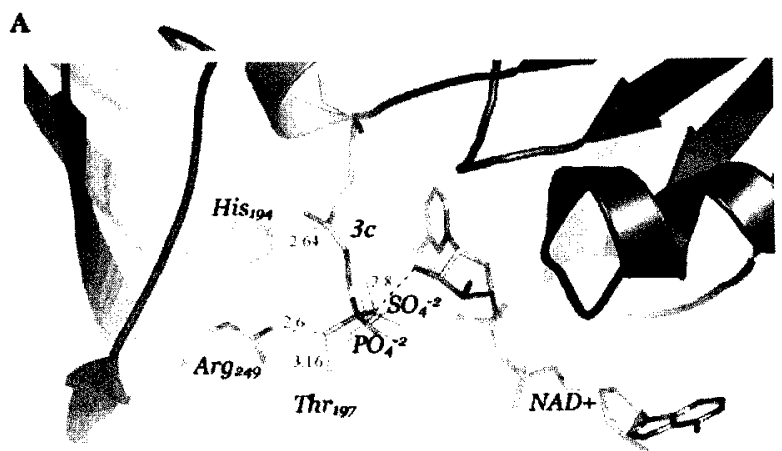

Figure 2: (A) Interaction profile of $3 \mathbf{c}$ in the $P_{i}$ binding site. The phosphoryl moiety, which is displaced $3.35 \AA$ from the previously reported position of L. mexicana $\mathrm{PO}_{4}{ }^{2-}$ and $4.81 \AA$ from the previously reported position of $T$. brucei $\mathrm{SO}_{4}{ }^{2-}$ (blue dashed lines), hydrogen bonds to residues Thr226 and Arg249 (red dashed lines) (B) Interaction profile of $3 \mathrm{c}$ in the $\mathrm{P}$ binding site The phosphoryl (B) Inten bron moiety hydrogen bonds to residues Thr 197, His 194, and Arg249 (red dashed lines). L. mexicana $\mathrm{PO}_{4}{ }^{2-}$ and T. brucei $\mathrm{SO}_{4}{ }^{2-}$ binding positions are also depicted. In a comparison of panels $A$ and $B$ of Figure 2 , it becomes clear that the $\mathrm{P}_{\mathrm{s}}$ binding site has a much more strict position. In fact, the $3 \mathrm{c}$ phosphoryl moiety is only $0.93 \AA$ from the previously reported position of L. mexicana $\mathrm{PO}_{4}{ }^{2-}$ and $0.70 \AA$ from the previously reported position of $T$. brucei $\mathrm{SO}_{4}{ }^{2-}$, 0.70 . frot in reprented for reas in cartoon representation, apart from residues Thr 197, His 194, Thr226, and Arg249 that have all atoms represented. L. mexicana $\mathrm{PO}_{4}{ }^{2-}$ and $T$. brucei $\mathrm{SO}_{4}{ }^{2-}$ atoms come from crystallographic superposition of IGYP and $1 \mathrm{~A} 7 \mathrm{~K}$ on the $3 \mathrm{c}-\mathrm{gGAPDH}$ structure. This figure was created in Pymol.

binding site in Leishmania mexicana gGAPDH (4l) and 4.81 $\AA$ from the sulfate binding site in Trypanosoma brucei gGAPDH (17) (Figure 2A). In this conformation, the 3c carbonyl group points to the positively charged $\mathrm{NAD}^{+}$ nicotinamide ring with the distance between $O_{1}$ of $3 \mathrm{c}$ and $\mathrm{N}_{1}$ of $\mathrm{NAD}^{+}$being $3.63 \AA$, longer than the usual length of the charge interaction predicted by Yun et al. (24).

In the $\mathrm{P}_{\mathrm{s}}$ conformation, the $\mathbf{3 c}$ phosphoryl group, which is located $0.93 \AA$ from the previous position described for the inorganic phosphate binding site in L. mexicana gGAP$\mathrm{DH}(4 I)$ and $0.70 \AA$ from the sulfate binding site in $T$. brucei gGAPDH (17), hydrogen bonds to residues Thr197 and Arg249 and to the $\mathrm{C}^{\prime}$-hydroxyl group of the ribose sugar of the cofactor (Figure 2B). In addition, its carbonyl group hydrogen bonds to His 194. Similar interactions should be present when the thioketal intermediate binds in the $P_{s}$ conformation. It should be stressed that in this conformation

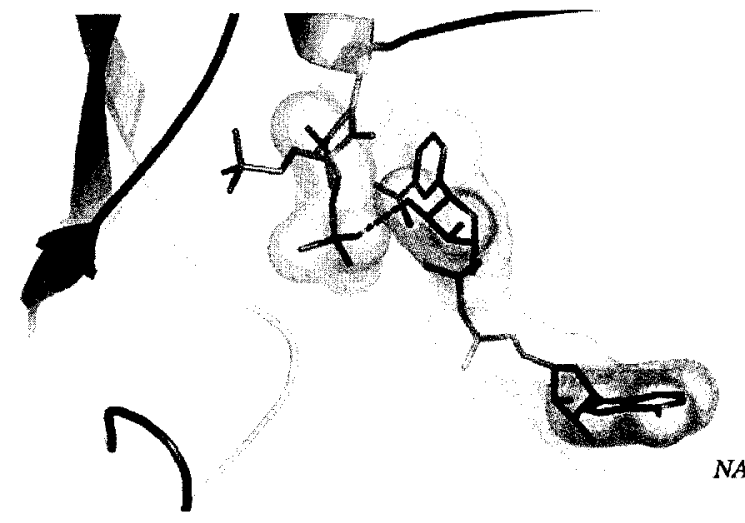

$N A D$

FIGURE 3: Interaction profile of $3 \mathbf{c}$ with NAD. When bonded in the $\mathrm{P}_{\mathrm{S}}$ conformation, the $3 \mathrm{c}$ phosphoryl moiety hydrogen bonds to NAD's ribose, which is $2.83 \AA$ from it. In fact, this interaction together with hydrophobic contacts between $3 \mathrm{c}$ and NAD, represented by surface complementarity, is supposed to hold the cofactor in place. When bonded in the $\mathrm{P}_{1}$ conformation (gray), $3 \mathrm{c}$ loses these in place. When bonded in the interactions to NAD. Protein structure is represented as a gray cartoon, and NAD and $3 \mathrm{c}$ are represented in sticks colored according to the following code: $\mathrm{C}$ atoms in light purple, $\mathrm{N}$ atoms in blue, $\mathrm{S}$ atoms in orange, $\mathrm{P}$ atoms in pink, and $\mathrm{O}$ atoms in red. This figure was created in Pymol.

Table 3: Comparison of the rms Differences $(\AA)$ in the

Superposition of $\mathrm{C} \alpha$ Atoms from Equivalent Domains in Each Pair of Subunits in the Enzyme ${ }^{a}$

\begin{tabular}{llcccc}
\hline & \multicolumn{4}{c}{ catalytic domain } \\
\cline { 3 - 6 } & & subunit A & subunit B & subunit C & subunit D \\
\hline \multirow{2}{*}{ coenzyme } & subunit A & & 0.57 & 0.82 & 0.73 \\
binding & subunit B & 0.21 & & 0.79 & 0.69 \\
domain & subunit C & 0.19 & 0.21 & & 0.74 \\
& subunit D & 0.20 & 0.22 & 0.18 & \\
\hline
\end{tabular}

a The catalytic domain is formed by residues $151-330$, and the NAD binding domain is formed by residues $1-150$ at the $\mathrm{N}$-terminus and residues $331-359$ at the $\mathrm{C}$-terminus.

the carbonyl group points away from the positively charged nitrogen of the nicotinamide moiety (Figure 3), once more excluding the possibility of charge interaction between $3 \mathrm{c}$ and $\mathrm{NAD}^{+}$.

Overall Structures. The monoclinic crystals of $T$. cruzi GAPDH contain one tetramer per asymmetric unit. The subunits were independently refined, allowing a detailed analysis of the local 222 symmetry. Superposition of $\mathrm{C} \alpha$ atoms from equivalent domains in each pair of subunits in the enzyme (Table 3 ) clearly shows that the catalytic domains are much more similar than the NAD binding domains, which is analogous to what was observed by Skarzynski et al. (Bacillus stearothermophilus) (16). This reflects the functionally important flexibility of the coenzyme binding domain needed to allow the rapid exchange of NAD in reduced and oxidized states during catalysis. Indeed, the structure of $T$. cruzi GAPDH complexed with the natural inhibitor chalepin (42) shows a large conformational change of the coenzyme binding domain, mainly described as a domain rotation of $\sim 4^{\circ}$. Also, in that report, only one monomer of the enzyme in the crystal has an observable bound inhibitor. Likewise, in the structure presented here, we find asymmetric binding of the inhibitor and cofactor to the four independent subunits of the enzyme. This observation suggests that in solution the enzyme-inhibitor complexes have a distribution of 
populations with different numbers of subunits occupied by the inhibitor, resulting in asymmetric particles which are subsequently selected by the crystallization process, to predominantly accommodate one particular conformer in the crystal lattice. Furthermore, this finding of alternative conformations for the bound inhibitor suggests that $\mathbf{3 c}$ has extended flexibility in the active site, which may also explain the absence of observable connected electron density in the Fourier maps of subunit A.

The comparison of the structure presented here with those of $T$. cruzi GAPDH in the holo form (22) and apo form complexed with the natural product inhibitor chalepin (42) indicates that the major changes are related to the orientation of Arg249. In Souza et al. (22) and Pavão et al. (42), where no phosphate ion or substrate analogue is present in the active site of T. cruzi GAPDH, Arg249 points to Asp210. In the 3c-gGAPDH complex, this residue points to Thr 197 and Thr199 and hydrogen bonds to phosphate groups both in $\mathrm{P}_{\mathrm{s}}$ and $\mathrm{P}_{\mathrm{i}}$ conformations (Figure $2 \mathrm{~A}, \mathrm{~B}$ ). Another interesting feature is the distance between $\mathrm{N} \epsilon$ of His 194 and $\mathrm{S} \delta$ of Cys 166, which ranges from $3.2 \AA$ in the holo structure to $3.7 \AA$ in the apo structure. In our structure, this distance ranges from 4.1 to $4.4 \AA$. The longer distance may be consequence of $3 c$ binding to the $\mathrm{P}_{\mathrm{i}}$ binding site. All other residues in the vicinity of the active site do not presen significant side chain displacement, apart from the loop from Ser224 to Ala229, which has its $\mathrm{C} \alpha$ atoms displaced toward the $\mathrm{P}_{\mathrm{i}}$ binding site by $0.55 \AA$, although side chain conformations remain unchanged. Similar behavior was previously reported in the crystallographic structure of $L$. mexicana gGAPDH, crystallized at low $\left(\mathrm{NH}_{4}\right)_{2} \mathrm{SO}_{4}$ concentration $(4 I)$, and in the hemiacetal intermediate of $E$. coli $\mathrm{GAPDH}$ (24)

\section{DISCUSSION}

Thioacyl Enzyme-Induced Structural Changes. Analysis of differences between the structure of apo- and holoGAPDH (10) confirms the conformational changes in the enzyme induced by cofactor binding. In addition to the coenzyme binding domain, the most significant of these structural changes involves the segment of polypeptide chain spanning residues 224-229. This portion of the backbone, which includes Thr226, contributes to the building of the $P_{i}$ site, and a small change in the shape of this fragment is essential for the formation of an effective $P_{i}$ site. Comparison of the distances between the main chain atoms of this loop portion for the holo form of $T$. cruzi gGAPDH (22) and the holo-thioacyl enzyme form (monomers B-D) reveals that the corresponding segment moves closer to the $\mathrm{P}_{\mathrm{j}}$ binding site in the holo-thioacyl enzyme. Thus, the distance between the $\mathrm{P}_{i}$ and this loop decreases to $0.55 \AA$. The same conformational change was observed in the crystallographic structure of the apothiohemiacetal enzyme of $E$. coli GAPDH (24) (residues 207-212) but to a lesser extent since $\mathrm{NAD}^{+}$ is not present. This experimental evidence suggests that the widest protein deformation amplitude is observed in the ternary complex in which the GAP induces an essential conformational change leading to the catalytic structure and not only by $\mathrm{NAD}^{+}$binding. As for many other enzymes, the productive conformation is obtained by cofactor binding (here $\mathrm{NAD}^{+}, \mathrm{ATP}$ for kinases) and also by substrate binding.
GAP Binding $P$. Site. When the GAP analogue is bound at the $P_{i}$ site, the interaction between the carbonyl of the thioester group and the positively charged nitrogen of the nicotinamide ring of $\mathrm{NAD}^{+}$is evidenced in the holo-thioacyl enzyme crystallographic structure. A similar interaction was proposed in the hemiacetal enzyme (24) of $E$. coli GAPDH in the model built by implementation of the $\mathrm{NAD}^{+}$unit in the X-ray structure. On the basis of this model, Park et al. (24) proposed that the GAP's phosphate moiety would be displaced from the $P_{i}$ to the $P_{s}$ site through a rotation of the $\mathrm{C} 1-\mathrm{C} 2$ covalent bond. Our results with the holo-acyl enzyme complex (Figure 3) suggest a different situation (see below).

$G A P$ Binding $P$, Site. The X-ray structure reveals two major points regarding the $P_{s}$ binding site. First, it is strictly defined and more specific in space than the $P_{i}$ site, as shown in $B$. stearothermophilus (16). This statement is corroborated by minor $\mathrm{P}_{\mathrm{s}}$ site position displacement in the $\mathbf{3 c}-\mathrm{gGAPDH}$ complex when compared to the L. mexicana $(0.93 \AA)(41)$ and T. brucei $(0.70 \AA)$ (17) structures (Figure $2 B$ ). Second, the flipping of the phosphoryl group occurs through a rotation around the cysteine sulfur atom-Cl bond and not around the $\mathrm{C} 1-\mathrm{C} 2$ bond as proposed by Park et al. for the hemiacetal intermediate through the modeling study. This is clearly ilustrated in Figure 3.

Mechanistic Aspects. Although compound 3c is not equivalent to GAP (absence of a hydroxyl group at C2 and the oxygen linked to the phosphorus is replaced with a carbon), the similarity, particularly in terms of chain length, is sufficiently good to gain additional clarification on the situation of the actual thioester intermediate. Compound $3 \mathrm{c}$ binds to the essential cyteine as does GAP, and the distance between the sulfur atom of Cys 166 and the phosphorus atom is the same in both compounds, a point which is essential in a discussion of the interactions of the phosphorus with the $P_{i}$ and $P_{s}$ sites.

The thioester intermediate obtained in the presence of $\mathrm{NAD}^{+}$gives a structure very close to that required for catalytic efficiency and provides evidence that after covalent binding, GAP induces an additional conformational change. The overall structure shows a major significant structural difference between the $P_{i}$ and $P_{s}$ binding sites: the rather flexible position of the $P_{i}$ site, which does not justify the possibility of a new $\mathrm{P}_{\mathrm{i}}$ binding site in the case of Leishmania and $E$. coli GAPDH, in contrast to the rather restricted situation of the $\mathrm{P}_{\mathrm{s}}$ binding site, at least as revealed from three different GAPDHs.

Our results are compatible with the currently accepted catalytic mechanism. Without ligand (monomer A), Cys 166 points toward His 194 , with the $\mathrm{S}-\mathrm{H}$ group in a favorable orientation for the transfer of its proton to the histidine acceptor. The nucleophile being formed at sulfur can then attack $\mathrm{Cl}$ of the substrate to form the thiohemiacetal intermediate, followed by the hydride ion transfer from $\mathrm{C}$ to NAD leading to the formation of the thioester, represented in our case by the 3c $\mathrm{P}_{\mathrm{i}}$ conformation; His 194, still protonated, is far from the $\mathrm{S}-\mathrm{C} 1$ bond $(\sim 4.6 \AA)$. Following the $\mathrm{P}_{\mathrm{i}}-\mathrm{P}_{\mathrm{s}}$ exchange, represented in our case by the $3 \mathrm{c} P$ conformation, there is a considerable approximation of the carbonyl of the ligand to His 194, which is now in a favorable position for mediating the back transfer of the proton to Cys 166 , completing the reaction cycle. 
These results give support to the flip-flop mechanism since the same covalent intermediate can bind either to the $P_{i}$ site or to the $P_{s}$ site as seen in subunits $B$ and $C$ (Figure IB shows $3 \mathbf{c}$ in subunit B). Although largely anticipated by previous authors $(16,23)$ and in agreement with the results of other authors (24), the proposed flip-flop mechanism, through a conformational isomerization step, would occur before the phosphorylation step and would take place during coenzyme exchange. The crystal structure of the holothioacyl gGAPDH complex supports the idea that this flipflop is likely related to the cofactor exchange process. An alternative interpretation where the characterized $P_{s}$ site would be the only one representative of the true complex formed with D-GAP, whereas the identified $P_{i}$ site would be one among several possibilities, seems unlikely Indeed, localization of the $\mathrm{P}_{\mathrm{i}}$ site obtained from the X-ray structure presented here is in agreement with other catalytic features

In the $P_{i}$ conformation, as underlined above, there is a strong interaction between the carbonyl group of the thioester and the nicotinamidium ring. However, in the $\mathrm{P}_{\mathrm{s}}$ conformation (at this stage, the cofactor is in its reduced form), the carbonyl group-NADH ring distance increases, weakening the corresponding interaction facilitating cofactor release Likewise, Arg249 may play a major role in this isomerization step. In fact, in the absence of substrate, Arg249 makes a salt bridge with Asp210 (22), but when the substrate is present, Arg249 becomes essential at the $P_{s}$ site and is 5.02 $\AA$ from the initial position. One interesting aspect of our structure is the participation of Arg249 in the phosphate coordination in both $\mathrm{P}_{\mathrm{i}}$ and $\mathrm{P}_{\mathrm{s}}$ conformers. In the $\mathrm{P}_{\mathrm{f}}$ conformation, Arg249 binds to the phosphate through the $\mathrm{N} \delta$ atom, whereas in the $\mathrm{P}_{\mathrm{i}}$ conformation, the binding is through N $\eta$ of the guanidinium moiety. Previously, Arg249 was supposed to be composed of only the $P_{s}$ binding site and its function in product release was also surmised on the basis of the large conformational change observed in ion free T. cruzi GAPDH structures (22).

Further important evidence comes from the comparison of partial $\mathrm{NAD}^{+}$occupation in monomers $\mathrm{B}$ and $\mathrm{C}$ (both conformations) and full occupation in monomomer $\mathrm{D}(\mathrm{P}$ conformation only), which strongly suggests that the presence of $\mathrm{NAD}^{+}$is related to the $\mathrm{P}_{\mathrm{s}}$ conformation. This might be a consequence of hydrogen bond stabilization due to phosphate group interaction with the ribose sugar of the coenzyme, possibly in either the oxidized or reduced cofactor states, as well as hydrophobic contacts between GAP and NAD ${ }^{+}$

The mechanistic steps highlighted by the crystallographic structure can be summed up as follows:

(i) GAP binds to the $P_{i}$ binding site, positioning the carbonyl group to interact with the positively charged nicotinamidium ring.

(ii) Hydrogen transfer to cofactor leads to a loss of charge interaction and displacement of the reduced cofactor.

(iii) The thioacyl intermediate flips to the $P_{s}$ binding site, and a new $\mathrm{NAD}^{+}$molecule is now stabilized through hydrogen bonding of the phosphate to ribose and hydrophobic contacts.

The results that we obtained with a close analogue of the thioester intermediate formed between GAPDH and its substrate, more precisely the analysis of the interactions of the two alternative conformations found in the crystal, provide a complementary piece of evidence for this sequence.

\section{SUPPORTING INFORMATION AVAILABLE}

Synthetic strategy for compounds 1c and 2c (Scheme 1) and $3 \mathbf{c}$ (Scheme 2) and detailed synthetic procedures for compounds 1c and 2c. This material is available free of charge via the Internet at http://pubs.acs.org

\section{REFERENCES}

1. Sirover, M. A. (1999) Biochim. Biophys. Acta 1432, 159-184.

2. Sunaga, K., Takahashi, H., Chuang, D. M., and Ishitani, R. (1995) Neurosci. Lett. 200, 133-136.

3. Schulze, H., Schuyler, A., Stuber, D., Dobeli, H., Langen, H., and Huber, G. J. (1993) Neurochem. 60, 1915-1922.

4. Burke, J. R., Enghild, J. J., Martin, M. E., Jou, Y. S., Myers, R. M., Roses, A. D., Vance, J. M., and Strittmatter, W. J (1996) Nat. Med. 2, 347-350.

5. Koshy, B . Matilla, T Burright, E. N. Merry, D. E. Fischbeck, K. H., Orr, H. T., and Zoghbi, H. Y. (1996) Hum. Mol. Genet. 5 , $1311-1318$.

6. Epner, D. E., Partin, A. W., Schalken, J. A., Issacs, J. T., and Coffey, D. S. (1993) Cancer Res. 53, 1995-1997.

7. Bakker, B. M., Michels, P. A. M., Opperdoes, F. R., and Westerhoff, H. V. (1999) J. Biol. Chem. 274 (21), 14551-14559.

8. Bressi, J. C., Verlinde, C. L. M. J., Aronov, A. M., Le Shaw, M., Shin, S. S., Nguyen, L. N., Suresh, S., Buckner, F. S., Van Voorhis, W. C., Kuntz, I. D., Hol, W. G. J., and Gelb, M. H. (2001) J. Med. Chem. 44, 2080-2093.

9. Engel, J. C., Franke de Cazzulo, B. M., Stoppani, A. O., Cannatta, J. J., and Cazzullo, J. J. (1987) Mol. Biochem. Parasitol. 26, 1-10.

10. Duggleby, R. G., and Dennis, D. T. (1974) J. Biol. Chem. 249, $167-174$.

11. Harrigan, P. J., and Trentham, D. R. (1973) Biochem. J. 135, 695703 .

12. Segal, H. L., and Boyer, P. D. (1953) J. Biol. Chem. 204, 265-

13. Harris, J. I., and Watres, M. (1976) in The Enzymes (Boyer, P. D., Ed.) Vol. 13, pp 1-49, Academic Press, New York.

14. Watson, H. C., Duée, E., and Mercer, W. D. (1972) Nat. New Biol. 240, 130

15. Moras, D., Olsen, K. W., Sabesan, M. N., Buehner, M., Ford, G. C. and Rossmann, M. G. (1975) J. Biol. Chem. 250, $9137-9162$.

16. Skarzynsi, T Moody, P. C. E and Wonacott, A. J. (1987) Mol. Biol $193,171-187$

7. Vellieux F. M. D., Hajdu, J., Verlinde, C. L. M. J., Groendijk, H., Read, R. J., Greenhough, T. J., Campbell, J. W., Kalk, K. H., H., Read, R. J., Greenhough, T. J., Campbell, J. W., Kalk, K. H., Littlechild, J. A., Watson, H. C., and Hol,
Natl. Acad. Sci. U.S.A. 20, 2355-2359.

Natl. Acad. Sci. U.S.A. 20, 2355-2359.
8. Tanner. J., Hecht, R. M. Pisegna, M., Seth, D. M., and Krause, 18. Tanner, J., Hecht, R. M., Pisegna, M., Seth, D.
K. L. (1994) Acta Crystallogr. D50, 744-748.

19. Korndörfer, I., Steipe, B., Huber, R., Tornschy, A., and Jaenicke, R. (1995) J. Mol. Biol. 246, 511-521.

20. Kim, H., Feil, l. K., Verlinde, C. L. M., Petra, P. H., and Hol, W G. J. (1995) Biochemistry 34, 14975-14986.

21. Duée, E., Olivier-Deyris, L., Fanchon, E., Corbier, C., Branlant, G., and Dideberg, O (1996) J. Mol. Biol. 257, 814-838.

22. Souza D. H. F. Garratt, R. C., Araujo, A. P. U., Guimarães, B. G. JCUS, W. D. P., Miche P. A. M. A. P. U., Gunnaert, V. and Oliva, G., Jesus, W. D. P., Michels, P. A. M.

23. Corbier, C. Michels, S., Wonacott, A. J., and Branlant, G. (1994) Biochemistry 33, 3260-3265.

24. Yun, M., Park, C. G., Kim, J. Y., and Park, H. W. (2000) Biochemistry 39, 10702-10710.

25. McCaul, S., and Byers, L. D. (1976) Biochem. Biophys. Res. Commun. $72,1028-1032$.

26. Cane, D. E., and Sohng, J. K. (1989) Arch. Biochem. Biophys. $270,50-54$.

27. Lambeir, A. M., Loiseau, A. M., Kuntz, D. A., Vellieux, F. M. Michels, P. A. M., and Opperdoes, F. R. (1991) Eur. J. Biochem. $198,429-436$

28. Sakai, K. J., Hasumi, K., and Endo, A. (1991) Biochim. Biophys. Acta 1077, 192-199.

29. Willson, M., Lauth, N., Périé, J., Callens, M., and Opperdoes, F. R. (1994) Biochemistry 33, 214-220. 


\section{Flip-Flop Mechanism of GAPDH}

30. Cane, D. E., and Sohng, J. K. (1994) Biochemistry 33, 65246530.

31. Polikarpov, I., Perles, L. A., de Oliveira, R. T., Oliva, G., Castellano, E. E., Garratt, R. C., and Craievich, A. (1998) J. Synchrotron Radiat. 5, 72-76.

32. Arndt, U. W., and Wonacott, A. J. (1997) The rotation methods in crvstallography, North-Holland Publishing Co., Amsterdam. 33. Otwinowski, Z., and Minor, W. (1997) Methods Enzymol. 276 $307-326$.

34. Navaza, J. (1994) Acta Crystallogr. A50, 157-163.

35. Brunger, A. T., Adams, P. D., Clore, G. M., Delano, W. L., Gros, P., Grosse-Kunstleve, R. W., Jiang, J.-S., Kuszewski, J., Nilges, M., Pannu, N. S., Read, R. J., Rice, L. M., Simonson, T., and Warren, G. L. (1998) Acta Crustallogr. D54, 905-921.
Biochemistry, Vol. 42, No. 23, 2003 7151

36. Lamzin, V. S., and Wilson, K. S. (1993) Acta Crystallogr. D49, $129-147$.

37. Jones, T. A., Zou, J. Y., Cowan, S. W., and Kjeldgaard, M. (1991) Acta Crystallogr. A47, 110-119.

38. Laskowski, R A Macarthur, M. W. Moss, D. S., and Thorton, J. M. (1993) J. Appl. Crystallogr. 26, 283-291.

39. Meloche H. P (1967) Biochemistry 6, 2273-2276.

40. Ramachandran, G. N., Ramakrishnar, C., and Sasisekhran, V. (1963) J. Mol. Biol. 7, 95-99.

41. Kim, H., and Hol, W. G. (1998) J. Mol. Biol. 278, 5-11.

42. Pavao, F., Castilho, M. S., Pupo, M. T., Dias, R. L. A., Correa, A. G., Fernandes, J. B., Da Silva, M. F. G. F., Mafezoli, J., Vieira, P. C., and Oliva, G. (2002) FEBS Lett. 520 (1-3), 13-17. BI0206107 


\section{Apêndice D}




\title{
Crystal structure of Trypanosoma cruzi glyceraldehyde-3-phosphate dehydrogenase complexed with an analogue of 1,3-bisphospho-D-glyceric acid Selective inhibition by structure-based design
}

\author{
Sylvain Ladame', Marcelo S. Castilho², Carlos H. T. P. Silva², Colette Denier', Véronique Hannaert', \\ Jacques Périé', Glaucius Oliva² and Michèle Willson' \\ ${ }^{1}$ Laboratoire de Synthèse et de Physico-Chimie de Molécules d'Intérêt Biologique UMR-CNRS 5068, Université Paul Sabatier, \\ Toulouse, France; ${ }^{2}$ Instituto de Fisica de São Carlos, Brazil; ${ }^{3}$ Research Unit for Tropical Diseases, Christian de Duve Institute of \\ Cellular Pathology and Laboratory of Biochemistry, Université Catholique de Louvain, Brussels, Belgium
}

We report here the first crystal structure of a stable isosteric analogue of 1,3-bisphospho-D-glyceric acid (1,3-BPGA) bound to the catalytic domain of Trypanosoma cruzi glycosomal glyceraldehyde-3-phosphate dehydrogenase (gGAPDH) in which the two phosphoryl moieties interact with Arg249. This complex possibly illustrates a step of the catalytic process by which Arg249 may induce compression of the product formed, allowing its expulsion from the active site. Structural modifications were introduced into this isosteric analogue and the respective inhibitory effects of the resulting diphosphorylated compounds on $T$. cruzi and
Trypanosoma brucei gGAPDHs were investigated by enzymatic inhibition studies, fluorescence spectroscopy, sitedirected mutagenesis, and molecular modelling. Despite the high homology between the two trypanomastid gGAPDHs ( $>95 \%$ ), we have identified specific interactions that could be used to design selective irreversible inhibitors against T. cruzi gGAPDH.

Keywords: 1,3-bisphospho-D-glyceric acid isosteric analogue; drug design; glyceraldehyde-3-phosphate dehydrogenase (GAPDH); Trypanosoma cruzi.
Trypanosomatids are flagellated protozoan parasites responsible for serious diseases in humans (sleeping sickness, Chagas disease, leishmaniases) and domestic animals in tropical and subtropical regions. Today, the medical and economic problems caused by the trypanosomiases represent a formidable obstacle to the development of many African and South American countries and rank among the first tropical diseases selected by the World Health Organization to develop new or more effective treatments [1] Owing to toxicity and lack of efficacy, most of the compounds currently used for chemotherapy are unsatisfactory and the design of novel classes of antitrypanosomatid drugs has become urgent. Glycolysis plays an

Correspondence to S. Ladame, University Chemical Laboratory, Cambridge University, Lensfield Road, Cambridge CB2 1EW, UK. Fax: + 441223 336913, Tel.: + 441223 762933,

E-mail: s1324@cam.ac.uk

Abbreviations: gGAPDH, glycosomal glyceraldehyde-3-phosphate dehydrogenase; 1,3-BPGA, 1,3-bisphospho-D-glyceric acid; GAP, glyceraldehyde 3-phosphate; HOP, [3(R)-hydroxy-2-oxo-4-phosphonoxybutyl]phosphonic acid; 3-PGA, 3-phosphoglycerate; PGK, phosphoglycerate kinase.

Enzymes: Trypanosoma cruzi glycosomal glyceraldehyde-3-phosphate dehydrogenase (EC 1.2.1.12; P22513); Trypanosoma brucei glycosoma glyceraldehyde-3-phosphate dehydrogenase (EC 1.2.1.12; P22512); yeast phosphoglycerate kinase (EC 2.7.2.3; P00560). (Received 14 July 2003, revised 11 September 2003, accepted 29 September 2003) important role in all human-infective Trypanosomatidae and is, in some members of this family, the only process providing ATP to the cell. Therefore, this pathway is considered a good target for drugs against the trypanosomiases and leishmaniases [2]. Studies of energy metabolism in Trypanosoma brucei have established that, unlike the insect form, the bloodstream form depends solely on glycolysis for energy production [3]. Biochemical studies with the Trypanosoma cruzi axenic amastigote intracellular form also suggest that carbohydrate catabolism is its major source of energy [4]. The glycolytic pathway of these parasites is unique in that most of its enzymes are present in peroxisome-like organelles called glycosomes. Our curren work focuses on the glycosomal glyceraldehyde-3-phosphate dehydrogenase (gGAPDH) as a target for inhibitor design. This enzyme has proven to be a promising targe because of several significant features of its involvement in the glycolytic process. (a) Computer simulation of glycolysis in bloodstream-form T. bruce $i$ suggested that, even by the partial inhibition of its activity, this enzyme may have significant control over the glycolytic flux and thus significantly reduce the ATP supply of the parasite [5-7]. (b) From the fact that a $95 \%$ deficiency of GAPDH in human erythrocytes does not cause any clinical symptoms, it was inferred that the enzyme in these blood cells has a low level of flux control; significant differences in flux contro between the corresponding enzymes of parasite and host cells would provide additional selectivity to drugs [8]. (c) The sequestering of the glycolytic pathway inside glycosomes has led to the endowment of unique kinetic and 
structural properties to several of its enzymes [2], including GAPDH [9]. (d) The possible selectivity of drugs has been proven with adenosine analogues which kill bloodstreamform $T$. brucei amastigotes within a few minutes without affecting the growth of fibroblasts $[10,11]$.

GAPDH catalyses the oxidation and phosphorylation of D-glyceraldehyde-3-phosphate (GAP) to 1,3-bisphospho-Dglyceric acid (1,3-BPGA) in the presence of $\mathrm{NAD}^{+}$and inorganic phosphate. The forward reaction mechanism has been extensively investigated [12-15] but the reverse reaction mechanism with 1,3-BPGA as substrate has not yet been clarified. Despite the large number of crystallographically determined 3D structures of GAPDHs from several organisms [16-29], there is none giving the detailed position of the substrate 1,3-BPGA in the active site during catalysis. This has rendered the mechanistic approach and the design of inhibitors such as 1,3-BPGA analogues far from easy. Indeed, the most potent and selective inhibitors of gGAPDH from parasites (T. brucei, Leishmania mexicana T. cruzi) described to date are mainly adenosine analogues $[10,11]$.

In order to design specific inhibitors for trypanomastid glycosomal GAPDHs, we are developing a new family of 1,3-BPGA substrate analogues. In the first step, to mimic the enzyme-substrate complex as closely as possible, we synthesized a stable molecule [3(R)-hydroxy-2-oxo-4-phosphonoxybutyl]phosphonic acid (HOP), with the highes similarity to the natural substrate $1,3-\mathrm{BPGA}$. We report here the refined crystal structure of a complex between the $T$. cruzi gGAPDH and this substrate isosteric analogue. On the basis of this crystal structure, we were able to design selective inhibitors for T. brucei and $T$. cruzi gGAPDHs that had no effect on rabbit muscle GAPDH, the mammalian enzyme used as a model of human GAPDH. Kinetic studies, site-directed mutagenesis, fluorescence spectroscopy, and molecular modelling were used to further characterize the specific binding modes of these 1,3-BPGA analogues to the two trypanosomatid enzymes.

\section{Materials and methods}

\section{Sources of substrates, cofactors and inhibitors}

The synthesis of 1,3-BPGA analogues used in this study has been described elsewhere [30-32]. $\mathrm{NADH}, \mathrm{NAD}^{+}$, 3-phosphoglycerate (3-PGA), ATP, rabbit muscle GAPDH and yeast phosphoglycerate kinase (PGK) were purchased from Sigma. GAP was prepared by hydrolysis of the diethylacetal ester according to the instructions of the manufacturer (Sigma).

\section{Cloning of the $T$. brucei gGAPDH into an expression vector}

The $T$. brucei gGAPDH gene was amplified from genomic DNA by PCR using the following specific oligonucleotides: a sense primer 5'-CAACAAATTTGCATATGACTATT AAAG-3' containing an $N$ deI site (underlined) next to the start codon of the T. brucei gGAPDH gene; an antisense primer 5'-CAGCCAAGCGCCTAGGGAGCGAGA AC-3', containing a Bam $\mathrm{HI}$ site (underlined) and starting
31 nucleotides downstream of the stop codon. The total volume of the amplification mixture was $50 \mu \mathrm{L}$ containing $1 \mu \mathrm{g}$ genomic DNA, 100 pmol each primer, $200 \mathrm{~mm}$ each of the four nucleotides, and $1 \mu \mathrm{L}$ Vent DNA polymerase (New England Biolabs) with the corresponding reaction buffer. PCR was carried out using the following programme: first 3 min at $95^{\circ} \mathrm{C} ; 30$ cycles of $1 \mathrm{~min}$ at $95^{\circ} \mathrm{C}, 1 \mathrm{~min}$ at $50^{\circ} \mathrm{C}$, $1 \mathrm{~min}$ at $72^{\circ} \mathrm{C}$; a final incubation of $10 \mathrm{~min}$ at $72^{\circ} \mathrm{C}$. The amplified fragment was digested with $N d e \mathrm{I}$ and $\mathrm{BamHI}$ and ligated into the vector pET15b (Novagen). The new recombinant plasmid named pET15b-TbGAPDH directs, under the control of the $\mathrm{T} 7$ promoter, the production of a fusion protein bearing an $\mathrm{N}$-terminal extension of 20 residues including a $(\mathrm{His})_{6}$ tag.

\section{Site-directed mutagenesis of $T$. brucei gGAPDH}

Site-directed mutagenesis of the T. brucei gGAPDH gene was performed on plasmid pET15b-TbGAPDH using PCR techniques as described by Mikaelian \& Sergeant [33] and using the Vent DNA polymerase. The $T$. brucei gGAPDH Thr196 ACA codon was changed into the Ala codon GCA and the Thr225 codon ACT was changed into the Ala codon GCT. The mutagenized GAPDH gene fragments were then excised from the plasmid by digestion with $S a l$ and SacI and used to replace the corresponding segment in the original plasmid containing the wild-type gene Mutagenized plasmids were then checked by sequencing before they were introduced into Escherichia coli for gene expression.

\section{Overexpression and purification of wild-type and mutant $T$. brucei gGAPDH}

T. brucei wild-type and mutated gGAPDH were over expressed in $E$. coli BL21(DE3) using the bacteriophage T7-RNA polymerase system [34]. E. coli cells containing the wild-type plasmid pET15b-TbGAPDH or its mutan derivatives were grown in $50 \mathrm{~mL}$ Luria-Bertani medium supplemented with $100 \mu \mathrm{g} \cdot \mathrm{mL}^{-1}$ ampicillin. Expression was induced at an $A_{600}$ of $0.5-0.8$ by addition of $1 \mathrm{~mm}$ isopropyl thio- $\beta$-D-galactoside, and growth was continued overnight at $30^{\circ} \mathrm{C}$. Cells were collected by centrifugation $(10000 \mathrm{~g}$, $10 \mathrm{~min}$ at $4^{\circ} \mathrm{C}$ ). The cell pellet was resuspended in $5 \mathrm{~mL}$ lysis buffer $(0.05 \mathrm{M}$ triethanolamine/ $\mathrm{HCl}$ buffer, $\mathrm{pH} 7.6$, $200 \mathrm{mM} \mathrm{KCl}, 1 \mathrm{mM} \mathrm{KH} \mathrm{PO}_{4}, 5 \mathrm{mM} \mathrm{MgCl}, 0.1 \%$ Triton $\mathrm{X}-100,1 \mu \mathrm{M}$ leupeptin, $1 \mu \mathrm{M}$ pepstatin and $1 \mu \mathrm{M}$ E64). Cells were lysed by two passages through an SML-Aminco French pressure cell at $5516 \mathrm{kPa}$. Nucleic acids were removed first by incubation with $100 \mathrm{U}$ Benzonase (Merck) for $30 \mathrm{~min}$ at $37^{\circ} \mathrm{C}$, and then with $5 \mathrm{mg}$ protamine sulfate for $15 \mathrm{~min}$ at room temperature. The lysate was centrifuged $\left(10000 \mathrm{~g}, 15 \mathrm{~min}\right.$ at $\left.4{ }^{\circ} \mathrm{C}\right)$, and the supernatant used for purification of recombinant enzyme by immobilized metalaffinity chromatography (Talon resin; Clontech) using the (His) 6 tag at the N-terminus of gGAPDH. The charged resin was first washed with lysis buffer plus $5 \mathrm{~mm}$ imidazole, then with lysis buffer plus $10 \mathrm{~mm}$ imidazole. The enzyme was subsequently eluted (1-mL fractions) with $100 \mathrm{~mm}$ imidazole in lysis buffer and stored at $4{ }^{\circ} \mathrm{C}$ in the elution buffer. T. brucei gGAPDH expressed in $E$. coli could be purified to homogeneity, as assessed by SDS/PAGE, with a 
yield of $1.7 \mathrm{mg}$ from a $50-\mathrm{mL}$ culture of recombinant bacteria.

\section{Preparation and purification of $T$. cruzi gGAPDH}

$T$. cruzi gGAPDH was expressed in $E$. coli and purified following the previously reported procedure [24]. No dithiothreitol was used in the purification buffer to avoid any reaction with the inhibitors.

\section{Co-crystallization assays}

Co-crystallization assays were carried out using a protein solution at $10 \mathrm{mg} \cdot \mathrm{mL}^{-1}$ preincubated with $2 \mathrm{~mm}$ inhibitor. Crystals of the complex gGAPDH-HOP were grown at

$18^{\circ} \mathrm{C}$ by hanging drop vapour diffusion, against a reservoir solution of $0.1 \mathrm{M}$ sodium cacodylate buffer, $\mathrm{pH} 7.3-7.5$ with $0.1 \mathrm{M}$ calcium acetate, $18 \%$ poly(ethylene glycol) 8000 $1 \mathrm{mM}$ EDTA and $1 \mathrm{~mm}$ sodium azide. The crystallization droplets were prepared with equal volumes of $\mathrm{gGAPDH}$ solution $(5 \mu \mathrm{L})$ and reservoir buffer $(5 \mu \mathrm{L})$. Flat small crystals appeared within 2 weeks.

\section{Data collection and processing}

A single crystal of gGAPDH-HOP complex was flashcooled to $100 \mathrm{~K}$ in an Oxford Cryostream Cooler. The cryoprotectant solution used consisted of $20 \%$ poly(ethylene glycol) 400 added to the above described reservoir solution. Monochromatic X-ray data collection was performed at the Brazilian National Synchrotron Light Laboratory (LNLS) [35] using $1.54 \AA$ as the incident wavelength. Diffraction spots were recorded on a MAR345 image plate using the oscillation method [36]. Data indexing and scaling were carried out with DENZO and SCALEPACK software, respectively [37]. Data collection and processing statistics are summarized in Table 1.

The crystals belong to the space group $\mathrm{P} 2_{1}$ with unit cell parameters $\mathrm{a}=81.76 \AA, \mathrm{b}=85.20 \AA, \mathrm{c}=106.42 \AA$ and $\beta=96.74^{\circ}$. Analysis of the crystal content reveals one tetramer per asymmetric unit, and a $V_{\mathrm{m}}$ value of $2.21 \AA^{3} \cdot \mathrm{Da}^{-1}$. The solvent content of the crystal is $47.4 \%$ (v/v).

\section{Structure determination and refinement}

The structure solution was determined by molecular replacement using the program AMoRe [38]. The native

Table 1. X-ray diffraction data collection and processing statistics.

\begin{tabular}{ll} 
Total measured reflections & 88606 \\
Number of unique reflections & 33568 \\
Resolution range & $8.0-2.75 \AA^{\mathrm{a}}$ \\
Overall completeness & $92.4 \%(92.8 \%)^{\mathrm{b}}$ \\
Overall $R_{\text {merge }}$ & $9.2 \%(30.4 \%)^{\mathrm{b}}$ \\
$I / \sigma I$ & $11.8(3.9)^{\mathrm{b}}$ \\
Redundancy & $2.6(2.3)^{\mathrm{b}}$ \\
\hline
\end{tabular}

${ }^{\text {a }}$ Dataset was collected from 20.0 to $2.75 \AA$ but only reflection from 8.0 to $2.75 \AA$ were considered for refinement. ${ }^{b}$ The values in parentheses correspond to the last resolution shell (2.81-2.75 $\AA$ ). tetrameric gGAPDH structure without cofactor and water molecules was used as the search model. AMoRe provided a clear Fourier solution, with correlation coefficient of $69.7 \%$ and $R_{\mathrm{factor}}=0.318$. The rotated and translated model was refined with the CNS suite of programs [39] using torsional molecular dynamics and maximum likelihood functions. The crystallographic $R_{\mathrm{factor}}$ and $R_{\mathrm{free}}$ values, as well as the stereochemical quality of the model, were monitored throughout the refinement with the program PROCHECK [40], and, whenever necessary, model building and computer graphics visualization were performed with the $\mathrm{O}$ software [41]. Analysis of difference maps in the active site of all monomers revealed clear electron density for the NAD cofactors included in the model. After several cycles of manual rebuilding and conjugated gradient minimization, 441 water molecules were added to the model using the program ARP [42]. Subsequent analysis of the difference Fourier map $\left(F_{\mathrm{o}}-F_{\mathrm{c}}\right)$ showed reasonable density for the inhibitor in the active site of monomer A (Fig. 1). At this point, one molecule of HOP was manually built into the $A$ subunit and the whole structure was further refined to the final $R_{\text {factor }}$ of 0.193 and the $R_{\text {free }}$ of 0.261 . The final refinement statistics are summarized in Table 2 .

\section{Assay of enzyme activities}

The activity of gGAPDH was assayed in both directions by spectrophotometrically monitoring the oxidation/reduction of NAD $(H)$. In the forward (glycolytic) reaction, this could be done directly by following the formation of NADH by GAPDH, using the substrate GAP at a saturating concentration of $0.8 \mathrm{mM}\left(K_{\mathrm{m}}=150 \mu \mathrm{M}\right)$ [43]. For the reverse (gluconeogenic) reaction, in which NADH oxidation was followed, a coupled assay system involving PGK was used to produce the substrate 1,3-BPGA. The assay mixture $(1 \mathrm{~mL})$ contained $0.1 \mathrm{M}$ triethanolamine $/ \mathrm{HCl}$ buffer (pH 7.6), $1 \mathrm{~mm}$ EDTA, $5.6 \mathrm{~mm}$ 3-PGA, $1 \mathrm{~mm}$ ATP, $5 \mathrm{mM} \mathrm{MgSO}_{4}, 0.42 \mathrm{~mm} \mathrm{NADH}$ and a large excess of yeast PGK (11 U). All reactions were carried out at $25^{\circ} \mathrm{C}$. The reaction was monitored by the absorbance change of NADH at $340 \mathrm{~nm}$ with a Perkin-Elmer spectrophotometer equipped with a kinetic accessory unit. Initial reaction rates were calculated from the slopes of the curves recorded during the first $3 \mathrm{~min}$ of the reaction and from the NADH concentrations using the value $\varepsilon_{340}=6.22 \mathrm{~mm}^{-1} \cdot \mathrm{cm}^{-1}$.

\section{Inhibition studies}

The inhibitory activities of ligands on enzymes (wild-type and mutants) were measured after preincubation of the enzyme with the compound for $5 \mathrm{~min}$ followed by addition of the reaction mixture to start the reaction. A possible effect of the inhibitors on the absorbance of NADH was checked. The concentration of inhibitor required for $50 \%$ inhibition ( $\mathrm{IC}_{50}$ ) was calculated from the percentage of remaining enzyme activity by comparison with an inhibitorfree control experiment and based on measurements at five different inhibitor concentrations. This was carried out for the reaction in both directions, each with its substrate at saturating concentration. The inhibition pattern and inhibition constants $\left(K_{\mathrm{i}}\right)$ were determined from LineweaverBurk plots. The inhibition with respect to 1,3-BPGA was 
Fig. 1. $F_{\mathrm{o}}-F_{\mathrm{e}}$ electron-density map, contoured at 6.0o (green) and 1.20 (brown), in the active site of $T$. cruzi gGAPDH. HOP is represented as thin lines, and protein atoms as thick lines. The $F_{\mathrm{o}}-F_{\mathrm{c}}$ electron-density map was generated in the absence of compound HOP.

Table 2. Final refinement statistics. Estimated coordinate errors based on $R_{\text {factor }}$ and $R_{\text {free }}$ are 0.34 and 0.48 , respectively.

\begin{tabular}{ll}
\hline Resolution range & $8.0-2.75 \AA$ \\
Number of amino acids per monomer & 359 \\
Number of water molecules & 453 \\
Number of inhibitor molecules & 1 \\
$R_{\text {factor }}$ & 0.193 \\
$R_{\text {free }}$ & $0.261^{\mathrm{a}}$ \\
Rms bond deviations & $0.0067 \AA$ \\
Rms angle deviations & $1.24^{\circ}$ \\
\hline
\end{tabular}

a The fraction of reflections used to calculate $R_{\text {free }}$ is $3 \%$.

studied at four different concentrations of 1,3-BPGA, which was produced by PGK auxiliary enzyme. The amount of 1,3-BPGA for the assay was directly proportional to the amount of ATP used by PGK to convert 3-PGA into 1,3BPGA. The inhibition kinetics studies were performed with four different concentrations of ATP $(250,350,500$ and $600 \mu \mathrm{M}$ ), which correspond to 1,3-BPGA concentrations of 2-5 times the $K_{\mathrm{m}}$ value of this substrate for GAPDH.

\section{Fluorescence measurements}

All fluorescence spectra were made at $20^{\circ} \mathrm{C}$ in $4 \mathrm{~mL}$ clearsided cuvettes using a Perkin-Elmer LS-50B computer controlled rationing luminescence spectrometer, equipped with a xenon discharge lamp, Monk-Gillieson type monochromators (excitation $200-800 \mathrm{~nm}$, zero-order selectable; emission $200-900 \mathrm{~nm}$, zero-order selectable), and a gated photomultiplier detector. For solute quenching, tryptophan was excited at $295 \mathrm{~nm}$ to avoid phenylalanine and tyrosine fluorescence. Excitation and emission spectra were recorded between 310 and $360 \mathrm{~nm}$ with excitation and emission slits set at $5 \mathrm{~nm}$. For determination of dissociation constants,

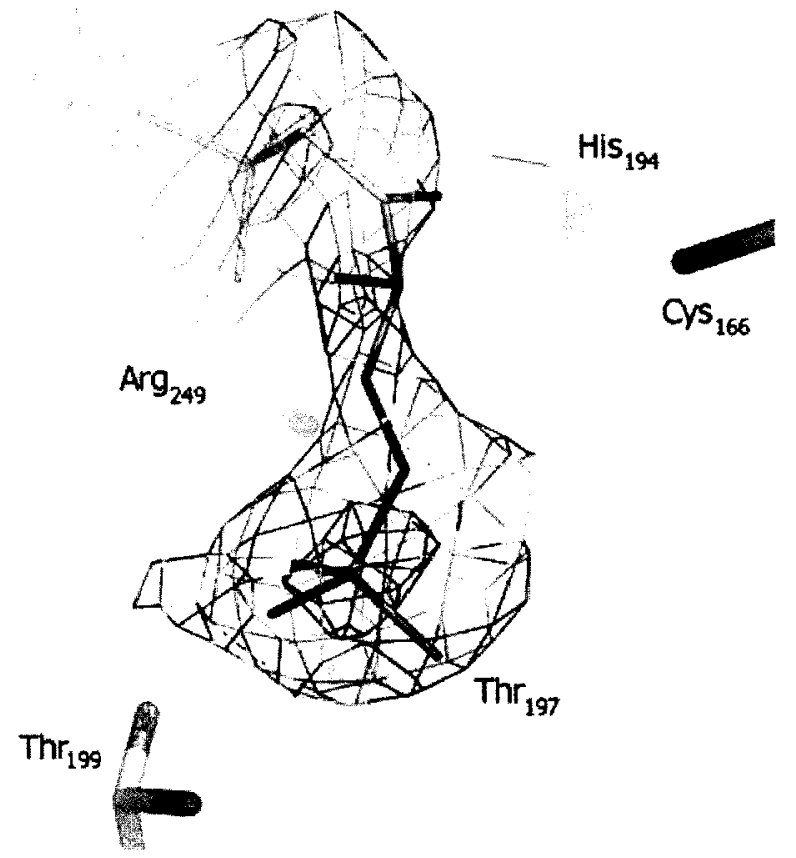

intensities at $330 \mathrm{~nm}$ were used. Absorbance and excitation spectra were recorded in the range $200-350 \mathrm{~nm}$, and the fluorescence spectra were recorded between $270 \mathrm{~nm}$ and $450 \mathrm{~nm}$. All fluorescence studies were performed in $0.1 \mathrm{M}$ triethanolamine/ $\mathbf{H C l}$ buffer $(\mathrm{pH} 7.5)$ with a $\mathrm{GAPDH}$ concentration of $6.5 \mu \mathrm{M}$ and variable quencher concentrations of 0-250 mM.

Quenching data were analysed by a least squares fit to the Stern-Volmer equation:

$$
I_{0} / I=1+K_{\mathrm{Sv}}[\mathrm{Q}]
$$

where $I_{0}$ and $I$ are fluorescence intensities in the absence and presence of quencher Q, and $K_{\mathrm{SV}}$ is the Stern-Volmer and presence of quencher Q, and $K_{\mathrm{SV}}$ is the Stern-Volmer
constant. Estimates of $K_{\mathrm{SV}}$ were obtained by using linear regression analysis with MICROCAL ORIGIN 4.00 (Microcal Software Inc., Northampton, PA, USA).

\section{Molecular modelling}

Modelling studies of the binary enzyme-inhibitor complexes were performed with the INSIGHT II/DISCOVER program (Insight II User Guide, version 2000; Accelrys Inc., San Diego, CA, USA), using molecular mechanics (consistent valor force field, CVFF), conjugate gradient minimization algorithm (CG) and implicit solvation conditions (water, $\varepsilon=80$ ). The crystal structure of the $T$. cruzi gGAPDHHOP complex was used as a framework on which all other inhibitors were built into gGAPDH's active site. Furthermore, the gGAPDH-HOP complex was superimposed on the $T$. brucei structure. Because $T$. cruzi and $T$. bruce gGAPDHs have highly similar active sites, the conformation of HOP inside the $T$. brucei active site was energy minimized and used as a framework for further modelling studies. Compounds 5, 6, 7 and 8 were built from the framework of HOP, and energy minimized as described 
above. For all these local minimum energy configurations, semiempirical quantum chemical calculations were performed in water, using the Austin model 1 (AM1) Hamiltonian. The electrostatic potential atomic charges (MOPAC keyword ESP) obtained from these single point calculations were used to superimpose the four structures on the basis of their field similarities, using the INSIGHT II/ SEARCH/COMPARE program. The orientations of each compound with respect to that of HOP were used as input for further optimizations, which were carried out inside the T. cruzi gGAPDH active site. During these simulations, T. cruzi gGAPDH atoms were kept constrained and inhibitor atoms were allowed to move freely within the active site. The same protocol was applied to T. brucei gGAPDH modelling studies.

\section{Results}

\section{D structure of the $T$. cruzi gGAPDH-HOP complex}

Quality of the structure ( $R C S B$ PDB accession No. IQXS). Despite the lack of NCS restraints during the refinement process, the electron-density maps calculated from the gGAPDH-HOP complex show good quality. This is not the case for surface loops comprising residues 65-74 99-103 and 117-121 in monomer $C$ and 99-102 in monomer $\mathrm{B}$ and several residues at the $\mathrm{N}$-terminus and C-terminus, which are poorly resolved. The stereochemistry of the structure is generally quite satisfactory, with more than $99 \%$ of the residues showing torsion angles in the favourable regions of the Ramachandran diagram [45] Only Val255 from all monomers are in unfavourable regions. Val255 is located in a loop between two consecutive $\beta$ strands. The unfavourable conformation observed for this residue is conserved in all other GAPDH structures available $[16,18,19,22,24-29]$ and seems important to maintain the correct positioning of the active residue Cys 166 and the nicotinamide ring of the $\mathrm{NAD}^{+}$cofactor during catalysis. The average isotropic temperature factor values for the main chain and all atoms of the 359 residues from each monomer are, respectively, $43.5 \AA^{2}$ and $43.8 \AA^{2}$ in monomer $\mathrm{A}, 46.8 \AA^{2}$ and $47.1 \AA^{2}$ in monomer $\mathrm{B}, 51.6 \AA^{2}$ and $51.9 \AA^{2}$ in monomer $\mathrm{C}$, and $43.2 \AA^{2}$ and $43.5 \AA^{2}$ in monomer $\mathrm{D}$.

It is not uncommon to find partial occupancy of $T$. cruzi gGAPDH active sites by ligands [28,29]. In the structure described here, the inhibitor is present in only one of the four subunits of the enzyme. This observation suggests that, in solution, the enzyme-inhibitor complexes have a distribution of populations with different numbers of subunits occupied by the inhibitor. This would result in asymmetric particles that would be subsequently selected during the crystallization process to predominantly accommodate one particular conformer in the crystal lattice.

gGAPDH-HOP interaction profile. The analysis of the complex (Fig. 1) reveals that the phosphate moiety is positioned in the so-called Ps binding site [25], where it hydrogen bonds to Thr197, Thr199 and Arg249 (Fig. 2) The position of this phosphate group is in good agreement with the previously reported Ps position for the sulfate and phosphate ions in the crystal structures of $T$. brucei and L. mexicana gGAPDHs (1.11 and $0.48 \AA$, respectively) (Fig. 3A). The phosphonate moiety in the gGAPDH-HOP complex binds to a phosphate-binding site not previously described. Its main interactions are with residues Ser247 and Arg249. In this novel position, it lies $5.38 \AA$ and $4.06 \AA$ from the previously reported $\mathrm{Pi}$ position for sulfate and
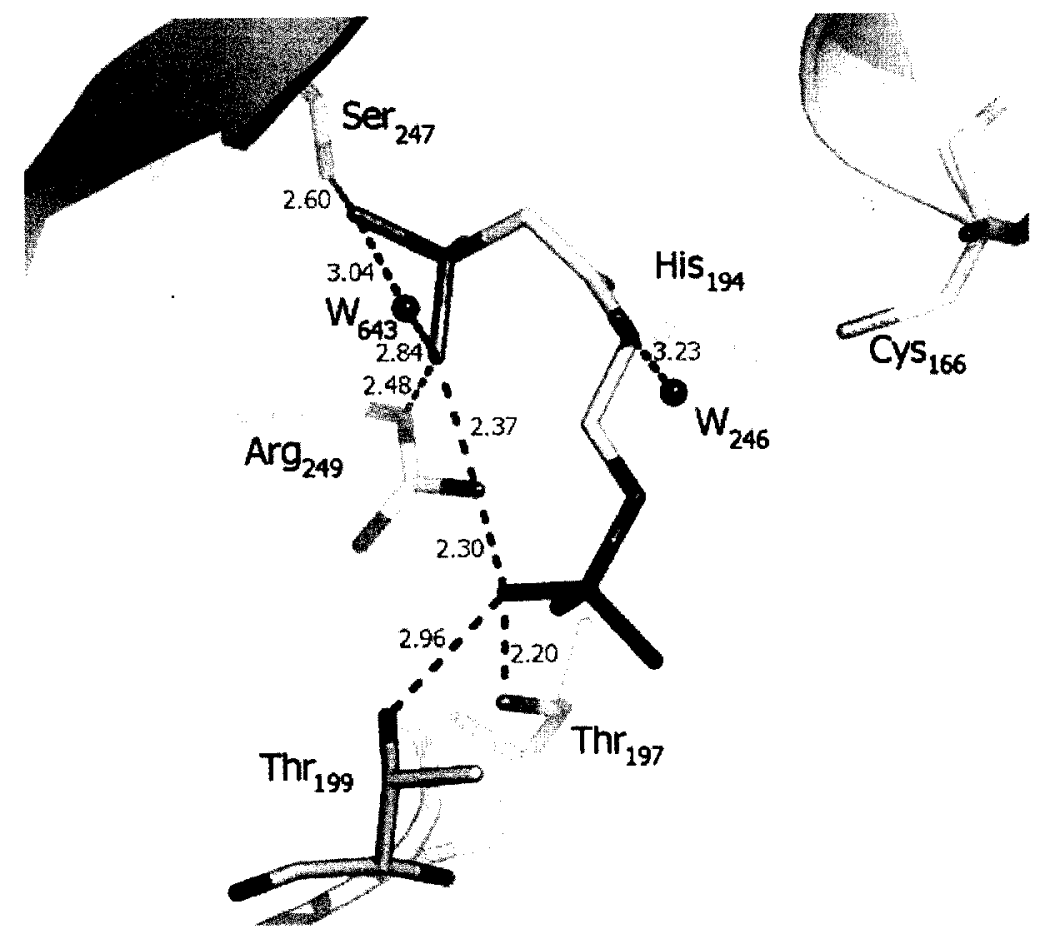

Fig. 2. HOP interaction profile in $T$. cruzi gGAPDH active site. The phosphate moiety hydrogen bonds with Arg249, Thr197 and Thr199 (blue dashed lines). The phosphonate moiety hydrogen bonds to Arg249, Ser247 (blue dashed lines) and its carbonyl group points to His 194. Two additional hydrogen bonds are formed with crystallographic water molecules. The protein atoms are depicted as a ribbon tracing except for the catalytic Cys 166 His 194 and other residues highlighted that interact with HOP. This figure was generated with PYMOL software [44] 


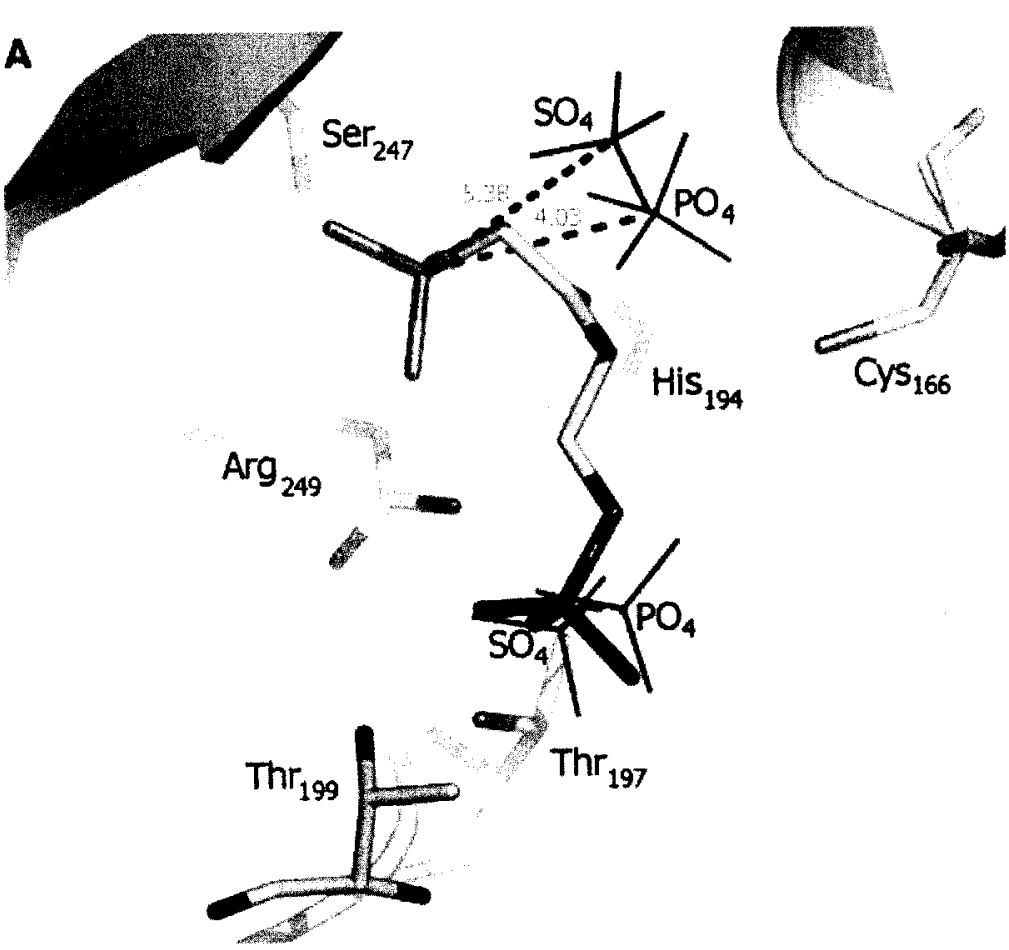

Fig. 3. gGAPDH-HOP interaction profile. (A) Comparison of phosphonate and phosphate positions of the gGAPDH-HOP complex with the previously described $T$. brucei sulfate position $\left(\mathrm{SO}_{4}\right)$ and $L$. mexicana phosphate position $\left(\mathrm{PO}_{4}\right)$. The phosphate at the Ps position agrees quite well with the previously described $\mathrm{SO}_{4}$ and $\mathrm{PO}_{4}$ positions - near

Thr197 and Thr199 residues - but the phosphonate group lies $\approx 4-5 \AA$ away from the previously described $\mathrm{Pi}$ interaction site. (B) This binding site has been described in previous work with a GAP analogue that covalently binds to Cys 166 [26]. L. mexicana $\mathrm{PO}_{4}{ }^{2-}$ and $T$. brucei $\mathrm{SO}_{4}{ }^{2-}$ atoms come from the crystallographic superimposition of PDB accession numbers $1 \mathrm{GYP}$ and $1 \mathrm{~A} 7 \mathrm{~K}$ on the gGAPDH-HOP structure. The covalently bound thioacyl intermediate analogue coordinates come from the crystallographic superimposition of PDB accession number $1 \mathrm{ML} 3$ on the gGAPDH-1 structure. Protein atoms are depicted in the cartoon except for catalytic Cys166, His 194 and other residues highlighted in the picture that interact with HOP. This figure was generated with PYMOL software [44].

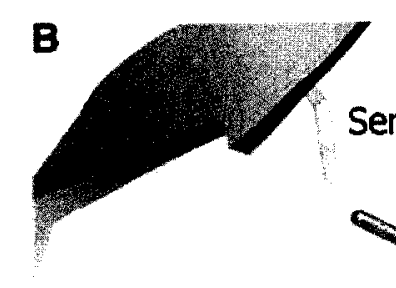

$\operatorname{ser}_{247}$
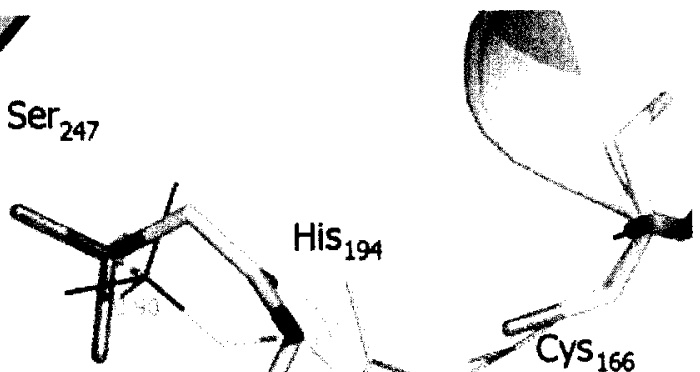

phosphate ions in T. brucei and $L$. mexicana gGAPDHs (Fig. 3A). However, this new phosphonate-binding site is very close to one that we recently identified in the crysta structure of $T$. cruzi gGAPDH complexed with a GAP analogue [29] (Fig. 3B). In this structure, the phosphonate moiety was interacting with residues Arg295 and Thr226 but was $3.35 \AA$ from the $\mathrm{Pi}$ position described for

mexicana gGAPDH. In the structure reported here, the phosphonate is $0.90 \AA$ from the phosphonate position in the gGAPDH-thioester complex (Fig. 3B). It should also be stressed that the hydroxy group in the $\mathrm{C} 2$ position with the $R$ configuration as in the substrate does not make any important interactions with residues of the active site of T. cruzi gGAPDH. 
Considering the resolution of the data, both possible orientations for HOP phosphoryl groups were assessed during the refinement protocol (phosphate or phosphonate moiety interacting at the Ps site). The orientation shown in Fig. 1 was chosen because it fitted the $F_{\mathrm{o}}-F_{\mathrm{c}}$ electrondensity map much better than the inverted conformation. Indeed we noticed that the C3 hydroxy moiety could not fit the electron-density map in the inverted conformation (data not shown).

\section{Inhibition of $T$. cruzi gGAPDH}

Inhibitor design. All structures of 1,3-BPGA analogues are given in Table 3. Inhibitors were designed from the reference compound 2-oxo-1,5-diphosphonopentane (5); its structure retains the overall size, the two phosphoryl moieties, and the carbonyl at the $\mathrm{C} 3$ position of the natural substrate. Based on this scaffold, structural diversity was introduced to retain a high similarity to 1,3-BPGA: the phosphate group and hydroxy group in the $\mathrm{C} 2$ position were maintained (compounds 2,3 and 4) with the aim of assessing their contribution to affinity. Then, to improve the affinity of compound 5, a series of chemical modifications were performed on the $\beta$-ketophosphonate motif. The introduction of one or two fluorine atoms on the $\alpha$-methylene group increased the acidity of the phosphonate, from 7.6 to 6.5 giving a $\mathrm{p} K_{\mathrm{a}}$ identical with that of the phosphate moiety [46] (compounds 6 and 7). The introduction of a nitrogen atom to replace the methylene group was also considered for its potential to hydrogen bond with the enzyme active site (compound 8).

Table 3. Inhibitory effect (IC ( $_{50}$ values) of 1,3-BPGA analogues on $T$. cruzi gGAPDH with respect to GAP and 1,3-BPGA. Each determination was performed in triplicate with a standard deviation of $\pm 4 \%$.

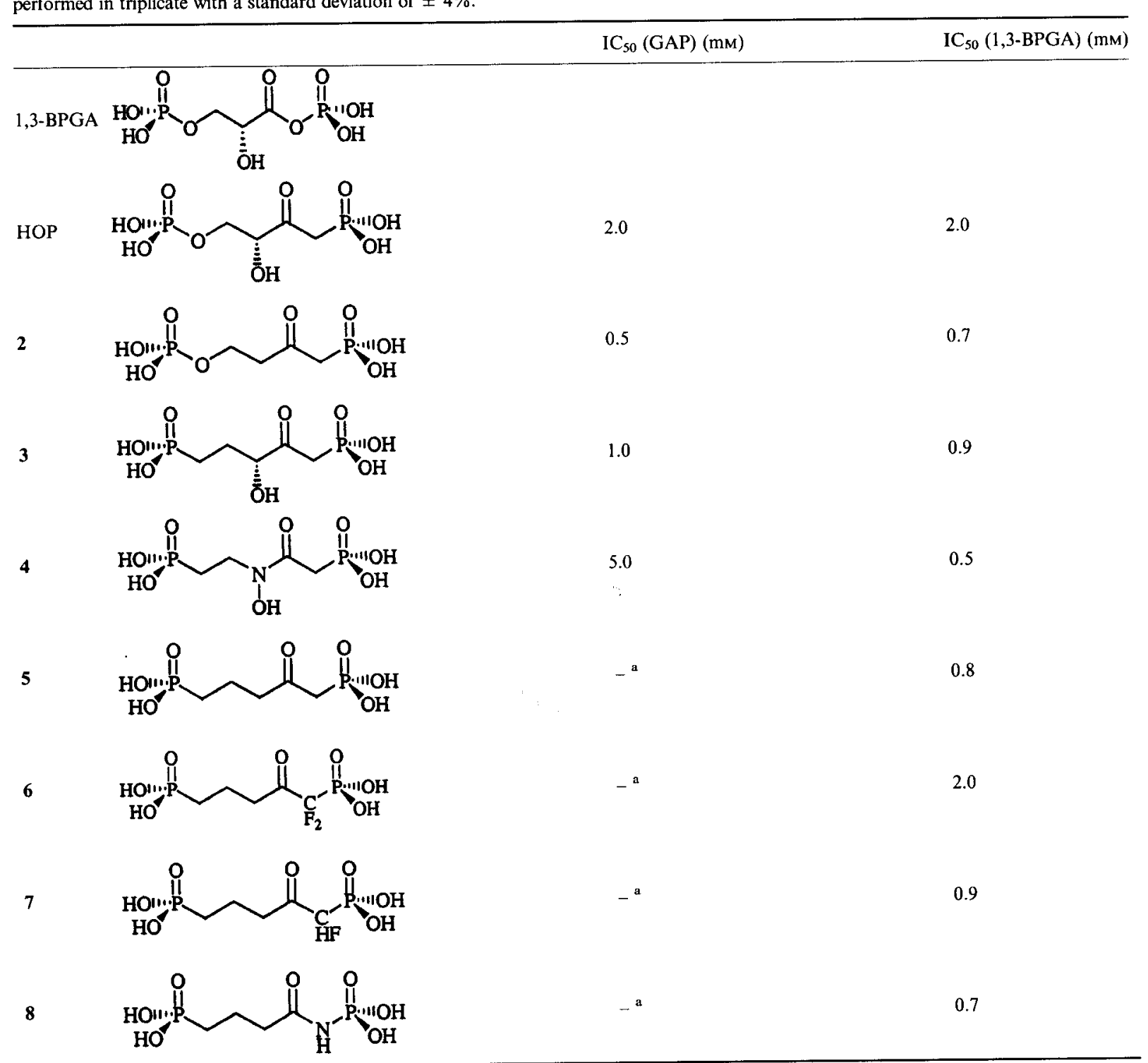

${ }^{\text {a }}$ No inhibition detected at a $5 \mathrm{~mm}$ concentration of ligand. 
Inhibition studies. Table 3 summarizes the inhibitory effects of these compounds on T. cruzi gGAPDH with respect to GAP and 1,3-BPGA. In both assays, these substrates were present at saturating concentrations. In the inhibition assays of the reverse reaction, a coupledenzyme assay system was used in which the reaction of GAPDH was initiated by an excess of yeast PGK producing the substrate 1,3-BPGA. Possible effects of inhibitors on yeast PGK activity were checked by running the enzymatic reaction of PGK alone. At the highest concentration of inhibitor $(10 \mathrm{mM})$, no significant effect on the enzyme activity was detected. Compounds HOP, 2 and 3, which have the greatest structural similarity to 1,3BPGA and bear either a hydroxy group on C3 or a phosphate group on $\mathrm{Cl}$, interacted with both GAP and 1,3-BPGA binding sites. However, they were completely nonselective with regard to both substrates. Surprisingly, the 1,3-BPGA isosteric analogue HOP proved to be the weakest inhibitor $\left(\mathrm{IC}_{50}=2 \mathrm{~mm}\right)$. These results show clearly that close structural similarity to $1,3-\mathrm{BPGA}$ is associated with decreased affinity and selectivity. Compounds 5-8, 1,5-diphosphonopentanes without a substituent at the $\mathrm{C} 2$ position, appeared to be selective inhibitors of $T$. cruzi gGAPDH with respect to 1,3-BPGA. No inhibition was detected with respect to GAP at a $5 \mathrm{~mm}$ concentration of inhibitor. This result parallels similar selective and specific inhibition of $T$. brucei gGAPDH by the same molecules (Table 4), as described in a previous report [30]. This result led us to investigate further the behaviour of both proteins with regard to these substrate analogues.

Table 4. Inhibitory effect $\left(\mathrm{IC}_{50}\right.$ values, $\left.\mu \mathrm{M}\right)$ of 1,3-BPGA analogues on $T$. cruzi and $T$. brucei gGAPDHs with respect to 1,3-BPGA. Each determination was performed in triplicate with a standard deviation of $\pm 4 \%$.

(1)

\section{Inhibition and site-directed mutagenesis} of $T$. brucei gGAPDH

In the absence of a 3D structure of a complex of $T$. bruce gGAPDH with an analogue of 1,3-BPGA, we chose to investigate the enzyme-inhibitor interactions by studying the kinetics of enzymatic inactivation with the native protein and with two proteins modified by site-directed mutagenesis.

Kinetics studies of $T$. brucei $g G A P D H$. Table 5 gives the inhibition constants $\left(K_{\mathrm{i}}\right)$ of the different compounds determined for the $T$. brucei enzyme. The inhibition kinetics data with respect to 1,3-BPGA were calculated from Lineweaver-Burk plots (1/v vs. 1/[substrate]) with an intercept on the $1 / v$ axis, at any concentration of inhibitor (data not shown). All compounds were fully competitive with respect to 1,3-BPGA, indicating a clear interaction at this substrate-binding site. The inhibition constants found for compounds 5,6 and 7 were in the range of the $K_{\mathrm{m}}$ values for 1,3-BPGA and even up to three times lower for compound 6

Selection of $T$. brucei gGAPDH residues to be mutated and measurement of kinetic parameters of the mutated enzyme forms. Residues Thr196 and Thr225 (which correspond to Thr197 and Thr226, respectively, in T. cruzi gGAPDH) were selected for the following reasons. (a) They are involved in the two phosphate-anion binding sites: Thr225 in the $\mathrm{Pi}$ site (for inorganic phosphate-binding site) and Thr196 in the Ps site (for the GAP C3-phosphatebinding site) which were identified in the 3D structures of both the $T$. brucei and T. cruzi enzymes. (b) Results from a mutagenesis study involving the whole set of residues constituting these phosphate-binding sites in the Bacillus stearothermophilus enzyme [47] allowed us to select the amino acids the substitution of which does not result in the total suppression of catalytic activity; threonines were selected because mutation of arginine involved in both $\mathrm{Pi}$ and Ps sites almost entirely abolished the enzyme's activity (for mutations at the Ps site), rendering any study of the inhibitory effect impossible. (c) Substitution of threonine residues by alanines was preferred to the isosteric $\mathrm{Thr}-\mathrm{Val}$ substitution, to avoid hypothetical hydrophobic interactions and to enable direct comparison between T. brucei and $B$ stearothermophilus mutants. The kinetic parameters of the wild-type enzymes and the various mutants from the two organisms (B. stearothermophilus [47] and T. brucei) are summarized in Table 6 . With all mutants, and for both organisms, a decrease in $k_{\text {cat }}$ for the forward reaction was observed. For T. brucei, however, and unlike B. stearothermophilus GAPDH, these decreases were more pronounced with the Pi mutant (Thr225Ala: $0.4 \%$ activity remaining) than the Ps mutant (Thr196Ala: 9\% activity remaining). For the trypanosome enzyme, $K_{\mathrm{m}}$ for 1,3-BPGA and GAP increased significantly in the Pi mutant; in the Ps mutant, $K_{\mathrm{m}}$ for GAP increased when the $K_{\mathrm{m}}$ of 1,3-BPGA stayed constant. This unchanged $K_{\mathrm{m}}$ parallels similar effects observed in the $B$. stearothermophilus enzyme: a decrease in $K_{\mathrm{m}}$ for GAP was reported [47] for threonine replacement in both Pi and Ps mutants, but no explanation was given to account for these observations. 
Table 5. Inhibition pattern of $T$. brucei gGAPDH with respect to 1,3-BPGA. Dissociation constants $\left(K_{\mathrm{d}}\right)$ were obtained from spectrofluorimetry measurements for $T$. brucei and T. cruzi gGAPDHs. All experiments were carried out in triplicate.

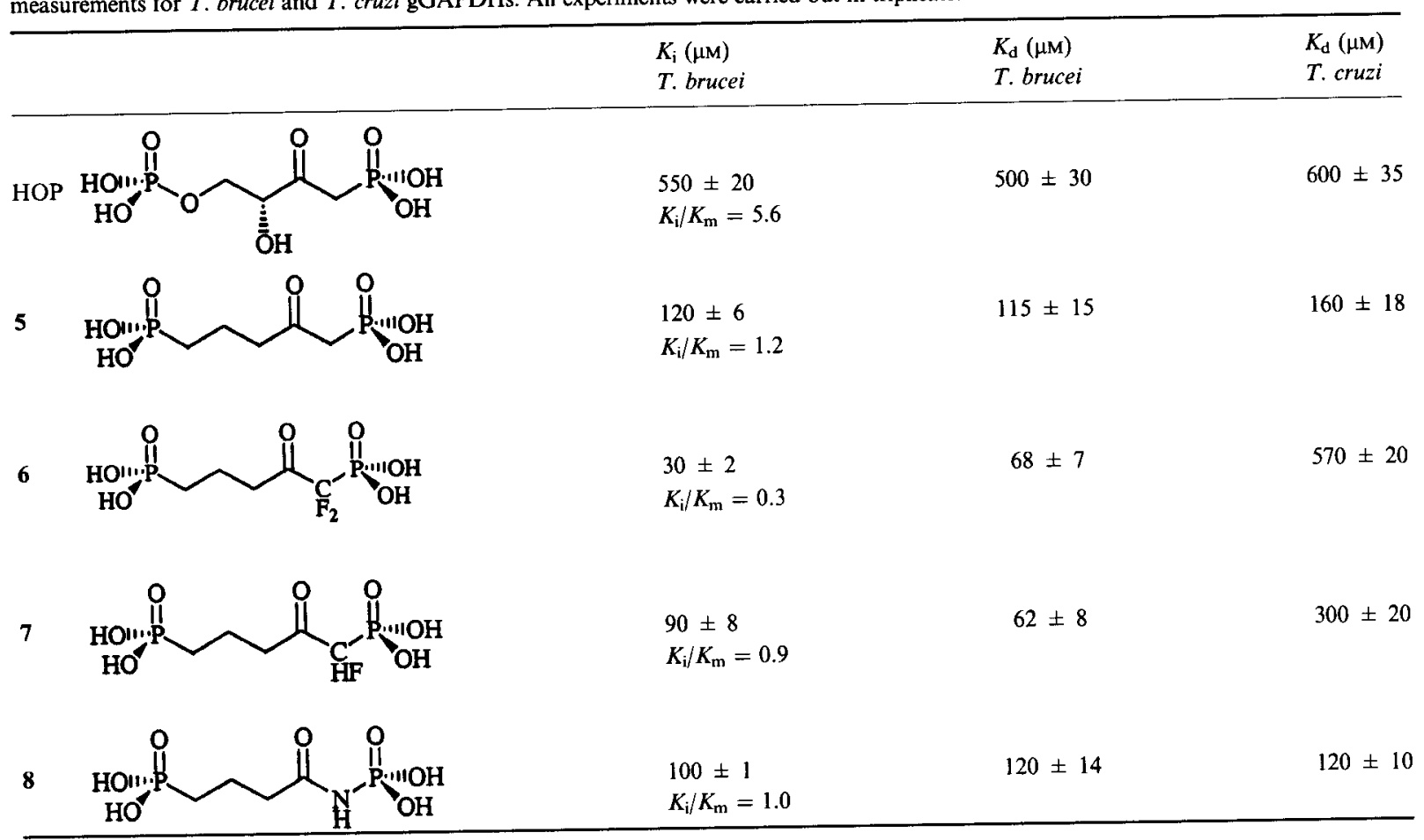

Table 6. Kinetic parameters of wild-type (WT) and mutant enzymes. $K_{\mathrm{m}}$ values are means based on three separate determinations. The substrate concentrations for the oxidative phosphorylation and the reductive dephosphorylation are given in Materials and methods.

\begin{tabular}{|c|c|c|c|c|c|c|}
\hline & \multicolumn{3}{|c|}{ B. stearothermophilus } & \multicolumn{3}{|l|}{ T. brucei } \\
\hline & WT & T179A (Ps site) & T208A (Pi site) & WT & T196A (Ps site) & T225A (Pi site) \\
\hline \multicolumn{7}{|l|}{$K_{\mathrm{m}}(\mu \mathrm{M})$} \\
\hline GAP & $800 \pm 90$ & $160 \pm 90$ & $250 \pm 20$ & $150 \pm 20$ & $235 \pm 18$ & $515 \pm 24$ \\
\hline$K_{\mathrm{cas}}\left(\mathrm{s}^{-1}\right)$ & $70 \pm 6$ & $2.6 \pm 0.2$ & $10.7 \pm 0.3$ & $50 \pm 0.5$ & $4.4 \pm 0.3$ & $0.2 \pm 0.05$ \\
\hline
\end{tabular}

Enzymatic inactivation studies were carried out on the two mutated $T$. brucei gGAPDHs in the presence of compounds HOP, 5, 6, 7 and 8. When all the 1,3-BPGA analogues were inhibiting $T$. brucei gGAPDH with $\mathrm{IC}_{50}$ between 65 and $2000 \mu \mathrm{M}$, no inhibitory effect was detected on either mutant enzyme (data not shown), even at very high inhibitor concentrations (up to $5 \mathrm{mM}$ ). These results indicate that modifications at either the Pi or Ps site completely abolished the inhibitory effect of these substrate analogues. This is consistent with a simultaneous interaction of the 1,3BPGA analogues at both Ps and Pi phosphate-binding sites.

\section{Comparison of the inhibition of $T$. cruzi and $T$. brucei gGAPDHs}

Inhibition. Table 4 summarizes the inhibitory effects $\left(\mathrm{IC}_{50}\right)$ of the glycosomal GAPDHs from $T$. brucei and T. cruzi by 1,3-BPGA analogues which are inactive on rabbit muscle
GAPDH. Strikingly, although the homology between these two proteins is greater than $95 \%$, different inhibitory effects were observed for these two enzymes: the 1,5-diphosphonopentanes proved to be between 2 and 30 times more active on $T$. brucei gGAPDH than they were on $T$. cruzi gGAPDH. The most significant differences were obtained with compounds 6 and 7 which bear two and one fluorine atoms on the $\mathrm{Cl}$ position, respectively. HOP, which had the closest structural similarity to the substrate 1,3-BPGA, had the same poor effect on both proteins.

Affinity values. For the T. brucei enzyme, the dissociation constants $\left(K_{\mathrm{d}}\right.$ in Table 5$)$ of all molecules, as measured by fluorescence spectroscopy, were very close to the $K_{\mathrm{i}}$ values $(K$ in Table 5) measured by inhibition kinetics. Therefore, these values were in the range of the substrate's $K_{\mathrm{m}}$, or even lower for fluorinated compounds 6 and 7. Surprisingly, nonfluorinated molecules 5 and 8 have very similar $K_{d}$ values for both 
the $T$. brucei and $T$. cruzi proteins. These $K_{d}$ values actually represent the ligand affinities for a nonactive conformation of the enzyme in the absence of substrate and cofactor

Molecular modelling. To elucidate the different behaviou of these inhibitors on the two trypanosomatid gGAPDHs, modelling studies of enzyme-inhibitor complexes were performed using Search/Compare and Discover modules from the Insight II package. Interestingly, despite the fact that the two proteins exhibit a high degree of homology, modelling studies showed different behaviours for 1,3BPGA analogues inside the $T$. cruzi and $T$. bruce $i$ gGAPDH active sites, as depicted in Fig. 4.

For $T$. cruzi gGAPDH, although the rmsd was greater in the Ps binding site, molecular modelling results (Fig. 4A) suggest that most inhibitors interact with the same residues as HOP. A particularly good result was found for compound $\mathbf{8}$, the most active compound against $T$. cruzi gGAPDH. Modelling results suggest that improved activity of this compound may be a result of hydrogen bonding between the hydroxyl of Thr167 of the protein and the amino group of compound $\mathbf{8}$. No other inhibitor offered such an interaction. For compounds 5-8, the interaction of one phosphonate group at the Ps site may be responsible for the inhibitory effect with respect to 1,3-BPGA. However, no strong interaction with the Pi site was found. As this Pi site was recently proposed to be the first binding site of GAP $[26,29]$, the absence of interactions at this site may explain the inactivity of compounds 5-8 with respect to GAP. T. brucei gGAPDH inhibitors show lower rmsd (Fig. 4) and a more bent conformation than $T$. cruzi gGAPDH inhibitors. In other words, the average value of interphosphate distances for $T$. cruzi gGAPDH inhibitors is larger $(6.87 \AA$ ) than the average value found for the $T$. bruce gGAPDH inhibitors $(6.40 \AA)$ (Table 7$)$. In fact, if interphosphate distances are plotted against $\mathrm{IC}_{50}$ values, an inverted-bell shape correlation becomes apparent for both $T$. bruce $i$ and $T$. cruzi gGAPDHs. This behaviour support the view that an ideal distance is required to obtain maximal inhibitory activity.

Despite great sequence conservation in the active site of the two trypanosomatid gGAPDHs, two minor structural differences may be responsible for the extended/bent conformation of inhibitors inside the active site: (a) substitution of Ser247 in $T$. cruzi gGAPDH by Ala246 in T. brucei gGAPDH; (b) different conformations adopted by Thr226/Thr225 in the two gGAPDHs.

In $T$. cruzi gGAPDH, Ser 247 and Thr226 compete with Arg249 for the phosphate groups in the inhibitors, thus Arg249 attracts them less strongly, allowing the inhibitors to adopt an extended conformation. In T. brucei gGAPDH, Arg248 is the main residue that interacts with these phosphate groups, once Ala246 does not have a suitable side chain and Thr225 is not oriented to interact with the inhibitors. A possible consequence of this interaction profile is the bent conformation of inhibitors in the T. brucei enzyme suggested by modelling studies.

\section{Discussion}

HOP was selected as a starting point for our inhibitor design studies, because its molecular structure has the closest similarity to the substrate 1,3-BPGA, keeping the overall size, the two phosphoryl moieties, the carbonyl at the $\mathrm{C} 2$ position and the $(R)$ configuration at the $\mathrm{C} 3$ carbon bearing the hydroxy group. Because of the low stability of the mixed anhydride present in 1,3-BPGA $\left(t_{1 / 2}=30 \mathrm{~s}\right)$ [48], this moiety was replaced by a $\beta$-ketophosphonate structure which is stable and not hydrolysable. The crystal structure reported here provides the first view of the closest 1,3 BPGA analogue bound to the catalytic domain of a GAPDH, with its two phosphoryl groups making a number of specific interactions.

The two phosphoryl moieties of HOP are bound to Arg249, a specific residue allegedly belonging to the Ps binding site, which serves as a linker between the phosphoryl groups of HOP. This ionic bridge induces a deformation bending of the analogue (no extended conformation between either $\mathrm{Pi}$ or $\mathrm{Ps}$ sites). This complex possibly illustrates a step of the catalytic process by which, after the phosphorylation step, Arg249 may induce compression of the product, to set it on its way for expulsion from the active site (or its introduction into the active site of the substrate in the reverse reaction). In this binary complex, the hydroxy group on $\mathrm{C} 3$ does not interact with residues of the active site, and all molecules bearing this $\mathrm{OH}$ are inhibitors with respect to both substrates. This hydroxy group is known to play an essential role in orientating the substrate GAP or 1,3-BPGA for the first step of the enzymatic process by keeping its $D$ conformation [26]. Our observations suggest that the substrate analogue is probably located elsewhere on the pathway of the multistep catalysis, where the $\mathrm{OH}$ interactions with residues of the active site are not required.

Using information on the 3D structure of the enzymeinhibitor complex, we introduced structural modifications in HOP and determined the respective inhibitory effects of the resulting compounds on the $T$. cruzi gGAPDH. Activity assays showed two different behaviour patterns for these inhibitors. First, the derivatives with the closest structural homology to the substrate behaved as inhibitors with respect to both substrates (GAP and 1,3-BPGA) and were completely nonselective as they inhibited the trypanosome and mammalian (rabbit muscle GAPDH) enzymes equally well [30]. Secondly, the 2-oxo-diphosphonopentanes 5, 6, and 8 were only inhibitors with respect to 1,3-BPGA and had no effect on the mammalian enzyme. However, the presence of one or two fluorine atoms on the $\beta$-ketophosphonate moiety (compounds 6 and 7), rendering the ionic interactions of the phosphonate group similar to those of the equivalent phosphate, did not improve the inhibition or the affinity. With a nitrogen atom (compound 8), however, a slightly additive inhibition and a good affinity $\left(K_{\mathrm{d}}\right.$ value, Table 5) were observed.

These same molecules displayed different inhibitory effects $\left(\mathrm{IC}_{50}\right)$ and affinity constants $\left(K_{\mathrm{d}}\right)$ with $T$. bruce gGAPDH (Table 4). These differences were unexpected as the proteins have very similar sequences and superimposable 3D structures [24]. Parallel studies of these effects allowed identification of the specific interactions between the inhibitors and the proteins. In the absence of a 3D structure for the enzyme from $T$. brucei complexed with an analogue of 1,3-BPGA, we could not directly identify the structural features that account for the difference between the two enzymes. Therefore, other approaches were used. 


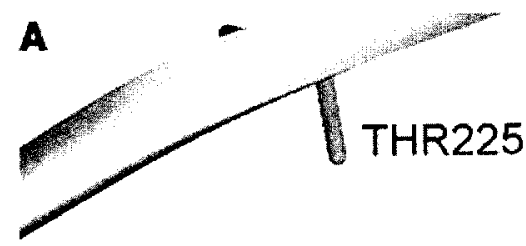

ALA246
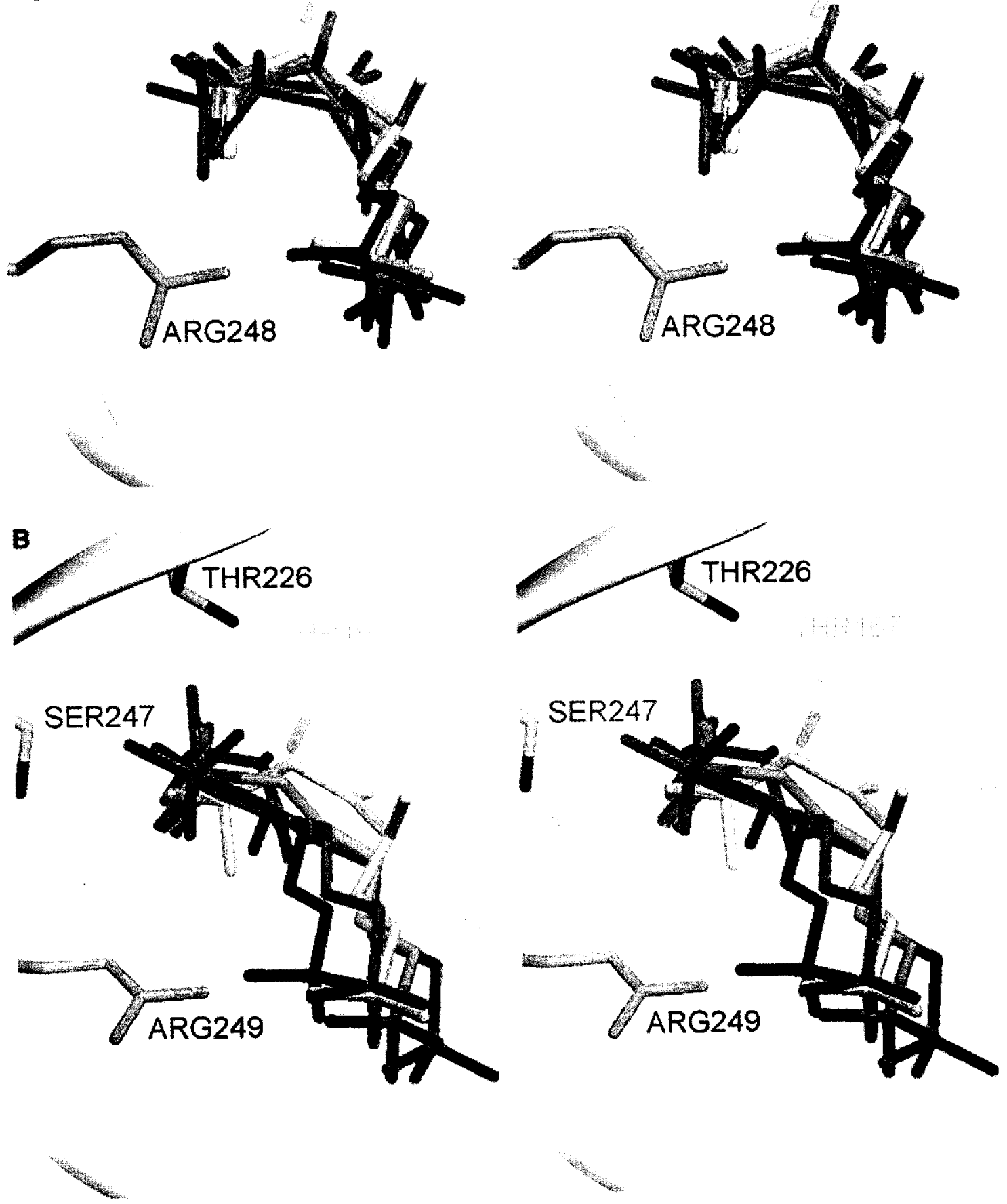

Fig 4. Steren diagrams of the active sites of $T$. brucei gGAPDH (A) and $T$. cruzi gGAPDH (B) containing their respective inhibitors which were superimposed after the minimization protocol. The inhibitors are shown in colours: HOP (yellow), compound 5 (coloured by atoms), compound 6 (cyan), compound 7 (green) and compound 8 (magenta).
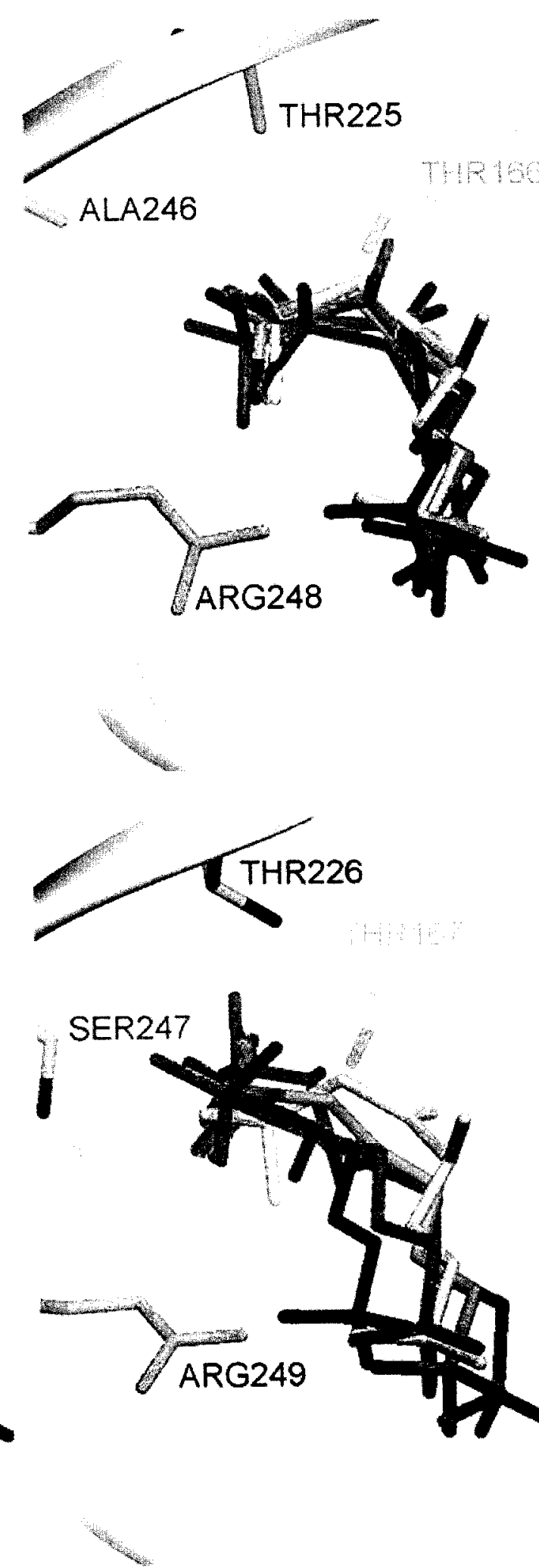
Table 7. Interphosphate distances of the T. cruzi GAPDH inhibitors, calculated after the simulations. The equivalent distances measured for the $T$. brucei GAPDH complexes are given in parentheses.

\begin{tabular}{ll}
\hline Compound & $D_{\text {P-P }}(\AA)$ \\
\hline HOP & $6.63(6.18)$ \\
5 & $7.17(6.32)$ \\
6 & $6.65(6.61)$ \\
7 & $7.21(6.58)$ \\
8 & $6.70(6.32)$ \\
\hline
\end{tabular}

First, for T. brucei gGAPDH, complete kinetic studies were performed to identify residues in the $\mathrm{Pi}$ and Ps binding sites. The results of these studies were confirmed by site-directed mutagenesis of specific residues of the two sites. Secondly, model building of the best inhibitors based on the refined structures of the two trypanosomatid GAPDHs strongly suggests that the contacts responsible for the inhibitory effects are different for the two proteins. Indeed, the modelling studies performed on the $T$. brucei enzyme showed that inhibitors are likely to be more bent than in the $T$. cruzi gGAPDH active site (Fig. 4). Therefore the electrostatic effects of the charges borne by the phosphonate moiety of the inhibitors become more significant with the former enzyme, and the more acidic group-bearing inhbitors 6 and 7 are the most efficient.

For $T$. cruzi GAPDH, our results are clearly correlated with a more extended conformation of the inhibitors (Table 7), accounting for weaker electrostatic interactions with Arg249; they also suggest an interaction of Thr167 through a specific hydrogen bond with the amino group of the $\beta$-ketophosphonate moiety in compound 8 . These findings will be taken into account in the design of the next generation of GAPDH inhibitors, particularly with respect to shape, charges and substituents. We will now focus on two strategic targets: (a) the methylene group of the $\beta$-ketophosphonate moiety for future modifications of molecules; (b) Thr167, close to the essential Cys166 (in T. cruzi) at the P binding site, to improve selective irreversible inhibitor previously considered [49] against $T$. cruzi gGAPDH.

Analysis of the effects in terms of interactions between these selective inhibitors and the proteins has allowed us to identify specific interactions with the trypanomastic gGAPDHs that may account for the differences in behaviour of the two proteins despite their great similarity. Othe factors may also be of some importance, including the conformational change of the protein. Indeed, besides the large differences observed between $K_{\mathrm{i}}$ and $K_{\mathrm{d}}$ values (Table 5), we have previously shown by kinetic analysis [49] that, during irreversible enzyme inhibition, $T$. bruce gGAPDH undergoes a conformational change before covalent binding. The actual difference between these enzymes may arise from their ability to involve different conformational changes in the presence of these inhibitors. A Fourier transform infrared study is in progress.

\section{Acknowledgements}

This work was performed within the joint co-operative programme between CAPES (Brazil) and the Comité Francais d'Evaluation de la Coopération Universitaire avec le Brésil (COFECUB) (contract no. 294
H99) which is fully acknowledged. We acknowledge La société de Secours des Amis des Sciences and the European Cooperation in the Field of Scientific and Technical Research COST-B9 for their financial support. We also thank P. A. Michels (Brussels) for helpful discussions.

\section{References}

1. WHO (2000) The World Health Report 2000: Health Systems Improving Performance. WHO, Geneva.

2. Verlinde, C.L.M.J., Hannaert, V., Blonski, C., Willson, M., Périé, J J., Forthergill-Gilmore, L.A., Opperdoes, F.R., Gelb, M.H., Hol, W. G.J. \& Michels, P.A.M. (2001) Glycolysis as a target for the design of new-trypanosome drugs. Drug Resistance Updates 4 , $50-65$.

3. Opperdoes, F.R. (1987) Compartmentation of carbohydrate metabolism in trypanosomes. Annu. Rev. Microbiol 41, 127-151.

4. Engel, J.C., Franke de Cazzulo, B.M., Stoppani, A.O., Cannata, J.J. \& Cazzulo, J.J. (1987) Aerobic glucose fermentation by Trypanosoma cruzi axenic culture amastigote-like forms during growth and differentiation to epimastigotes. Mol. Biochem. Parasitol. 26, 1-10.

5. Bakker, B.M., Michels, P.A.M., Opperdoes, F.R. \& Westerhof H.V. (1997) Glycolysis in bloodstream form Trypanosoma bruce can be understood of the kinetics of the glycolytic enzymes. J. Biol. Chem. 272, 3207-3215.

6. Bakker, B.M., Michels, P.A.M., Opperdoes, F.R. \& Westerhof, H.V. (1999) What controls glycolysis in bloodstream form Trypanosoma brucei? J. Biol. Chem. 274, 14551-14559.

7. Bakker, B.M., Mensonides, F.I.C., Teusink, B., van Hoek, P., Michels, P.A.M. \& Westerhoff, H.V. (2000) Compartmentation protects trypanosomes from the dangerous design of glycolysis. Proc. Natl Acad. Sci. USA 97, 2087-2092.

8. Schuster, R. \& Holzhütter, H.G. (1995) Use of mathematica models predicting the metabolic effect of large scale enzyme activity alterations. Application to enzyme deficiencies of red blood cells. Eur. J. Biochem. 229, 403-418.

9. Lambeir, A.M., Loiseau, A.M., Kuntz, D.A., Vellieux, F.M., Michels, P.A.M. \& Opperdoes, F.R. (1991) The cytosolic and glycosomal glyceraldehyde-3-phosphate dehydrogenase from Trypanosoam brucei. Kinetic properties and comparison with homologous enzymes. Eur. J. Biochem. 198, 429-435.

10. Aronov, A.M., Suresh, S., Buckner, F., Van Voorhis, W.C. Verlinde, C.M.M. Opperdoes, F.R., Hol, W.G.J. \& Gelb, M.H. (1999) Structure-based design of submicromolar, biologically active inhibitors of trypanosomatid glyceraldehyde-3-phosphate dehydrogenase. Proc. Natl Acad. Sci. USA 96, 42734278.

11. Bressi, J.C Verlinde C.L.M.J., Aronov, A.M., Le Shaw, M. Shin, S.S., Nguyen, LN N Suresh, S., Buckner, F.S., Van Voorhis, W.C., Kuntz, I.D., Hol, W.G.J. \& Gelb, M.H. (2001) Adenosine analogues as selective inhibitors of glyceraldehyde-3-phosphate dehydrogenase of Trypanosomatidae via structure-based drug design. J. Med. Chem. 44, 2080-2093.

12. Duggleby, R.G. \& Dennis, D.T. (1974) Nicotinamide adenine dinucleotide-specific glyceraldehyde 3-phosphate dehydrogenas from Pisum sativum. Assay and steady state kinetics. J. Biol. Chem. 249, 167-174.

13. Trentham D.R. (1971) Reaction of glyceraldehyde-3-phosphate dehydrogenase facilitated by oxidized nicotinamide-adenine dinucleotide. Biochem. J. 122, 59-69.

14. Segal, H.L. \& Boyer, P.D. (1953) The role of sulfhydryl groups in the activity of D-glyceraldehyde-3-phosphate dehydrogenase J. Biol. Chem. 204, 265-281.

15. Harris, J.I. \& Waters, M. (1974) Glyceraldehyde-3-phosphate dehydrogenase. Enzymes 13, 1-49. 
16. Watson, H.C., Duée, E. \& Mercer, W.D. (1972) Low resolution structure of glyceraldehyde-3-phosphate dehydrogenase. Nat. New Biol. 240, 130-139.

17. Moras, D., Olsen, K.W., Sabesan, M.N., Buehner, M., Ford, G.C. \& Rossmann, M.G. (1975) Studies of the asymmetry in the threedimensional structure of lobster D-glyceraldehyde-3-phosphate dehydrogenase. J. Biol. Chem. 250, 9137-9162.

18. Skarzynski, T., Moody, P.C.E. \& Wonacott, A.J. (1987) Structure of holo-glyceraldehyde-3-phosphate dehydrogenase from Bacillus stearothermophilus at $1.8 \AA$ A resolution. J. Mol. Biol. 193, 171-187.

19. Vellieux, F.M.D., Hajdu, J., Verlinde, C.L.M.J., Groendijk, H. Read, R.J., Greenhough, T.J., Campbell, J.W., Kalk, K.H., Littlechild, J.A Watson, H.C. \& Hol, W.G.J. (1993) Structure of glycosomal glyceraldehyde-3-phosphate dehydrogenase from Trypanosoma brucei determined from Laue data. Prac. Natl Acad. Sci. USA 20, 2355-2359.

20. Tanner, J., Hecht, R.M., Pisegna, M., Seth, D.M. \& Krause, K.L (1994) Preliminary crystallographic analysis of glyceraldehyde-3phosphate dehydrogenase from the extreme thermophile thermusaquatus. Acta Crystallogr. D 50, 744-748.

21. Korndörfer, I., Steipe, B., Huber, R., Tornschy, A. \& Jaenicke, R (1995) The crystal structure of holo-glyceraldehyde-3-phosphat dehydrogenase from the hyperthermophilic bacterium Thermogota maritima at $2.5 \AA$ resolution. J. Mol. Biol. 246, 511-521.

22. Kim, H., Feil, I.K., Verlinde, C.L.M., Petra, P.H. \& Hol, W.G.J. (1995) Crystal structure of glycosomal glyceraldehyde-3-phosphate dehydrogenase from Leishmania mexicana. Implications for structure-based drug design and a new position for the inorganic phosphate binding site. Biochemistry 34, 14975-14986.

23. Duée, E., Olivier-Deyris, L., Fanchon, E., Corbier, C., Branlant, G. \& Dideberg, O. (1996) Comparison of the structures of wildtype and a N313T mutant of Escherichia coli glyceraldehyde-3phosphate dehydrogenase. Implication for NAD binding and cooperativity. J. Mol. Biol. 257, 814-838.

24. Souza, D.H.F., Garratt, R.C., Araùjo, A.P.U., Guimarães, B.G. Jesus, W.D.P., Michels, P.A.M., Hannaert, V. \& Oliva, G. (1998) Trypanosoma cruzi glycosomal glyceraldehyde-3-phosphate dehydrogenase: structure, catalytic mechanism and targeted inhibitor design. FEBS Lett. 424, 131-135.

25. Corbier, C., Michels, S., Wonacott, A.J. \& Branlant, G. (1994) Characterization of the two anion-recognition sites of glyceraldehyde-3-phosphate dehydrogenase from Bacillus stearothermophilus by site-directed mutagenesis and chemical modification. Biochemistry 33, 3260-3265.

26. Yun, M. Park, C.G., Kim, J.Y. \& Park, H.W. (2000) Structural analysis of glyceraldehyde-3-phosphate dehydrogenase from Escherichia coli: direct evidence of substrate binding and cofactorinduced conformational changes. Biochemistry 39, 10702-10710.

27. Kim, H. \& Hol, W.G.J. (1998) Crystal structure of Leishmania mexicana glycosomal glyceraldehyde-3-phosphate dehydrogenase in a new crystal form confirms the putative physiological active site structure. J. Mol. Biol. 278, 5-11.

28. Pavao, F., Castilho, M.S., Pupo, M.T., Dias, R.L.A., Correa, A.G. Fernandes, J.B., Da Silva, M.F.G.F., Mafezoli, J., Vieira, P.C. \& Oliva, G. (2002) Structure of Trypanosoma cruzi glycosomal glyceraldehyde-3-phosphate dehydrogenase complexed with chalapin, a natural product inhibitor at $1.95 \AA$ resolution. FEBS Lett. 520 (1-3), 13-17.

29. Castilho, M.S., Pavao, F., Oliva, C., Ladame, S., Willson, M. \& Périé, J. (2003) Evidence for two phosphate binding sites of an analogue of the thioacyl intermediate for the Trypanosoma cruz glyceraldehyde-3-phosphate dehydrogenase-catalyzed reaction from its crystal structure. Biochemistry 42, 7143-7151.

30. Ladame, S Bardet, M. Périé, J. \& Willson, M. (2001) Selective inhibition of Trypanosoma brucei glyceraldehyde-3-phosphate dehydrogenase by 1,3-diPG analogues. Bioorg. Med. Chem. 9, 773-783.

31. Ladame, S., Claustre, S. \& Willson, M. (2001) Selective phosphorylation on primary alcohols of unprotected polyols. Phosphorus Sulfur Silicon 174, 37-47.

32. Ladame, S., Périé, J. \& Willson, M. (2002) A convenient synthesis of dibenzyl $\alpha, \alpha$-difluoromethyl- $\beta$-ketophosphonates. Eur. J. Org. Chem. 15, 2640-2648.

33. Mikaelian, I. \& Sergeant, A. (1992) A general and fast method to generate multiple site directed mutations. Nucleic Acids Res. 20 376.

34. Studier, F.W., Rosenberg, A.H., Dunn, J.J. \& Dubendorff, J.W. (1990) Use of T7RNA polymerase to direct expression of cloned genes. Methods Enzymol. 185, 60-89.

35. Polikarpov, I, Perles, L.A., de Oliveira, R.T., Oliva, G., Castellano, E.E., Garratt, R.C. \& Craivich, A. (1998) Set-up and experimental parameters of the protein crystallography beamline at the Brazilian National Synchrotron Laboratory. J. Synchr. Rad. 5, 72-76.

36. Arnt, U.W. \& Wanacott, A.J. (1997) The Rotation Methods in Crystallograph. North Holland Publishing Co., Amsterdam.

37. Otwinowski, Z. \& Minor, W. (1997) Processing of X-ray diffraction data collected in oscillation mode. Methods Enzymol. 276, 307-326.

38. Navaza, J. (1994) AMoRe: an automated package for molecular replacement. Acta Crystallogr. A 50, 157-163.

39. Brunger, A.T., Adams, P.D., Clore, G.M., Delano, W.L., Gros, P Grosse-Kunstleve, R.W., Jiang, J.-S., Kuszewski, J., Nilges, M. Pannu, N.S., Read R J. Rice, L.M. Simonson, T. \& Warren, G.L. (1998) Crystallography \& NMR system: a new software suite for macromolecular structure determination. Acta Crystallogr. D 54, 905-921.

40. Laskowski, R.A. Macarthur, M.W., Moss, D.S. \& Thorton, J.M (1993) PROCHECK: a program to check the stereochemical quality of protein structures. J. Appl. Crystallogr. 26, 283-291.

41. Jones, T.A., Zou, J.Y., Cowan, S.W. \& Kjeldgaard, M. (1991) Improved methods for building protein models in electron-density maps and the location of errors in these models. Acta Crystallogr. A. 47, 110-119.

42. Lamzin, V.S. \& Wilson, K.S. (1993) Automated refinement of protein models. Acta Crystallogr. D 49, 129-147.

43. Misset, O. Bos, O.J.M. \& Opperdoes, F.R. (1986) Glycolytic enzymes of Trypanosoma brucei. Simultaneous purification, intraglycosomal concentrations and physical properties. Eur. J. Biochem. 157, 441-453.

44. Delano, W.L. (2002) The PyMOL User's Manual. DeLano Scientific, San Carlos, CA.

45. Ramachandran, G.N., Ramakrishnan, C. \& Sasisekharan, V. (1963) Stereochemistry of polypeptide chain configurations. J. Mol. Biol. 7, 95-99.

46. Jakeman, D.L., Ivory, A.J., Williamson, M.P. \& Blackburn, G.M (1998) Highly potent bisphosphonate ligands for phosphoglycerate kinase. J. Med. Chem. 41, 4439-4452.

47. Michels, S., Rogalska, E. \& Branlant, G. (1996) Phosphat binding sites in phosphorylating glyceraldehyde-3-phosphate dehydrogenase from Bacillus stearothermophilus. Eur. J. Biochem. $235,641-647$

48. Trentham, D.R. (1971) Rate determining processs and the number of simultaneously active sites of D-glyceraldehyde-3-phosphate dehydrogenase. Biochem. J. 37, 8551-8563.

49. Willson, M., Lauth, N., Périé, J., Callens, M. \& Opperdoes, F. (1994) Inhibition of glyceraldehyde-3-phosphate dehydrogenase by phosphorylated epoxides and $\alpha$-enones. Biochemistry 33, 214-220. 